\title{
Inferring the Thermomechanical State of the Lithosphere Using Geophysical and Geochemical Observables
}

by

William Joseph Shinevar

B.Sc. in Geology - Physics/Mathematics and B.A. in German Studies

Brown University, 2015

Submitted to the Department of Earth, Atmospheric, and Planetary Sciences

in partial fulfillment of the requirements for the degree of

Doctor of Philosophy in Geophysics

at the

MASSACHUSETTS INSTITUTE OF TECHNOLOGY

and

WOODS HOLE OCEANOGRAPHIC INSTITUTION

September 2021

(C) 2021 Massachusetts Institute of Technology. All rights reserved.

Author

William Joseph Shinevar

MIT-WHOI Joint Program in Oceanography/Applied Ocean Science and Engineering Massachusetts Institute of Technology \& Woods Hole Oceanographic Institution

July 27, 2021

Certified by

Dr. Oliver Jagoutz Associate Professor of Geology, Department of Earth and Planetary Sciences Massachusetts Institute of Technology Thesis Supervisor

Certified by

Dr. Mark D. Behn

Associate Professor in Earth and Environmental Sciences

Boston College

Thesis Supervisor

Accepted by

Dr. Oliver Jagoutz

Associate Professor of Geology, Department of Earth and Planetary Sciences

Massachusetts Institute of Technology

Chair, Joint Committee for Marine Geology \& Geophysics 


\title{
Inferring the Thermomechanical State of the Lithosphere Using Geophysical and Geochemical Observables
}

by

\author{
William Joseph Shinevar
}

Submitted to the MIT-WHOI Joint Program in Oceanography and Applied Ocean Science and Engineering on July 27, 2021 in Partial Fulfillment of the Requirements for the Degree of Doctor of Philosophy in Geophysics.

\begin{abstract}
This thesis focuses on interpreting geophysical and geochemical observables in terms of the thermomechanical state of the lithosphere. In Chapter 1, I correlate lower crustal rheology with seismic wave speed. Compositional variation is required to explain half of the total variability in predicted lower crustal stress, implying that constraining regional lithology is important for lower crustal geodynamics. In Chapter 2, I utilize thermobarometry, diffusion models, and thermodynamic modelling to constrain the ultrahigh formation conditions and cooling rates of the Gore Mountain Garnet Amphibolite in order to understand the rheology of the lower crust during orogenic collapse. In Chapter 3, I interpret geophysical data along a 74 Myr transect in the Atlantic to the temporal variability and relationship of crustal thickness and normal faults. In Chapter 4, I constrain the error present in the forward-calculation of seismic wave speed from ultramafic bulk composition. I also present a database and toolbox to interpret seismic wave speeds in terms of temperature and composition. Finally, in Chapter 5 I apply the methodology from Chapter 4 to interpret a new seismic tomographic model in terms of temperature, density, and composition in order to show that the shallow lithospheric roots are density unstable.

Thesis Supervisor: Dr. Oliver Jagoutz

Title: Full Professor in Earth, Atmospheric, and Planetary Sciences

Massachusetts Institute of Technology

Thesis Supervisor: Dr. Mark D. Behn

Associate Professor in Earth and Environmental Sciences

Boston College
\end{abstract}




\section{Acknowledgements}

This thesis would not be possible without the vast support of friends, coworkers, mentors, and all the helpful hands (and paws) over the last 6 years.

First off, I want to thank both of my thesis advisors, Mark Behn and Oli Jagoutz, who have greatly helped develop me as a scientist. Their focus on testable, quantifiable hypotheses using a diverse range of observables and models has greatly influenced and improved my own science. Their patience with and encouragement of my detour-prone academic journey helped me begin to grasp the intricate and deeply interdisciplinary nature of geology. I will always appreciate their healthy skepticism of themselves and others as well as them pushing me to go further in my science. I thank Oli for teaching me how to sledge rocks and Mark for the many cups of espresso throughout my graduate program.

I thank my parents for always encouraging me to learn. Without their support, I would have never gained my scientific curiosity.

I thank my husband, Yu-Kang, who I've grown so much with over the last six years. His supportive smile, understanding of the stresses of a graduate program, and willingness to listen to my rants on figure-making have been helpful, especially throughout COVID lockdown.

I thank the members of my thesis committee, Matej Pec, Brad Hager, and Dan Lizarralde, who have taken time to deeply consider, criticize, and improve the science in this thesis.

I thank previous advisors and teachers who inspired me to continue studying and researching geology after university, including Greg Hirth, Marc Parmentier, Don Forsyth, Karen Fischer, Jan Tullis, and Reid Cooper.

I thank all the scientists who have helped me learn methodologies or given me access to scientific instruments, including but not limited to Tim Grove for help with the rock saw, microscope, and microprobe, Neel Chatterjee for help with the microprobe, Jake Setera for help with the Rutgers LA-ICPMS, Kristen Bergmann for access to her microscope, Jahan Ramezani with the help with mineral separation, Meghan Jones for advice using MBSystem, Jay Ague and J. O. Eckert, Jr for analyses at the Yale microprobe, Seth Kruckenberg with help with EBSD measurements, Maurice Tivey, John Greene, and Masako Tominaga for advice on processing magnetic datasets. I also thank Bonnie Barton for access to samples at Gore Mountain.

I thank coworkers besides my advisors who have challenged, inspired, and improved my scientific work like Eva Golos, Jill VanTongeren, and the SCARF cruise people and co-authors. Special thanks to Jean-Arthur Olive who correctly supported naming the discovered oceanic core complex the Kafka Dome. I thank my office mates, Fiona Clerc, Stephanie Krein, Patrick Beaudry, and Max Collinet, who were always willing to chat about geology and more, keeping me motivated through the slow times. I also thank my lab members and fellow graduate students who suffered my complaints throughout my Ph.D. and helped me keep captivated by all the amazing fields of work. Lab mates like Craig Martin, Ben Klein, Zach Molitor, Joshua Murray, and Hannah Mark were always open to my intrusions into their offices to distract us all from work with coffee or lunch, and to tell me no matter how many times I asked, that I did need to write the Gore Mountain paper myself. When those intrusions failed, the office of I thank the office of Marjorie Cantine, Maya Stokes, and Sam Goldberg for being similarly 
dismissive to my complaints. I thank Ben Urann and all others who were happy to go do field work me for a weekend.

I also thank all my friends who have supported me throughout my time as a graduate student: going to the gym, grabbing coffee and pastries, eating a wonderful variety of foods, listening to my rants whether science-related and not, and suffering my cocktail inventions. Special thanks to Jake and Ryan for attempting to untilt me in DotA. Without good friends keeping me cheerful, especially during COVID, this thesis would have never reached fruition.

I'd like to thank all the MIT and WHOI administrators who helped me along the way including Roberta Allard, Megan Jordan, Lea Fraser, Julia Westwater, Annora Borden, Yanick Pierre, Brandon Milardo, Jennifer Fentress, Kris Kipp, Daisy Caban, Brenda Carbone, Christine Charette, Sally Houghton, Kelly Servant, and Mira Parsons. Funding for this research was provided by an MIT Presidential Fellowship, MIT Student Research Funds, the National Science Foundation Division of Earth Sciences (EAR) and Ocean Sciences (OCE) grants EAR-16-24109, EAR-17-22932, EAR-1722935, OCE-14-58201, and SCEC Awards 16106 and 17202., SCEC, Geological Society of America Graduate Student Research Fellowship, WHOI Ocean Venture Fund, and the WHOI Academic Programs Office. 


\section{Table of Contents:}

\begin{tabular}{lr} 
Abstract & 3 \\
Acknowledgements & 4 \\
List of Figures & 9 \\
List of Tables & 11 \\
Introduction & 13 \\
Chapter 1: Inferring crustal viscosity from seismic velocity: Application to the lower \\
crust of Southern California & 18 \\
Abstract & 19 \\
Introduction & 20 \\
Methods & 21 \\
Application to Southern California & 28 \\
Discussion & 31 \\
Conclusions & 34 \\
Acknowledgements & 35 \\
Figures & 36 \\
Tables & 36 \\
\hline
\end{tabular}

Chapter 2: Gore Mountain Garnet Amphibolite records UHT Conditions:

Implications for the Rheology of the Lower Continental Crust During Orogenesis 44

$\begin{array}{ll}\text { Abstract } & 45\end{array}$

$\begin{array}{ll}\text { Introduction } & 46\end{array}$

$\begin{array}{ll}\text { Background } & 47\end{array}$

Field Relations $\quad 50$

Lithologic Descriptions $\quad 51$

Analytical Methods $\quad 55$

Whole-Rock Chemistry $\quad 59$

$\begin{array}{ll}\text { Mineral Chemistry } & 61\end{array}$

$\begin{array}{ll}\text { Geochronology } & 64\end{array}$

$\begin{array}{ll}\text { Thermometry } & 66\end{array}$

$\begin{array}{ll}\text { Garnet Diffusion Modelling } & 68\end{array}$

$\begin{array}{ll}\text { Thermodynamic Modelling } & 71\end{array}$

$\begin{array}{ll}\text { Discussion } & 73\end{array}$

$\begin{array}{ll}\text { Conclusion } & 79\end{array}$

$\begin{array}{lr}\text { Acknowledgments } & 80\end{array}$ 
Figures

Tables

Chapter 3: Causes of oceanic crustal thickness oscillations along a 74-Myr MidAtlantic Ridge flow line

Abstract

Introduction

Geologic Setting

Observations: Underway Geophysical Data Collection

Time-Series Analysis

Discussion

Conclusion

Acknowledgements

Figures

Chapter 4: WISTFUL: Whole-Rock Interpretative Seismic Toolbox for Ultramafic Lithologies

Abstract

Introduction

Previous Work

Uncertainty in Seismic Wave Speed Forward Calculations

WISTFUL

General User Interfaces

Summary

Figures

Tables

Chapter 5: Mantle Thermochemical Variations beneath the Continental United States Through Petrologic Interpretation of Seismic Tomography

Abstract

Introduction

Geological setting and previous study results

Methodology

Results

Model Validation

Density and Stability of Cratonic Roots

Conclusion

Figures 
Chapter 6: Concluding Remarks

Figures

References 


\section{List of Figures}

Figure 1.1 - Viscosity as a function of composition and wave speed. 36

Figure 1.2 - Goodness of fit for viscosity wave speed relation 37

Figure 1.3 - Geophysical data of Southern California 38

Figure 1.4 - Predicted Viscosity of Southern California Lower Crust 39

Figure 1.5 - Profiles of topography and viscosity along A-A' transect 40

Figure 1.6 - Viscosity as a function of temperature 41

Figure 1.7 - Observed and predicted seismic-aseismic schematic $\quad 42$

Figure 2.1 - Regional geological map of the Adirondack Highlands 81

Figure 2.2 - Outcrop geologic map $\quad 82$

Figure 2.3 - Outcrop photo of Gore Mountain $\quad 83$

Figure 2.4 - Thin section photos of Gore Mountain rocks 84

Figure 2.5 - Whole-rock major element chemistry of Gore Mountain rocks 86

Figure 2.6 - Whole-rock trace elements of Gore Mountain rocks 87

Figure 2.7 - Garnet major element chemistry. $\quad 88$

Figure 2.8 - Garnet element map for sample 17-ADK-09G. 89

Figure 2.9 - Mineral trace elements $\quad 90$

Figure 2.10 - Plagioclase chemistry $\quad 92$

Figure 2.11 - Pyroxene chemistry 93

Figure 2.12 - Biotite and amphibole chemistry 94

Figure 2.13 - Zircon CL images $\quad 95$

Figure 2.14 - Zircon ages and trace element chemistry 96

Figure 2.15 - GMGA Thermobarometry 97

Figure 2.16 - GMGA Cooling History 98

Figure 2.17 - Garnet Diffusion Profiles 99

Figure 2.18 - Phase diagrams for the GMGA 100

Figure 2.19 - P-T-t path of the GMGA 101

Figure 2.20 - Thermobarometry in the Adirondack Highlands 102

Figure 2.21 - Predicted Adirondack Highlands viscosities and schematic diagram 103

Figure 3.1 - Shipboard and regional data sets along the SCARF cruise track 129

Figure 3.2 - Observed and synthetic magnetic anomalies 131

Figure 3.3 - Shipboard geophysical datasets and derived geophysical parameters 132

Figure 3.4 - Cumulative frequency distribution of fault throw 134

Figure 3.5 - Bathymetry and gravity of the Kafka Dome 136

Figure 3.6 - Power spectral density of bathymetry and gravity 137

Figure 3.7 - Admittance and coherence 139

Figure 3.8 - Schematic diagram of causes for oceanic crustal thickness variations 140

Figure 3.9 - Fault Spacing, M, and crustal thickness 141

Figure 4.1 - Workflow for WISTFUL 165

Figure 4.2 - Experimental vs. thermodynamically-derived bulk moduli 166 
Figure 4.3 - Laboratory measured vs. predicted seismic wave speed

Figure 4.4 - Phase and seismic wave speed error

Figure 4.5 - Mineral prediction error for preferred solution model

Figure 4.6 - Seismic wave speed error for preferred solution model

Figure 4.7 - Compositional histograms for the ultramafic database

Figure 4.8 - Ultramafic database peridotite ternary diagram

Figure 4.9 - Snapshot of calculateWaveSpeedFiles.mlx

Figure 4.10 - Snapshot of relations GUI

Figure 4.11 - Snapshot of geotherms GUI 175

Figure 4.12 - Snapshot of inversion GUI 176

Figure 5.1 - MITPS_20 seismic wave speed 208

Figure 5.2 - Schematic diagram of WISTFUL inversion 209

$\begin{array}{ll}\text { Figure 5.3 - Best-fit temperature } & 210\end{array}$

Figure 5.4 - Temperature distribution histogram 211

Figure 5.5 - Best-fit Mg\# 212

Figure 5.6 - Best-fit $\mathrm{Al}_{2} \mathrm{O}_{3} \quad 213$

Figure 5.7 - Best-fit density 214

Figure 5.8 - Comparison of model and xenolith-estimated composition 215

Figure 5.9 - Comparison of model and geochemically estimated temperatures 216

Figure 5.10 - Buoyancy number for the continental US 217

Figure 5.11 - Instability timescales for Rayleigh-Taylor instabilities 218

Figure 5.12 - Unstable thicknesses and instability times for cratonic delamination 219

Figure 6.1 - Wave speeds from global tomographic models binned by spreading rate

Figure 6.2 - Predicted wave speeds from geodynamic grain size models 226 


\section{List of Tables}

Table 1.1 - Parameter values for Eq. 7a and 7b

Table 2.1 — Sample names, locations, and modal proportions 104

Table 2.2 - Measurement type, age, temperatures, and distance from Gore Mountain used to constrain the GMGA cooling history 106

Table 4.1 — Newly input elastic moduli and derivatives 177

Table 4.2 - List of solution models tested 179

Table 4.3 - Functions, files, and databases $\quad 180$ 
"Blieb das unerklärliche Felsgebirge. - Die Sage versucht das Unerklärliche zu erklären. Da sie aus einem Wahrheitsgrund kommt, mu $\beta$ sie wieder im Unerklärlichen enden."

"There remains the inexplicable mass of rock. The legend tries to explain the inexplicable. As it comes out of the substratum of truth it has in turn to end in the inexplicable." -Prometheus, Franz Kafka 


\section{Introduction}

This thesis focuses on interpreting geophysical and geochemical observables in order to provide new constraints on the thermal, chemical, and mechanical state of lithosphere over time. The lithosphere is the rigid outermost layer of Earth, composed of the crust and the upper mantle, usually on the order of $100 \mathrm{~km}$ thick. The lithosphere forms the plates described in plate tectonics and moves slowly over the hot, ductile, and convecting mantle. As the lithosphere ages, it loses heat via conduction and become denser than the underlying mantle. Eventually the density of the lithosphere increases sufficiently that the cold plate subducts back into the mantle. This subduction drives plate motions, and causes the mantle to upwell and form new lithosphere at mid-ocean ridges.

The thermal and chemical structure of the lithosphere controls its density as well as its rheology, or how the lithosphere deforms. Unfortunately, it is impossible to directly sample the deep lithosphere today. The world's deepest borehole sampled to only a depth of $\sim 12 \mathrm{~km}$ (Kozlovsky, 1987), a third of the way through the average continental crustal thickness. Instead, geoscientists must use geophysical observables such as seismic travel times, magnetic anomalies, surface heat flow, and gravity, as well as the geochemistry of rocks found at the surface to constrain the structure of the lithosphere.

This thesis consists of five chapters focusing on developing and using methodologies to constrain thermal, compositional, and mechanical differences in continental and oceanic lithosphere. Three chapters focus on the interpretation of seismic wave speed. Seismic tomography inverts seismic wave speed from seismic travel times using the same techniques that produce images in magnetic resonance imaging (MRI) scans. These techniques are the highest-resolution constraints on properties of the deep lithosphere (Anderson and Dziewonski, 1984). Seismic wave speeds are dependent on the elastic moduli and density of the minerals present in the rock. The stable constituent minerals and their moduli are in turn dependent on pressure, temperature, and composition. Therefore, seismic wave speed has the potential to relate composition and temperature to rheology and density.

In Chapter 1, I investigate the role of composition on the viscosity, how resistive a material is to ductile deformation, of the lower crust through a joint inversion of seismic P-wave $\left(V_{p}\right)$ and $\mathrm{S}$-wave $\left(V_{s}\right)$ speeds. This work extends previous research demonstrating 
robust relationships between seismic velocity and crustal composition (e.g., Christensen and Mooney, 1995; Christensen, 1996), as well as composition and viscosity (e.g., Bürgmann and Dresen, 2008). To quantify this relation, I use a Gibbs-free energy minimization program Perple_X (Connolly, 2009) along with experimentally-derived mineral moduli to calculate mineral assemblages and seismic wave speeds for a global compilation of crustal whole-rock compositions. For each of these mineral assemblages, I estimate aggregate viscosity for each sample by using an isotropic mixing model (Huet et $a l ., 2014)$ and the strength of each individual mineral based on laboratory experiments. I find that seismic wave speed and aggregate crustal viscosity correlate well for most crustal conditions. Thus, with the seismic wave speed, temperature, pressure, and strain rate of the lower crust, one can calculate the regional lower crustal viscosity. I apply this method using geophysical data for Southern California predicting that lower crustal viscosity varies regionally by four orders of magnitude and lower crustal stress varies by three orders of magnitude. At least half of the total variability in stress can be attributed to compositional changes, implying that regional lithology has a significant effect on lower crustal geodynamics. Predicting the depth of the brittle-ductile transition along the predicted temperature profiles for Southern California with this methodology; however, cannot explain the shallow the seismic-aseismic transition depths observed in the earthquake record. I interpret this discrepancy to reflect the importance of fabric development, a weakening mechanism in the ductile deformation of rocks that is not incorporated in the mixing model.

Chapter 4 continues the interpretation of seismic wave speeds, but focuses on the mantle. In order to interpret temperature and composition from seismic wave-speed, I create WISTFUL (Whole-Rock Interpretative Seismic Toolbox For Ultramafic Lithologies). WISTFUL consists of a database of 4333 peridotites and 481 pyroxenites, their elastic moduli, mineral modes, and seismic wave speeds, and a set of functions and general-user interfaces to interpret mantle seismic wave speeds. To constrain the error present in these forward calculations, I assess two types of uncertainties in the relationship between seismic wave speed and whole-rock composition: (1) uncertainty in the elastic property measurements and mixing equations to determine the bulk properties, and (2) uncertainty in the predicted mineral assemblage and composition. Regarding the 
first source of uncertainty, I show experimental seismic wave speed measurements on ultramafic lithologies are reproducible with updated mineral endmember moduli and mixing methodologies. To constrain the second source of uncertainty, I compare predicted mineral assemblages and seismic wave speeds for 130 well-studied peridotite and pyroxenite xenoliths using five sets of solution models to the observed modal assemblages and estimated seismic wave speeds. All forward calculations of seismic wave speed in WISTFUL utilize the set of solution models that best reproduce the xenolith mineral assemblages and estimated wave speeds.

In Chapter 5, I utilize the WISTFUL toolbox from Chapter 4 to analyze MITPS_20 (Golos et al., 2020), a joint body and surface wave tomographic inversion for $V_{p}$ and $V_{s}$ with high resolution in the shallow mantle beneath the continental United States. I constrain temperature and compositional variations at 60 and $80 \mathrm{~km}$ depth in the mantle lithosphere using two different anelastic correction methods. I find temperature variations beneath the continental United States up to $800-900^{\circ} \mathrm{C}$ at $60 \mathrm{~km}$ and $80 \mathrm{~km}$, larger than previously found. East of the Rocky Mountains is generally cold, with higher temperatures on the eastern margins. Within the east, long-wavelength thermal variations are present, some correlated with surface expressions of rifting events. The west is generally hot with highest temperatures found under Holocene volcanoes. In order to strengthen the method's results, I compare best-fit temperature and compositions with recently (<10 Ma) erupted xenolith compositions, xenolith thermobarometry, and primary magma thermobarometry. Model estimates agree well with temperature and compositions from xenoliths in the southwestern US, but I find a temperature discrepancy between both anelasticities for magmatic temperature estimates for melting at $60 \mathrm{~km}$. I interpret this discrepancy to be due to the differences in seismic resolution and the scale at which the magmatic temperatures sample, as well as errors in the anelastic formulations. Both anelasticity models predict that the eastern United States is depleted compared to the western United States. Furthermore, the chemical depletion in the east does not fully compensate for the densification due to temperature. This implies that the deep lithospheric roots of ancient continents are unstable and will eventually delaminate back into the mantle. 
In addition to the analysis of seismic models, the other two chapters focus on interpreting lithospheric properties through other geophysical or geochemical observables. Chapter 2 describes gravity, magnetic, and bathymetry data collected along a continuous 1400-km-long spreading-parallel flow line across the Mid-Atlantic Ridge. The transect spans from $28 \mathrm{Ma}$ on the African Plate to $74 \mathrm{Ma}$ on the North American plate. These observables are useful because you can date the crust using magnetic anomalies and calculate crustal thickness with bathymetry and gravity data. Crustal thicknesses vary from 3-9 km, a significant range, suggesting significant tectonic and magmatic fluctuations in the formation of oceanic crust over the last $74 \mathrm{Myr}$. With timeseries of these geophysical observables, I apply a technique called spectral analysis, which identifies strongest frequencies within the datasets. Bathymetry and gravity show diffuse power at >1 Myr and multiple concurrent peaks at shorter periods. I discuss possible explanations including large-scale mantle thermal and compositional heterogeneities, variations in upper mantle flow, and detachment faulting. The shorter period peaks could be explained faulting, the presence of magma solitons, and/or regularly spaced short-wavelength mantle compositional heterogeneities. All these variations are caused at the ridge during lithospheric formation. Fault spacing also varies over longer periods (>10 Myr), which I interpret to reflect long-lived changes in the fraction of tectonically- vs. magmatically- accommodated extensional strain. This is further supported by the discovery of an off-axis oceanic core complex (here named the Kafka Dome). Fault spacing negatively correlates with gravity-derived crustal thickness, supporting a link between magma input and fault style at mid-ocean ridges.

In addition to geophysical measurements, another way to understand the thermal state of the lithosphere is to look at the tectonically exhumed surface exposures of mid and lower crustal rocks. Closely investigating these rocks, geologists are able to decipher the pressure-temperature-time path of the rocks to better understand what may be occurring in the inaccessible lower crust today. Chapter 2 describes a petrographic, geochronological, and geochemical analysis of the Gore Mountain Garnet Amphibolite (GMGA) in the Adirondack Highlands, NY, USA. The GMGA hosts the world's largest garnets (up to $1 \mathrm{~m}$ diameter). Field relations, whole rock, and mineral major and trace element chemistry suggest that these rocks formed via a prograde hydration reaction of a 
metagabbro during an increase in pressure and temperature. Laser ablation-inductively coupled plasma mass spectrometry U-Pb geochronology applied to metamorphic zircon dates this reaction to $1053.9 \pm 5.4 \mathrm{Ma}(2 \sigma ; \mathrm{MSWD}=0.94)$, during the peak of Ottawan Orogeny (1090-1020 Ma) and in agreement with previous estimates. Our results on peak metamorphic P-T conditions based on thermobarometry, diffusion models, and thermodynamic modelling indicate that these rocks formed at ultra-high temperature (UHT, $>900^{\circ} \mathrm{C}$ ) conditions $\left(\mathrm{P}=9-10 \mathrm{kbar}, \mathrm{T}=950 \pm 40^{\circ} \mathrm{C}\right.$ ), significantly hotter than previously estimated. Diffusion models pinned by nearby cooling ages require the GMGA to initially cool quickly, followed by cooling roughly a quarter the rate. The twostage cooling history for the GMGA could reflect initial advection-dominated cooling followed by conduction-dominated cooling once flow ceases. The Ottawan Orogeny is often compared with the modern Himalayan Orogeny due to the duration and estimated thermal structure. These results suggest that the Adirondacks was hot enough to undergo topography-driven lower crustal flow similar to that hypothesized for modern Tibet.

This thesis highlights the varied state of the lithosphere using combination of geophysical observables with petrologic and field observations. To conclude (Chapter 6), I discuss future directions to advance the work that I have presented in this thesis, including further constraints on crustal compositions from seismic wave speed as well as analysis of global seismic models' variations in differences between fast and slow spreading ridges. 


\section{Chapter 1:}

\section{Inferring crustal viscosity from seismic velocity: Application to the lower crust of Southern California}

This chapter was originally published as: Shinevar, W. J., Behn, M. D., Hirth, G., \& Jagoutz, O. (2018). Inferring crustal viscosity from seismic velocity: Application to the lower crust of Southern California. Earth and Planetary Science Letters, 494, 83-91. doi.org/10.1016/j.epsl.2018.04.055 . Used with permission as granted in the original copyright agreement. 


\begin{abstract}
We investigate the role of composition on the viscosity of the lower crust through a joint inversion of seismic P-wave $\left(V_{p}\right)$ and $\mathrm{S}$-wave $\left(V_{S}\right)$ velocities. We determine the efficacy of using seismic velocity to constrain viscosity, extending previous research demonstrating robust relationships between seismic velocity and crustal composition, as well as crustal composition and viscosity. First, we calculate equilibrium mineral assemblages and seismic velocities for a global compilation of crustal rocks at relevant pressures and temperatures. Second, we use a rheological mixing model that incorporates single-phase flow laws for major crust-forming minerals to calculate aggregate viscosity from predicted mineral assemblages. We find a robust correlation between crustal viscosity and $V_{p}$ together with $V_{s}$ in the $\alpha$-quartz regime. Using seismic data, geodetic surface strain rates, and heat flow measurements from Southern California, our method predicts that lower crustal viscosity varies regionally by four orders of magnitude, and lower crustal stress varies by three orders of magnitude at $25 \mathrm{~km}$ depth. At least half of the total variability in stress can be attributed to composition, implying that regional lithology has a significant effect on lower crustal geodynamics. Finally, we use our method to predict the depth of the brittle-ductile transition and compare this to regional variations of the seismic-aseismic transition. The variations in the seismic-aseismic transition are not explained by the variations in our model rheology inferred from the geophysical observations. Thus, we conclude that fabric development, in conjunction with compositional variations (i.e., quartz and mica content), is required to explain the regional changes in the seismic-aseismic transition.
\end{abstract}




\section{Introduction}

The viscosity structure of the lower crust and upper mantle controls deformation processes such as post-seismic creep (e.g., Freed et al., 2007), lower crustal flow (e.g., Clark et al., 2005), post-glacial isostatic rebound (e.g., Jull and McKenzie, 1996), and orogenesis. Estimates of crustal and upper mantle viscosity are typically constrained by analyses of post-seismic relaxation, paleolake shoreline deflection, global flow and stress models, and laboratory derived flow laws for crust-forming rocks and minerals (e.g., Bürgmann and Dresen, 2008; Thatcher and Pollitz, 2008). In most previous studies based on laboratory data the rheology of the lower continental crust was approximated using a flow laws for a dominant mineral phase (e.g., quartz or feldspar). However, the lower crust is composed of multiple mineral phases with variable strength and abundances that are controlled by the bulk composition, pressure, and temperature conditions. Thus, to accurately calculate crustal viscosity, composition, pressure, and temperature must be constrained.

Seismic P-wave $\left(V_{p}\right)$ and S-wave $\left(V_{s}\right)$ velocities are frequently used as a proxy for crustal composition. Christensen and Mooney (1995) measured $V_{p}$ for a variety of igneous and metamorphic rocks and compared the measurements to average continental crustal seismic profiles. With knowledge of field geology, they created a petrological model of the continental crust. Rudnick and Fountain (1995) estimated average mid and lower crustal compositions by comparing the predicted $V_{p}$ of granulites to $V_{p}$ profiles constructed for typical tectonic environments. Christensen (1996) added $V_{s}$ to the analysis of crustal composition and showed that crustal $V_{p} N_{s}$ ratios are nominally independent of temperature, but sensitive to quartz abundance, with a strong linear correlation between $V_{p} / V_{s}$ and silica content (between 55 and $75 \mathrm{wt} \% \mathrm{SiO}_{2}$ ). More recently, Shillington et al. (2013) and Jagoutz and Behn (2013) combined thermodynamic modeling, $V_{p} V_{s}$, and $V_{p}$ to constrain the composition of arc lower crust, showing that the additional information provided by $V_{p} N_{s}$ gives a much tighter constraint on composition than is obtained by $V_{s}$ alone. Other studies have linked seismic data to the mechanical properties of the crust. For example, Lowry and Pérez-Gussinyé (2011) found a relationship between $V_{p} N_{s}$ and effective elastic thickness in the western United States, pointing toward a relationship between seismic velocity and viscosity. 
Here, we investigate the relationship between aggregate viscosity and seismic velocities by calculating a fit between viscosity (estimated using multi-phase rheological mixing theory) and seismic $\mathrm{P}$-wave and S-wave velocity for a wide range of crustal compositions at typical crustal pressures and temperatures. Our analyses show that while neither $V_{p}$ nor $V_{s}$ alone robustly predict aggregate viscosity, together $V_{p}$ and $V_{s}$ predict aggregate viscosity within a factor of 2 at most crustal conditions. We apply our method to calculate the viscosity of the lower crust in Southern California, taking advantage of data from a densely instrumented region. We discuss the benefits and limitations of our methodology in the context of constraining compositional controls on upper and lower crustal viscosity - and compare the predicted depth to the brittle-ductile transition with observed seismic-aseismic transitions.

\section{Methods}

To estimate aggregate crustal viscosity from $V_{p}$ and $V_{s}$ data, we use the following 4-step approach: 1) create a rock database that spans crustal composition space; 2) calculate equilibrium mineral assemblages and seismic velocities for each composition in the rock database over a range of relevant pressure $(P)$ and temperature $(T) ; 3)$ calculate the aggregate viscosity for each composition at all $P$ - $T$ conditions; and 4) compile our estimates of $V_{p}, V_{s}$, and aggregate viscosity over crustal $P-T$ space to derive a generic relationship between viscosity and $P, T, V_{p}, V_{s}$, and stress or strain rate. Finally, because viscosity is strongly sensitive to temperature, one must incorporate additional constraints when applying our methodology to specific geologic settings. Below, we describe each of these steps as well as our methodology for constraining crustal temperatures in Southern California.

\subsection{Compositional Database for Crustal Rocks}

To create a compositional database for crustal rocks, we take all available whole rock compositions for the continental US and Alaska from Earthchem (www.earthchem.org). We filter out carbonates (> $2 \mathrm{wt} \% \mathrm{CO}_{2}$ ) and samples with oxide analyses that sum to less than $95 \mathrm{wt} \%$ or more than $102 \mathrm{wt} \%$. To this dataset, we add arc rocks from the compilation of Kelemen and Behn (2016), which includes Archean and

post-Archean massif data from Hacker et al. (2015), crustal xenolith and amphibolite data from Huang et al. (2013), and lavas and plutonic rocks from the Aleutians, Izu-Bonin- 
Marianas, Kohistan (Jagoutz and Schmidt, 2012), and Talkeetna (Kelemen et al., 2014) arcs. The final crustal database includes 96,388 samples. To facilitate the thermodynamic calculations presented below, we sub-sampled this database by first sorting the compositions by wt $\% \mathrm{SiO}_{2}$ and then taking every 28 th sample, creating a representative database of 3442 samples. Sub-sampling does not alter the frequency distribution for any of the major oxides (Supplemental Figure 1); a principal component analysis of the total and sub-sampled data sets produces similar sub-spaces (Supplemental Tables 1 and 2). Thus, the relationships derived from the sub-sampled data accurately reflect those present in the total composition space.

\subsection{Calculation of Equilibrium Mineral Assemblages and Seismic Velocity}

To calculate the equilibrium mineral assemblage for each composition, we use the Gibbs free energy minimization routine Perple_X (Connolly, 2009). We calculate mineral assemblages over crustal temperatures $\left(300-1000^{\circ} \mathrm{C}\right)$ and pressures $(0.1-1.2 \mathrm{GPa})$. We assume a minimum equilibrium temperature of $500^{\circ} \mathrm{C}$, a reasonable lower bound for net transfer reactions under hydrous crustal conditions (Austrheim, 1998). The lower continental crust typically contains $0-1 \mathrm{wt} \% \mathrm{H}_{2} \mathrm{O}$ (Huang et al., 2013). In this study, we only consider anhydrous mineral assemblages and incorporate the influence of $\mathrm{H}_{2} \mathrm{O}$ through its effect on the viscosity of nominally anhydrous mineral phases (see below). The role of hydrous phases (e.g., amphibole and mica) is ignored in our calculations due to the complexities of quantitatively incorporating their effects on rheology (Shinevar et al., 2015); however, we discuss their potential role on crustal viscosity in the Section 4.

For all Perple_X calculations, we assume that $25 \mathrm{~mol} \%$ of the total iron oxide is ferric (Cottrell and Kelley, 2011; Kelley and Cottrell, 2012); variations in this value have little influence on aggregate viscosity and seismic wave speeds. Solution models for crustal minerals are taken from Hacker (2008). Seismic velocities are calculated using a compilation of mineral properties (Abers and Hacker, 2016) implemented into Perple_X with the $\alpha-\beta$ quartz implementation used by Jagoutz and Behn (2013)

\subsection{Calculation of Aggregate Viscosity}

To calculate crustal viscosity at a given condition, we employ mixing theory to determine the aggregate viscosity for each equilibrium mineral assemblage. We only consider deformation via wet dislocation creep. This assumes that diffusion creep is not 
an important mechanism controlling the rheology of the lower crust (see Section 4 for further discussion). Theoretical and experimental investigations show a power law relation between stress $(\sigma)$ and strain rate $(\dot{\epsilon})$ with the form:

$$
\dot{\epsilon}=A f_{H_{2} O}{ }^{r} \sigma^{n} \exp \left(\frac{-(E+P V)}{R T}\right) \text {, }
$$

where $A$ is the pre-exponential factor, $f_{\mathrm{H}_{2} \mathrm{O}}$ is water fugacity, $r$ is the fugacity exponent, $n$ is the stress exponent, $E$ is the activation energy, $V$ is the activation volume, and $R$ is the gas constant. To estimate water fugacity, we use an exponential fit to water fugacity values along crustal geotherms (Shinevar et al., 2015):

$$
f_{\mathrm{H}_{2} \mathrm{O}}=a_{\mathrm{H}_{2} \mathrm{O}} B_{1} \exp \left(-\frac{B_{2}+P B_{3}}{R T}\right)
$$

where $a_{\mathrm{H}_{2} \mathrm{O}}$ is the water activity and $B_{1}, B_{2}$, and $B_{3}$ are empirically fit constants. We explore fugacity values using water activities between 0.01 and 1. Aggregate viscosities are calculated for strain rates ranging from $10^{-12}$ to $10^{-16} \mathrm{~s}^{-1}$ and shear stresses ranging from 1 to $100 \mathrm{MPa}$.

The effective viscosity of major crust-forming minerals varies by almost 3.5 orders of magnitude at $650^{\circ} \mathrm{C}$ - between the strongest minerals (olivine and pyroxene) and the weakest anhydrous mineral (quartz) (Figure 1). Here we consider five major crust-forming minerals: quartz, feldspar (plagioclase + alkali feldspar), pyroxene (orthopyroxene + clinopyroxene), garnet, and olivine. Wet dislocation creep flow laws for quartz, feldspar, pyroxene, and olivine are taken from Hirth et al. (2001), Rybacki et al. (2006), Dimanov and Dresen (2005), and Hirth and Kohlstedt (2003), respectively. The pyroxene flow law was modified by introducing a linear water fugacity term, in which the published pre-exponential coefficient is recalculated accordingly $(A=$ $A_{\text {experimental }} / \mathrm{f}_{\mathrm{H} 2 \mathrm{O}}$ for the experimental fugacity). The pre-exponential coefficients are corrected to express the relationship between the second invariants of stress and strain rate rather than uniaxial or simple shear. All garnet flow laws (e.g., Karato et al., 1995; $\mathrm{Xu}$ et al., 2013) found in the literature predict effective viscosities lower than plagioclase at lower crustal conditions (see Supplementary Figure S2 of Shinevar et al. (2015)), but abundant field evidence suggests that garnet is stronger than plagioclase at crustal conditions (e.g., Ji and Martignole, 1994). Thus, we assume that garnet has the same 
viscosity as pyroxene, which is $1-2$ orders of magnitude greater than plagioclase at crustal conditions.

For many bulk compositions, phase equilibrium calculations predict additional mineral phases; we only calculate viscosity for samples comprised of $>90$ vol \% quartz, feldspar, pyroxene, garnet and olivine. This condition is met for $>95 \%$ of the compositions in our representative database at every $P-T$ condition; only these samples are included in our inversion described below. We assume that remaining secondary phases (<10 vol\%) have a negligible effect on the bulk viscosity (see Section 4 for further discussion on the role of hydrous phases).

We use the mixing model of Huet et al. (2014) to estimate aggregate viscosity from the calculated mineral modes. This mixing model is based on the minimization of power dissipation during deformation. Huet et al. (2014) define the effective aggregate viscosity as:

$$
\eta_{\text {aggregate }}=\sum_{i} \frac{\phi_{i} n_{i}}{n_{i}+1} \prod_{i}\left(\eta_{i} \frac{n_{i}+1}{n_{i}}\right)^{\frac{\phi_{i} \alpha_{i} n_{i}}{\sum_{i} \phi_{j} \alpha_{j} n_{j}}}
$$

where $\phi_{i}$ and $n_{i}$ are the volume percentage and stress exponent of phase $i$, respectively, and the parameter $\alpha$ is defined for each phase as $\alpha_{i}=\prod_{i \neq j}\left(n_{j}+1\right)$. This method assumes that the rock is homogeneous and isotropic. As noted above we use single-phase flow law parameters for wet dislocation creep for all phases. Figure 1a shows the strong dependence of aggregate viscosity on composition (as reflected by silica content) using Eq. (3).

\subsection{Local Inversion of Viscosity from Seismic Velocity}

We invert for a relationship between viscosity and $V_{p}$ and $V_{s}$ using all compositions at each individual $P, T$, strain rate, and water activity. The goal of this exercise is to deduce where in crustal parameter space a robust relationship exists between viscosity and seismic velocity. For instance, Figure 1 shows relationships between $\mathrm{SiO}_{2}, V_{p}, V_{s}$, and aggregate viscosity at hot lower crustal condition (0.6 GPa, $650^{\circ} \mathrm{C}, 10^{-15} \mathrm{~s}^{-1}, a_{\mathrm{H}_{2} \mathrm{O}}=1$ ). $V_{S}$ (which can be constrained regionally from ambient noise tomography and surface wave studies) provides a poor fit to aggregate viscosity (Figure 1b). By contrast, $V_{p}$ (which is typically obtained from body waves, active source studies, or assumptions regarding Poisson's ratio) constrains aggregate viscosity to one order of 
magnitude (Figure 1c). Combining $V_{p}$ and $V_{s}$ improves this fit to less than half an order of magnitude (Figure 1d).

The relationship between aggregate viscosity and seismic velocity is based on the functional form of the flow laws. By definition, viscosity $(\eta)$ is defined as the ratio of stress to strain rate. Using Eq. (1), we formulate viscosity as a function of strain rate $\left(\eta_{\dot{\epsilon}}\right)$ or stress $\left(\eta_{\sigma}\right)$ :

$$
\begin{aligned}
& \eta_{\dot{\epsilon}}=\dot{\epsilon}^{\frac{1}{n}-1} f_{H_{2} O} O^{-\frac{r}{n}} A^{\frac{-1}{n}} \exp \left(\frac{(E+P V)}{n R T}\right) \\
& \eta_{\sigma}=\sigma^{1-n} f_{H_{2} O} O^{-r} A^{-1} \exp \left(\frac{(E+P V)}{R T}\right) .
\end{aligned}
$$

Taking the logarithm of Eqs. (4a) \& (4b) gives:

$$
\begin{aligned}
& \log \left(\eta_{\dot{\epsilon}}\right)=\left(\frac{1}{n}-1\right) \log (\dot{\epsilon})-\frac{r}{n} \log \left(f_{H_{2} O}\right)-\frac{1}{n} \log (A)+\frac{E+P V}{n R T} \\
& \log \left(\eta_{\sigma}\right)=(1-\mathrm{n}) \log (\sigma)-r \log \left(f_{H_{2} O}\right)-\log (A)+\frac{E+P V}{R T} .
\end{aligned}
$$

Because the stress exponent $n$ and fugacity exponent $r$ are similar between flow laws at a given set of $P-T-\dot{\epsilon}-f_{\mathrm{H}_{2} \mathrm{O}}$ or $P-T-\sigma-f_{\mathrm{H}_{2} \mathrm{O}}$ conditions, we assume the first two terms are constant. The latter two terms (which include the pre-exponential factor, activation energy, and activation volume) are approximated as linear combinations of $V_{p}$ and $V_{s}$. With these assumptions, the relationship between viscosity and $V_{p}$ and $V_{s}$ becomes:

$$
\log (\eta)=a+b V_{p}+c V_{s}
$$

where $a, b$, and $c$ are constants. Using the calculated aggregate viscosities and seismic velocities for each composition, we calculate a least squares fit to determine the values of $a, b$, and $c$ at each $P-T-\dot{\epsilon}-f_{\mathrm{H}_{2} \mathrm{O}}$ or $P-T-\sigma-f_{\mathrm{H}_{2} \mathrm{O}}$ condition. We refer to these fits as "local inversions" because the parameters are only fit at a single condition.

Figures $2 \mathrm{a}$ and $\mathrm{b}$ show the $\mathrm{R}^{2}$ values for the local strain rate and stress inversions over a range of $P-T$ conditions. Fits for the parameters in Eq. (6) provide a good estimate of viscosity for both constant strain rate and stress $\left(\mathrm{R}^{2}>0.8\right)$ in the $\alpha$-quartz regime, but a poor fit in the $\beta$-quartz regime. The $\alpha-\beta$ quartz transition occurs around $750^{\circ} \mathrm{C}$ at $25 \mathrm{~km}$ depth (Fig. 2). The inversion fits well and produces residuals that form a Gaussian distribution around $0 \log _{10}(\mathrm{~Pa} \cdot \mathrm{s})$ in the $\alpha$-quartz regime because quartz, feldspar, and the mafic minerals (olivine, pyroxene, and garnet) form three distinct regions in velocity- 
viscosity space (Figure 1). In the $\beta$-quartz regime, the inversion fails due to the sharp increase in the bulk modulus of quartz-bearing rocks, resulting in a $V_{p}$ comparable to mafic compositions (Supplemental Figure 2). Because $\alpha$ - and $\beta$-quartz have similar effective viscosities, the mapping from velocity to viscosity becomes multivalued in the $\beta$-quartz field, producing poor fits (Figure 2).

To create a generic inversion for viscosity that is valid across crustal conditions, we parameterize the constants $a, b$, and $c$ in Eq. (6) as a function $P-T-\dot{\epsilon}-f_{\mathrm{H}_{2}} \mathrm{O}$ or $P-T-\sigma$ $f_{\mathrm{H}_{2} \mathrm{O}}$. The $\log$ strain rate and $\log$ stress dependence of $\log$ viscosity is linear (Eq. 5a and 5b). Inputting fugacity from Eq. (2) into Eq. (5) and using logarithm identities, it can be shown that the water activity dependence of the log viscosity is also linear. Based on the general expectation that rheological properties scale with the elastic properties (Karato, 2012), we parameterize $\log (A), E$, and $V$ as linear combinations of $V_{p}$ and $V_{s}$ (similar to Eq. 6). This results in the following equations for constant strain rate and stress:

$$
\begin{gathered}
\log _{10}\left(\eta_{\dot{\epsilon}}\right)=a_{1}+a_{2} \log _{10} \dot{\epsilon}+a_{3} \log _{10} a_{H_{2} O}+\frac{1000 a_{4}}{T}+\frac{1000 a_{5} P}{T}+ \\
b_{1} V_{p}+\frac{1000 b_{2} V_{p}}{T}+\frac{1000 b_{3} P V_{p}}{T}+c_{1} V_{s}+\frac{1000 c_{2} V_{s}}{T}+\frac{1000 c_{3} P V_{s}}{T} \\
\log _{10}\left(\eta_{\sigma}\right)=a_{1}+a_{2} \log _{10} \sigma+a_{3} \log _{10} a_{H_{2} O}+\frac{1000 a_{4}}{T}+\frac{1000 a_{5} P}{T}+ \\
b_{1} V_{p}+\frac{1000 b_{2} V_{p}}{T}+\frac{1000 b_{3} P V_{p}}{T}+c_{1} V_{s}+\frac{1000 c_{2} V_{s}}{T}+\frac{1000 c_{3} P V_{s}}{T}
\end{gathered}
$$

with $\eta$ in $\mathrm{Pa} \cdot \mathrm{s}, T$ in $\mathrm{K}, P$ in $\mathrm{Pa}, V_{p}$ and $V_{s}$ in $\mathrm{km} \mathrm{s}^{-1}, \sigma$ in $\mathrm{Pa}$, and $\dot{\epsilon}$ in s${ }^{-1}$. Using all of the calculated velocity and viscosity data in the $\alpha$-quartz field, we invert for the parameters in Equations (7a) \& (7b) (Table 1). Equation (7a) fits the data with a RMSE of 0.18 $\log _{10}(\mathrm{~Pa} \cdot \mathrm{s})$ and a $\mathrm{R}^{2}$ of 0.96; Equation (7b) fits the data with an RMSE of $0.86 \log _{10}(\mathrm{~Pa} \cdot \mathrm{s})$ and a $\mathrm{R}^{2}$ of 0.94 . The error is larger for the constant stress fit because the viscosities at constant stress vary more than for constant strain rate. These fits produce Gaussian residuals (Supplemental Figures $3 \& 4$ ).

The error in the generic aggregate viscosity-velocity inversion is approximately the same as the average error calculated over the $\alpha$-quartz regime from the local inversions at each $P$ - $T$ condition (compare Figures $2 \mathrm{c} \& 2 \mathrm{~d}$ to Figures $2 \mathrm{a} \&$ $2 b)$. Moreover, the resulting generic inversion for aggregate viscosity agrees with intuition; aggregate viscosity decreases with increasing temperature, strain rate and water 
activity, but increases with increasing pressure. Further, aggregate viscosity increases with increasing $V_{p}$, and for most conditions, decreases with increasing $V_{s}$. Aggregate viscosity also scales positively with $V_{p} / V_{s}$ at a given set of $P$ - $T$ conditions; however, the best fits are found by including independent estimates of $V_{p}$ and $V_{s}$.

We have investigated the sensitivity of our approach at conditions appropriate for the lower crust. For a $V_{p}$ of $7.0 \mathrm{~km} \mathrm{~s}^{-1}$ and a $V_{s}$ of $4.0 \mathrm{~km} \mathrm{~s}^{-1}$ at $0.8 \mathrm{GPa}$, a change in temperature from $650^{\circ} \mathrm{C}$ to $750^{\circ} \mathrm{C}$ decreases the aggregate viscosity by a factor of 3.9 . For comparison, a change in $V_{p}$ or $V_{s}$ by $0.2 \mathrm{~km} \mathrm{~s}^{-1}$ at the same P-T conditions promotes a change in viscosity by a factor of 1.5 or 1.4 , respectively. A factor of 10 increase in strain-rate produces a factor of 5 decrease in strain rate. A factor of 10 decrease in water activity results in a factor of 1.9 increase in viscosity.

\subsection{California Input Data and Geotherm Calculations}

To use Eq. (7a) to investigate the viscosity structure of Southern California, we need seismic velocity data as well as the $P-T-\dot{\epsilon}-a_{\mathrm{H}_{2} \mathrm{O}}$ conditions in the crust. Our inversion method requires independently calculated $\mathrm{P}$ and $\mathrm{S}$-wave velocities. Assuming a constant $V_{p} / V_{s}$ ratio negates the compositional effects that our method aims to quantify as shown in Figure 1. For seismic data, we use the Community Velocity Model-S4.26 (Lee et al., 2014), which provides independent constraints on $V_{p}$ and $V_{s}$ (Figure $3 \mathrm{a}$ and b). In some regions the velocities predicted by the Community Velocity Model (CVM), are not consistent with the velocities calculated from any of the compositions in our database. We do not plot viscosities in our figures when the CVM velocity is more than $0.1 \mathrm{~km} \mathrm{~s}^{-1}$ different than the $V_{p}$ and $V_{s}$ calculated for all of the samples in our database at the inferred $P-T$ conditions. Many of the areas with the largest error are mountainous (Sierra Nevadas and Transverse Ranges), suggesting errors due to topographic effects not accounted for in the CVM (Lee et al., 2014). Velocity errors are shown for $25 \mathrm{~km}$ depth in Supplemental Figure 5 and along a cross section across the Mojave in Supplemental Figure 6.

To account for the wide variation in deformation rates across Southern California, we approximate strain rate in the lower crust with the second invariant of surface strain rate from (Kraner et al., 2018)(Figure 3c). We acknowledge the uncertainties in applying surface strain rates to the viscously deforming lower crust (e.g. 
interseismic elastic strain buildup at the surface and strain localization in the viscous regime), however it is a good starting point for accounting for regional variations in strain rate. To estimate pressure at depth, we use an average continental crustal density of 2800 $\mathrm{kg} \mathrm{m}^{-3}$. We use a water activity of 1 . To estimate temperature within the crust, we rely on heat flow measurements from Williams and Deangelo (2011) and the SMU Geothermal Database (http://geothermal.smu.edu/gtda/). We first use a natural neighbor scheme to interpolate the heat flow data to the same grid as the seismic velocity model. We then calculate temperature as a function of depth at each grid point assuming a steady-state 1$\mathrm{D}$ geotherm following the assumption that the heat production in the upper crust accounts for $40 \%$ of the measured surface heat flow (Pollack and Chapman, 1977). We assume a constant heat production in the upper crust ( $<15 \mathrm{~km}$ depth). Varying the distribution of heat flow in the upper crust does not have a large impact on our estimate of lower crustal temperatures. We assume a constant lower crust heat production of $0.5 \mu \mathrm{W} \mathrm{m}^{-3}$ based on average values for exposed lower crustal rocks in the Sierra Nevadas (Brady et al., 2006). Thermal conductivity is taken to be a function of temperature (Durham et al., 1987):

$$
k(\mathrm{~T})=2.264-\frac{618.2}{T}+3.0\left(\frac{355.6}{T}-0.3205\right)
$$

where $k$ is thermal conductivity in $\mathrm{W} \mathrm{m}^{-1} \mathrm{~K}^{-1}$ and $T$ is temperature in $\mathrm{K}$. At $20^{\circ} \mathrm{C}$, the thermal conductivity is $3.0 \mathrm{~W} \mathrm{~m}^{-1} \mathrm{~K}^{-1}$. To remove unrealistic horizontal temperature gradients, we diffuse the temperature field horizontally for five million years assuming

constant boundary temperature and a thermal diffusivity of $10^{-6} \mathrm{~m}^{2} \mathrm{~s}^{-1}$. Figure $3 \mathrm{~d}$ shows the resulting temperature field at $25 \mathrm{~km}$ depth, which predict geothermal gradients ranging from $15-35^{\circ} \mathrm{C} \mathrm{km}^{-1}$. Sources of error in our geotherm calculation include: (1) error in the heat flow measurements; (2) regions where the geotherm is not in steady state (e.g., due to rifting in the Salton Trough, active delamination in the southern Sierra Nevadas (Zandt et al., 2004), or fluid transport); and (3) regions where heat production does not follow our scaling assumption.

\section{Application to Southern California}

The prolonged tectonic evolution of the plate boundary between the Pacific/Farallon and North American plates has produced a heterogeneous lower crust throughout Southern California. This compositional variability, combined with the 
availability of high-resolution seismic and heat flow data, make Southern California an excellent testing ground for our methodology. In addition, there is a wide array of geologic, geochemical, and geophysical data available on the California lower crust with which to compare the predicted viscosity structure.

Using Eq. (7a) with our predicted temperatures, surface strain rates, and velocities from the CVM, we calculate aggregate viscosities ranging from $10^{21}-10^{25} \mathrm{~Pa} \cdot \mathrm{s}$ at $25 \mathrm{~km}$ depth (Figure 4a). To highlight compositional variations, we plot $\log _{10} \frac{\eta_{\text {aggregate }}}{\eta_{\text {plagioclase }}}$ where $\eta_{\text {plagioclase }}$ is the viscosity calculated by the wet plagioclase flow law at the same conditions (Figure 4b). Because quartz is the only phase we consider that is weaker than plagioclase, $\log _{10} \frac{\eta_{\text {aggregate }}}{\eta_{\text {plagioclase }}}<0$ (yellow) indicate a rheologically significant fraction of quartz; $\log _{10} \frac{\eta_{\text {aggregate }}}{\eta_{\text {plagioclase }}}>0$ (blue) indicate a rheologically significant fraction of mafic minerals. Our method suggests that the Sierra Nevada and the Salton Trough are comprised of more felsic and more mafic lithologies, respectively. These results agree with the inferred presence of a 30-35 km thick granitic batholith beneath the Sierra Nevada (Ducea and Saleeby, 1998)and evidence for large mafic additions to the lower crust of the Salton Trough (Lachenbruch et al., 1985).

Further, using the input surface strain rate (Kraner et al., 2018) and the aggregate viscosity, we calculate the viscous stress field at $25 \mathrm{~km}$ depth. The viscous stress varies between $0.7 \mathrm{MPa}$ and $7 \mathrm{GPa}$ (Figure 4c). To illustrate regions predicted to be in the brittle regime at $25 \mathrm{~km}$ depth, we compare the viscous stress to the frictional stress calculated assuming strike-slip conditions with a hydrostatic pore-fluid pressure (Zoback and Townend, 2001, Eq. 7b) and a friction coefficient of 0.6. The high viscous stresses in the two coldest regions (the Transverse Ranges and the Western Sierra Nevadas) clearly exceed the brittle strength (contoured by red lines in Figure 4c), in agreement with the presence of earthquakes below $25 \mathrm{~km}$ in the Transverse Ranges. The viscous stress is relatively continuous with the largest gradients coinciding with the largest temperature gradients. Plotting stress from Figure $4 \mathrm{c}$ against temperature from Figure $3 \mathrm{~d}$, indicates a one and a half order of magnitude variation in stress at a given temperature due to compositional and strain rate effects (Figure 4d). 
A cross section of the predicted viscosities across the northern Mojave (Figure 5) indicates both vertical and horizontal variations in composition in Southern California (as depicted by the change in $\left.\log _{10} \frac{\eta_{\text {aggregate }}}{\eta_{\text {plagioclase }}}\right)$. The crust becomes more mafic towards the east in the Mojave (i.e., $\log _{10} \frac{\eta_{\text {aggregate }}}{\eta_{\text {plagioclase }}}$ increases) and is most felsic (i.e., lowest $\left.\log _{10} \frac{\eta_{\text {aggregate }}}{\eta_{\text {plagioclase }}}\right)$ under the Sierra Nevadas and Coast Ranges. In general, the upper crust has an aggregate viscosity less than plagioclase; $\log _{10} \frac{\eta_{\text {aggregate }}}{\eta_{\text {plagioclase }}}$ increases with depth in accord with the abundance of mafic lower crustal xenoliths from the Cima volcanic field (Hanchar et al., 1994). The crustal aggregate viscosities also agree well with independent analyses of post-seismic creep $\left(\eta>10^{21} \mathrm{~Pa} \cdot \mathrm{s}\right)$ in the Mojave Desert (Freed and Bürgmann, 2004; Freed et al., 2007).

To isolate the role of composition, we normalize the aggregate viscosity at a depth of $25 \mathrm{~km}$ (Figure 4a) to two constant strain rates and compare it to single-phase flow laws for major crust forming minerals (Figure 6). The normalized aggregate viscosities at 25 $\mathrm{km}$ depth vary by almost four orders of magnitude over a temperature range of approximately $400^{\circ} \mathrm{C}$ (Figure 6). Overall, plagioclase provides the best approximation to the aggregate viscosities. However, at any given temperature, the variation due to composition ranges up to one and a half orders of magnitude. Thus, although the plagioclase flow law captures the general variability of viscosity with temperature, the role of composition should be considered in geodynamic models of compositionally heterogeneous regions like Southern California.

Finally, the temperature dependence of the aggregate viscosities is slightly less than plagioclase - implying that the bulk behavior of the crust can be characterized by a lower activation enthalpy over stress exponent ratio $(E / n)$. Fitting an Arrhenius relation to the aggregate viscosities at $25 \mathrm{~km}$ depth using a stress exponent of 3.5 (derived from Eq. 7a), the aggregate flow law $\left(\mathrm{R}^{2}\right.$ of 0.91 and $\mathrm{RMSE}$ of $\left.0.25 \log _{10}(\mathrm{~Pa} \cdot \mathrm{s})\right)$ for Southern California is

$$
\dot{\epsilon}=A f_{H_{2} O}{ }^{1} \sigma^{3.5} \exp \left(\frac{-E}{R T}\right) \text {. }
$$


where $\mathrm{E}=340 \pm 20 \mathrm{~kJ} \mathrm{~mol}^{-1}$ and $\log _{10}(\mathrm{~A})=-23.9 \pm 0.2 \log _{10}\left(\mathrm{~Pa}^{-3.5} \mathrm{~s}^{-1}\right)($ black line in Figure 6). This aggregate flow law has an $E / n$ ratio of $96 \mathrm{~kJ} \mathrm{~mol}^{-1}$; the plagioclase flow law has $E / n=115 \mathrm{~kJ} \mathrm{~mol}^{-1}$ (Dimanov and Dresen, 2005).

\section{Discussion}

In this section, we discuss the implications and limitations of our methodology. First, we discuss weakening mechanisms that are not included and their potential effects on crustal viscosity in Southern California. Second, we compare the depth of the brittle-ductile transition predicted by our method to the seismic-aseismic transition and discuss implications for the compositional effects on crustal strength profiles.

\subsection{Weakening Mechanisms}

Our methodology calculates aggregate viscosity assuming isotropic material properties. In addition, we do not consider the effects of hydrous phases, melt, grain size reduction/diffusion creep, and/or strain localization and fabric formation in shear zones. Below we describe the effects of each of these weakening mechanisms on our predicted viscosity.

The presence of water in the lower crust stabilizes hydrous minerals such as amphibole and mica. While the flow laws for these minerals are poorly constrained, some information on their strength is available. Amphibole is relatively strong, with a viscosity comparable to that of pyroxene (Hacker and Christie, 1990). Thus, the addition of amphibole is unlikely to dramatically alter the viscosity of mafic rocks from our estimates. The effect of micas is more uncertain. Existing flow laws for biotite (e.g., Kronenberg et al., 1990) indicate that biotite is stronger than wet quartz at most lower crustal conditions $\left(\mathrm{T}>400^{\circ} \mathrm{C}\right)$. However, experiments on quartz-muscovite aggregates indicate a factor of 2 weakening with the addition of $\sim 15 \mathrm{vol} \%$ mica at $800^{\circ} \mathrm{C}$ (Tullis and Wenk, 1994; Tokle et al., 2013). Recalculating equilibrium modes for our total rock database with $0.5 \mathrm{wt} \% \mathrm{H}_{2} \mathrm{O}$, we calculate $0-15$ vol\% mica in felsic rocks $\left(\mathrm{SiO}_{2}>55 \mathrm{wt}\right.$ $\%)$ and $0-7$ vol \% mica in mafic rocks $\left(\mathrm{SiO}_{2}<55 \mathrm{wt} \%\right)$. These values imply that the addition of hydrous phases to our relationship between seismic velocities and viscosity would be most significant for felsic rocks. Thus, in regions of low $V_{p} / V_{s}$, where felsic 
rocks are predicted to dominate (e.g., Jagoutz and Behn, 2013; Shillington et al., 2013; Hacker et al., 2015), our methodology may systematically overpredict viscosity by up to a factor of two.

At high temperatures and pressures the breakdown of hydrous phases leads to partial melting of the lower crust for certain compositions. These effects are particularly important in compressional regions where the crust is thick (e.g., Tibet) and/or in regimes with high heat flow. Melt decreases viscosity and seismic velocity, especially $V_{s}$, though the exact form of the relationships for crustal rocks remain poorly constrained. For this reason, we have omitted the effect of melt in our predictions. Further, we note that for crustal pressures, melt is typically present only in the $\beta$-quartz regime, where we have already shown our inversion poorly constrains viscosity. Thus, if melt is present in regions such as the Salton Trough (Lachenbruch et al., 1985), additional considerations are required to estimate the regional viscosity and stress state. One method to estimate melt is to use magnetotelluric data (Rippe and Unsworth, 2010). Therefore, it may be possible to invert magnetotelluric and seismic data together to estimate possible rock type and melt fraction in order to bound viscosity.

Another assumption of our methodology is that deformation occurs by wet dislocation creep. For actively deforming regions like Southern California, wet dislocation creep flow laws agree best with viscosities inferred from post seismic creep (e.g., Freed and Bürgmann, 2004; Behr and Hirth, 2014). While diffusion creep is an important mechanism within shear zones, at many lower crustal conditions the equilibrium grain size is typically too large for diffusion creep to be a dominant mechanism (Bürgmann and Dresen, 2008). The impact of shear zones depends on the magnitude of weakening and the volume of the rock the shear zones comprise. For the case of shear zones in mafic rocks, microstructural analyses indicate shear zones decrease the aggregate viscosity by a factor of two to four (Mehl and Hirth, 2008).

Lastly, the Huet et al. (2014) model can only be applied on a scale over which the rock is considered isotropic. In reality, deformation is often localized in shear zones within the lower crust (e.g., Bürgmann and Dresen, 2008; Behr and Platt, 2012) resulting in foliated rocks. Where there is a shear zone fabric, the viscosity is best approximated by the weakest connected phase. The effect of fabric formation is largest at low temperature 
where the single-phase rheologies differ the most (Figure 6). Moreover, fabric formation likely affects felsic rocks more than mafic rocks, because felsic rocks weaken to a quartz rheology (e.g., Tullis, 2002), while mafic rocks weaken to a plagioclase rheology (e.g., Mehl and Hirth, 2008). The arrows in Figure 7c illustrate this effect.

\subsection{Seismic-Aseismic Transition and the Brittle-Ductile Transition}

Seismic-aseismic transition, the depth below which few earthquakes occur, is frequently interpreted as the brittle-ductile transition (e.g., Sibson, 1982). Others interpret seismic-aseismic transition as the depth where friction changes from velocity-weakening to velocity-strengthening (e.g., Scholz, 2002). Here we compare the seismic-aseismic transition in Southern California to the depth of the brittle-ductile transition. We define the locking depth as the depth above which $95 \%$ of earthquakes epicenters are located. We use only A and B quality earthquakes from the Southern California Earthquake Data Catalog (http://scedc.caltech.edu/eq-catalogs/) and calculate a locking depth where there are more than 30 magnitude $>3.0$ earthquakes in a $15 \mathrm{~km}$ radius.

The seismic-aseismic transition changes abruptly across the San Andreas Fault (Figure 7a), with the average locking depth deepening from $9 \pm 4 \mathrm{~km}$ to $15 \pm 3 \mathrm{~km}$ from east to west. To evaluate the role of temperature and composition on locking depth, we determine the temperature at the locking depth as inferred from the heat flow data. Histograms of temperature at the locking depth exhibit Gaussian distributions with distinct regional means east $\left(204^{\circ} \mathrm{C}\right)$ and west $\left(341^{\circ} \mathrm{C}\right)$ of the San Andreas (Figure $\left.7 \mathrm{~d}\right)$. We define the depth to the brittle-ductile transition (Figure $7 b$ ) as the depth where the stress predicted from the aggregate viscosity becomes less than the frictional stress. Frictional stress is calculated assuming a hydrostatic pore-fluid pressure for strike-slip conditions with a friction coefficient of 0.6 (Zoback and Townend, 2001, Eq. 7b).

The brittle-ductile transition is systematically deeper than the seismic-aseismic transition across Southern California. In addition, the brittle-ductile transition does not display an abrupt change across the San Andreas Fault. The difference between the seismic-aseismic transition and the brittle-ductile transition may arise due to fabric formation and/or the presence of hydrous phases. Further, the larger difference between the brittle-ductile transition and the locking depth east of the San Andreas could be linked to compositional variations, where foliated quartz-rich rocks promote more viscous 
weakening at lower temperatures (Figure 7c). In fact, the quartzite flow law predicts the eastern locking depths accurately for an average strain rate and geotherm near the San Andreas Fault (Figure 7d). It is more difficult to constrain what controls the locking depth west of the San Andreas Fault. The locking depth is clearly shallower than the brittle-ductile transition calculated with an aggregate viscosity for either a gabbro or granite, yet significantly deeper than quartz (Figure 7d). The relatively shallow locking depth could be caused by viscous weakening due to the presence of hydrous phases, a transition to a more lithostatic effective stress (c.f., Hirth and Beeler, 2015), and/or a transition to velocity-strengthening friction.

\section{Conclusions}

We investigate a new methodology to predict aggregate crustal viscosity given a strain rate, pressure, temperature, and independent estimates of $V_{p}$ and $V_{s}$. Our methodology is robust in the $\alpha$-quartz regime, but is not robust in the $\beta$-quartz regime. Because we do not incorporate hydrous phases, melt, diffusion creep, or strain localization, our aggregate viscosities represent an upper bound, but likely give accurate estimate in regions where strain localization is less important (e.g., higher temperatures).

Applying our methodology to Southern California, we find that viscosity varies by up to four orders of magnitude at $25 \mathrm{~km}$ depth, with at least a one and a half order of magnitude variation due to composition and the remainder due to variations of temperature and strain rate. The aggregate viscosity of the Southern Californian lower crust resembles the wet dislocation creep flow law for plagioclase but is stronger than plagioclase at high temperatures. To address this misfit, we also calculate a best-fit aggregate flow law for Southern California. However, we emphasize that the viscosities calculated using any single flow law would not accurately depict regional variation due to composition. Thus, while temperature is the dominant effect for many actively deforming regions like Southern California, compositional effects are significant and need to be accounted for in geodynamical models of crustal flow. Our method is general, and can easily be applied to other regions; such analyses will be most successful if high quality geophysical data are available to constrain temperature, seismic velocities, and strain rates. 
We find that the seismic-aseismic transition deepens abruptly from east to west across the San Andreas Fault. Locking depths east of San Andreas Fault are well fit by the brittle-ductile transition calculated using a quartzite flow law. This observation suggests the importance of fabric formation in shear zones in felsic lithologies immediately beneath the seismogenic zone, in which case the weakest phase (quartz) controls the effective viscosity. The deeper locking depths west of the San Andreas Fault likely reflect changes in composition that inhibit formation of fabrics with a quartzdominated rheology.

\section{Acknowledgements}

We would like to thank Wayne Thatcher and David Chapman for their helpful discussions on temperature calculations. We would also like to thank Michael Oskin for an insightful discussion on how to best validate and discuss our methodology. We thank Roland Bürgmann, John Platt, and Editor J.P. Avouac for helpful reviews that improved this manuscript. Funding was provided by NSF Grants EAR-16-24109 (MB), EAR-1722932 (MB), EAR-16-24178 (GH), EAR-17-22935 (OJ), and SCEC Awards 16106 and $17202(\mathrm{GH}, \mathrm{MB})$. 


\section{Figures}

a)

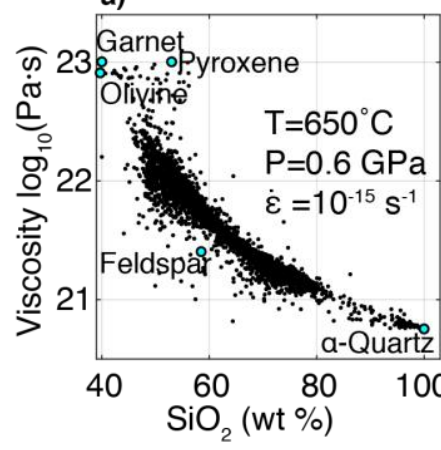

b)

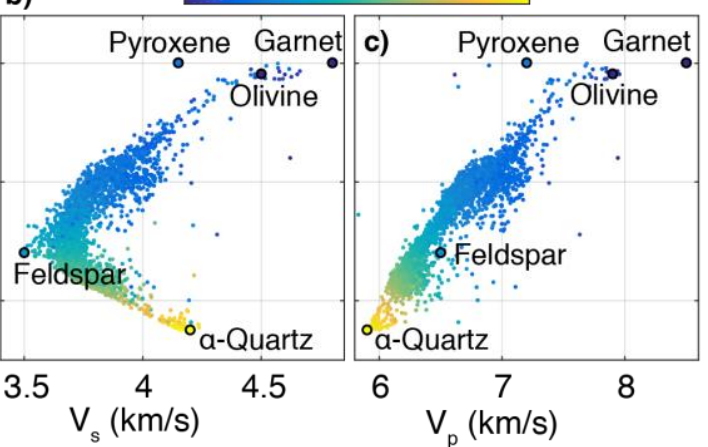

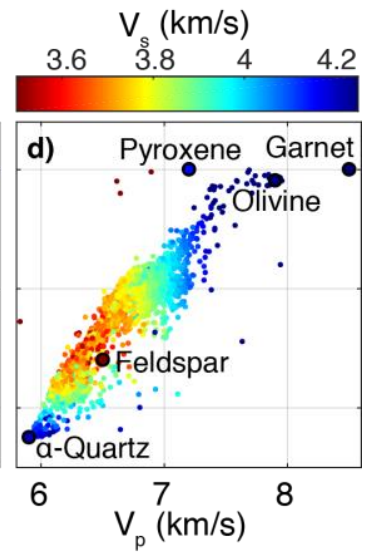

Figure 1.1: a) Calculated aggregate viscosity as a function of $\mathrm{SiO}_{2}$ for the total rock database at $\left.\mathrm{T}=650^{\circ} \mathrm{C}, \mathrm{P}=0.6 \mathrm{GPa}, \dot{\epsilon}=10^{-15} \mathrm{~s}^{-1}, a_{\mathrm{H}_{2} \mathrm{O}}=1.0 . \mathbf{b}+\mathbf{c}\right)$ Viscosity as a function of $V_{s}$ (left) and $V_{p}$ (right) colored by wt $\% \mathrm{SiO}_{2}$. d) Viscosity as a function of $V_{p}$ colored by $V_{s}$. See Section 2 for explanations of total rock database, velocity calculations, and viscosity calculations. 


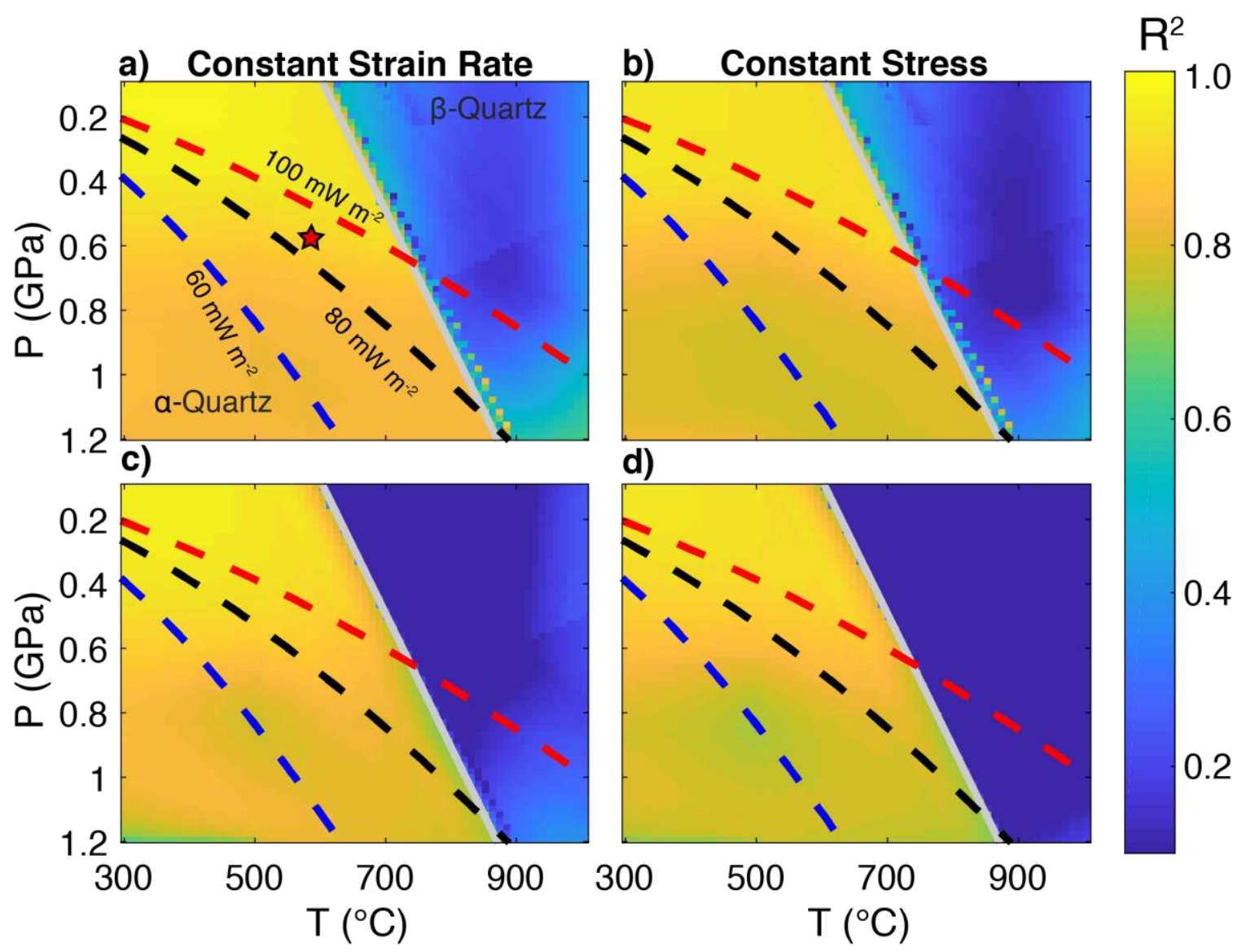

Figure 1.2: $\mathbf{a}$ and $\mathbf{b}$ ) Each point in these figures denotes $R^{2}$ (goodness of fit) for fits at a constant $P-T$ (Eq. 6) and either constant strain rate (left) or stress (right) $\left(\dot{\epsilon}=10^{-15} \mathrm{~s}^{-1}\right.$ or $\sigma=10 \mathrm{MPa}, a_{\mathrm{H}_{2} \mathrm{O}}=1.0$ ). Grey line denotes the $\alpha-\beta$ quartz transition. 60 (blue, $\sim 15^{\circ} \mathrm{C} / \mathrm{km}^{-1}$ ), 80 (black, $\sim 20^{\circ} \mathrm{C} / \mathrm{km}^{-1}$ ), and 100 (red, $\sim 26^{\circ} \mathrm{C} \mathrm{km}^{-1}$ ) $\mathrm{mW} \mathrm{m}^{-2}$ geotherms shown for reference. Red star denotes the conditions in Figure 1. c and d) Each point in these figures denotes the $\mathrm{R}^{2}$ for the generic fit at that P-T condition (Eq. $7 \mathrm{a}$ and $7 \mathrm{~b}$ respectively) using all the data from the $\alpha$ quartz regime. 
a)

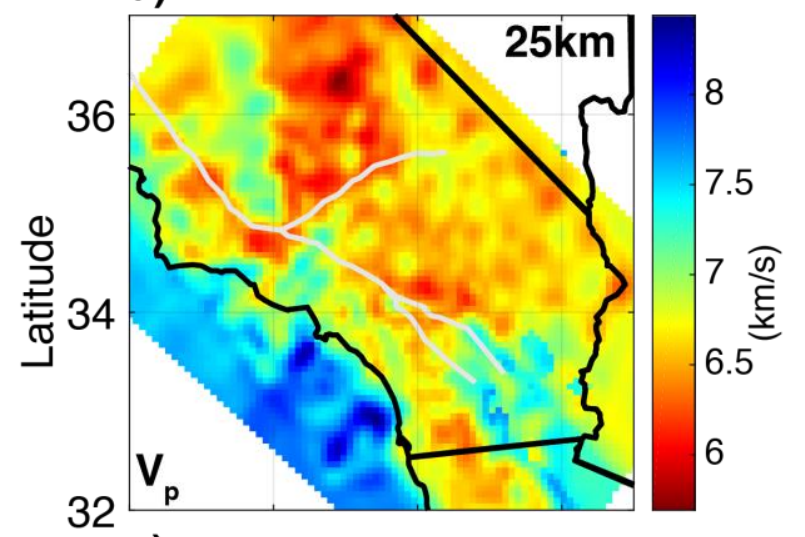

c)

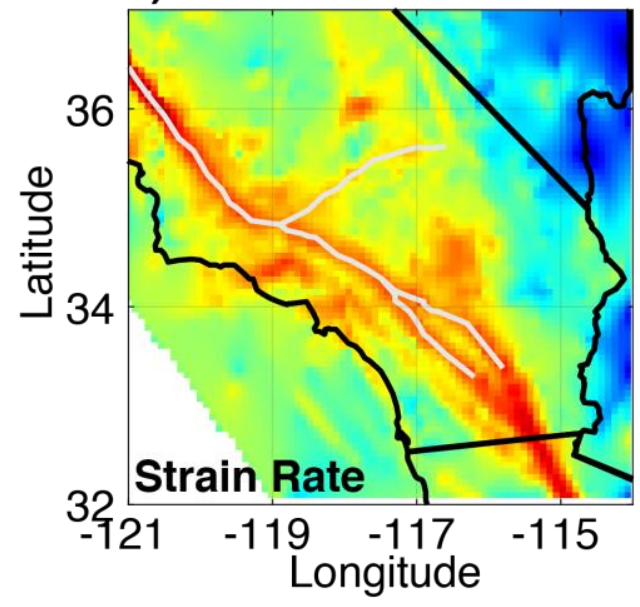

b)

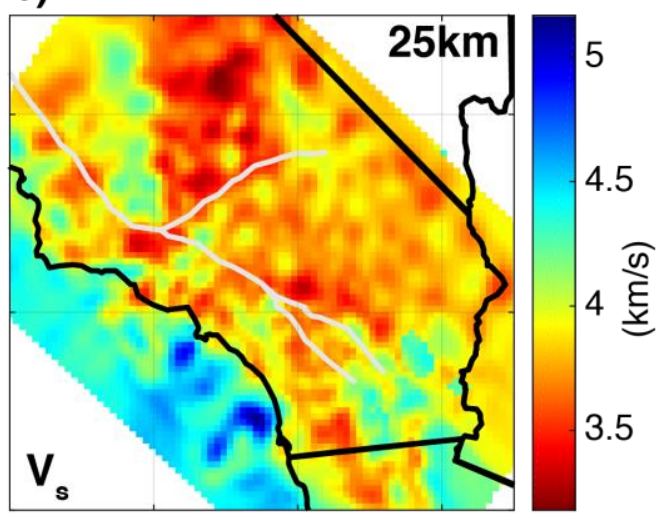

d)

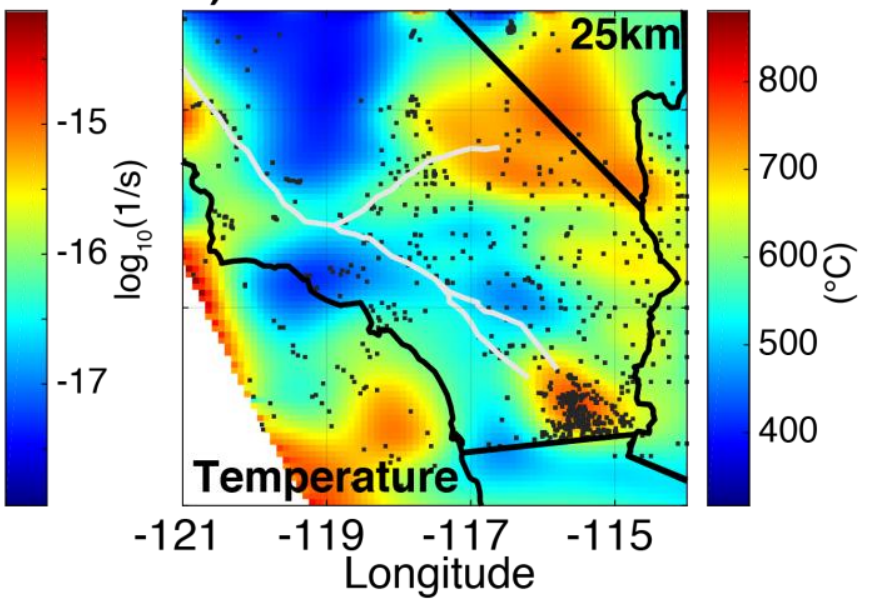

Figure 1.3: a+b) $V_{p}$ (left), $V_{s}$ (right) at $25 \mathrm{~km}$ depth from the Community Velocity Model-S4.26 (Lee et al., 2014). White regions indicate areas outside of model domain or with predicted mantle velocities. c) Second invariant of surface strain rate (Kraner et al., 2018). d) Modeled temperature of Southern California at $25 \mathrm{~km}$ depth (see Section 2 for discussion). Grey lines indicate the San Andreas, Garlock, and San Jacinto Faults. 
a)

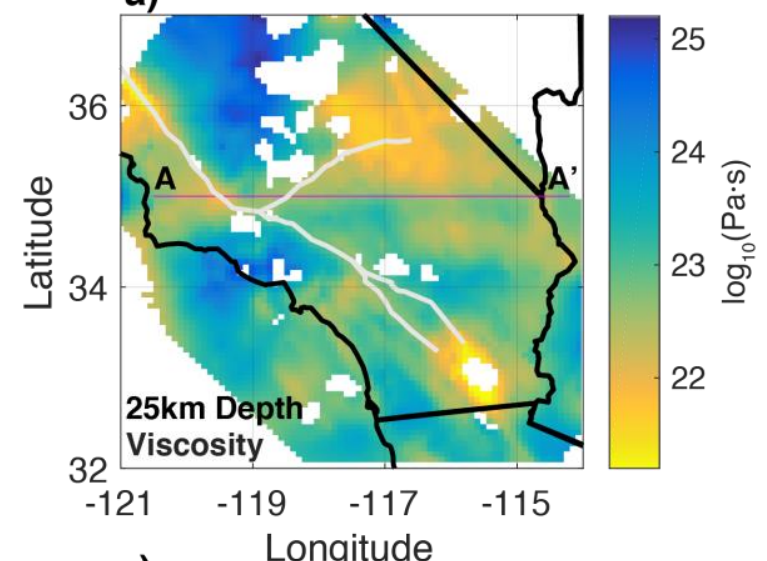

b)

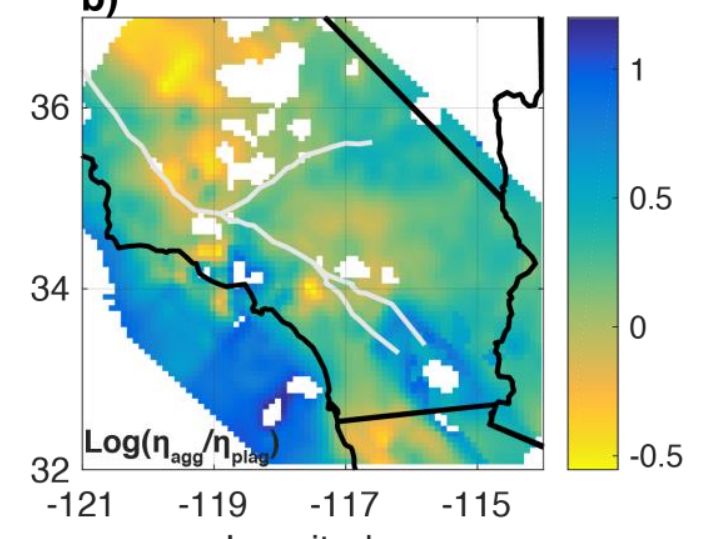

d) Longitude

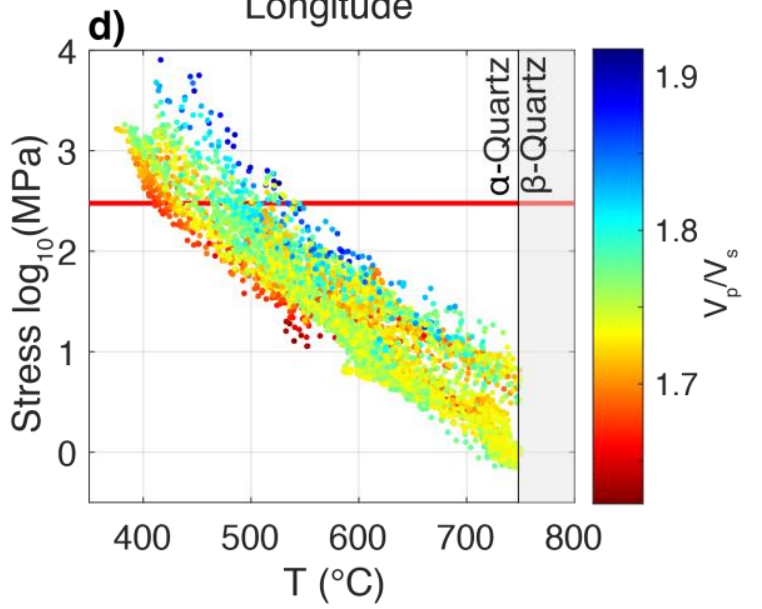

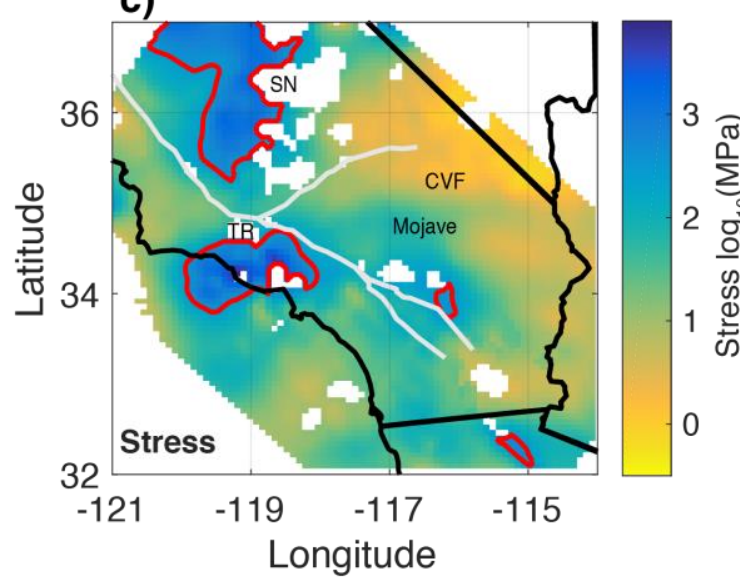

Figure 1.4: a) Viscosities calculated for Southern California at $25 \mathrm{~km}$ depth using Eq. (7a) using data shown in Figure 3 assuming $a_{H_{2} \mathrm{O}}=1.0$. b) $\log _{10} \frac{\eta_{\text {aggregate }}}{\eta_{\text {plagioclase }}}$ the same depth (see Section 3 for explanation). c) Ductile stress field at the same depth. Red lines contour areas where the predicted ductile stress is greater than the yield stress. White regions denote regions lacking data, regions predicted to be in the $\beta$ quartz regime $\left(\mathrm{T}>750^{\circ} \mathrm{C}\right.$ at $25 \mathrm{~km}$ depth), or regions where the seismic velocities are greater than error away from predicted possible velocities used to fit the model. Grey lines indicate the San Andreas, Garlock, and San Jacinto Faults. Pink line denotes location for Figure 5. CVF= Cima Volcanic Field, SN: Sierra Nevadas, TR: Transverse Ranges d) Stress from c) scattered against the temperature field (Figure $3 \mathrm{~d}$ ) colored by $V_{p} / V_{s}$. Red line depicts the yield stress. 


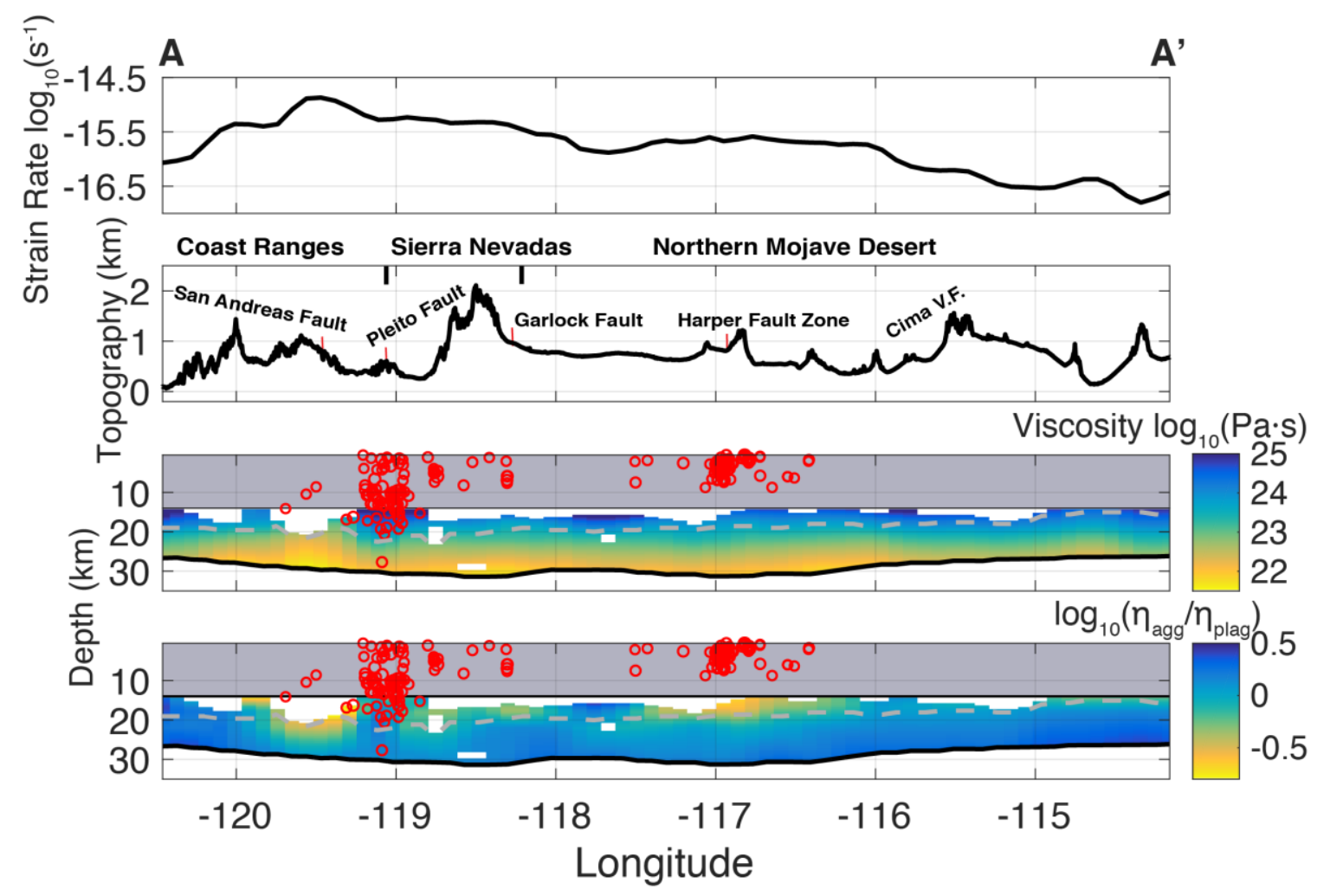

Figure 1.5: Strain rate, topography, predicted viscosity, and $\log _{10} \frac{\eta_{\text {aggregate }}}{\eta_{\text {plagioclase }}}$ (see Section 3 for explanation) along the Mojave at $35^{\circ} \mathrm{N}$ (A-A' in Figure 4). Black lines denote the Moho. Grey dashed line indicates predicted brittle-ductile transition. Red dots indicate earthquake epicenters within $10 \mathrm{~km}$ north or south of the cross section. White regions denote regions lacking data, regions predicted to be in the $\beta$ quartz regime, or regions where the seismic velocities are greater than error away from predicted possible velocities used to fit the model. Grey box denotes upper crust where velocity calculations have misfit with predicted possible velocities, most likely due to porosity effects. 
a)

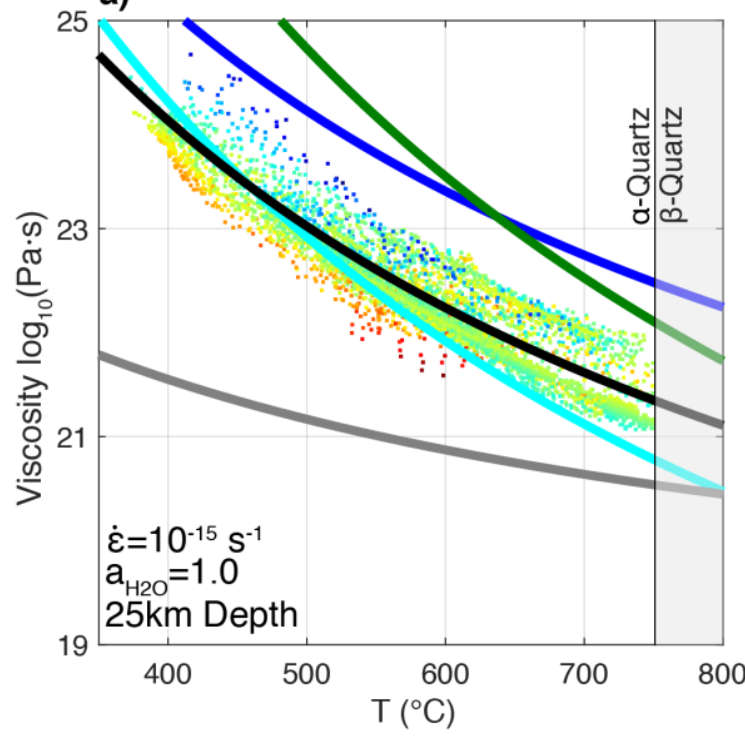

b)

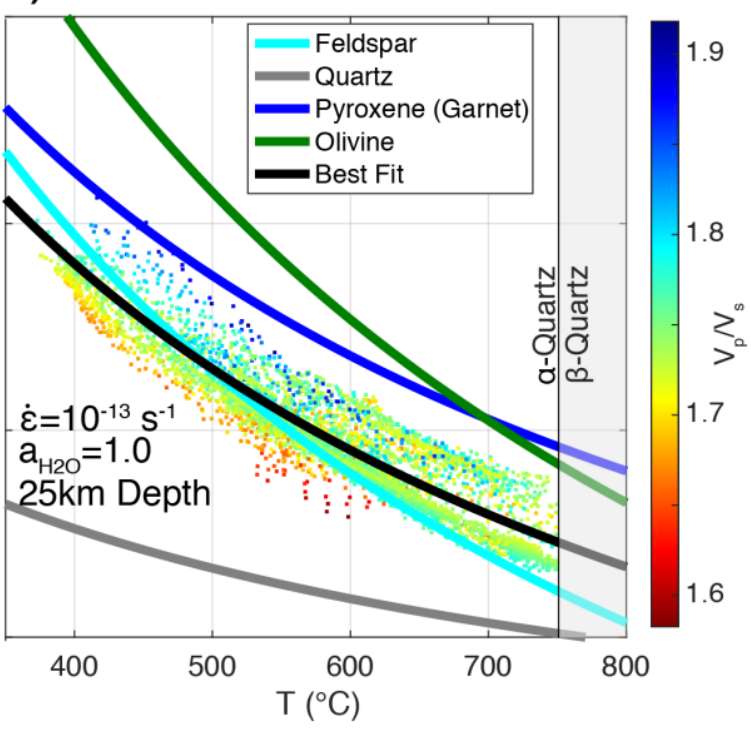

Figure 1.6: Viscosity at each grid point from Figure 4a plotted versus temperature calculated at $25 \mathrm{~km}$ depth corrected to a $\dot{\epsilon}$ of $10^{-15} \mathrm{~s}^{-1}$ (left) or $10^{-13} \mathrm{~s}^{-1}$ (right) colored by $V_{p} / V_{s}$. Solid lines represent the predicted viscosities for quartz(grey) (Hirth et al., 2001), plagioclase(light blue) (Rybacki et al., 2006), pyroxene(dark blue) (Dimanov and Dresen, 2005), and olivine(green) (Hirth and Kohlstedt, 2003). Note that garnet is assumed to follow the same flow law as pyroxene (see text for discussion). The black line represents the best-fit flow law to the scattered data. 

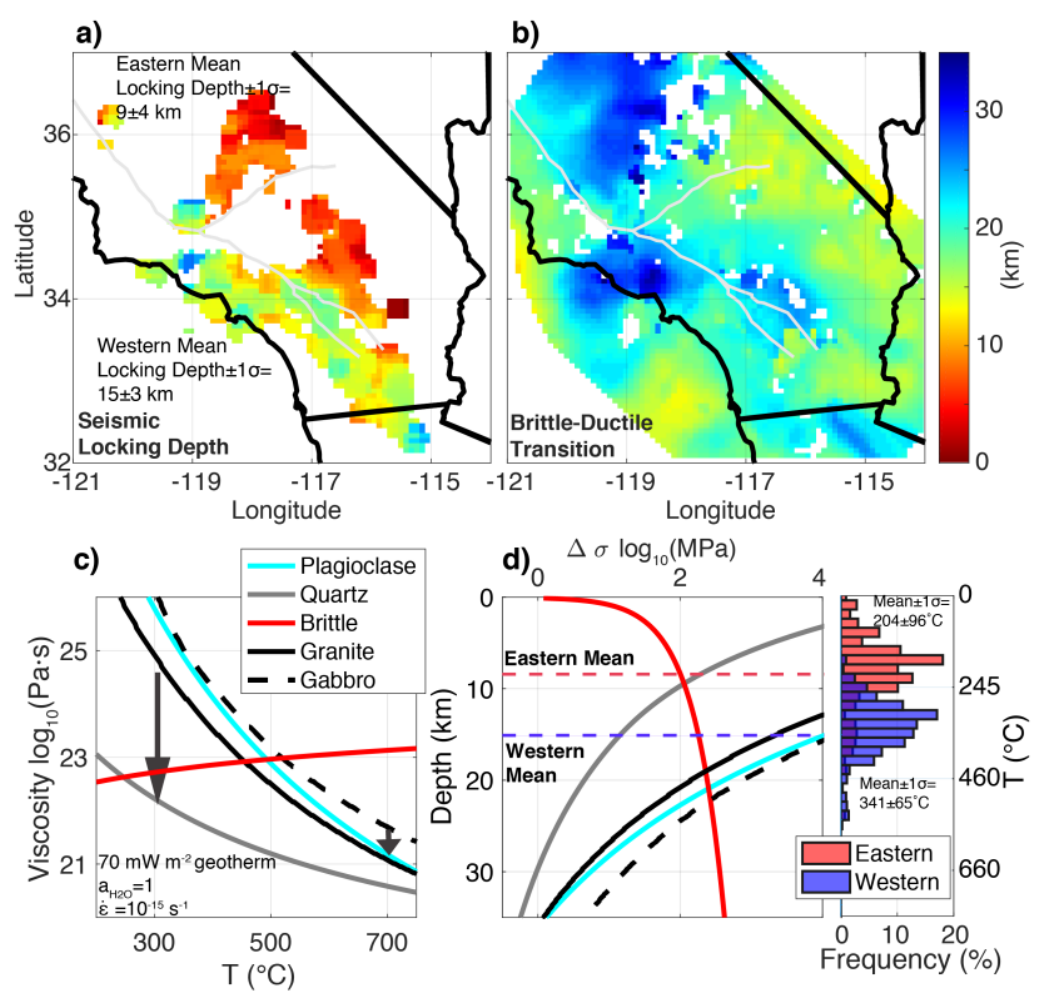

Figure 1.7: a) Observed regional seismic-aseismic transition. b) Predicted brittle-ductile transition, white regions are where the velocity model outputs were continuously anomalous until at least $20 \mathrm{~km}$ depth. c) Viscosity along a $70 \mathrm{~mW} \mathrm{~m}{ }^{-2}\left(\sim 17^{\circ} \mathrm{C} \mathrm{km}^{-1}\right)$ geotherm for quartz and plagioclase wet dislocation creep flow laws as well as calculated aggregate viscosities for a granite and basalt from the rock database. Black arrows show the rheologic effect of fabric formation weakening the granite and gabbro flow laws to their weakest phase, quartz and plagioclase respectively. d) Christmas tree stress diagram of a) showing the differential stress as a function of depth for various flow laws and the eastern (solid) and western (dashed) mean locking depths are plotted. Eastern (red) and western (blue) locking depth temperature distributions are shown along the geotherm for reference. 


\section{Tables}

\begin{tabular}{|c|c|c|}
\hline Parameter (units) & $\begin{array}{l}\text { Constant Strain Rate } \\
\text { (Eq. 7a) }\end{array}$ & $\begin{array}{l}\text { Constant Stress } \\
\text { (Eq. 7b) }\end{array}$ \\
\hline $\mathbf{a}_{1}\left(\log _{10}(\mathrm{~Pa} \cdot \mathrm{s})\right)$ & -0.3780 & 7.4290 \\
\hline $\mathbf{a}_{2}\left(\log _{10}(\mathrm{~Pa} \cdot \mathrm{s}) \cdot \log _{10}(\mathrm{~s})\right)$ & -0.7123 & -2.4975 \\
\hline a3 $\left(\log _{10}(\mathrm{~Pa} \cdot \mathrm{s})\right)$ & -0.2877 & -1.0000 \\
\hline $\mathbf{a}_{4}\left(\log _{10}(\mathrm{~Pa} \cdot \mathrm{s}) \cdot \mathrm{K}\right)$ & 5.2041 & -9.2960 \\
\hline $\mathbf{a}_{5}\left(\log _{10}(\mathrm{~Pa} \cdot \mathrm{s}) \cdot \mathrm{K} \cdot \mathrm{GPa}^{-1}\right)$ & 2.7066 & 11.9028 \\
\hline $\mathbf{b}_{1}\left(\log _{10}(\mathrm{~Pa} \cdot \mathrm{s}) \mathrm{s} \mathrm{km}^{-1}\right)$ & -2.3587 & -8.4493 \\
\hline $\mathbf{b}_{2}\left(\log _{10}(\mathrm{~Pa} \cdot \mathrm{s}) \cdot \mathrm{s} \cdot \mathrm{K} \cdot \mathrm{km}^{-1}\right)$ & 3.1622 & 11.7487 \\
\hline $\mathbf{b}_{3}\left(\log _{10}(\mathrm{~Pa} \cdot \mathrm{s}) \cdot \mathrm{s} \cdot \mathrm{K} \cdot \mathrm{km}^{-1} \cdot \mathrm{Pa}^{-1}\right)$ & $0.0455 * 1 \mathrm{e}-9$ & $-0.2711 * 1 e-9$ \\
\hline $\mathbf{c}_{1}\left(\log _{10}(\mathrm{~Pa} \cdot \mathrm{s}) \cdot \mathrm{s} \cdot \mathrm{km}^{-1}\right)$ & 5.5208 & 13.7598 \\
\hline $\mathbf{c}_{2}\left(\log _{10}(\mathrm{~Pa} \cdot \mathrm{s}) \cdot \mathrm{s} \cdot \mathrm{K} \cdot \mathrm{km}^{-1}\right)$ & -5.3804 & -13.0257 \\
\hline $\mathbf{c}_{3}\left(\log _{10}(\mathrm{~Pa} \cdot \mathrm{s}) \cdot \mathrm{s} \cdot \mathrm{K} \cdot \mathrm{km}^{-1} \cdot \mathrm{Pa}^{-1}\right)$ & $-0.8413 * 1 \mathrm{e}-9$ & $-2.9594 * 1 \mathrm{e}-9$ \\
\hline
\end{tabular}

Table 1.1: Parameter values for Eq. $7 \mathrm{a}$ and $7 \mathrm{~b}$. 


\section{Chapter 2:}

\section{Gore Mountain Garnet Amphibolite records UHT Conditions: Implications for the Rheology of the Lower Continental Crust During Orogenesis}

This chapter was originally published as: Shinevar, W. J., Jagoutz, O., \& VanTongeren, J. A. (2021). Gore Mountain Garnet Amphibolite records UHT Conditions: Implications for the Rheology of the Lower Continental Crust During Orogenesis. Journal of Petrology. doi.org/10.1093/petrology/egab007 . Used with permission as granted in the original copyright agreement. 


\begin{abstract}
The Gore Mountain Garnet Amphibolite (GMGA), part of the Mesoproterozoic Grenville province in the Adirondack Highlands, NY, USA, is an iconic rock type known for hosting the world's largest garnets (up to $1 \mathrm{~m}$ diameter). We present a new detailed petrographic study of these rocks. Field relations, whole rock, and mineral major and trace element chemistry suggest that these rocks formed via a prograde hydration reaction of a metagabbro during an increase in pressure and temperature. Laser ablationinductively coupled plasma mass spectrometry (LA-ICPMS) U-Pb geochronology applied to zircon interpreted to be metamorphic in origin dates this reaction to 1053.9 $\pm 5.4 \mathrm{Ma}(2 \sigma ; \mathrm{MSWD}=0.94)$, during the Ottawan Orogeny (1090-1020 Ma). Our results on peak metamorphic P-T conditions based on thermobarometry, diffusion models, and thermodynamic modelling indicate that these rocks formed at ultra-high temperature $\left(\mathrm{UHT},>900^{\circ} \mathrm{C}\right)$ conditions $\left(\mathrm{P}=9-10 \mathrm{kbar}, \mathrm{T}=950 \pm 40^{\circ} \mathrm{C}\right)$, significantly hotter than previously estimated. Diffusion models pinned by nearby cooling ages require the GMGA to initially cool quickly $\left(9.1{ }^{\circ} \mathrm{C} \mathrm{Myr}^{-1}\right)$, followed by slower cooling $\left(2.6{ }^{\circ} \mathrm{C}\right.$ $\left.\mathrm{Myr}^{-1}\right)$. The two-stage cooling history for the GMGA could reflect initial advectiondominated cooling followed by conduction-dominated cooling once flow ceases. Our results suggest that the region was hot enough to undergo topography-driven lower crustal flow similar to that hypothesized for modern Tibet for 20-0 Myr (25-0 Myr when the effects of melt are included).
\end{abstract}




\section{INTRODUCTION}

The rheology of the lithosphere controls how orogens evolve and is dominantly controlled by the lithospheric thermal structure (Ranalli, 1997; Bürgmann and Dresen, 2008; Shinevar et al., 2018). Understanding the thermal evolution of the lithosphere during orogenesis is critical to understanding the stress state and dynamics occurring in the lower crust of the modern-day Himalayan Orogeny. Super-solidus temperatures have been hypothesized for the lower crust of Tibet to explain geophysical observations of highconductivity (Chen et al., 1996; Unsworth et al., 2005), low seismic velocity (Makovsky et al., 1996; Nelson et al., 1996), and the low lower crustal viscosities required to produce a low relief, but topographically high plateau (Bird, 1991; Royden et al., 1997). Geotherms for tectonically active areas are difficult to constrain from surface heat flow measurements due to the variable crustal distribution of heat-producing elements and unconstrained thermal advection due to melt and fluids (Chapman, 1986).

Fortunately, the Grenville Province in the northeastern United States exposes a suite of metamorphic lower crustal rocks formed during a continent-continent collisional orogenesis associated with the assembly of the supercontinent Rodinia $~ 1.3-0.9$ billion years ago (McLelland et al., 1996, 2010a; Rivers, 1997, 2008, 2015; Carr et al., 2000; Rivers et al., 2002; Li et al., 2008a). Grenville-age rocks consist of low-pressure schists to eclogite facies rocks, which allow for the tectonic reconstruction of several episodes of deformation, magmatism, and metamorphism in the mid-lower crust (Rivers, 1997, 2008, 2012). Furthermore, the final phase of Grenville mountain building, the Ottawan Orogeny (1090-1020 Ma), is considered an example of a large hot orogeny similar to the modern Himalayan Orogeny due to granulite facies temperatures and structural evidence for lower crustal channel flow (Jamieson et al., 2002, 2007, 2010; Rivers, 2009, 2015). Therefore,

studying the thermal evolution of the lower crust during the Ottawan Orogeny can improve our constraints on the thermal regime and hence rheology and dynamics of modern orogenesis.

Within the Grenville Province, in the Adirondack Mountains of New York, USA, are several notable and unique rock exposures including massif anorthosites and the spectacular Gore Mountain Garnet Amphibolite (GMGA) with single garnet crystals up to $1 \mathrm{~m}$ diameter. Early studies concluded that the GMGA resulted from prograde 
metamorphism of the nearby metagabbro via the intrusion of a melt (Miller, 1938; Levin, 1950). Later studies noted near isochemical major element whole rock compositions of the GMGA and nearby metagabbro, arguing that the GMGA formed during metamorphism of the metagabbro due to the intrusion of a saline lower crustal fluid rather than a melt (Buddington, 1939; Bartholome, 1960; Luther, 1976; McLelland and Selleck, 2011). Previous authors (Goldblum and Hill, 1992; McLelland and Selleck, 2011) argued that the fluid causing this metamorphism rose in a high-temperature shear zone formed due to the contrasting rheologies of the metagabbro and adjacent feldspar-rich lithologies. Existing pressure-temperature (P-T) estimates based on garnet-clinopyroxene Fe-Mg thermometry indicates that the GMGA formed at peak metamorphic temperatures $775-926^{\circ} \mathrm{C}$ assuming 7.5 kbar pressure (Sharga, 1986). Recent work, however, has documented evidence for ultra-high temperature metamorphism within the Adirondacks (Alcock et al., 2004) suggesting that peak P-T conditions regionally may have been greater than previously thought.

Here we present detailed petrological analysis, geochronology, diffusion modelling, and thermodynamic modelling in order to better constrain the timing and duration of the metamorphic P-T conditions that gave rise to these megacrystic garnet outcrops. Our results have implications for the nature of the lower crust during long-lived continent-continent collisions and subsequent orogenic collapse.

\section{BACKGROUND}

The Adirondack Mountains in northern New York, USA form a circular region of $\sim 260 \mathrm{~km}$ diameter and topography up to 1,620 $\mathrm{m}$ (Figure 1). Today, the Adirondack Mountains have a 45-50 km thick crust, thicker than the surrounding $~ 40 \mathrm{~km}$ thick Grenville age crust (Li et al., 2018). The Adirondack Mountains are a southwestern portion of the Grenville Province and divided topographically into the Adirondack Highlands in the southeast, which consists mainly of granulite-facies orthogneisses, and the Adirondack Lowlands in the northwest, which consists mostly of amphibolite-grade metasedimentary and metaigneous rocks. The Carthage-Colton shear zone (CCMZ, Figure 1) separates the two regions.

The Adirondack Mountains record hundreds of millions of years of geological history. The oldest rocks in the Adirondacks Highlands are metasediments that are crosscut 
by highly deformed ca. 1330-1307 Ma calc-alkaline tonalites in the southern and eastern Highlands (McLelland et al., 1988, 2010a; McLelland and Chiarenzelli, 1990). The tonalites are thought to have formed within a continental arc on the Laurentian margin. Fragments of this margin subsequently rifted away between 1.4-1.3 Ga (Hanmer et al., 2000). Following rifting, basin closure lead to the Elzevirian Orogeny (1250-1220 Ma) and renewed subduction-related magmatism recorded in the Adirondack Highlands (McLelland et al., 2001; Chiarenzelli et al., 2010). Approximately $30 \mathrm{Myr}$ after the Elzevirian Orogeny, the Adirondack Highlands-Green Mountain Belt collided with southeast Laurentia causing the Shawinigan Orogeny (1190-1140 Ma) (Wasteneys et al., 1999). During the end of this orogeny, the 1170-1130 Ma anorthosite-mangeritecharnockite-granitoid (AMCG) suite intruded into the Adirondack Highlands (Hamilton et al., 2004; McLelland et al., 2004). The AMCG suite is typically associated with leucogabbros, gabbros, norites, oxide-apatite gabbronorites, oxide-rich gabbronorites, and nelsonites (Buddington, 1939, 1952; Isachsen, 1969; Emslie and Hunt, 1990; McLelland and Whitney, 1990; Seifert et al., 2010). The AMCG suite includes the coarse-grained, Proterozoic massif-type anorthosites throughout the Grenville Province. The main anorthosite massifs in the Adirondacks are the Marcy Massif in the northern Adirondack Highlands and the Oregon Dome in the central Adirondack Highlands (Figure 1).

The last major regional thermotectonic event recorded in the Adirondack Highlands was the collision of Amazonia with Laurentia, resulting in the Ottawan Orogeny (1090$1020 \mathrm{Ma}$ ) (McLelland et al., 2001). The Lowlands contains Ar-Ar Ottawan amphibole ages, but lacks Ottawan $\mathrm{U}-\mathrm{Pb}$ rutile ages, constraining the Lowlands peak temperatures between $500-750^{\circ} \mathrm{C}$ during the Ottawan Orogeny (Mezger et al., 1993; Streepey et al., 2001; Dahl et al., 2004; McLelland et al., 2013). Originally peak pressure-temperature (PT) conditions for the Adirondack Highlands during the Ottawan Orogeny were thought to be between $700-850^{\circ} \mathrm{C}$ and 7-8 kbar (Bohlen et al., 1985; Valley et al., 1990) with the highest P-T conditions in the northwestern portion near the Marcy Massif. However, more recent studies have shown that high temperatures $\left(>800^{\circ} \mathrm{C}\right)$ occurred throughout the central and southern Adirondack Highlands, suggesting a more homogeneous, granulite facies temperature during the Ottawan Orogeny throughout the Adirondack Highlands (Spear and Markussen, 1997; Pattison et al., 2003; Darling et al., 2004; Peck et al., 2004; Storm and 
Spear, 2005, 2009; Chiarenzelli et al., 2011). Similarly, studies investigating anatectic events at $\sim 1050 \mathrm{Ma}$ in the northern and central Adirondack Highlands posit the possibility that temperatures could have reached ultra-high temperature conditions (UHT, $>900^{\circ} \mathrm{C}$ ) during peak metamorphism (Alcock et al., 2004; Bickford et al., 2008). The Lyon Mountain Granite (now the Lyon Mountain Granite Gneiss) (LMG) intruded into the north and east Adirondack Highlands after the metamorphic peak of the Ottawan Orogeny and are the youngest igneous rocks in the Adirondack Highlands, emplaced at 1060-1047 Ma (Selleck et al., 2005; Valley et al., 2011; Chiarenzelli et al., 2017). Valley et al. (2011) argued that the preservation of typical igneous minerals in a 1047.5 $\pm 2.2 \mathrm{Ma}$ fayalite granite and the lack of much penetrative deformation in most of the LMG suggests that most Ottawan prograde metamorphism in the Adirondacks ended by ca. 1045 Ma. The Rigolet phase of the Grenville Orogeny (ca. 1000-980 Ma (Rivers, 2008)) was relatively mild in the Adirondack Highlands producing a few pegmatites and zircon overgrowths, but did not reset Adirondacks monazite U-Pb ages (Lupulescu et al., 2011; Wong et al., 2012; McLelland, 2016).

Previous studies argued that the GMGA formed during the Ottawan Orogeny due to hydration of the adjacent AMCG-related olivine-metagabbro (Buddington, 1939; Bartholome, 1960; Luther, 1976; McLelland and Selleck, 2011). Metamorphic P-T conditions have been estimated using experimentally constrained phase diagrams by (Luther, 1976) at 7-8 kbar and $700-800^{\circ} \mathrm{C}$. Fe- $\mathrm{Mg}$ clinopyroxene-garnet thermometry (Ellis and Green, 1979) applied to the adjacent gabbroic anorthosite produces temperatures from $774-926^{\circ} \mathrm{C}$ assuming $7.5 \mathrm{kbar}$ pressure (Sharga, 1986). Previous authors (Luther, 1976; McLelland and Selleck, 2011) hypothesized the garnet formation reaction to be

$$
\begin{gathered}
\text { Plagioclase+olivine+spinel+orthopyroxene }+\mathrm{H}_{2} \mathrm{O} \rightarrow \\
\text { garnet+amphibole. }
\end{gathered}
$$

The discovery of metastable cristobalite inclusions in the megacrystic garnets led Darling et al. (1997) to hypothesize that the garnet formation reaction included melting consistent with the presence of felsic, partly pegmatitic dykes within the GMGA that have two concordant zircon ages with a weighted average of $1008 \pm 10 \mathrm{Ma}(2 \sigma)$ using sensitive highresolution ion micro- probe (SHRIMP) (Figure 8, McLelland and Selleck, 2011). 
Previous garnet trace element and zircon $\mathrm{U}-\mathrm{Pb}$ geochronology have been conducted

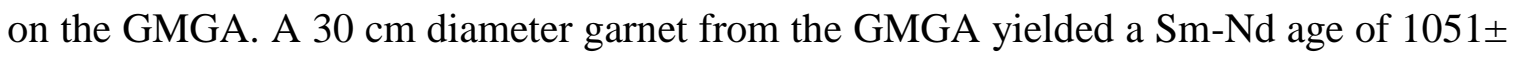
$4 \mathrm{Ma}$, while a $14 \mathrm{~cm}$ garnet gave a rim age of $1029 \pm 3 \mathrm{Ma}$ and a core age of $1018 \pm 7 \mathrm{Ma}$ (Mezger et al., 1992). Another Sm-Nd isochron using a garnet of unknown size gave an age $1059 \pm 19 \mathrm{Ma}$ (Basu et al., 1989). More recent analyses on a $\sim 8 \mathrm{~cm}$ diameter garnet produced a Sm-Nd age of 1061 $12 \mathrm{Ma}$ and a Lu-Hf age of $1087+25 /-27 \mathrm{Ma}$, though the Lu-Hf age is corrected for an estimated zircon content (Scherer et al., 2000). Improved methods that avoid zircon dissolution give garnet Lu-Hf ages of 1046.6 $\pm 6.1 \mathrm{Ma}$ for two $1.5 \mathrm{~cm}$ diameter garnets (Connelly, 2006). Multi-grain thermal ionization mass spectrometry of zircons separated from the GMGA produced a concordant $\mathrm{U}-\mathrm{Pb}$ metamorphic zircon age of $1055 \pm 2 \mathrm{Ma}$ (Scherer et al., 2000). This zircon age agrees with the SHRIMP ${ }^{207} \mathrm{~Pb} /{ }^{206} \mathrm{~Pb}$ zircon age of $1048 \pm 10 \mathrm{Ma}(2 \sigma ; \mathrm{MSWD}=0.7)$ found in irregular metamorphic rims in the nearby Oregon Dome ferrodiorite (Hamilton et al., 2004).

\section{FIELD RELATIONSHIPS}

While megacrystic garnet amphibolite occurs throughout the Adirondack Highlands (red stars, Fig. 1), the most spectacular outcrops of these rocks are exposed at the Barton Garnet Mine, located in North Creek, NY. The Gore Mountain garnet deposit is a $\sim 50 \mathrm{~m}$ by $600 \mathrm{~m}$ east-west trending outcrop of megacrystic garnet amphibolite, sometimes referred as "black ore" (Figure 2). The garnets were mined and pulverized for industrial abrasives such as in sandpaper or polishing rouge. The ore contact dips slightly to the west (Levin 1950). The mine consists of a set of multilevel pits that increase in altitude towards the east with 10-20 m steps. There exist two separate types of megacrystic garnet amphibolite, one with plagioclase in the matrix (light red, Figure 2), and one without plagioclase in the matrix (dark red, Figure 2), here labeled as garnet hornblendite.

To the north of the GMGA, an olivine-bearing metagabbro crops out that contains plagioclase clouded with numerous exsolved spinel crystals. This lithology is referred to as the 'spinel-clouded plagioclase metagabbro'. Similar spinel-clouded plagioclase metagabbros in the Adirondack Highlands are interpreted to be related to, and are coeval with, the ca. 1150 Ma AMCG suite magmatism (McLelland and Chiarenzelli, 1989; McLelland et al., 2004). Between the megacrystic GMGA and spinel-clouded plagioclase metagabbro (olive green, Figure 2), a 2-3 m wide transition rock exists here 
named the 'recrystallized metagabbro' (Figure 3, bottom middle). Across this transition, grain size increases by more than an order of magnitude (amphibole grain size increases from $\sim 1 \mathrm{~mm}$ to $\sim 1 \mathrm{~cm}$, garnet grain size increases from $<1 \mathrm{~mm}$ to up to $40 \mathrm{~cm}$ in scale) and the green, inclusion filled plagioclase grains grade into white, recrystallized plagioclase grains towards the GMGA.

To the east and west of the GMGA is a garnet-bearing meta-anorthosite, sometimes referred to as the "white ore" (purple, Figure 2), which contains garnets typically $<5 \mathrm{~cm}$ in diameter (Sharga 1986). Luther (1976) found a sheared, anorthositic xenolith in the eastern transition between the GMGA and the spinel-clouded plagioclase metagabbro suggesting that the metagabbro intruded into the gabbroic anorthosite. The link between metagabbro emplacement and AMCG magmatism is further supported by exposure of coronitic spinel-clouded plagioclase metagabbro adjacent to AMCG-related magmatism in Ontario, Canada having baddeleyite ages of ca. $1170 \mathrm{Ma}$ (Davidson and

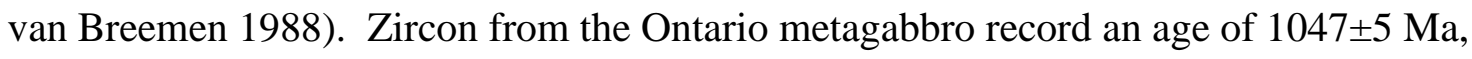
and other Adirondack metagabbros also yield ages between 1060-1030 Ma; these ages have been interpreted as zircon formation owing to granulite-facies metamorphism or metasomatism during the Ottawan Orogeny (Davidson and van Breemen, 1988; Hamilton et al., 2004).

Farther to the west of the western anorthosite, and south of the GMGA, is a metasyenite (light purple, Figure 2), also referred to as a syenite or charnockite (McLelland and Selleck, 2011) or syenitic granulite (Luther, 1976). At the southern boundary between the GMGA and metasyenite is a $\sim 1 \mathrm{~m}$ thick shear zone of gabbroic anorthosite reported by Luther (1976), though the authors were unable to verify this due to access issues. A later vertical fault is inferred from the presence of slickenlines in debris near the southern contact.

\section{LITHOLOGIC DESCRIPTIONS}

Textural relations of all the rock types investigated are described below. Most samples for this study were taken in or near Pit 4 of the Barton Garnet Mine (Figure 2, 3). GPS coordinates of samples are listed in Table 1 with mineral modes-

\section{Spinel-clouded Plagioclase Metagabbro}


The spinel-clouded plagioclase metagabbro (Figure 3, bottom left) is a mediumgrained $(0.25-10 \mathrm{~mm})$ rock composed of plagioclase (29-49 vol. \%), clinopyroxene (10.531 vol. \%), garnet (10-23 vol. \%), orthopyroxene (2-9.5 vol. \%), amphibole (4-10 vol. \%), biotite (1-8 vol. \%), olivine (0-5 vol. \%), and accessory phases of hercynitic spinel, magnetite, ilmenite, iron sulfides. In thin section, a relict subophitic magmatic texture is preserved composed of originally $\sim 10 \mathrm{~mm}$ large euhedral plagioclase laths and anhedral clino- and orthopyroxene (Figure 4a). Other minor primary igneous minerals are olivine, which is found in the core of olivine-pyroxene-garnet coronas (Luther, 1976). The original igneous texture was overprinted during metamorphic re-equilibration. The original $\sim 10$ $\mathrm{mm}$ large pyroxene recrystallized into $2-5 \mathrm{~mm}$ size grains. Larger pyroxene grains have exsolution lamella of the opposing pyroxene. The plagioclase is characterized by numerous hercynitic spinel exsolutions in the core of recrystallized minerals making the plagioclase cloudy. Locally biotite inclusions occur in plagioclase. The rims of plagioclase grains are often clear and lack inclusions. Fine-grained $(<0.5 \mathrm{~mm})$ garnet occurs at the contact between plagioclase and pyroxene, often forming garnet coronas around plagioclase outlining the original plagioclase grain size. These garnets form a symplectite with finegrained $(0.25-1 \mathrm{~mm})$ euhedral clinopyroxene and orthopyroxene. Fine-grained $(0.5-2 \mathrm{~mm})$ biotite-amphibole clusters locally rim the plagioclase laths (Figure 4a).

\section{Recrystallized metagabbro}

The recrystallized metagabbro (Figure 3, bottom middle) is a medium-grained (0.5-5 mm) rock composed of plagioclase (30.5-48 vol. \%), amphibole (27-39 vol. \%), garnet (15.5-19 vol. \%), clinopyroxene (4-13 vol \%), biotite (1-6 vol. \%), and orthopyroxene (1.5-4.5 vol \%) with accessory phases hercynite, apatite, magnetite, and iron sulfides. In thin section, 1-5 mm anhedral plagioclase grains and 2-3 mm grain size amphibole-biotite clusters form a granoblastic texture with regions of fine grained $(<1$ $\mathrm{mm}$ ) garnet-orthopyroxene-clinopyroxene symplectites (Figure 4b). Most plagioclase grains lack inclusions, but locally some grains have biotite and spinel inclusions. Some plagioclase grains have polysynthetic twinning. Grains of amphibole and biotite form larger clusters $(\sim 10 \mathrm{~mm}, 33-40 \mathrm{vol} . \%)$ than observed in the spinel-clouded plagioclase metagabbro ( $\sim \mathrm{mm}, 12-16 \mathrm{vol}$. \%). Fine grained $(0.25-1 \mathrm{~mm})$ metamorphic garnet forms symplectites with fine-grained $(<0.5 \mathrm{~mm})$ orthopyroxene and clinopyroxene. Garnet 
grains are larger in the recrystallized metagabbro $(0.25-1 \mathrm{~mm})$ than in the spinel-clouded plagioclase metagabbro $(<0.5 \mathrm{~mm})$ and formed by plagioclase, orthopyroxene, and clinopyroxene reacting to garnet. Despite textural differences the recrystallized metagabbro and the spinel-clouded plagioclase metagabbro have the same whole rock chemistry (Electronic Appendix 1, Figure 5) and similar mineral chemistry (Electronic Appendix 2). Therefore, we interpret this rock to be a more deformed and hydrated version of the spinel-clouded plagioclase metagabbro.

\section{Gore Mountain Garnet Amphibolite and Hornblendite}

The GMGA (Figure 3, bottom right) is a very coarse-grained $(2-40 \mathrm{~cm})$ rock composed of amphibole (46-68 vol. \%), plagioclase (0-29 vol. \%), garnet (15-24 vol. $\%)$, orthopyroxene (0-3 vol. \%), and biotite ( $0-2$ vol. \%) with accessory magnetite, ilmenite, zircon, spinel, apatite, chlorite, iron sulfides, and quartz. The most distinctive feature of this rock is the megacrystic garnet porphyroblasts (regularly $1-40 \mathrm{~cm}$ in diameter), which are often rimmed by thick $(1-5 \mathrm{~cm}$ thick) coarse grained $(\sim \mathrm{cm})$ amphibole. Some garnet grains are rimmed by a thin ( $<3 \mathrm{~mm}$ thick) medium grained $(\sim 1$ $\mathrm{mm}$ ) plagioclase, which is then surrounded by a thicker (1-3 cm thick) coarse-grained $(\sim 1-3 \mathrm{~cm})$ amphibole (Figure 4c). Locally, and especially towards the southern fault zone, garnet is rimmed by coarse-grained $(>1 \mathrm{~cm})$ biotite instead of amphibole. Although amphibole rims around garnet are common, not all megacrystic garnets exhibit them.

Garnet megacrysts have many fine- to coarse-grained $(0.2-15 \mathrm{~mm})$ inclusions of orthopyroxene, amphibole, biotite, chlorite, plagioclase, magnetite, iron-sulfides, quartz, apatite, rutile, zircon, ilmenite. Inclusion minerals can also include dolomite (McLelland and Selleck, 2011) and cristobalite (Darling et al., 1997). Electron backscatter diffraction (EBSD) shows that the garnet porphyroblasts lack subgrain boundaries associated with polycrystalline aggregates (Figure 4d). Thus, the megacrystic garnet porphyroblasts are single crystals. The garnets are always rutilated (Figure 4e), with rutile grains exsolving along the garnet <111> directions (Figure 4f). Rutile inclusions sometimes coexist with ilmenite and/or zircon and are 5-40 $\mu \mathrm{m}$ wide. No rutile exists in the matrix. On the outcrop-scale, megacrystic garnet also occur in a vein-like fashion (McLelland and Selleck, 2011). Some plagioclase grains have polysynthetic twinning and inclusions of spinel, amphibole, and biotite. The matrix of these rocks is granoblastic consisting of 
coarse-grained $(0.5-3 \mathrm{~cm})$ amphibole, medium-grained $(0.5-1 \mathrm{~cm})$ plagioclase, and medium-grained $(3-5 \mathrm{~mm})$ orthopyroxene. In the matrix, away from the garnet, orthopyroxene-plagioclase-amphibole symplectites occur at the boundaries of amphibole and plagioclase grains.

Within the GMGA outcrop, there are local outcrops of a garnet hornblendite (dark red, Figure 2). The garnet hornblendite is a medium grained to megacrystic $(0.5-40 \mathrm{~cm})$ rock composed of amphibole (61-79 vol. \%), garnet (0-24 vol. \%), orthopyroxene (1019 vol. \%), and biotite (4-8 vol. \%) with accessory phases of clinopyroxene, plagioclase, ilmenite, rutile, apatite, magnetite, iron sulfides, and zircon. Garnet often occurs as megacrystic garnet $(1-40 \mathrm{~cm})$ porphyroblasts, as in the GMGA, with similar inclusions surrounded by coarse-grained $(1-5 \mathrm{~cm})$ euhedral amphibole. Locally garnet occurs as elongated, anhedral, medium grains (1-5 mm) with embayments occupied by mediumgrained $(\sim 1 \mathrm{~mm})$ anhedral amphibole (Figure $4 \mathrm{~g})$. Orthopyroxene occurs as fine-grained $(\sim 0.5 \mathrm{~mm})$ anhedral grains surrounded by amphibole. If present, fine grained $(0.1-0.5$ $\mathrm{mm}$ ) anhedral plagioclase occurs near garnet grains. Portions of the hornblendite are garnet-free.

\section{Gabbroic Anorthosite}

The gabbroic anorthosite is a medium- to coarse-grained $(0.1-15 \mathrm{~cm})$ rock composed of plagioclase (74-83 vol. \%), garnet (5-12 vol. \%), amphibole (5 vol. \%), biotite (1-8 vol. \%), orthopyroxene (0-6 vol. \%), and clinopyroxene (0-6 vol. \%) with accessory phases of ilmenite, magnetite, zircon, and apatite. Some sections of this rock contain $\sim 1 \mathrm{~cm}$ megacrysts of orthopyroxene, clinopyroxene, and or plagioclase. West of the GMGA deposit, the gabbroic anorthosite contains megacrystic garnet porphyroblasts, commonly $1-5 \mathrm{~cm}$ diameter with some up to $15 \mathrm{~cm}$ diameter. They increase in size towards the fault. The garnet porphyroblasts can be rutilated and are often surrounded with thin ( 1 mm thick) fine-grained $(0.5-1 \mathrm{~mm})$ plagioclase rims. This rock is often strongly horizontally foliated showing bands of mafic minerals. The western portion of this outcrop is strongly lineated, with lineations defined by strung out garnet porphyroblasts plunging slightly to the west with trails of mafic minerals. In thin section, a blastomylonitic texture is formed by the fine-grained $(0.5-1 \mathrm{~mm})$ recrystallized 
plagioclase (Figure 4h). Sericite and other phyllosillicates have been found in samples of gabbroic anorthosite near the southern wall fault (Sharga, 1986).

\section{Metasyenite}

The metasyenite is a medium-grained $(1-4 \mathrm{~mm})$ rock composed of microcline (54-83 vol. \%), plagioclase (8-24 vol. \%), quartz (0-12 vol. \%), amphibole (1-7 vol. \%), clinopyroxene (1-6 vol. \%), and orthopyroxene (1-5 vol. \%) with accessory phases of garnet, apatite, and oxides (Luther 1976). The metasyenite has a well-developed foliation defined by bands rich in mafic minerals. In thin section, a granoblastic texture is formed by medium grained $(0.2-4 \mathrm{~mm})$ microcline with perthitic twinning and fine grained $(\leq 1$ $\mathrm{mm}$ ) anhedral amphibole, orthopyroxene, clinopyroxene, and biotite grains. Locally, garnet surrounded by thin ( 1 mm thick) amphibole rims can be present (Luther 1976). Zircons separated from a sample of the metasyenite from the Gore Mountain Ski Lift parking lot has been dated with $\mathrm{U}-\mathrm{Pb}$ sensitive high resolution ion micro- probe

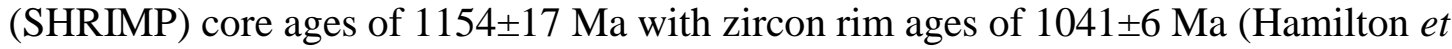
al., 2004).

\section{ANALYTICAL METHODS}

Fifteen samples were studied in detail in this study (Table 1): two gabbroic anorthosites (15-ADK-11, 15-ADK-14), two spinel-clouded plagioclase metagabbros (17-ADK-07, 17-ADK-08), three recrystallized metagabbros (15-ADK-02, 17-ADK-10, 17-ADK-12), six megacrystic garnet amphibolites (15-ADK-12, 15-ADK-5A, 15-ADK9A, 15-ADK-13, 17-ADK-09, 17-ADK-11), and two garnet hornblendites (15-ADK-07, 17-ADK-03).

\section{Thin Section Preparation}

When foliation and/or lineation was present, thin sections were prepared perpendicular to foliation and parallel to lineation. The large garnet thin section described here (17-ADK-09G) was made from a near-spherical garnet sample with matrix surrounding. The garnet was measured using calipers and cut so that the produced thin section would represent a representative cross-section through the center of the grain. Mineral proportions are calculated by point counting of the thin sections with $>500$ points using ImageJ (Schneider et al., 2012). For megacrystic samples, >1 m scale pictures were point counted to distinguish the amount of megacrystic garnet from matrix. Multiple 
matrix thin sections were then point counted to estimate the range of matrix mineral percentages. Final modal estimates for the megacrystic samples were then calculated by combining these two estimates. Mineral modes for each sample are listed in Table 1.

\section{Whole-Rock Chemistry}

Major and trace element concentrations of bulk rock samples were determined using a ThermoARL Perform'X X-ray fluorescence (XRF) spectrometer and by Laser Ablation-Inductively Coupled Plasma Mass Spectrometry (LA-ICP-MS) at the Hamilton Analytical Lab at Hamilton University. Replicate analyses of bulk rock samples were run from aliquots of the same crushed and powdered material. All measured powders were homogenized from 1.4-2.5 kg samples to account for medium grain size. Weights for each individual sample are listed with whole-rock chemistry in Electronic Appendix 1.

\section{Mineral Chemistry}

Major element compositions of all mineral phases were determined using wavelength-dispersive spectrometry (WDS) on the 5-spectrometer JEOL 8200 electron microprobe (EPMA) at the Massachusetts Institute of Technology (MIT). All major element measurements were acquired using a $15-\mathrm{kV}$ accelerating voltage, $10 \mathrm{nA}$ beam current, and $1 \mu \mathrm{m}$ spot sizes, except for plagioclase analyses, which required a $20 \mu \mathrm{m}$ spot size. Measuring times were $40 \mathrm{~s}$ for all elements and minerals, except rutile, which used 200s to optimize counting statistics for $\mathrm{Zr}$ measurement. Background counting times were half of the peak counting time. All data was reduced using the CITZAF correction package (Armstrong, 1995) to obtain quantitative analyses. Counting statistics uncertainties are typically in the range of 0.02-0.06 wt\%. WDS chemical mapping for the $\mathrm{Mg}, \mathrm{Fe}, \mathrm{Ca}, \mathrm{Mn}$, and $\mathrm{P}$ in garnet were acquired using the JEOL JXA-8530F field emission gun electron probe microanalyzer (FEG-EPMA) and Probe for EPMA software at Yale University using $15 \mathrm{kV}, 150 \mathrm{nA}$, and a $150 \mathrm{~ms}$ dwell time. Major element mineral chemistry is reported in Electronic Appendix 2.

\section{Electron Backscatter Diffraction}

Electron backscatter diffraction (EBSD) is used to characterize microstructural relationships and quantify patterns of crystallographic orientations for the megacrystic garnet grains. EBSD analyses were performed in the Department of Earth and Environmental Sciences at Boston College using a Tescan MIRA3 LMU FEG-SEM 
equipped with an Oxford Instruments Symmetry (EBSD) detector. EBSD data were acquired using an accelerating voltage of $25 \mathrm{kV}$ and beam currents ranging from 25-50 $\mathrm{nA}$. The analytical method is described in detail by Prior et al. (1999).

\section{Zircon Separation}

Zircon was separated from one sample (17-ADK-09) of GMGA through standard crushing and magnetic-/ gravimetric-separation techniques at MIT. We first separated by hand a large garnet megacryst, abrading away any other phases in the exterior with a metal brush. We extracted a few dozen small $(<50 \mu \mathrm{m})$ rounded zircons from the garnet portion of this rock. No zircons were extracted from the matrix. After crushing the garnet and matrix portions separately, both portions were individually washed and then magnetically separated using first a hand magnet and then the Frantz isodynamic separator (at $0.6 \mathrm{~A}, 20^{\circ}$ slide angle). The non-magnetic fractions were then separated by density using methyl iodide. Zircons were hand picked under a binocular microscope in ethanol from the least magnetic mineral separate. The grains were placed on a piece of tape and covered with epoxy resin in a cylindrical frame. After hardening, the tape was removed and the crystals were polished. Cathodoluminescent (CL) imaging was done on all the mounted and polished zircons at MIT on the JEOL-JXA-733 Superprobe using a $15 \mathrm{kV}$ accelerating voltage, $10 \mathrm{nA}$ beam current.

\section{Mineral Trace Element Chemistry and Geochronology}

Trace element and isotope concentrations for all mineral phases were obtained at Rutgers University using the Thermo Scientific iCAP Qc inductively coupled mass spectrometery (ICP-MS) system coupled to a Photon Machines $193 \mathrm{~nm}$ laser ablation

system. Ablation was carried out using 20 or $35 \mu \mathrm{m}$ spot size, a fluence of $5.0 \mathrm{~J} / \mathrm{cm}^{2}$, and a frequency of $10 \mathrm{~Hz}$. Spots were analyzed in rim or core sections of the zircon grains. Each analysis consisted of the collection of an approximately 20s gas background followed by 30s of ablation. The carrier gas was purged through the system for $20 \mathrm{~s}$ after ablation in order to return to normal background values. All measurements were recorded on the masses ${ }^{7} \mathrm{Li},{ }^{24} \mathrm{Mg},{ }^{29} \mathrm{Si},{ }^{43} \mathrm{Ca},{ }^{44} \mathrm{Ca},{ }^{45} \mathrm{Sc},{ }^{49} \mathrm{Ti},{ }^{51} \mathrm{~V},{ }^{52} \mathrm{Cr},{ }^{56} \mathrm{Fe},{ }^{60} \mathrm{Ni},{ }^{85} \mathrm{Rb}$, ${ }^{88} \mathrm{Sr},{ }^{89} \mathrm{Y},{ }^{91} \mathrm{Zr},{ }^{93} \mathrm{Nb},{ }^{133} \mathrm{Cs},{ }^{137} \mathrm{Ba},{ }^{139} \mathrm{La},{ }^{140} \mathrm{Ce},{ }^{141} \mathrm{Pr},{ }^{146} \mathrm{Nd},{ }^{147} \mathrm{Sm},{ }^{153} \mathrm{Eu},{ }^{157} \mathrm{Gd},{ }^{159} \mathrm{~Tb}$, ${ }^{163} \mathrm{Dy},{ }^{165} \mathrm{Ho},{ }^{166} \mathrm{Er},{ }^{169} \mathrm{Tm},{ }^{172} \mathrm{Yb},{ }^{175} \mathrm{Lu},{ }^{178} \mathrm{Hf},{ }^{181} \mathrm{Ta},{ }^{200} \mathrm{Hg},{ }^{204} \mathrm{~Pb},{ }^{206} \mathrm{~Pb},{ }^{207} \mathrm{~Pb},{ }^{208} \mathrm{~Pb}$, ${ }^{232} \mathrm{Th},{ }^{235} \mathrm{U},{ }^{238} \mathrm{U}$. Glass standards NIST610 and NIST612 were regularly analyzed for 
continuous calibration. Natural zircon standards (91500, Plešovice, R33 and Mud Tank) were also analyzed regularly as secondary standards to confirm accuracy of zircon measurements. Data were processed in LASY BOY (Sparks, 2001) using analytical values from microprobe measurements of $\mathrm{Ca}$ for internal standards for amphibole, garnet, clinopyroxene, and plagioclase, using microprobe measurements of Si for orthopyroxene, and using the stoichiometric value of $\mathrm{Zr}$ within zircon as an internal standard for zircon. Data processing was performed using the Iolite software package version 3.6 (Paton et $a l .$, 2011) along with Isoplot toolbox (Vermeesch, 2018). All reported errors are propagated errors calculated within Iolite. Trace element mineral chemistry is reported in Electronic Appendix 2.

The zircon standard 91500 (Wiedenbeck et al., 1995) was the primary standard used during the session and was run after every 5 to 7 unknowns. As trace elements and $\mathrm{Pb}$ isotopes were measured simultaneously in small spot sizes $(20-35 \mu \mathrm{m})$, the counting statistics error on ${ }^{207} \mathrm{~Pb}$ was high. We therefore give results in terms of ${ }^{206} \mathrm{~Pb} /{ }^{238} \mathrm{U}$ ages. 91500 (1065 Ma) was analyzed a total of 28 times, yielding a weighted mean ${ }^{206} \mathrm{~Pb} /{ }^{238} \mathrm{U}$ age of $1062.4 \pm 6.6 \mathrm{Ma}(2 \sigma ; \mathrm{MSWD}=0.41)$. The results from the 91500 standard were used to apply a final fractionation correction to the unknowns via a bracketing approach. The zircon standards Plešovice (Sláma et al., 2008), Mud Tank (Black and Gulson, 1978), and R33 (Black et al., 2004) were also analyzed during the session and were processed in the same manner as the unknowns. The Plešovice (337.13 Ma) standard was analyzed a total of 24 times, yielding a weighted mean ${ }^{206} \mathrm{~Pb} /{ }^{238} \mathrm{U}$ age of $339.4 \pm 1.7 \mathrm{Ma}$ $(2 \sigma ;$ MSWD $=0.47)$. The Mud Tank $(732 \mathrm{Ma})$ standard was analyzed 24 times, yielding a weighted mean ${ }^{206} \mathrm{~Pb} /{ }^{238} \mathrm{U}$ age of $727.3 \pm 7.0 \mathrm{Ma}(2 \sigma ; \mathrm{MSWD}=0.65)$. The R33 standard (419 Ma) was analyzed 23 times, yielding a weighted mean ${ }^{206} \mathrm{~Pb} /{ }^{238} \mathrm{U}$ age of $430.1 \pm 3.1$ Ma $(2 \sigma ; M S W D=2.42)$. We note that our R33 standard reported is older than the published value. This could be due to heterogeneity of the standard, or an underestimate of the reported propagated error. We do not correct for the error in our secondary standards, but note that the zircon ages discussed here are extremely close to the age of 91500 (1065 Ma). Despite the poor counting statistics on ${ }^{207} \mathrm{~Pb}$, trace elements measured for 91500 agree well with known trace element concentration (Wiedenbeck et al., 2004), showing that zircon trace elements are accurate (Supplemental Figure 1). 


\section{Thermodynamic Modelling}

To calculate the equilibrium mineral assemblage, densities, and seismic velocities for each composition, we use the Gibbs free energy minimization routine Perple_X version 6.8.7 (Connolly, 2009). All thermodynamic modelling was performed in the 10 component NCKFMASHTO $\left(\mathrm{Na}_{2} \mathrm{O}-\mathrm{CaO}-\mathrm{K}_{2} \mathrm{O}-\mathrm{FeO}-\mathrm{MgO}-\mathrm{Al}_{2} \mathrm{O}_{3}-\mathrm{SiO}_{2}-\mathrm{H}_{2} \mathrm{O}-\mathrm{TiO}_{2}-\mathrm{O}_{2}\right)$ compositional system, the thermodynamic data set of Holland and Powell (2011), and the following solution models: augite and hornblende (Green et al., 2016); garnet, orthopyroxene, biotite, staurolite, cordierite, and chlorite (White et al., 2014a); olivine and epidote (Holland and Powell, 2011); magnetite-spinel (White et al., 2002); ilmenitehematite (White et al., 2000); C1 plagioclase and K-feldspar (Holland and Powell, 2003); and muscovite-paragonite (White et al., 2014b). Pure phases included quartz, rutile, titanite, and aqueous fluid. We use ferric-ferrous iron ratios from previous whole-rock measurements calculated via wet chemical methods (Luther, 1976).

\section{WHOLE-ROCK CHEMISTRY}

We analyzed major and trace element samples of two recrystallized metagabbros (15-ADK-02, 17-ADK-12), one spinel-clouded plagioclase metagabbro (17-ADK-08), one garnet hornblendite (15-ADK-07), and one gabbroic anorthosite (15-ADK-14). Accurately constraining the bulk rock chemistry of megacrystic rocks is difficult due to the limited number of grains homogenized for the measurement. Luther (1976) reports bulk chemistry from two $70 \mathrm{~kg}$ GMGA samples. Given a whole-rock density of $3000 \mathrm{~kg}$ $\mathrm{m}^{-3}$ and garnet grains that are on average $10 \mathrm{~cm}$ diameter and comprise $\sim 20 \mathrm{vol} . \%$ of the rock, each measurement analyzed $<10$ garnet porphyroblasts. To achieve representative whole-rock measurements, we chose samples with medium or smaller garnet grain size $(<5 \mathrm{~mm})$, notably much smaller than average for the garnet hornblendite. Thus for the 2.5 kg garnet hornblendite sample 15-ADK-07, our measurement includes 3200-6400 garnet grains assuming that garnet is 10-20 vol. \% of the rock, a whole rock-density of $3000 \mathrm{~kg}$

$\mathrm{m}^{-3}$, and an average garnet grain size of $5 \mathrm{~mm}$. All whole-rock chemistry from this study and Luther (1976) is reported in Electronic Appendix 1.

The spinel-clouded plagioclase metagabbro, recrystallized metagabbro, and the GMGA all have similar whole-rock compositions reflecting their similar plagioclase, garnet, and amphibole/pyroxene compositions and modal proportions. These rocks have 
high $\mathrm{Al}_{2} \mathrm{O}_{3}\left(16.09-18.43\right.$ wt. \%), restricted $\mathrm{X}_{\mathrm{Mg}}\left(\right.$ molar $\mathrm{Mg} /\left(\right.$ molar $\mathrm{Mg}+$ molar $\left.\left.\mathrm{FeO}_{\mathrm{T}}\right)\right)$ $(0.62-0.64)$ and $\mathrm{K}_{2} \mathrm{O}(0.45-0.71 \mathrm{wt} \%)$, and slightly variable $\mathrm{CaO}(7.85-8.71 \mathrm{wt} \%)$ and $\mathrm{Na}_{2} \mathrm{O}$ (1.85-3.25 wt. \%) (Figure 5). The GMGA differs mostly from the metagabbros in $\mathrm{H}_{2} \mathrm{O}$ content based on hydrous mineral modes $\left(\sim 0.5\right.$ wt. $\% \mathrm{H}_{2} \mathrm{O}$ for metagabbros, $\sim 1-1.5$ wt. $\% \mathrm{H}_{2} \mathrm{O}$ for $\mathrm{GMGA}$ ) and $\mathrm{FeO} / \mathrm{Fe}_{2} \mathrm{O}_{3}(0.02-0.18$ for metagabbros, $0.14-0.30$ for GMGA) (Luther 1976). These bulk compositions fit within contours of whole-rock compositions of Adirondack AMCG-related magmatism (Seifert et al., 2010) with the exception that they have higher $\mathrm{X}_{\mathrm{Mg}}$ at a given $\mathrm{SiO}_{2}$ (Figure 5). The garnet hornblendite and garnet-free hornblendites have differing whole-rock compositions from the metagabbros and GMGA reflecting the dominant modal proportions of amphibole and garnet. The hornblendites have lower $\mathrm{Al}_{2} \mathrm{O}_{3}$ (10.43-15.91 wt. \%), $\mathrm{Na}_{2} \mathrm{O}$ (1.27-2.1 wt. \%), $\mathrm{K}_{2} \mathrm{O}\left(0.18-0.53\right.$ wt. \%), and $\mathrm{CaO}\left(4.33-7.52\right.$ wt. \%), slightly higher $\mathrm{X}_{\mathrm{Mg}}(0.62-0.66)$ compared to the metagabbros and GMGA. The hornblendites do not plot within the contours of AMCG related magmatism, having distinctly lower $\mathrm{CaO}$ as well as higher $\mathrm{X}_{\mathrm{Mg}}$ for their $\mathrm{SiO}_{2}$. The gabbroic anorthosites have compositions reflecting their dominant plagioclase modal assemblages. Compared with the metagabbros, they have lower $\mathrm{X}_{\mathrm{Mg}}(0.31-0.55)$ and slightly higher $\mathrm{CaO}$ (9.74-10.84 wt. \%), $\mathrm{Na}_{2} \mathrm{O}$ (2.81-4.19 wt. $\%), \mathrm{K}_{2} \mathrm{O}\left(0.73-0.91\right.$ wt. \%), and $\mathrm{Al}_{2} \mathrm{O}_{3}(20.47-24.23$ wt. \%). The gabbroic anorthosites plot within the contours of AMCG related magmatism (Figure 5).

Whole-rock trace element concentrations in the spinel-clouded plagioclase metagabbro and the recrystallized metagabbros are nearly identical (Figure 6). The profiles have $\mathrm{Gd}_{\mathrm{n}} / \mathrm{Lu}_{\mathrm{n}}$ between 1.31-1.65, $\mathrm{Dy}_{\mathrm{n}} / \mathrm{Yb}_{\mathrm{n}}$ between $1.12-1.25, \mathrm{Sm}_{\mathrm{n}} / \mathrm{Nd}_{\mathrm{n}}$ between 0.75-0.81, and $\mathrm{Eu}^{*}\left(2 \mathrm{xEu}_{\mathrm{n}} /\left(\mathrm{Sm}_{\mathrm{n}}+\mathrm{Gd}_{\mathrm{n}}\right)\right)$ between 1.22-1.33, fitting at the more depleted range of regional coronitic AMCG-related metagabbros (Seifert et al., 2010; Regan et al., 2011). The garnet hornblendite has a similar trace element profile compared to the metagabbros $\left(\mathrm{Gd}_{\mathrm{n}} / \mathrm{Lu}_{\mathrm{n}}=1.31, \mathrm{Dy}_{\mathrm{n}} / \mathrm{Yb}_{\mathrm{n}}=1.11, \mathrm{Sm}_{\mathrm{n}} / \mathrm{Nd}_{\mathrm{n}}=0.80, \mathrm{Eu}^{*}=1.16\right)$, but is depleted by a factor of $\sim 2$ for rare earth elements (REE). The gabbroic anorthosite also has a similar-shaped trace element profile compared to the metagabbros $\left(\mathrm{Gd}_{\mathrm{n}} / \mathrm{Lu}_{\mathrm{n}}=1.74\right.$, $\mathrm{Dy}_{\mathrm{n}} / \mathrm{Yb}_{\mathrm{n}}=1.27, \mathrm{Sm}_{\mathrm{n}} / \mathrm{Nd}_{\mathrm{n}}=0.73$ ), though its $\mathrm{Eu}^{*}$ is lower (0.94) and the REE concentrations are enriched by a factor of $\sim 2$. Whole-rock trace elements estimated for the bulk rock using modal proportions, mineral trace element measurements, and mineral 
densities from Abers and Hacker (2016) agree well with the measured whole-rock trace elements for the spinel-clouded plagioclase metagabbro (Supplemental Figure 2).

\section{MINERAL CHEMISTRY}

\section{Garnet}

Garnet porphyroblasts in the GMGA and garnet hornblendite have cores with $\mathrm{X}_{\mathrm{Mg}}$ ranging from $0.33-0.37$ and rims with $\mathrm{X}_{\mathrm{Mg}}$ ranging from 0.41-0.45 (Electronic Appendix $2 \mathrm{a}, \mathrm{b})$. Garnets found in both metagabbro lithologies have the same range of $\mathrm{X}_{\mathrm{Mg}}$, but typically have a higher grossular component than the garnets from the GMGA ( 13-15 mol \% grossular as compared to 8-10 mol \% typical of GMGA garnet) (Figure 7). The garnet in the gabbroic anorthosite is zoned with decreasing $\mathrm{X}_{\mathrm{Mg}}$ from core to rim (Sharga 1986).

Major element profiles across three garnet porphyroblasts were analyzed (Electronic Appendix 2b). Two (15-ADK-5A and 15-ADK-9A) show a homogeneous core with an increased $\mathrm{X}_{\mathrm{Mg}}$ over the $\sim 0.5 \mathrm{~cm}$ near the rim (Supplemental Figure 4). One $\sim 8 \mathrm{~cm}$ diameter garnet (17-ADK-09G) shows a core and mantle zonation in major elements (Figure 8). In this garnet, large inclusions of amphibole, plagioclase, biotite, and orthopyroxene tend to form concentric rings around the zonal boundaries, suggesting that the garnet grew quickly enough to engulf $1-2 \mathrm{~cm}$ wide inclusions. The calcium content is variable even within sections of constant Fe, $\mathrm{Mg}$, and $\mathrm{Mn}$. The garnet shows increased $\mathrm{Mn}$ at the very edge of its rim, suggesting small amounts of garnet resorption (de Béthune et al., 1975). Redistributing the backdiffused rim Mn following the diffusive edge pattern (c.f. figure 6, Spear, 2014), we estimate the garnet 17-ADK-09G radius decreased by $\sim 0.35 \mathrm{~mm}$. Given a current radius of $5 \mathrm{~cm}$, the garnet could only have decreased in volume by $2 \%$, suggesting very minor garnet resorption. At the top of the garnet image is a low-Fe region, which does not reflect the sinistrally sheared shape of the garnet overall. $\mathrm{P}$ contents in the garnet are uniform with the exception of the low-Fe overgrowth, which also contains no apatite inclusions, likely showing that this low-Fe, late stage growth occurred when the surroundings were undersaturated in a phosphate mineral.

Trace elements in garnet porphyroblasts are not homogeneous within a single garnet (red curves, Figure 9a). The two measurements nearest to the rim and one measurement in the core have higher $\mathrm{Dy}_{\mathrm{N}} / \mathrm{Yb}_{\mathrm{N}}(1.27-2.55)$ than the other measurements 
(0.76-1.00), potentially from variable amounts of clinopyroxene and orthopyroxene in the formation reaction. The GMGA garnets have slightly negative to positive $\mathrm{Eu}^{*}$ anomalies (0.77-1.74) indicating that plagioclase was a reactant. The trace elements of garnets in the metagabbros vary with $\mathrm{Dy}_{\mathrm{N}} / \mathrm{Yb}_{\mathrm{N}}$ ranging from $0.34-1.09$, indicating a generally lower in HREE content to the GMGA, although there is some overlap (yellow curves, Figure 9a). Garnets from the metagabbros also range from slightly negative to positive Eu* (.97-2.38) similar to the garnet porphyroblasts.

\section{Plagioclase}

Plagioclase in the metagabbros range in anorthite content from 30-49 mol. \% $\left(\mathrm{An}_{30-49)}\right.$ and orthoclase content from 0.5-10.8 mol. \% (Electronic Appendix 2c, Figure 10). The spinel-clouded plagioclase has FeO contents up to 2.2 wt $\%$, whereas the clear plagioclase rims or grains in the spinel-clouded plagioclase metagabbro have $\mathrm{FeO}$ contents up to $0.29 \mathrm{wt} \%$. The clear plagioclase rims are slightly reduced in An. Some plagioclase grains in the recrystallized metagabbros are heavily zoned, with cores having $\mathrm{An}_{30-35}$ and rims having $\mathrm{An}_{43-49}$. Increased FeO content is associated with increased orthoclase, $\mathrm{MgO}$, and $\mathrm{TiO}_{2}$ content, with some plagioclase grains having orthoclase content $>10$ mol. $\%, \mathrm{FeO}>2$ wt. $\%, \mathrm{TiO}_{2}>1$ wt. $\%$, and $\mathrm{MgO}>1.3$ wt. \%. This high $\mathrm{FeO}$ spinel-clouded plagioclase is unusual, but has been previously reported in other gabbroic rocks in the Adirondacks and elsewhere with measured FeO contents up to 1.7 wt. \% (Whitney, 1972; Wass, 1973; Armbrustmacher and Banks, 1974). These studies argue that the high $\mathrm{FeO}$ plagioclase was stable at magmatic temperatures, and the spinel exsolved during cooling.

Plagioclase in the gabbroic anorthosite range from $\mathrm{An}_{50-72}$ and $\mathrm{FeO}$ contents between 0.13-0.38 wt. \%. Plagioclase in the GMGA range in $A_{19-74}$ with smaller orthoclase contents $(0.2-1.2 \mathrm{~mol}$. \%) and FeO contents (0.04-0.68 wt. \%). Two plagioclase inclusions in GMGA garnet porphyroblasts have $\mathrm{FeO}$ contents $>0.6$ wt. \% Plagioclase inclusions in the garnet porphyroblast from sample 17-ADK-09 range from $\mathrm{An}_{39-45}$, while the matrix plagioclase grains range from $\mathrm{An}_{49-53}$. Trace element profiles for metagabbros and GMGA plagioclase grains show similar trace element concentrations with positive Eu* anomalies (10.7-30.2) (Figure 9b).

\section{Pyroxenes}


Clinopyroxene is only observed in metagabbro. All clinopyroxene grains are either diopside or augite. $\mathrm{X}_{\mathrm{Mg}}$ in the clinopyroxene ranges from 0.74-0.81 (Figure 11, Electronic Appendix 2d). Orthopyroxene $\mathrm{X}_{\mathrm{Mg}}$ in the GMGA matrix ranges $0.68-0.72$ (Figure 11, Electronic Appendix 2e).

Orthopyroxene inclusions in the GMGA have cores with $\mathrm{X}_{\mathrm{Mg}}$ between $0.63-0.64$ and rims between $0.63-0.72$. Two orthopyroxene inclusions in garnet porphyroblasts are observed with $>6 \mathrm{wt} \% \mathrm{Al}_{2} \mathrm{O}_{3}$. The orthopyroxene in the garnet hornblendite ranges from $\mathrm{X}_{\mathrm{Mg}}$ between 0.71-0.75. The orthopyroxene in the metagabbros range from $\mathrm{X}_{\mathrm{Mg}}$ of $0.68-$ 0.77. Orthopyroxene in the gabbroic anorthosite have $\mathrm{X}_{\mathrm{Mg}}$ from 0.64-0.67.

Trace elements of the spinel-clouded plagioclase metagabbro clinopyroxene and orthopyroxene show depletion in HREE, likely due to re-equilibration in the presence of garnet (Figure 9c). Orthopyroxene Eu* ranges from 1.12-1.31 and clinopyroxene $\mathrm{Eu}^{*}$ ranges from $0.83-1.78$, indicating that the pyroxenes re-equilibrated while plagioclase was being consumed during the garnet forming reaction.

\section{Hydrous Phases}

Biotite in the spinel-clouded and recrystallized metagabbros has $\mathrm{TiO}_{2}$ contents ranging from 4.95-7.95 wt. \% (Figure 12a, Electronic Appendix 2f) and $\mathrm{X}_{\mathrm{Mg}}$ ranging from 0.66-0.72. Meanwhile, biotite in the GMGA has higher $\mathrm{X}_{\mathrm{Mg}}$ between $0.72-0.75$ and lower $\mathrm{TiO}_{2}$ contents between 2.0-4.2 wt. \%. Matrix biotites have lower $\mathrm{TiO}_{2}$ than inclusion biotite. Biotite in the gabbroic anorthosite also has high $\mathrm{TiO}_{2}(5.3$ wt. \%), but lower $\mathrm{X}_{\mathrm{Mg}}(0.66)$.

Amphiboles are mostly ferroan paragasite in the spinel-clouded plagioclase metagabbro and gabbroic anorthosite, mostly paragasitic in recrystallized metagabbro, and mostly tschermakitic in the GMGA (Electronic Appendix 2g). One inclusion of gedrite with $\mathrm{X}_{\mathrm{Mg}}=0.44$ was found as an inclusion in a garnet porphyroblast. With increasing hydration and modal fraction of amphibole, trace elements such as $\mathrm{TiO}_{2}$ decrease from values greater than 4 wt. \% in the spinel-clouded plagioclase metagabbros to $<1 \mathrm{wt} . \%$ in the GMGA (Figure $12 \mathrm{~b}$ ). $\mathrm{X}_{\mathrm{Mg}}$ is slightly lower in the spinel-clouded plagioclase metagabbros (0.64-0.69) and gabbroic anorthosite (0.66), and amphiboles besides the gedrite inclusion in the GMGA and recrystallized metagabbro have slightly higher $\mathrm{X}_{\mathrm{Mg}}(0.65-0.72)$. Amphibole in the spinel-clouded plagioclase metagabbros are 
depleted in their HREE's and enriched in the LREE's. In contrast, amphiboles in the recrystallized metagabbros and GMGA are very similar (Figure 9d) with relatively flat trace element patterns in equilibrium with the garnet porphyroblast trace element profiles (see DISCUSSION).

\section{Spinel}

Hercynitic spinel inclusions inside plagioclase in the spinel-clouded plagioclase metagabbro have $\mathrm{X}_{\mathrm{Mg}}$ of 0.32-0.49 (Electronic Appendix 2g). A spinel inclusion in a garnet porphyroblast has $\mathrm{X}_{\mathrm{Mg}}=0.41$.

\section{GEOCHRONOLOGY}

We determined trace element concentrations and $\mathrm{U}-\mathrm{Pb}$ ages of 44 zircon grains from a megacrystic garnet amphibolite to understand the relationship between, and timing of, metamorphic garnet and zircon formation. All of the U-Pb LA-ICPMS ages presented here were separated from GMGA sample 17-ADK-09 and are reported with zircon trace

elements in Electronic Appendix 3. The silica content of our laser-ablation measurements suggests that all measurements were made on zircon and not baddeleyite. Wetherill plots and CL images including the laser spot location of each analyzed zircon grain is available in Electronic Appendix 4.

Many separated zircons under CL have a turtleshell texture (Figure 13). This texture has been found in similar granulite-facies metagabbros in other Adirondacks metagabbros (McLelland et al., 2004) as well as in the Sveconorwegian Province in southern Scandinavia, where the texture was interpreted to be caused by the recrystallization of baddeleyite clusters into zircon as silica activity in the rock increases during prograde metamorphism (Beckman et al., 2017; Beckman and Möller, 2018). Zircon recrystallization around baddeleyite clusters is also observed in thin section in similar Grenville-age spinel-clouded plagioclase metagabbros in Ontario (Davidson and van Breemen, 1988). One possible reaction that increases silica activity is garnet growth due to the influx of fluid or melt (see DISCUSSION). Another interpretation for this zircon texture is radiation damage(Nasdala et al., 2003).

We calculate a weighted mean age of unmixed zircon analyses to date the garnet formation assuming that the garnet reaction was the last event to reset the metamorphic zircons. 44 concordant $\left(<4 \%\right.$ discordance $\left.\left(1-\left({ }^{206} \mathrm{~Pb} /{ }^{238} \mathrm{U} \text { age } /{ }^{207} \mathrm{~Pb} /{ }^{235} \mathrm{U} \text { age }\right)\right)^{*} 100\right)$ 
zircon ${ }^{206} \mathrm{~Pb} /{ }^{238} \mathrm{U}$ ages give a weighted mean age of $1053.9 \pm 5.4 \mathrm{Ma}(2 \sigma ; \mathrm{MSWD}=0.94)$

(Figure 14a). This age agrees well with previous GMGA multi-grain TIMS age of $1055 \pm 2$ (Scherer et al., 2000) as well as the SHRIMP ${ }^{207} \mathrm{~Pb} /{ }^{206} \mathrm{~Pb}$ age of $1048 \pm 10 \mathrm{Ma}(2 \sigma$; MSWD $=0.7$ ) found in irregular metamorphic rims in the nearby Oregon Dome ferrodiorite (Hamilton et al., 2004). In order to most reliably estimate the age of the Ottawan metamorphic event, we exclude the two youngest ages and five older ages from the weighted mean since they do not overlap with the weighted mean age within $2 \sigma$ error. Including these zircons does not greatly change our weighted average age (1055.9 \pm 4.9 Ma, MSWD 2.51), but greatly reduces the p-value of the weighted age (1.6e-8 for all concordant measurements or 0.58 for old and young ages removed). One young age is located on a rim (Figure 13, grain 34) while the other young age is measured at the turtleshell-textured side of a grain with oscillatory zoning (grain 7). The two younger zircons record a weighted mean age of $1010.7 \pm 17(2 \sigma ; \mathrm{MSWD}=0.66)$, which could be explained by late stage overgrowth, as pegmatites crosscutting the GMGA record two concordant zircon ages with a weighted average of $1008 \pm 10 \mathrm{Ma}(2 \sigma)$, suggesting there was fluid or melt present in the GMGA until the end of the Ottawan orogeny (McLelland and Selleck, 2011). The five older concordant zircon analyses record a weighted mean age of $1118.4 \pm 16.9 \mathrm{Ma}(2 \sigma ; \mathrm{MSWD}=0.70)$. The older zircon ages could be explained as inherited ages from the original AMCG igneous age (1170-1130 Ma). Wetherill plots of these groups are shown in Supplemental Figure 3.

Most turtleshell zircon grains show evidence of being in disequilibrium with the garnet. Most of the Ottawan age turtleshell zircons have high Lu/Dy ratios (>10) similar to the oldest concordant zircons, which, if inherited from the original igneous formation, did not grow in the presence of garnet (Figure 14b). We use Dy here instead of a LREE like La since Dy is the lightest REE above limit of detection for all zircon analyses. Lower Lu/Dy $(<10)$ ratios are observed for zircon which equilibrated with garnet (Hokada and Harley, 2004). Excluding the two youngest concordant turtleshell zircons, Ottawan-age zircons with other textures dominantly have Lu/Dy < 10 (Figure 14b). Previous analyses of $\mathrm{Hf}$ isotopes also show that the zircon and garnet in the GMGA are also in disequilibrium (Scherer et al., 2000). Lastly, the zircon ages tend to predate garnet Lu-Hf and Sm-Nd geochronology for Gore Mountain, though those dates have high 
variance (1018-1087 Ma, see BACKGROUND). This could also be due to the closure temperatures for a $1 \mathrm{~mm}$ garnet under slow cooling $\left(\sim 2{ }^{\circ} \mathrm{C} \mathrm{Myr}^{-1}\right)$ being $\sim 700^{\circ} \mathrm{C}$ for the $\mathrm{Sm}-\mathrm{Nd}$ system and $\sim 850{ }^{\circ} \mathrm{C}$ for the Lu-Hf system (Smit et al., 2013). Thus, either 1) the metamorphic zircon recrystallized or reset before garnet growth due to some other increase in silica activity, e.g. a silica rich fluid, and did not re-equilibrate afterwards, or 2) the metamorphic zircons recrystallized during garnet growth, but did not exchange trace elements with the matrix as there are turtleshell zircons with >1130 Ma concordant

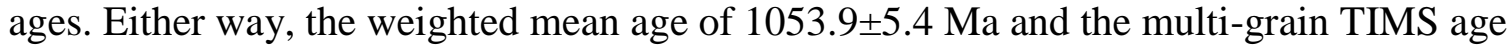
of $1055 \pm 2 \mathrm{Ma}$ (Scherer et al. 2000) should be an upper bound on the garnet formation age. Additional high-resolution single zircon dates are necessary to better constrain formation timescale for the garnet porphyroblasts and how recrystallized zircon trace elements and isotopic systems re-equilibrate with the surrounding minerals.

\section{THERMOMETRY}

Finding the peak P-T conditions of slow-cooled multiply deformed granulitefacies rocks is difficult given that they re-equilibrate as they cool. Two estimates of GMGA formation conditions have been made: 1) Luther (1976) estimated that the garnet amphibolite formed at $\sim 800^{\circ} \mathrm{C}$ and $\sim 7 \mathrm{kbar}$ based on experimental phase diagrams (Kushiro and Yoder, 1966) (grey box, Figure 15), and 2) Sharga (1986) reported a mean Fe-Mg garnet-clinopyroxene thermometry (Ellis and Green, 1979) of $878 \pm 58(1 \sigma)$ (individual measurements ranging from $774-926^{\circ} \mathrm{C}$ ) assuming $\mathrm{P}=7.5 \mathrm{kbar}$ in the adjacent gabbroic anorthosite (blue line, Figure 15a).

Quartz is present in the GMGA only as inclusions within garnet. One orthopyroxene-plagioclase-quartz inclusion in garnet was measured in sample 15-ADK13. Another hornblende-plagioclase-quartz inclusion in garnet was measured in sample 15-ADK-12. All mineral pairs for geobarometry are reported in Electronic Appendix 5. The orthopyroxene-plagioclase-quartz (Perkins and Chipera, 1985) and hornblendeplagioclase-quartz inclusion barometers (Kohn and Spear, 1990) predict pressures from 9-10 kbar assuming $800^{\circ} \mathrm{C}$ and $10.5-11.5 \mathrm{kbar}$ assuming $950^{\circ} \mathrm{C}$ (red, yellow, and green lines Figure 15a).

Hornblende-plagioclase thermometry (Holland and Blundy, 1994) is more reliable at constraining peak temperature conditions than $\mathrm{Fe}-\mathrm{Mg}$ thermometers due to the 
significantly slower diffusion of $\mathrm{Ca}$ and $\mathrm{Na}$ in plagioclase and hornblende compared to $\mathrm{Fe}$ and Mg in ferromagnesian phases (Grove et al., 1984; Cherniak and Dimanov, 2010). We use measured core values of adjacent hornblende-plagioclase pairs for temperature estimates. Since the hornblende is texturally metamorphic, we interpret the hornblendeplagioclase thermometry to represent P-T conditions from the Ottawan metamorphic event. Hornblende-plagioclase thermometry from the metagabbros and GMGA gives an average of $842 \pm 43^{\circ} \mathrm{C}(1 \sigma)$ with a maximum temperature of $923^{\circ} \mathrm{C}$ assuming $\mathrm{P}=10 \mathrm{kbar}$ (orange line, Figure 15). All mineral pairs for hornblende-plagioclase thermobarometry are reported in Electronic Appendix 5. We do not report any pyroxene pair thermometry in the metagabbros here as it is uncertain whether the temperature records the last equilibration during cooling from original igneous temperatures or a metamorphic temperature.

Recent studies have shown that exsolved rutile needles along the $\langle 111\rangle$ directions in garnet occur during cooling of ultra-high pressure and/or ultra-high temperature garnets (Axler and Ague, 2015; Keller and Ague, 2019). Due to the extremely slow diffusion of $\mathrm{Zr}$ in garnet, the $\mathrm{Zr}$-in-rutile (ZIR) thermometer (Tomkins et al., 2007) should record the temperature at which the needles exsolve. Previous studies (Ague et al., 2013; Axler and Ague, 2015) applying this thermometer to exsolved rutile needles in garnet have corroborated their ZIR temperatures with other high temperature thermobarometry, showing that applications of this methodology on exsolved rutile needles in garnet is robust. This thermometer assumes the presence of zircon and quartz, both of which are found as inclusions within the megacrystic garnets. We measured 65 rutile grains from four megacrystic garnet samples, requiring that all rutile measurements have $\mathrm{MgO}+\mathrm{CaO}+\mathrm{SiO}_{2}+\mathrm{MnO}+\mathrm{Al}_{2} \mathrm{O}_{3}<1.0 \mathrm{wt} \%$ indicating a lack of garnet contamination in the measurement (Supplemental Table 5c). Even in the case of garnet contamination, garnets were measured to have $\sim 20 \mathrm{ppm} \mathrm{Zr}$, so any contamination would only lower our temperature estimates.

The ZIR temperatures range from $786-1043^{\circ} \mathrm{C}$. The ZIR temperatures are well approximated by two normal distributions with peaks at $870 \pm 30^{\circ} \mathrm{C}$ and $985 \pm 30^{\circ} \mathrm{C}(1 \sigma)$ at $10 \mathrm{kbar}$ (black line, Figure 15a, b). The means and variances are fit using the MATLAB function fitgmdist assuming two distributions. There is no correlation between rutile $\mathrm{ZrO}$ 
concentrations and distance from rim in any garnet. The rutile $\mathrm{ZrO}$ concentrations may be kinetically controlled during rutile exsolution and thus not accurately record exsolution temperatures. We find this unlikely, as kinetic processes would not produce clear clusters of rutile $\mathrm{ZrO}$ concentrations and the high temperatures $\left(>850^{\circ} \mathrm{C}\right)$ estimated by all thermometers are suggestive of equilibrium conditions. Multiple clusters of rutile exsolution temperatures in garnet have been noted in previous studies and has been interpreted as due to the potential re-equilibration with coexisting zircon grains or continuous exsolution of rutile grains during cooling (Ague et al., 2013; Axler and Ague, 2015). The $870^{\circ} \mathrm{C}$ peak agrees well with the mineral-pair thermobarometers. The UHT ZIR temperatures come from the two larger garnet samples $(4-5 \mathrm{~cm}$ radius, $17-A D K-$ 09G, 17-ADK-11) with the thickest rutile needles $(>10 \mu \mathrm{m})$. The thicker rutile needles record the full range of temperatures within the lower peak (Figure 15). The thinner needles $(5-10 \mu \mathrm{m})$ are more uniform in $\mathrm{Zr}$ concentration (Figure 15b). We interpret this as the thinner needles re-equilibrated via diffusion during cooling whereas the larger rutile needles retained their original $\mathrm{Zr}$ concentrations.

\section{GARNET DIFFUSION MODELLING}

To test our estimates of ultra-high temperature ZIR temperatures, we apply diffusion modelling on the major element profiles of the four GMGA garnet porphyroblasts we measured ZIR temperatures in.. Since we have knowledge of the maximum formation age of the garnets, major element profiles of the garnets, and compiled various mineral-cooling age-temperatures nearby ( $<25 \mathrm{~km}$ away) Gore Mountain (Table 2), we utilize a grid-search algorithm to find the best-fit initial temperature to produce the garnet major element profiles. Our multicomponent diffusion model is conducted following the multi-component diffusion equations (Lasaga, 1979),

$$
\frac{d \boldsymbol{c}}{d t}=\boldsymbol{\nabla} \cdot(D \boldsymbol{\nabla c})
$$

where $c$ is the molar fractions of the divalent cations and $D$ is the multicomponent diffusion matrix. We solve the diffusion equation using a centered finite difference scheme in spherical coordinates assuming that the garnet only has compositional variation in the radial direction. Our model uses a fixed composition boundary condition at the rim and a symmetric boundary condition at the core. The garnet diffusivity tensor is 
calculated using diffusivities from Chu and Ague (2015). This approach takes into account garnet composition, oxygen fugacity, temperature, and pressure effects assuming ideal mixing of the endmember components. We use the mantle garnet composition to calculate the diffusivity tensor to significantly reduce computation time. Using a positionvariable diffusivity tensor does not significantly change our results. We correct the fugacity to fayalite-magnetite-quartz (FMQ) due to the observation of magnetite inclusions in garnet. For the oxygen fugacity correction, we use the FMQ fugacity parameterization from O'Neill (1987) with the pressure dependence from Huebner (1971) as well as the carbon-carbon dioxide oxygen fugacity from Jakobsson and Oskarsson (1994). For all diffusion calculations, we assume a constant pressure of $10 \mathrm{kbar}$.

Our grid search algorithm varies the following parameters: the initial temperature ( $\mathrm{T}_{\mathrm{init}}$ ), the $\mathrm{Ca}, \mathrm{Mg}$, and $\mathrm{Fe}$ boundary condition molar values for the rim ( $\mathrm{Mn}$ is fixed by the other three), and the position of the zonal boundaries in garnet samples that necessitate multiple zones, and the composition of each zone. The range of investigated compositions for each rim and zone are based around the maximum and minimum values within each profile. Investigated boundary positions for the sample are based on the position of interpreted zones if they exist in the profile. We investigate $\mathrm{T}_{\text {init }}$ between 800$1050{ }^{\circ} \mathrm{C}$.

For each run, we implement a two-stage linear cooling history (Figure 16), starting at each run's $T_{\text {init, }}$, and then pinning the temperature path to mineral closure temperature ages from nearby studies (Table 2). The initial cooling rate occurs between the formation of the Gore Mountain garnets at $1055 \mathrm{Ma}$ and the nearby titanite $\mathrm{U}-\mathrm{Pb}$ ages of $1033 \mathrm{Ma}$, which agrees with nearby monazite U-Pb ages (Mezger et al., 1991). We use a titanite $\mathrm{U}-\mathrm{Pb}$ closure temperature of $750^{\circ} \mathrm{C}$ as evidenced by recent analyses (Spencer et al., 2013) for the pinned temperature at $1033 \mathrm{Ma}$. After $1033 \mathrm{Ma}$, the cooling rate is fixed at $2.6{ }^{\circ} \mathrm{C} \mathrm{Myr}^{-1}$ following the mineral cooling ages and closure temperatures as well as

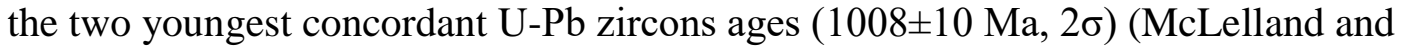
Selleck, 2011) from pegmatites that cross cut the GMGA to constrain when the GMGA must be at a temperature below the wet granite minimum. We conclude calculations once temperature cools below $500{ }^{\circ} \mathrm{C}$ when diffusion in garnet becomes negligible and then calculate a normalized root mean square error (NRMSE) for each result against the 
analytical profile. We exclude the eight analyses closest to the rim in our model of garnet profile 17-ADK-09 and the one closest rim analysis of garnet profile 17-ADK-11 due to evidence of late stage growth or resorption effects, e.g. stark increases in Ca and $\mathrm{Mn}$.

We apply our grid-search algorithm to four garnet major-element profiles (Figure 17, Supplemental Figures 4). Our model predicts a best-fit $\mathrm{T}_{\text {init }}=950{ }^{\circ} \mathrm{C}$ for three garnet profiles samples (17-ADK-09G, 15-ADK-05A, Figure 17, 17-ADK-11, Supplemental Figure 4) and $1000^{\circ} \mathrm{C}$ for one sample (15-ADK-09A, Supplemental Figure 4). The model result using the lower ZIR temperature $\left(\mathrm{T}_{\text {init }}=870{ }^{\circ} \mathrm{C}\right)$ is shown for comparison (blue line, Figure 17). Thus, the diffusion model find UHT conditions as the best-fit initial condition for each garnet profile, regardless of whether the garnet had measured UHT ZIR temperatures. This supports the hypothesis that the thinner rutile needles potentially reequilibrated during cooling, whereas the thicker needles retained their original temperatures.

We estimate an uncertainty of $\pm 40^{\circ} \mathrm{C}$ on the diffusion temperature estimate since $40^{\circ} \mathrm{C}$ increases the NRMSE by 5\% (Supplemental Figure 5). To further constrain the sensitivity of our diffusion model temperature estimate, we test the sensitivity of different parameters. Lowering the assumed pressure to $7 \mathrm{kbar}$ instead of $10 \mathrm{kbar}$ reduces the bestfit $\mathrm{T}_{\text {init }}$ by $20{ }^{\circ} \mathrm{C}$. Similarly, $\mathrm{T}_{\text {init }}$ is mostly insensitive to changing the titanite $\mathrm{U}-\mathrm{Pb}$ age; e.g. changing the pivot age to $1020 \mathrm{Ma}$ instead of $1033 \mathrm{Ma}$ decreases the best-fit $\mathrm{T}_{\text {init }}$ by only $20^{\circ} \mathrm{C}$. Likewise, changing the garnet formation age to $1065 \mathrm{Ma}$ instead of $1055 \mathrm{Ma}$ decreases the best-fit $\mathrm{T}_{\text {init }}$ by $30^{\circ} \mathrm{C}$ and changing the garnet formation age to $1045 \mathrm{Ma}$ increases $\mathrm{T}_{\text {init }}$ by $40{ }^{\circ} \mathrm{C}$. Holding the initial temperature constant for the first $5 \mathrm{Myr}$ of the diffusion model, approximating prograde diffusion, decreases the best-fit $\mathrm{T}_{\text {init }}$ by $20^{\circ} \mathrm{C}$.

The best-fit initial temperature found from this diffusion model is likely an upper bound on initial temperature, as prograde diffusion and garnet growth is excluded from our model. The use of step functions as boundaries between zones can overestimate temperature in diffusion models if the initial boundary was sloped. Since the characteristic diffusion length scale between the rim, mantle, and core are similar in the multi-zoned samples (17-ADK-09G and 17-ADK-11), we argue that the constant coremantle initial condition created by relatively instantaneous growth and prograde diffusion is insignificant and that step-functions work well to approximate the boundaries. This is 
further supported by the major-element WDS map of garnet 17-ADK-09G showing increased abundance of inclusions coinciding spatially with major changes in major element compositions (Figure 8). Another potential reason for the higher $\mathrm{T}_{\text {init }}$ compared to the thermobarometry is that the cooling path was pinned to constantly decrease through the nearby cooling ages, thus ignoring any potential variations in cooling rate such as prolonged peak Ottawan conditions or potential temperature increases due to the Rigolet phase of the Grenville Orogeny ( 1010-980 Ma). Such effects would also decrease our best-fit $\mathrm{T}_{\text {init }}$. Conversely, other diffusion-model based studies of the Adirondacks predict even higher initial cooling rates after peak Ottawan conditions (Storm and Spear, 2005; Bonamici et al., 2015). Enforcing higher initial cooling rates $\left(>50{ }^{\circ} \mathrm{C} \mathrm{Myr}^{-1}\right)$ would necessitate drastically increasing $\mathrm{T}_{\text {init }}\left(>1000{ }^{\circ} \mathrm{C}\right)$ to fit our diffusion profile. A likely scenario is that peak conditions were higher, but cooling was faster than a constant rate from the garnet formation age and initial temperature to monazite and titanite cooling ages and temperatures. In summary, garnet major element diffusion profiles (best-fit $\mathrm{T}_{\text {init }}=950-1000 \pm 40{ }^{\circ} \mathrm{C}$ ) support the interpretation that the UHT ZIR thermometry $\left(985 \pm 30{ }^{\circ} \mathrm{C}\right)$ is robust and not an artifact of non-equilibrium processes.

\section{THERMODYNAMIC MODELLING}

Another way to further refine P-T constraints is through matching observed mineral assemblages and modes with thermodynamic modelling of bulk compositions. Due to the similar whole-rock compositions of both metagabbros and GMGA (Figure 5), we argue that the GMGA was only hydrated, and not enriched in any other fluid-mobile elements. Pseudosection modelling of the metagabbro composition with various water contents at the P-T consistent the higher thermobarometric peaks $\left(985 \pm 30^{\circ} \mathrm{C}, 10 \pm 1 \mathrm{kbar}\right)$ agrees with the observed assemblages of the metagabbros and GMGA (Figure 18). Since we observe biotite inclusions in the garnet, biotite existed during garnet formation and cannot be only retrograde as the phase diagrams suggest (purple curves). The presence of biotite in the GMGA and nearby metagabbros at high temperatures is likely due their high $\mathrm{TiO}_{2}$ contents, which stabilizes biotite to higher temperatures (Douce, 1993).

Although the high pressures and temperatures estimated by thermobarometry and diffusion modelling are usually associated with amphibole-free granulite facies metamorphism, Perple_X modelling predicts amphibole is stable in wet (1 wt. \% $\mathrm{H}_{2} \mathrm{O}$ ) 
conditions at temperatures up to $1200{ }^{\circ} \mathrm{C}$ at $10 \mathrm{kbar}$ (Figure $18 \mathrm{c}$ ), $300{ }^{\circ} \mathrm{C}$ above the solidus, in line with melting experiments (e.g. Rapp and Watson, 1995).

Increasing water content from damp $(0.5 \mathrm{wt} \%)$ to wet $(1 \mathrm{wt} . \%)$ in the metagabbro composition lowers the expected grossular content by 3-5 mol. \% (20-23 mol. \% to 1719 mol. \%) at all subsolidus P-T conditions due to the lack of clinopyroxene in the wet composition. While the thermodynamic models are unable to reproduce the observed garnet grossular content (8-14 mol. \% in the GMGA and $13-15 \mathrm{~mol} . \%$ in the metagabbro, Figure 7), we interpret the difference in grossular content between the GMGA and metagabbro to be caused by variation in hydration.

Assuming a wet composition ( $1 \mathrm{wt} . \% \mathrm{H}_{2} \mathrm{O}, \sim 50$ vol. $\%$ amphibole, reasonable for the GMGA), our thermodynamic modelling predicts mineral assemblage of amphibole, clinopyroxene, garnet, orthopyroxene, and melt at $985^{\circ} \mathrm{C}$ and 10 kbar. Melt in plagioclase-amphibole aggregates becomes interconnected and able to segregate somewhere between 2-5 vol. \% (Wolf and Wyllie, 1995), suggesting that for melt volumes $<5 \%$, melt can be retained and reintegrated. Since the GMGA is similar in bulk composition to the protoliths, we take the 5 vol. \% melt contour (dashed blue line) to be a maximum temperature $\left(970^{\circ} \mathrm{C}, 10 \mathrm{kbar}\right.$ for $\left.1 \mathrm{wt} . \% \mathrm{H}_{2} \mathrm{O}\right)$. Furthermore, since there is no clinopyroxene in the matrix or as garnet inclusions in the GMGA, and since we observe quartz inclusions in the GMGA, the pseudosection modelling requires the temperature to be $<960^{\circ} \mathrm{C}$ at $10 \mathrm{kbar}$, consistent with the diffusion model and the colder end of the UHT ZIR thermometry.

Since the garnets show no evidence of significant garnet resorption texturally or chemically, another limitation on the peak P-T conditions of the GMGA is the volume of garnet present ( $<25$ vol \%, dashed red contours, Figure 19). Furthermore, thermodynamic modelling constrains the pressure to be within 8.5-10 kbar due to the volume of garnet predicted. Above $10 \mathrm{kbar}$ at temperatures $<1000^{\circ} \mathrm{C}$, thermodynamic modelling predicts expects $>25 \mathrm{vol} \%$ garnet in the damp metagabbro (Figure 18b), which is not observed. Below $8.5 \mathrm{kbar},<10 \mathrm{vol} \%$ garnet is predicted at temperatures $>850{ }^{\circ} \mathrm{C}$ in the wet metagabbro composition (Figure 18b,c). Regional pressure estimates of 7-8 kbar at any temperature $>800^{\circ} \mathrm{C}$ predict $0-5$ vol. $\%$ garnet. Thus, the higher pressures $(10 \pm 1 \mathrm{kbar})$ found in the mineral-pair barometers are in better agreement with modal proportions 
predicted by thermodynamic modelling. Synthesizing the mineral-pair barometry, the ZIR thermometry, the diffusion model temperature estimate, and constraints from thermodynamic modelling and observed modal assemblage, we estimate peak P-T conditions to be $950 \pm 40^{\circ} \mathrm{C}$ and $9-10 \mathrm{kbar}$.

Due to the megacrystic grain size of the garnet, not all of the garnets may have been in compositional equilibrium during metamorphism. Subtracting and renormalizing half of the garnet chemistry from the wet metagabbro composition produces a similar phase diagram, with clinopyroxene, amphibole, garnet, plagioclase, quartz, and ilmenite being stable at $950^{\circ} \mathrm{C}, 10 \mathrm{kbar}$ (Supplemental Figure 6). Fractionating garnet increases the bulk $X_{\mathrm{Mg}}$, potentially causing the higher rim $\mathrm{X}_{\mathrm{Mg}}$ as observed in all garnets and higher biotite $\mathrm{X}_{\mathrm{Mg}}$ in the GMGA biotite compared to the biotite in the metagabbros (Figure 12a). Trace amounts ( $<1$ vol. \%) of clinopyroxene are predicted to stabilize due to increased $\mathrm{Na}_{2} \mathrm{O}$ contents, decreased $\mathrm{Al}_{2} \mathrm{O}_{3}$, and only slightly decreased $\mathrm{CaO}$ due to garnet fractionation. Since we do not observe clinopyroxene in the GMGA matrix or as garnet inclusions, fractionation was likely less than half the garnet volume.

\section{DISCUSSION}

\section{P-T-t Path}

Based on our results we propose the following revised cooling path and metamorphic reactions for the Gore Mountain-related rocks (Figure 19):

a) The metagabbro protolith is part of the 1170-1150 Ma AMCG suite magmatic episode (Hamilton et al., 2004; McLelland et al., 2004). This is supported by the fact that the major elements of the spinel-clouded plagioclase metagabbro and GMGA overlap with the compositional range of the AMCG-related rocks (Figure 5). The spinel-clouded plagioclase metagabbro preserves a remnant magmatic texture of euhedral plagioclase and anhedral clino- and orthopyroxene. Since the AMCG suite magmatism follows tholeiitic major-element trends (Seifert et al., 2010), this textural observation requires that the metagabbro emplacement pressure is $<7 \mathrm{kbar}$, since at $\mathrm{P} \geq 7 \mathrm{kbar}$, an anhydrous tholeiitic melt crystallizes clinopyroxene at higher or similar temperatures than plagioclase (Villiger et al., 2007). The high orthoclase content plagioclase grains in the metagabbros suggest igneous temperatures $>1000^{\circ} \mathrm{C}$ (Fuhrman and Lindsley, 1988). This is similar to the expected intrusion P-T conditions of the Marcy Massif anorthosite (7-8 
kbar, Regan et al., 2019) at 1050-1150 ${ }^{\circ} \mathrm{C}$ (Ashwal, 1982; Spear and Markussen, 1997)). The primary igneous phases were high-Fe plagioclase, olivine, clinopyroxene, orthopyroxene, and Fe-Ti oxides based on thermodynamic modeling and coronal textures in similar metagabbros (Whitney, 1972; Whitney and McLelland, 1973; Johnson and Carlson, 1990).

(b) After crystallization, we assume the region underwent isobaric cooling until the start of the Ottawan orogeny (1090 Ma, McLelland et al., 2001). A limitation on the P-T-t path is the volume of garnet present ( $<25 \mathrm{vol} \%$, dashed contours, Figure 19). Since the garnets in the spinel-clouded plagioclase metagabbro show no evidence of significant garnet resorption texturally or chemically, the P-T-t path must not have cooled below $600^{\circ} \mathrm{C}$, assuming an emplacement pressure of $6 \mathrm{kbar}$, before the Ottawan metamorphic event.

(c) During Ottawan convergence, the crust thickened (Rivers, 2012, 2015). Garnets can be formed via metamorphic reactions as well as magmatic processes. We argue that the lack of a sharp contact between the metagabbro and GMGA (Figure 3, bottom middle), their similar bulk chemistry, and the presence of unique inclusions such as high-Ti biotite and Fe-enriched plagioclase suggest that the GMGA metamorphosed from the metagabbros (Bartholome, 1960; Luther, 1976; McLelland and Selleck, 2011). The hydration of the metagabbro must have taken place during the garnet reaction:

Plagioclase+Spinel+Ilmenite+Olivine+Orthopyroxene+Clinopyroxene+Fluid $\rightarrow$

$$
\text { Biotite+Amphibole+Garnet+Quartz } \pm \text { Melt }
$$

based on the change of modes predicted by thermodynamic modelling for the dry spinelclouded plagioclase metagabbro at box (b) in Figure 19 to the wet metagabbro at box (d) as well as the remnant modal mineralogy of the spinel-clouded plagioclase metagabbro and megacrystic garnet inclusions. The $\mathrm{cm}$-thick euhedral amphibole rims in our model are not due to decompression since no kelyphytic or symplectic amphibole rims are observed (Dégi et al., 2010), but rather a reaction product that surrounded the growing garnet, as previously hypothesized (Bartholome, 1960). Since biotite and amphibole are common inclusions in garnet porphyroblasts, the garnet likely formed during fluid infiltration and heating. While no quartz is found in the GMGA matrix, quartz inclusions are found in garnet. Thus, reaction (2) increases the silica activity since quartz is a 
product. This increase could have recrystallized the baddeleyite grains into turtleshell zircons. The precise timescale of this reaction requires high-resolution dating, but given the agreement between concordant multigrain TIMS age and our zircon weighted average age (1053.9 $\pm 5.4 \mathrm{Ma})$ suggests this reaction occurred ca. $1055 \mathrm{Ma}$.

The spinel-clouded plagioclase metagabbros and the GMGA experienced the same P-T-t path and have nearly the same bulk composition, but produced drastically different grain size and textures. We argue that the megacrystic garnets must form due to a larger quantity of the fluid phase, as the metagabbros also contain metamorphic biotite and amphibole (Luther 1976). The larger amount of the fluid and/or melt in the GMGA relative to the metagabbros increased the ionic diffusivity such that garnet growth was strongly favored over garnet nucleation (Luther, 1976; Goldblum and Hill, 1992; McLelland and Selleck, 2011). The fluid likely rose in a shear zone formed from the contrasting strengths of the metagabbros and nearby feldspar-rich lithologies (Goldblum and Hill, 1992). This hypothesis explains why the garnet porphyroblasts concentrate within $50 \mathrm{~m}$ at the southern contact of the GMGA with the metasyenite as well as the decreasing amount of hydrous phases observed further into the spinel-clouded plagioclase metagabbro.

(d) The solidus for the metagabbro composition with $1 \mathrm{wt} . \% \mathrm{H}_{2} \mathrm{O}$ (based on 50 vol. \% amphibole in the garnet amphibolite) is predicted to be $940{ }^{\circ} \mathrm{C}$ at $10 \mathrm{kbar}$. At $950^{\circ} \mathrm{C}$ and 1 wt. $\% \mathrm{H}_{2} \mathrm{O}$, thermodynamics modelling predicts 0.4 vol. \% melt. Thus, during the peak temperature conditions, the most hydrated portions of the GMGA melted (Figure 18c, d), but the proportion of melt was likely too small to segregate, allowing the GMGA to retain a similar bulk composition to the metagabbro protolith (Figure 5). In the most hydrated portions, melt could have become interconnected and segregated. The prediction of melt is also supported by odd high-T inclusions in the garnet such as cristobalite and high-Na assemblages predicted to be melt-inclusions (Darling et al., 1997; Ferrero et al., 2019). The crosscutting pegmatites, which post-date the GMGA (McLelland and Selleck, 2011), could be a portion of melt product that segregated.

(e) Assuming a two-stage cooling history pinned by nearby cooling ages, our diffusion model finds that a fast initial cooling $\left(\sim 9.1{ }^{\circ} \mathrm{C} \mathrm{Myr}^{-1}\right)$ occurs from $1055 \mathrm{Ma}$ to $\sim 1030 \mathrm{Ma}$ (Fig. 16). At $\sim 1030 \mathrm{Ma}$, the slow regional cooling rate $\left(\sim 2.6^{\circ} \mathrm{C} \mathrm{Myr}^{-1}\right)$ is 
defined by the nearby cooling ages. This agrees with other estimates of a rapid Ottawan cooling event at roughly 1055 Ma followed by slow cooling afterwards (Storm and Spear, 2005; Bonamici et al., 2015), though our fast cooling is slower than predicted in those studies $\left(9.1{ }^{\circ} \mathrm{C} \mathrm{Myr}^{-1}\right.$ compared to $\left.>50{ }^{\circ} \mathrm{C} \mathrm{Myr}^{1}\right)$. Pressure must decrease during cooling, as thermodynamic modelling predicts $>25$ vol \% garnet with isobaric cooling. Furthermore, orthopyroxene-plagioclase-amphibole symplectites are observed in the GMGA matrix away from megacrystic garnet and suggest that the retrograde cooling path passed from the garnet+plagioclase+amphibole field into the garnet+plagioclase+amphibole+orthopyroxene field (Figure 18c), similar to previous hypotheses for these symplectites (Hollocher, 2008). We place the cooling path through the previous regional P-T estimate of the Adirondack Highlands (750-850 $\left.{ }^{\circ} \mathrm{C}, 7-8 \mathrm{kbar}\right)$ to be consistent with previous thermobarometric studies (Figure 20).

\section{Fluid Source of the GMGA}

Four hypotheses are possible for the source of fluid: 1) surface water came through a deep fault, 2) a hydrous silicic melt created by the amphibole-out reaction in the crust below the Highlands, or 3) dehydration of lower crustal rocks that had not fully dehydrated during the Elzevirian orogeny and advection of the resulting fluid or melt upwards in dike-like features through the GMGA(Luther, 1976), 4) the crystallization of the Ottawan magmatism (the LMG) released fluids which infiltrated and hydrated the GMGA (McLelland and Selleck, 2011).

Garnet porphyroblasts contain dolomite inclusions, suggesting that whatever fluid intruded into the metagabbros had $\mathrm{CO}_{2}$ as well as $\mathrm{H}_{2} \mathrm{O}$. This observation is further supported by evidence for $\mathrm{a}_{\mathrm{H} 2 \mathrm{O}}<0.2$ during the Ottawan by many mineral buffers (Valley et al., 1990) interpreted as the result of metamorphosing already dehydrated metasediments and igneous rocks after the Elzevirian orogeny (1190-1140 Ma). This would suggest the fluid is more likely to come from sources with carbonate such as metasediments, though $\mathrm{CO}_{2}$ could also be added into lower crustal melt through reactions. We prefer the addition of a saline-lower crustal fluid to the addition a silicic melt, as unless the silicic melt was in equilibrium with the metagabbro cumulate, the intrusion of melt would modify bulk composition of the GMGA relative to the metagabbro, which we do not observe. 


\section{Adirondack Ottawan peak P-T conditions}

Our results show that the formation of the GMGA requires ultra-high temperatures $\left(>900^{\circ} \mathrm{C}\right)$, pressures of 9-10 kbar, and a pervasive fluid source. These P-T conditions are higher than previously estimated for the Adirondacks $\left(700-850^{\circ} \mathrm{C}, 6-8\right.$ kbar), but are not out of place considering more recent higher temperature estimates including one other UHT estimate near the Marcy Massif (Figure 20). The locations of megacrystic garnet outcrops (red stars, Figure 20) could represent regions with both high P-T conditions and the presence of $\mathrm{H}_{2} \mathrm{O}\left(\right.$ and $\mathrm{CO}_{2}$ ) bearing fluid. This combination is unlikely to be realized throughout the entire lower crust during orogenesis and metamorphism. In the Adirondack Highlands only a few older migmatites bear Ottawanage zircon rims, suggesting that fluid content and/or temperature could have been variable (light blue circles, Figure 20) during peak metamorphism. In addition, spinelclouded plagioclase metagabbros similar to the ones at Gore Mountain crop out near the Marcy Massif in the northern Adirondack Highlands (Figure 1), but are not associated megacrystic garnet amphibolites. Ottawan-age pegmatites (dark blue circles, Figure 20) along the eastern edge of the Marcy Massif show that there was likely fluid present in some regions near metagabbro locations. Thus, the absence of megacrystic garnet amphibolites can be plausibly explained by slightly lower peak pressure-temperature conditions during metamorphism in the Marcy Massif region.

\section{Implications for modern orogenesis}

Topography-driven lower crustal channel flow, hypothesized to explain the low relief, but topographically high Tibetan Plateau (Bird, 1991; Royden et al., 1997; Clark and Royden, 2000), requires $>10 \mathrm{~km}$ thick lower crustal portions with effective viscosities $\leq 10^{19} \mathrm{~Pa}$ s along with large topographic variations (Clark and Royden, 2000; Beaumont et al., 2004; Grujic, 2006; Gerya et al., 2008). To estimate the range of potential effective viscosities for the Adirondack Highlands during the end of the Ottawan Orogeny, we use the wet anorthite dislocation creep flow law (Rybacki et al., 2006)

$$
\dot{\epsilon}=A f_{H_{2} O}^{r} \sigma^{n} \exp \left(\frac{-(E+P V)}{R T}\right)
$$


where $\dot{\epsilon}$ is the strain rate, $\mathrm{A}$ is the pre-exponential factor $\left(10^{0.2} \mathrm{MPa}^{-3} \mathrm{~s}^{-1}\right), f_{H 2 O}$ is the water fugacity, $r$ is the water fugacity exponent (1), $\sigma$ is the second invariant of the deviatoric stress, $n$ is the stress exponent (3), $E$ is the activation energy ( $\left.345 \mathrm{~kJ} \mathrm{~mol}^{-1}\right), V$ is the activation volume $\left(38 \times 10^{-6} \mathrm{~m}^{3} \mathrm{~mol}^{-1}\right), P$ the pressure, $R$ the universal gas constant $\left(8.314 \mathrm{~J} \mathrm{~mol}^{-1}\right)$, and $T$ the temperature in Kelvin. We use the wet anorthite flow law because the Adirondack Highlands are dominated by feldspar-rich lithologies and the wet anorthite flow law best also approximates viscosity estimates lower crustal rocks (Rybacki and Dresen, 2004; Bürgmann and Dresen, 2008; Shinevar et al., 2018). We approximate water fugacity using an exponential fit at crustal conditions

$$
f_{H 2 O}=a_{H 2 O} A_{1} \exp \left(-\frac{A_{2}+P A_{3}}{R T}\right),
$$

where $a_{H 2 O}$ is the water activity and $A_{1}, A_{2}$, and $A_{3}$ are empirically fit constants (5521 $\mathrm{MPa}, 31.28 \mathrm{~kJ} / \mathrm{mol}$, and $-2.009 \times 10^{-5} \mathrm{~m}^{3}$ respectively) (Shinevar et al., 2015). We use a $\mathrm{a} 2 \mathrm{O}=0.1$ based on constraints from previous studies based on mineral buffers $\left(\mathrm{a}_{2} \mathrm{O}<0.2\right.$, Valley et al., 1990). Effective viscosity $(\eta)$ is calculated as

$$
\eta=\frac{\sigma^{1-n}}{2 A f_{H 2 O}} \exp \left(\frac{-E+P V}{R T}\right) \frac{2}{3^{(n+1) / 2}}
$$

The right-most fraction adjusts the flow law derived from an axial compression experiment for triaxial stress conditions as described in Gerya, (2009). We calculate viscosities for a range of possible stresses (0.1-10 MPa) along the cooling path derived from our garnet diffusion model (Figure 16), though we note that the P-T experienced by the GMGA may have been exceptional for the Highlands (Figure 20).

The lower crust at the depths of the GMGA of the Ottawan orogeny was weak enough to allow topography-driven lower crustal flow for 0-20 Myr at $10 \mathrm{kbar}$ after peak metamorphic P-T conditions with no effect of melt (Figure 21a). At $\sigma=1 \mathrm{MPa}, \mathrm{P}=10$ kbar, $a_{H 2 O}=0.1$, and $\mathrm{T}=875^{\circ} \mathrm{C}$, produces a viscosity of $1.22 \times 10^{19} \mathrm{~Pa}$. Lower crustal flow is only possible for temperatures $>875^{\circ} \mathrm{C}$ at $\sigma=1 \mathrm{MPa}$ without other weakening effects or at higher deviatoric stresses $(>1 \mathrm{MPa})$ at $875^{\circ} \mathrm{C}$. The addition of $\leq 12 \mathrm{vol} . \%$ melt weakens feldspar-rich lithologies by a factor of 3-5 (Dimanov et al., 1998). If partial melt and fluids in the lower crust are retained as seen by late Ottawan pegmatites and fluid alteration, topography-driven lower crustal flow could persist for 0-25 Myr at 
$10 \mathrm{kbar}$. Even with the weakening effect of melt and UHT temperatures, viscosities less than $10^{19}$ are not possible for low deviatoric stress invariants ( $\left.<0.1 \mathrm{MPa}\right)$. The durations predicted assuming the GMGA cooling history (Fig. 19) at higher deviatoric stress invariants ( $\geq 1 \mathrm{MPa}$ ) are similar to the formation timescale of the Tibetan plateau (ca. 1020 Myr) (Harrison et al., 1992). Topography-driven lower crustal flow advects granulitefacies material into colder geotherms until flow stops, after which conduction becomes the dominant cooling mechanism (Figure 21b). This geophysical sequence for the Adirondack Highlands could explain the high initial cooling rate dominated by advection followed by second slower cooling rate dominated by conduction required by diffusion modelling from this and other studies (Storm and Spear, 2005; Bonamici et al., 2015).

\section{CONCLUSION}

Here we compiled petrological analysis, thermobarometry, diffusion modelling, and thermodynamic modelling to show that the megacrystic Gore Mountain Garnet Amphibolite (GMGA) formed at ultra-high temperature P-T conditions (9-10 kbar, $950 \pm 40{ }^{\circ} \mathrm{C}$ ). Garnet major element diffusion models suggest that following garnet formation, the GMGA cooled at $\sim 9.1{ }^{\circ} \mathrm{C} \mathrm{Myr}^{-1}$ followed by a slower $2.6{ }^{\circ} \mathrm{C} \mathrm{Myr}^{-1}$ constrained by nearby ( $<25 \mathrm{~km}$ away) mineral closure temperature-ages. The GMGA formed during crustal thickening in the Ottawan orogeny due to an influx of fluid into a spinel-clouded plagioclase metagabbro related to the 1170-1130 AMCG suite magmatism. Dating of metamorphic zircon constrains the garnet formation age to be 1053.9 $\pm 5.4 \mathrm{Ma}$ in agreement with previous ages based on zircon and garnet geochronology. The spinel-clouded plagioclase metagabbro is the protolith as evidenced by garnet porphyroblast inclusion chemistry, whole-rock composition, and the gradual transition from the metagabbro into the garnet amphibolite. The $\mathrm{cm}$-thick euhedral amphibole rims are not decompression rims, but rather the reaction product that surrounded the growing garnet porphyroblasts. This metamorphic reaction formed some melt as predicted by thermodynamic modelling and the existence of high-T inclusions (Darling et al., 1997; Ferrero et al., 2019), potentially forming the nearby gabbroic anorthosite based on whole rock trace elements. The cooling history for the Adirondack Highlands suggests that the region was hot enough to undergo topography-driven lower crustal flow similar to hypothesized for modern Tibet for 0-20 Myr depending on the 
deviatoric stress second invariant (0-25 Myr when the effects of melt are included). The two-stage cooling history for the GMGA from UHT conditions could reflect initial advection-dominated cooling due to topography-driven lower crustal flow, followed by conduction-dominated cooling once flow ended.

\section{ACKNOWLEDGEMENTS}

We thank Bonnie Barton for access to the mine and ability to collect samples. We thank Neel Chatterjee for help with the microprobe. We thank Jake Setera for help with the LA-ICPMS and data processing. We thank Seth Kruckenberg for help with EBSD measurements. We thank Benjamin Klein, Ben Urann, and Craig Martin for help during fieldwork and insightful discussions. We thank J.O. Eckert, Jr. for help mounting and measuring our large garnet sample at the Yale microprobe. We thank the reviewers, John Aleinikoff, Chloë Bonamici, and Jay Ague, for careful and insightful comments that greatly helped our paper. We also thank the editors, Alasdair Skelton and Georg Zellmer, for handling this manuscript and for their helpful comments. We thank Geological Society of America Graduate Student Research Fellowship, Woods Hole Oceanographic Institute Ocean Venture Fund, and Massachusetts Institute of Technology Student Research Funds for funding this study. Additionally, the work of WJS and OJ was supported by NSF-EAR 1722935. 


\section{Figures}

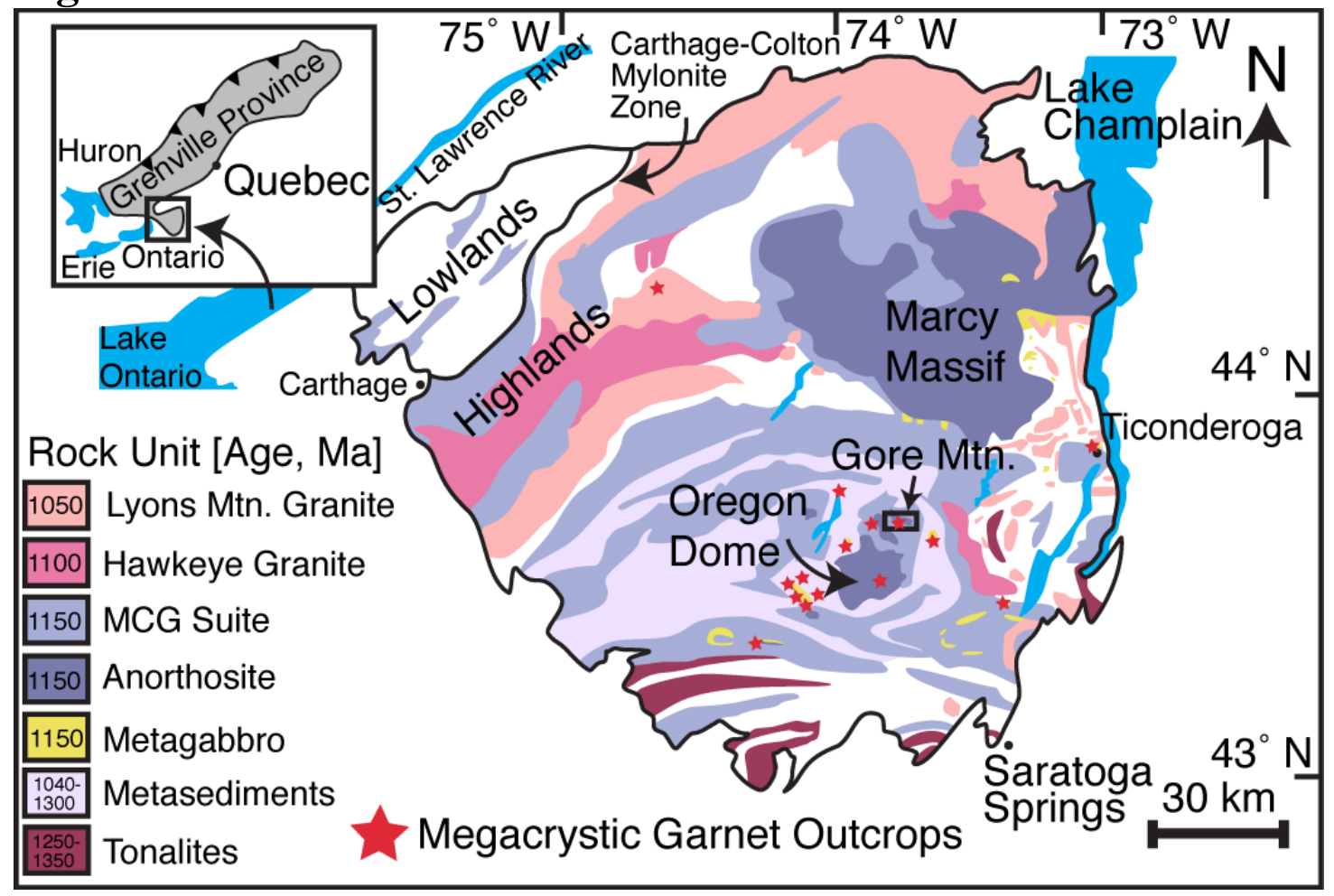

Figure 2.1: Regional geological map of the Adirondack Highlands. Modified after McLelland et al. (2010b). Red stars indicate an outcrop exposure with megacrystic garnets after McLelland and Selleck (2011). MCG: mangerite-charnockite-granitoid. 


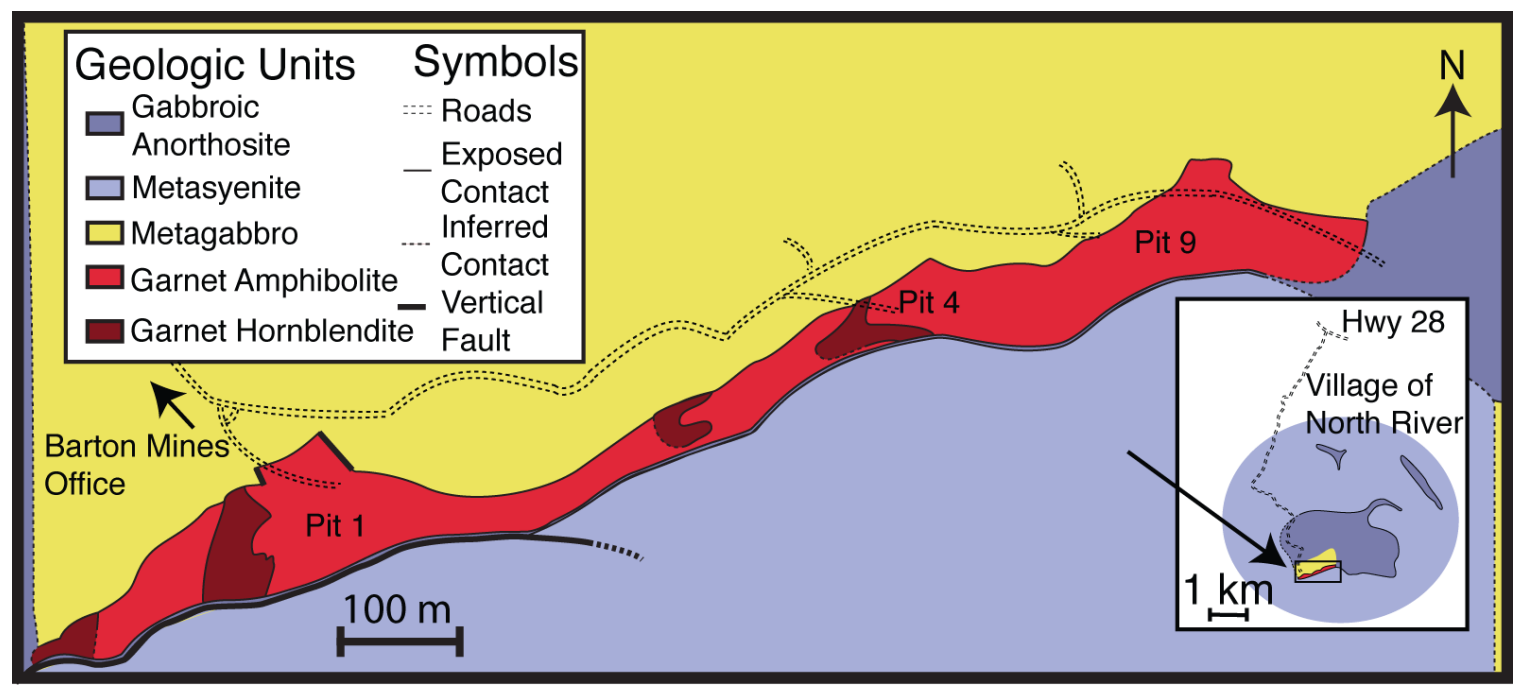

Figure 2.2: Outcrop map of Gore Mountain, modified after Luther (1976). Bottom left is the black box in Figure 1 . 


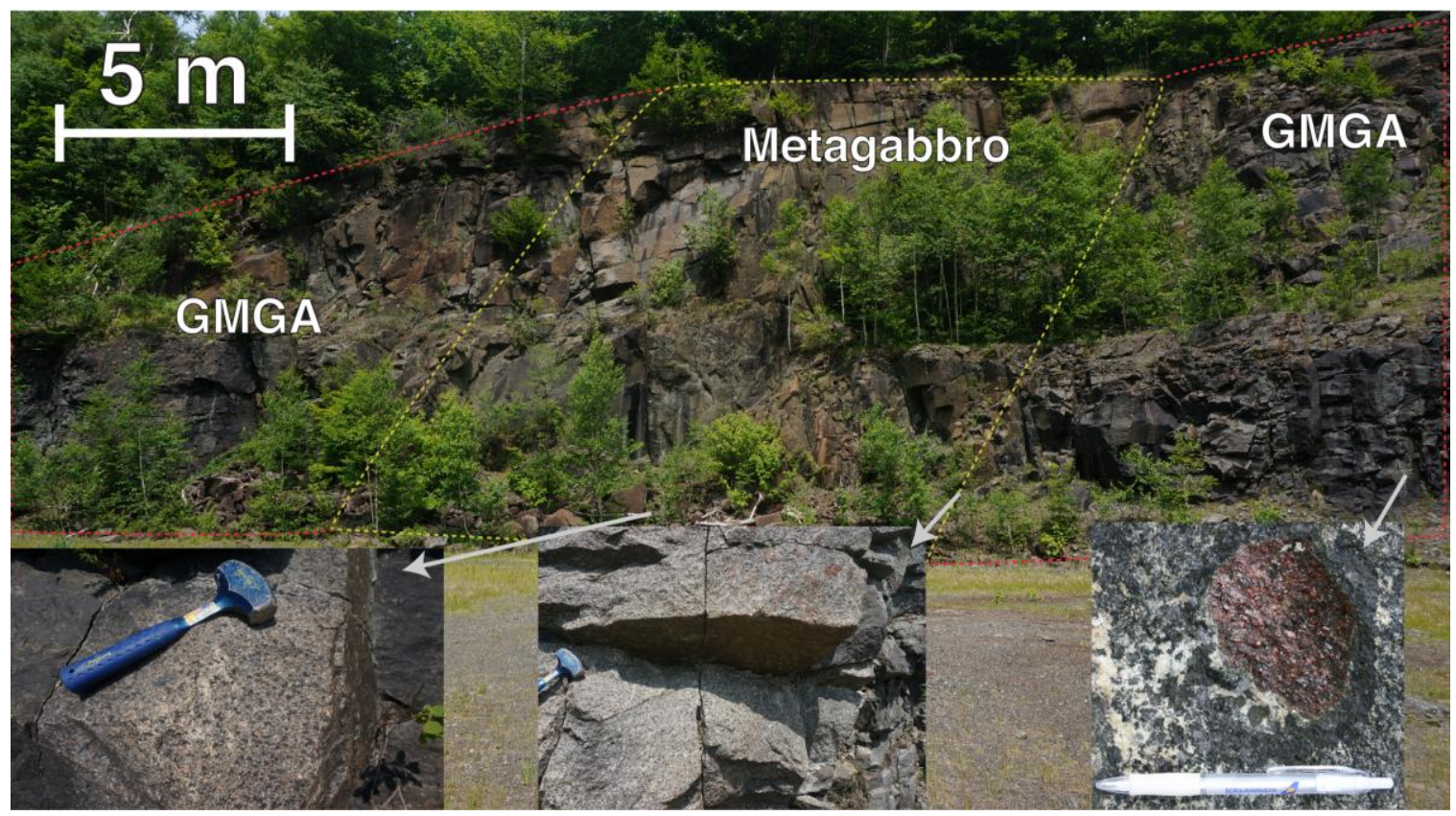

Figure 2.3: North facing outcrop photo in Pit 4 (Figure 2) with scale bar in the top left. Dashed yellow outline shows the outcrop region with spinel-clouded plagioclase metagabbro or recrystallized metagabbro where the red outline shows the region of the GMGA. Three close up pictures showing the spinel-clouded plagioclase metagabbro (left), the gradual transition between the recrystallized metagabbro and the GMGA (middle), and a close up of a megacrystic garnet from the GMGA (right). Rock hammer and pen for scale. 

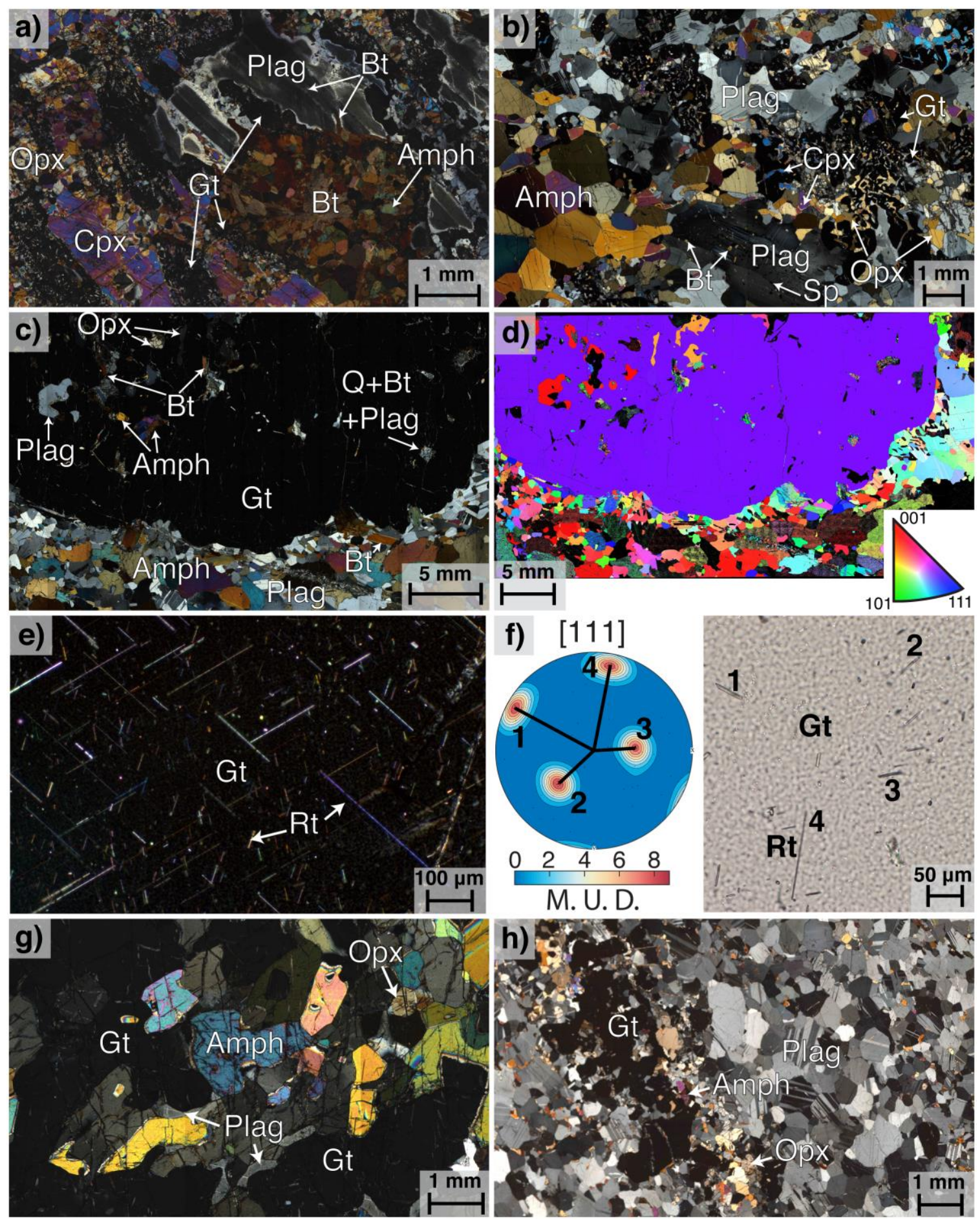

Figure 2.4: a) Cross-polarized light (XPL) image of the spinel-clouded plagioclase metagabbro (17-ADK-08), b) XPL image of the recrystallized metagabbro (15-ADK-02), c) XPL image of the garnet amphibolite (15-ADK-13), d) Inverse pole map of panel c showing that the garnet grain is a single crystal, e) rutile exsolutions in the garnet of the GMGA (17-ADK-09G), f) Pole figure for the [111] shown alongside a plane-light image of rutile exsolutions from the same sample (15-ADK-13) in the same orientation. M.U.D 
(multiple of uniform density) describes the strength of the pole direction. A M.U.D. of 1 represents random fabric, while higher numbers show the most likely [ $\left[\begin{array}{lll}1 & 1 & 1\end{array}\right]$ direction. Numbers 1-4 exhibit rutile exsolutions along all four [ [1 111 1] directions. g) XPL image of the garnet hornblendite (17-ADK-03), h) XPL image of the gabbroic anorthosite (15ADK-11). Mineral abbreviations: amphibole (Amph), biotite (Bt), clinopyroxene (Cpx), garnet $(\mathrm{Gt})$, orthopyroxene (Opx), plagioclase (Plag), quartz $(\mathrm{Q})$, rutile $(\mathrm{Rt})$, and spinel $(\mathrm{Sp})$. 

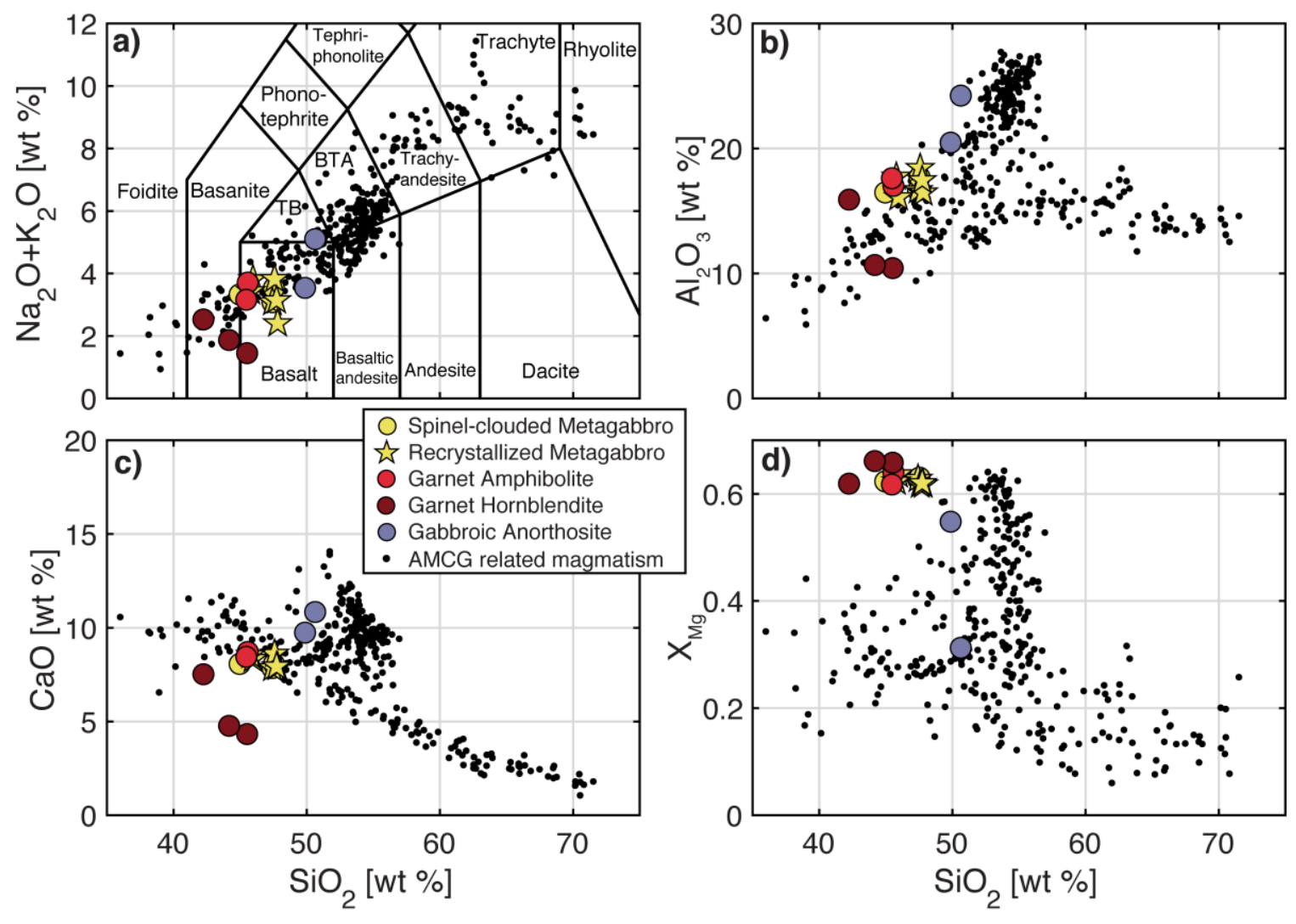

Figure 2.5: Total alkali silica (a) and Harker diagrams (b-d) for Gore Mountain rocks from this study and Luther (1976). AMCG related magmatism data taken from Seifert et al. (2010). Rock abbreviations in (a): trachybasalt (TB) and basaltic trachyandesite (BTA). 


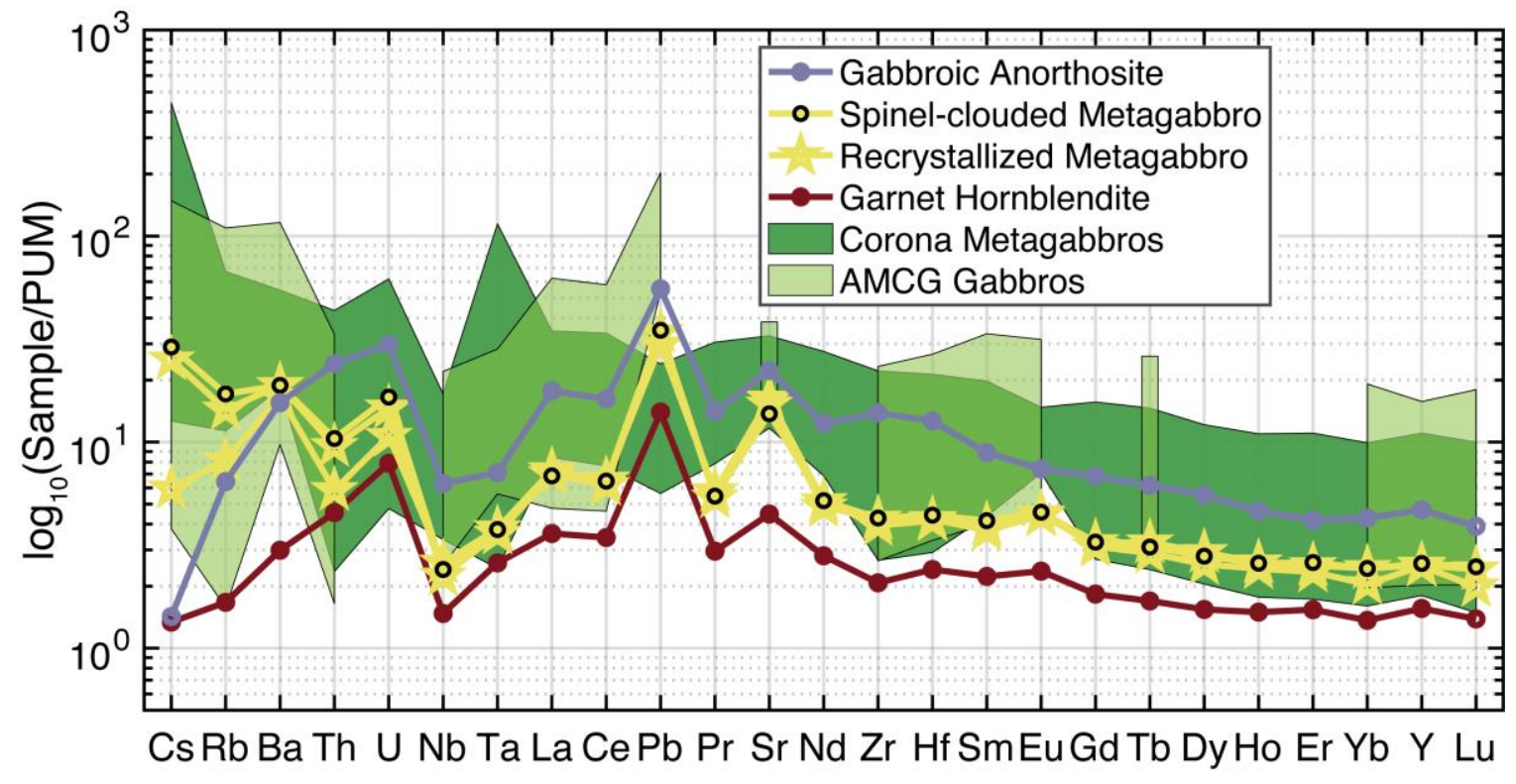

Figure 2.6: Trace elements for Gore Mountain rocks normalized to Primitive Upper Mantle (Sun and McDonough, 1989) plotted alongside range of trace elements from Adirondacks coronitic metagabbros (Regan et al., 2011) and AMCG related gabbros (Seifert et al., 2010). 


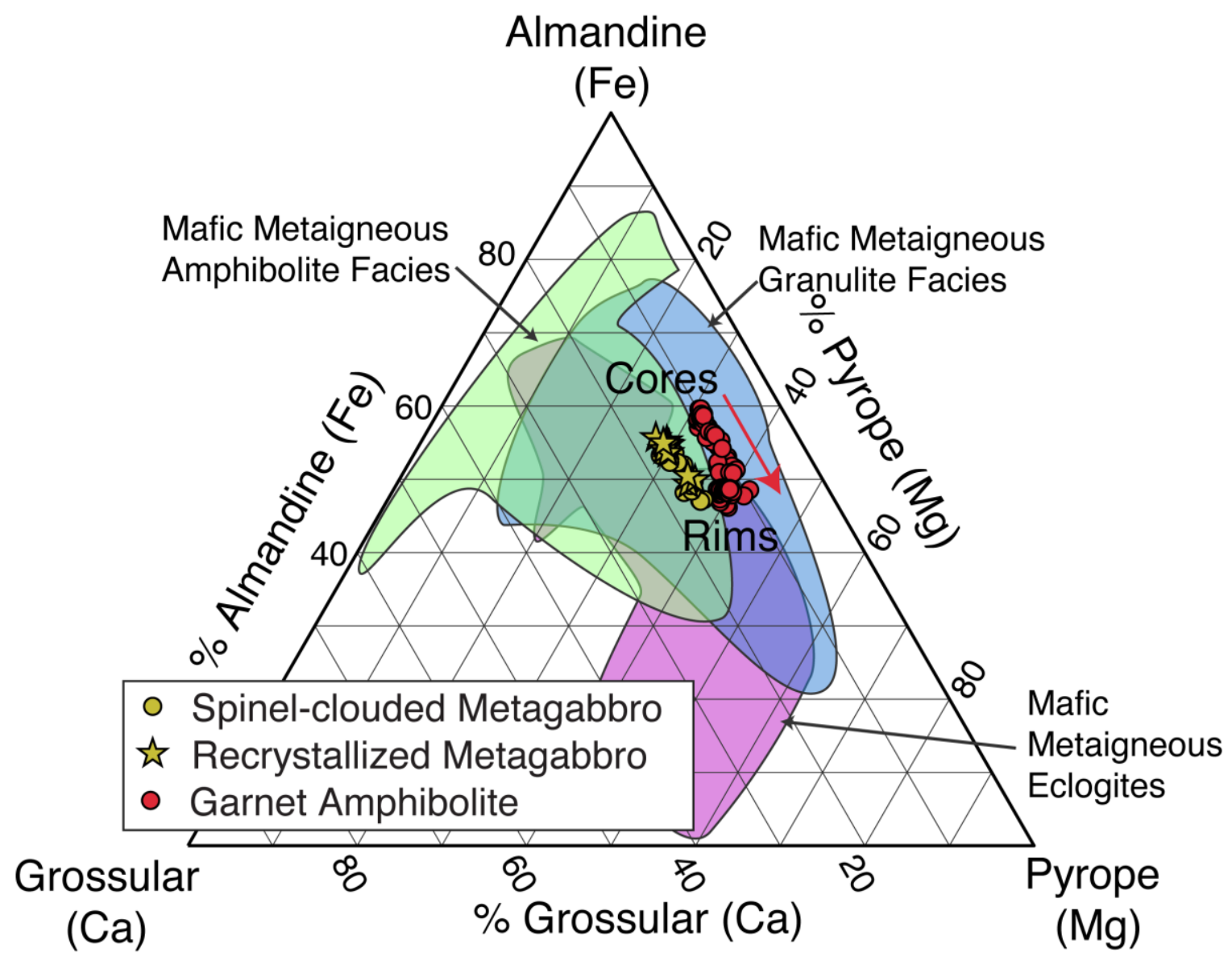

Figure 2.7: Garnet major element chemistry plotted with contours denoting mafic metaigneous garnet chemistry compilations for different metamorphic facies (Krippner et al., 2014). 


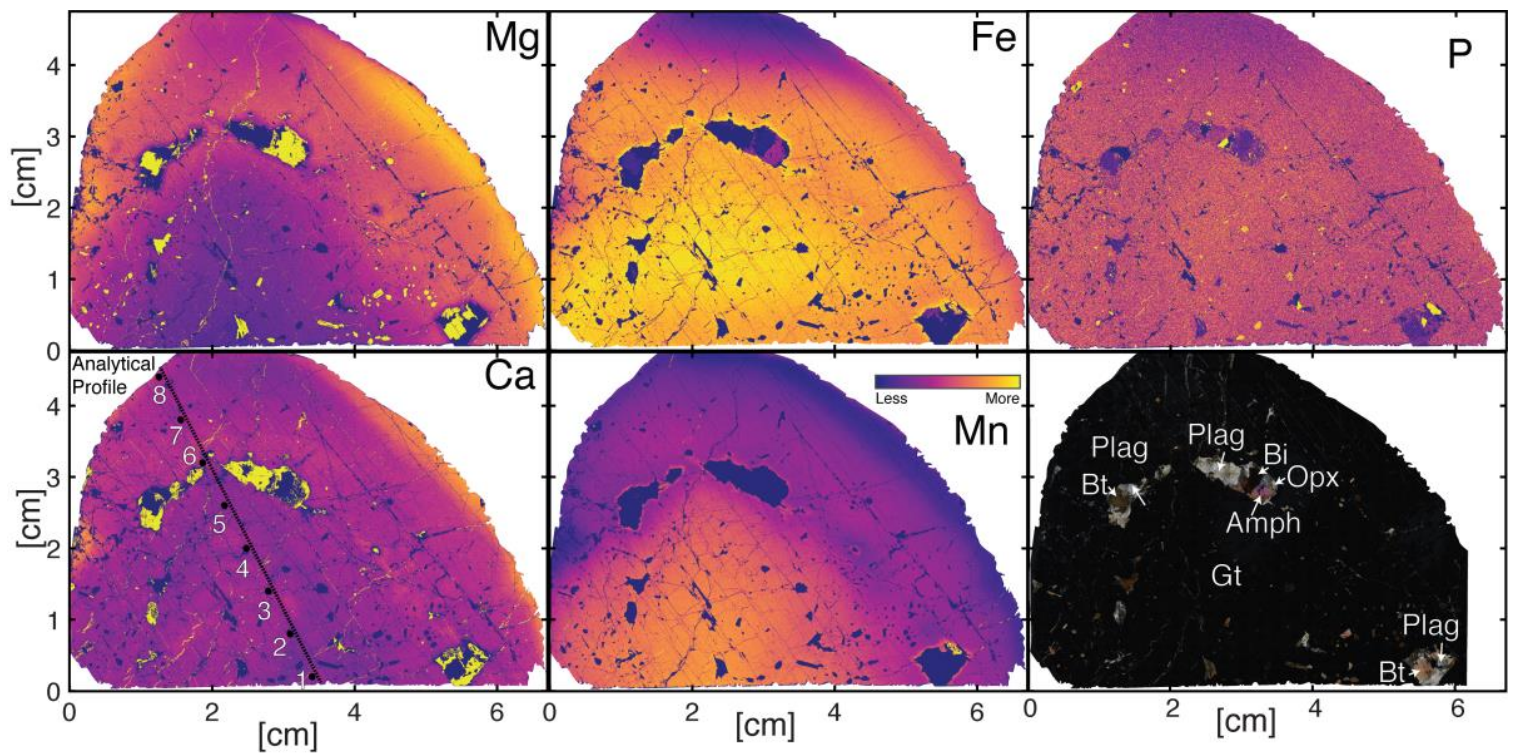

Figure 2.8: $\mathrm{Mg}, \mathrm{Fe}, \mathrm{P}, \mathrm{Ca}$, and $\mathrm{Mn}$ maps with a XPL thin section photo image of garnet porphyroblast (17-ADK-09G). The profile for major and trace elements discussed in Figures 9 and 17a signified by the numbered points and dashed line in the bottom left. Mineral abbreviations follow Figure 5 caption. 

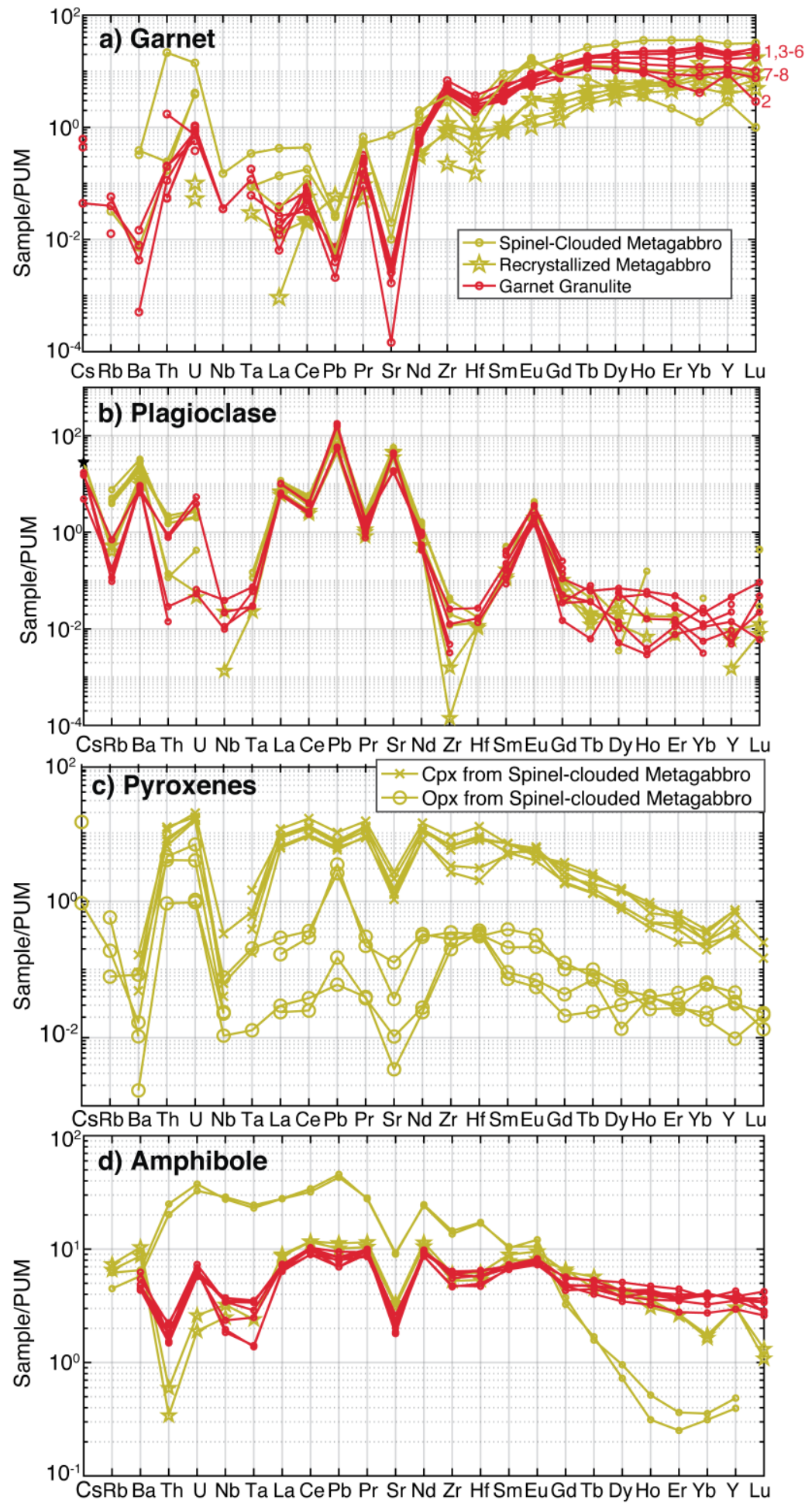

Figure 2.9: Trace elements for a) garnet, b) plagioclase, c) pyroxenes, d) amphibole normalized to Primitive Upper Mantle (Sun and McDonough, 1989). Red lines represent trace element measurements from GMGA, yellow lines represent trace elements from the spinel-clouded plagioclase metagabbros, and yellow stars represent measurements from 
recrystallized metagabbros. Numbers in red in a) correspond to the point locations shown from sample 17-ADK-09 in Figure 8 bottom left. 

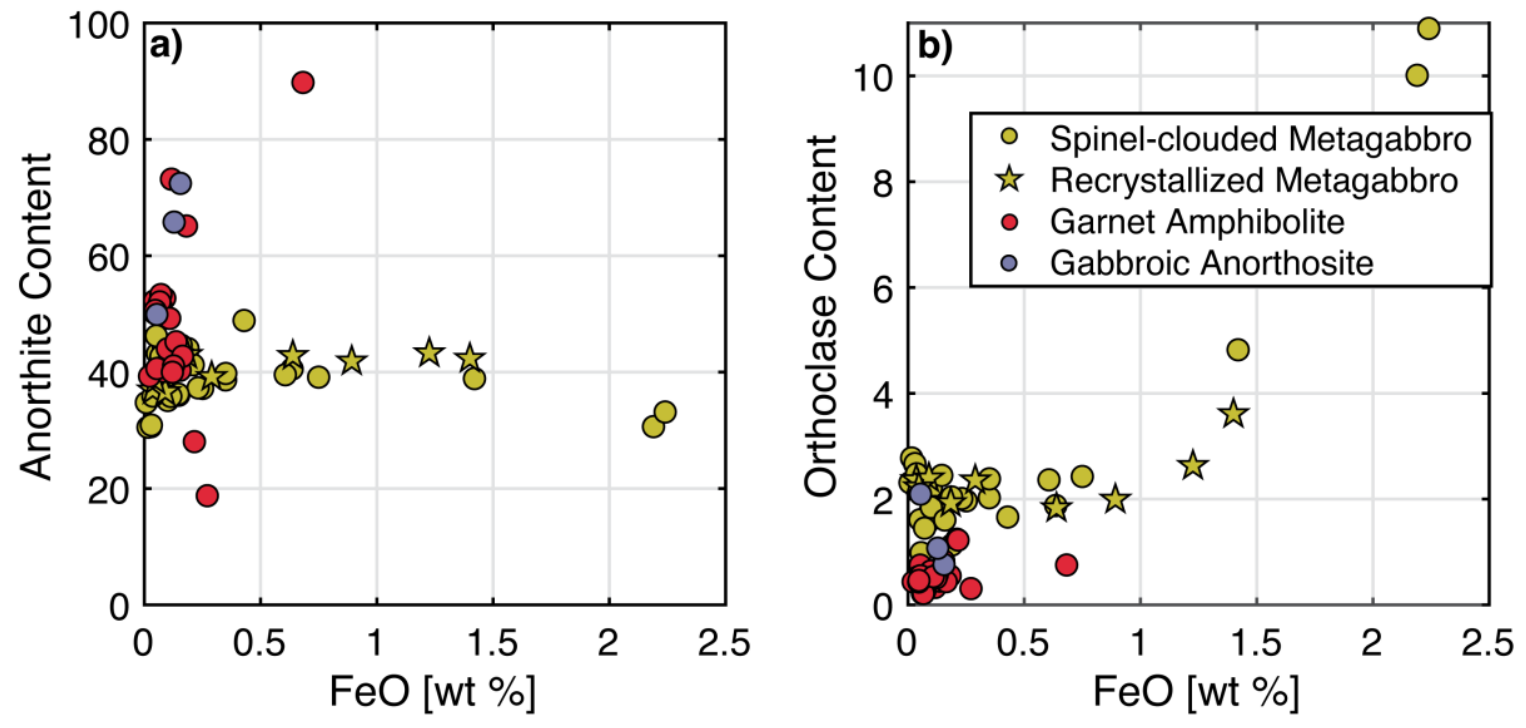

Figure 2.10: a) Anorthite and b) orthoclase contents of plagioclase plotted against FeO. 


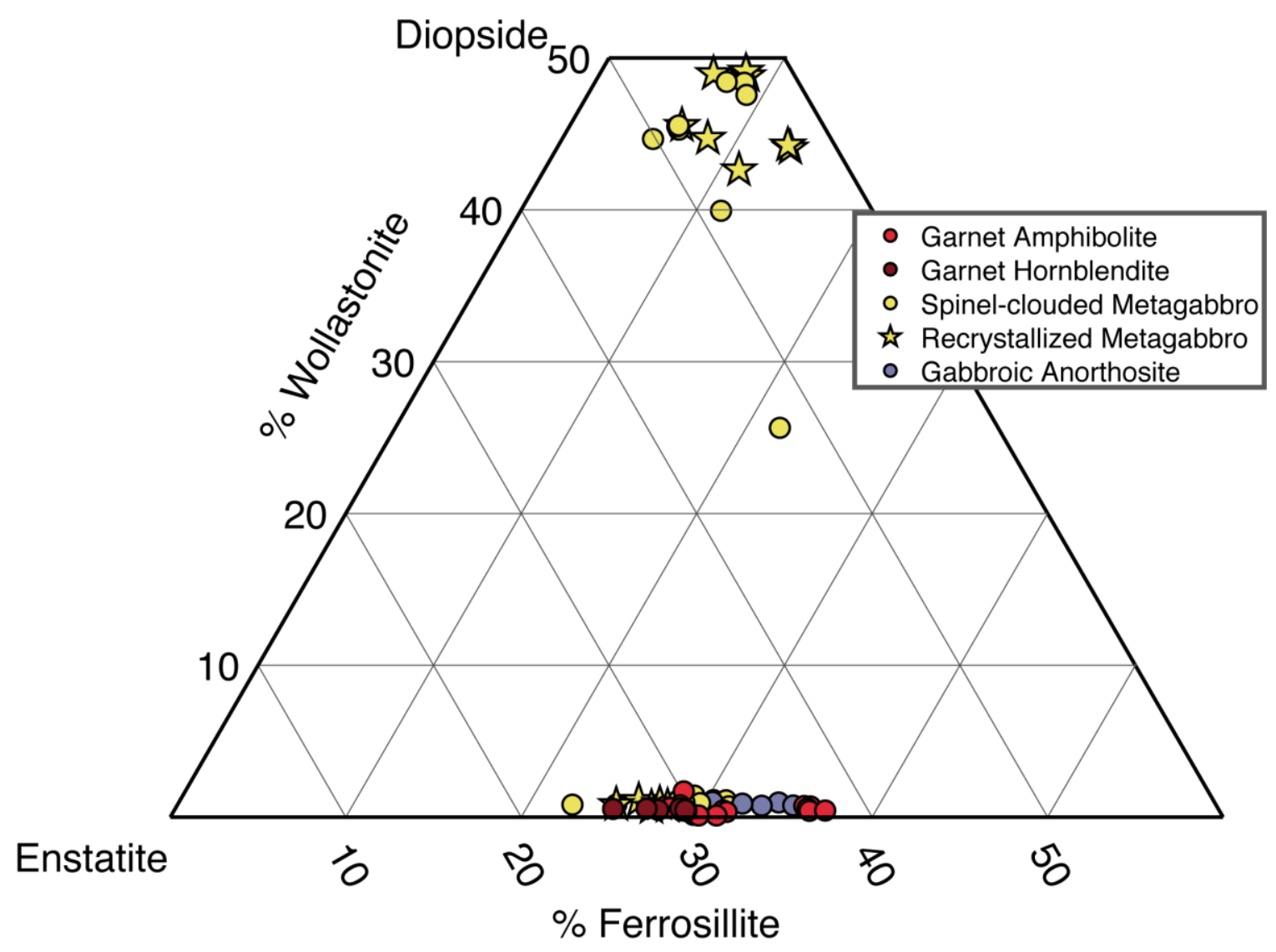

Figure 2.11: Pyroxene quadrilateral for all orthopyroxene and clinopyroxene measured in Gore Mountain associated units. 

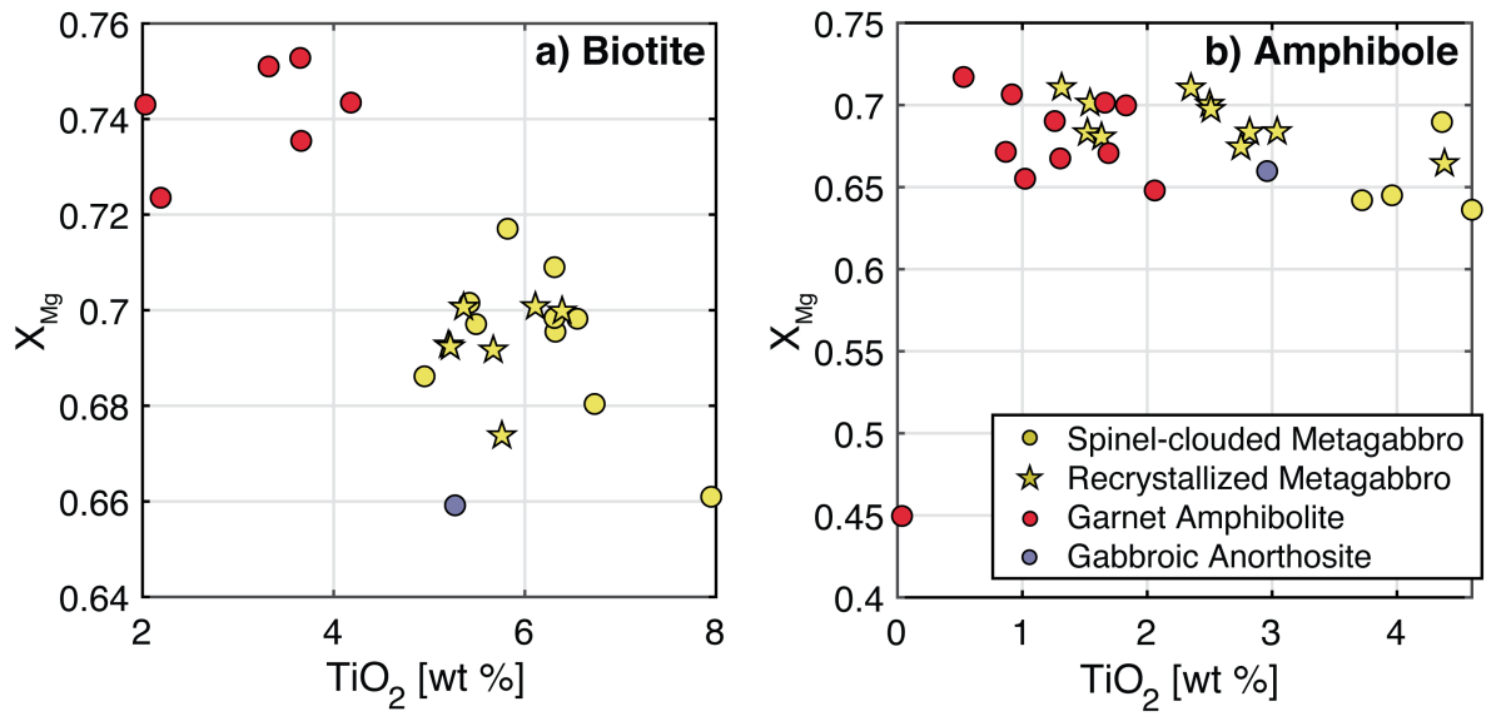

Figure 2.12: a) Biotite and b) amphibole $\mathrm{X}_{\mathrm{Mg}}$ plotted against $\mathrm{TiO}_{2}$. 


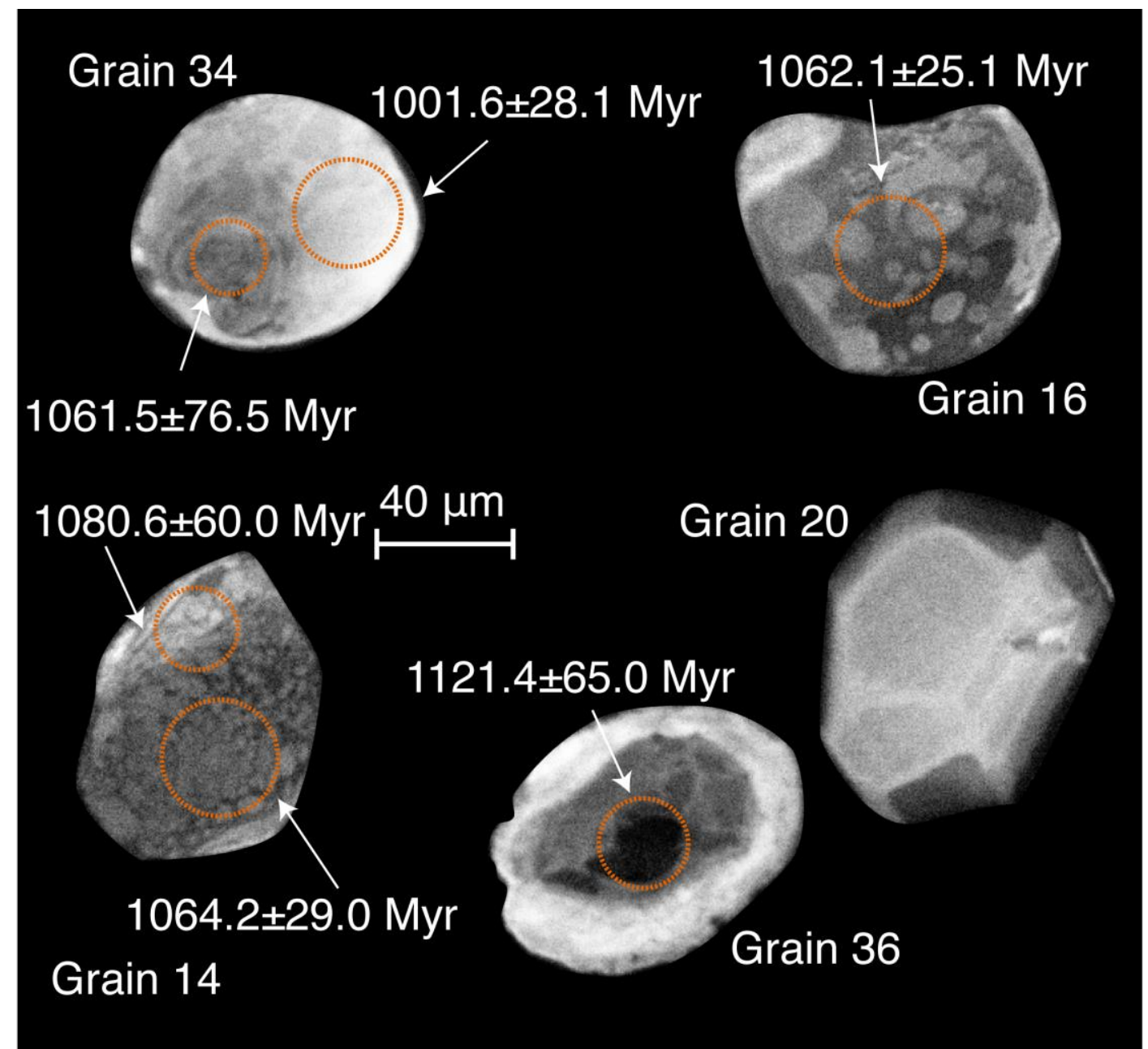

Figure 2.13: Representative CL images for zircon textures: turtleshell with bright rim (grain 34), turtleshell texture (grains 14 and 16), , igneous texture (grains 20 and 36). Orange dashed circles mark the locations of concordant ${ }^{206} \mathrm{~Pb} /{ }^{238} \mathrm{U}$ age analyses with $2 \sigma$ uncertainty. 

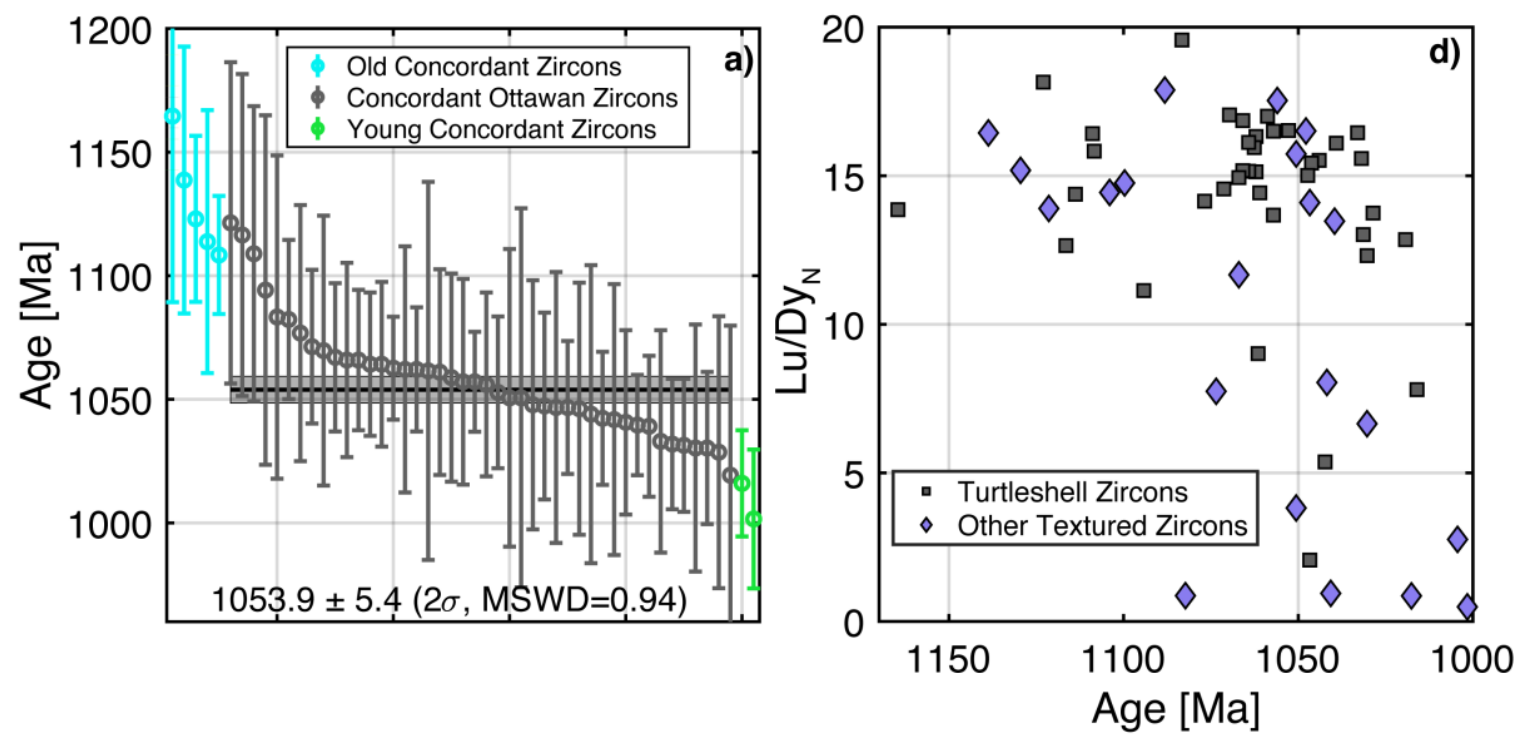

Figure 2.14: a) Rank-order plot of concordant ( $<4 \%$ discordance) of zircon ${ }^{206} \mathrm{~Pb} /{ }^{238} \mathrm{U}$ ages with $2 \sigma$ error. The green are concordant zircons excluded to improve the p-value of a single mean age as discussed in Geochronology. The black horizontal line denotes the weighted average ${ }^{206} \mathrm{~Pb} /{ }^{238} \mathrm{U}$ age with $2 \sigma$ error (grey bar). b) Lu/Dy normalized to PUM plotted against ${ }^{206} \mathrm{~Pb} /{ }^{238} \mathrm{U}$ age for all concordant turtleshell and other textured zircons. 

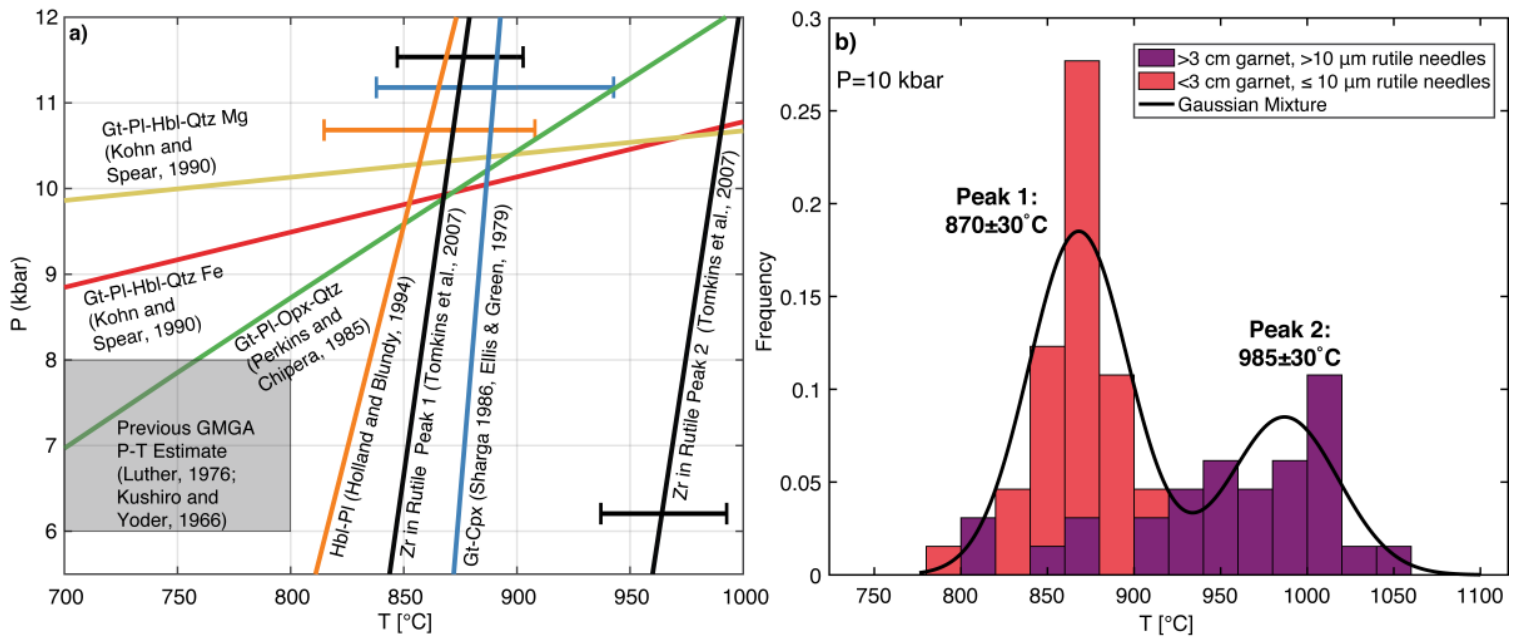

Figure 2.15: a) Results from thermobarometry analyses for the GMGA and related metagabbros. b) Frequency histogram of ZIR temperatures with fitted normal distributions (black lines). 


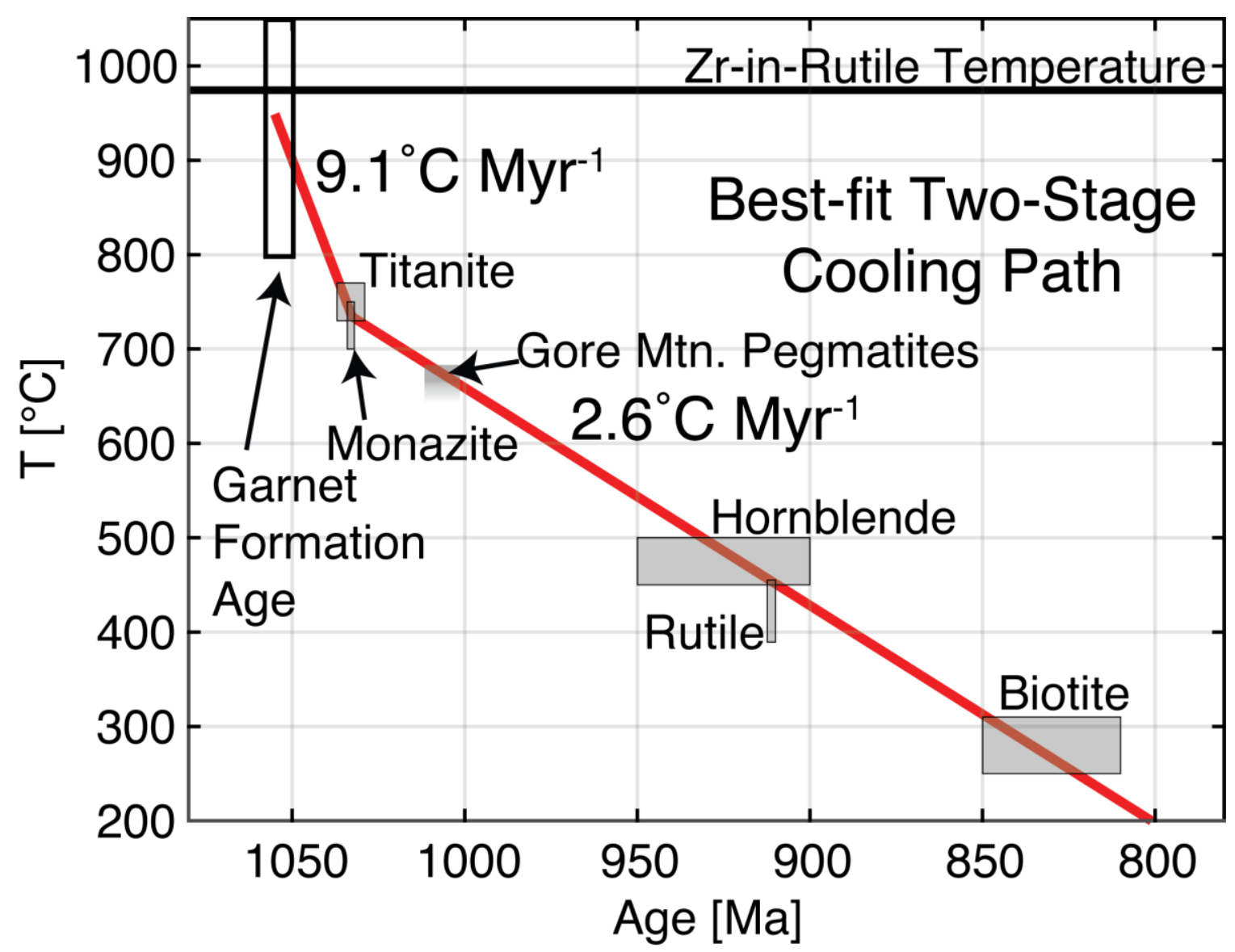

Figure 2.16: Best-fit cooling history of the GMGA (red line). The initial cooling rate $(9.1$ $\left.{ }^{\circ} \mathrm{C} \mathrm{Myr}{ }^{-1}\right)$ is found from the best-fit initial temperature $\left(950{ }^{\circ} \mathrm{C}\right)$ and the second, lower cooling rate is best fit from cooling ages. Solid grey boxes denote local cooling ages $(<25$ $\mathrm{km}$ from Gore Mountain) listed in Table 2. The garnet formation box depicts our U-Pb zircon estimate for garnet formation age and the range of initial model temperatures $\left(800-1050^{\circ} \mathrm{C}\right)$. The Gore Mtn. pegmatite age (transparent grey box) require the GMGA to have been at a temperature below the wet granite minimum for the pegmatites to crystallize. 

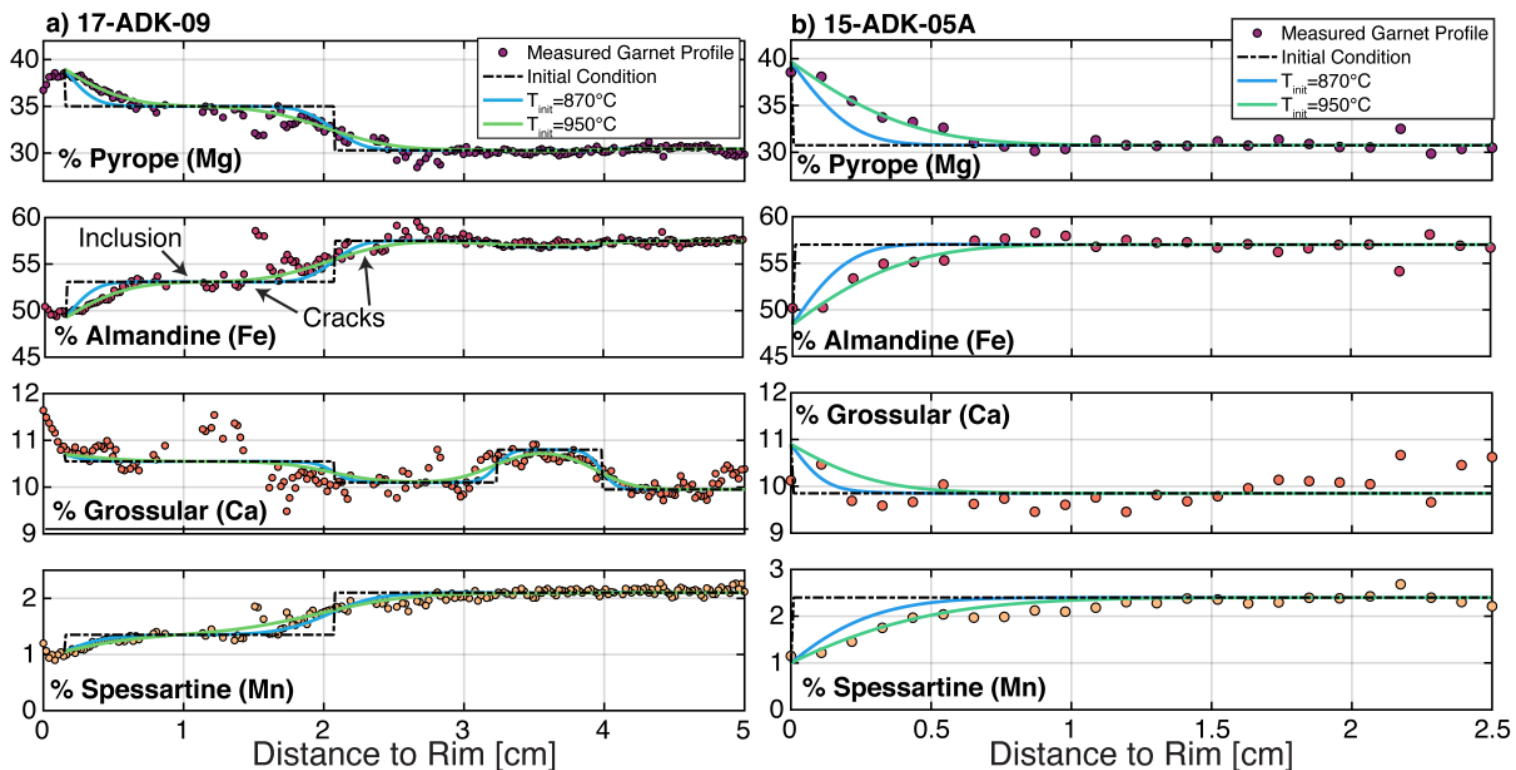

Figure 2.17: Measured garnet compositions (colored points) for sample 17-ADK-09 along line A-A' (Figure 9) (a) and sample 15-ADK-05A (b) compared with the multicomponent diffusion initial condition (dashed black line), the model result using the bestfit $\mathrm{T}_{\text {init }}\left(950^{\circ} \mathrm{C}\right.$, blue line), as well as the model result using a lower $\mathrm{ZIR} \mathrm{T}_{\text {init }}\left(870^{\circ} \mathrm{C}\right.$, green line) for comparison. 

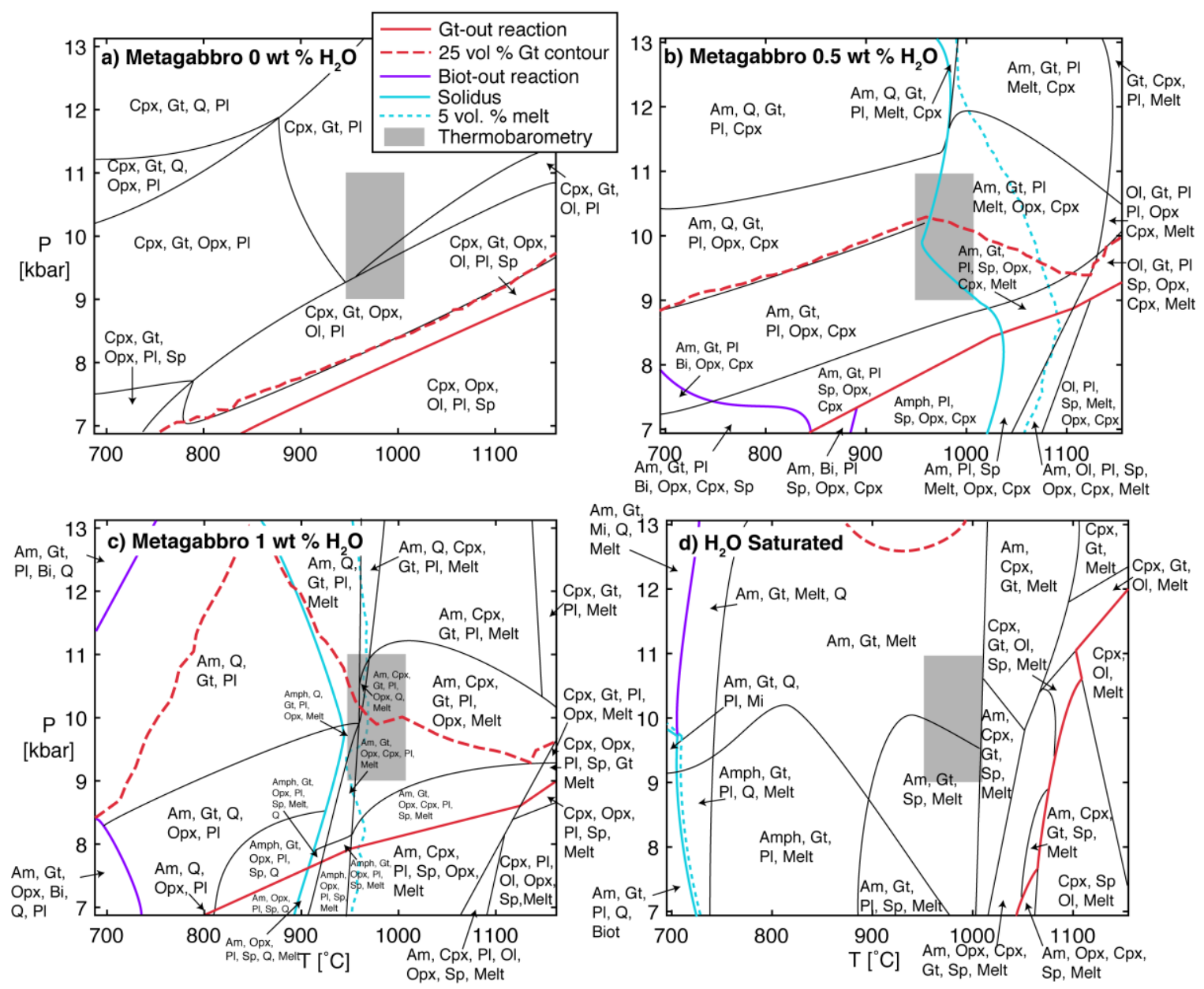

Figure 2.18: Phase diagrams for the spinel-clouded plagioclase metagabbro (17-ADK08) bulk composition with increasing water contents from $0 \mathrm{wt}$. \% to water saturated. Accessory phases such as oxides are excluded for simplicity. Phase abbreviations are Am (amphibole), Opx (orthopyroxene), Cpx (clinopyroxene), Bi (biotite), Gt (garnet), Sp (spinel), Pl (plagioclase), Mi (mica), Ol (olivine), Q (quartz). Grey box indicates the upper ZIR thermobarometry estimate $\left(985 \pm 40{ }^{\circ} \mathrm{C}, 10 \pm 1 \mathrm{kbar}\right)$. 


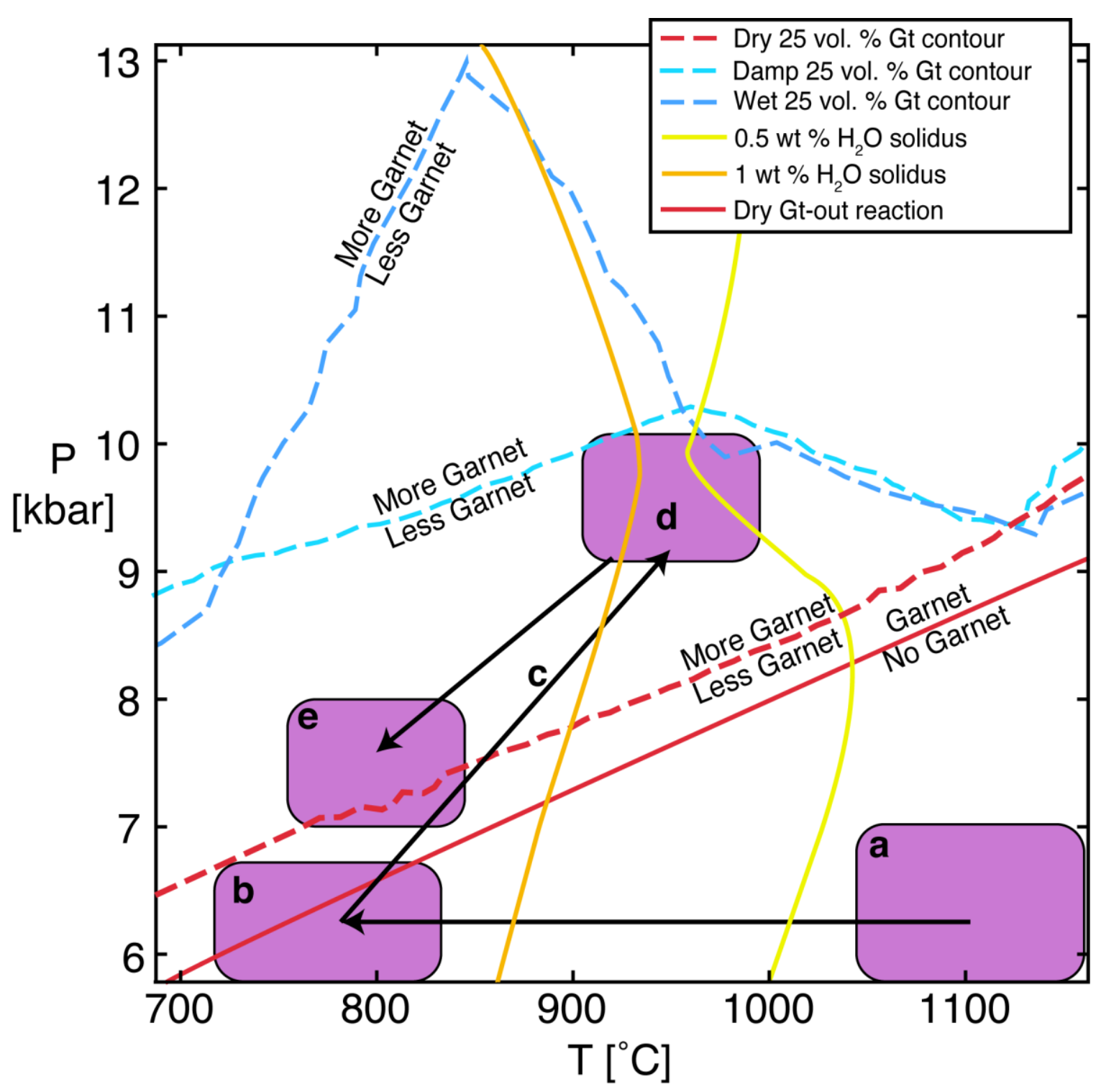

Figure 2.19: P-T-t path for the GMGA. Dashed lines show the dry, damp, and wet 25 vol. \% garnet contours and solid lines show the damp and wet solidus. Damp and wet refer to 0.5 and $1.0 \mathrm{wt} \% \mathrm{H}_{2} \mathrm{O}$ respectively. Grey box signifies the thermobarometry estimate. a) Crystallization of gabbroic cumulate, $1100-1150{ }^{\circ} \mathrm{C},<7 \mathrm{kbar}, 1150-1130 \mathrm{Ma}$, b) Isobaric cooling, 1130-1090 Ma c) Ottawan Thickening and Heating, Garnet Formation, $1090-1055 \mathrm{Ma}$ d) Peak GMGA P-T conditions, crustal anatexis $950 \pm 40^{\circ} \mathrm{C}$, 9 10 kbar, $1055 \mathrm{Ma}$ e) Orogenic Collapse and Cooling, 1055-1010 Ma. 


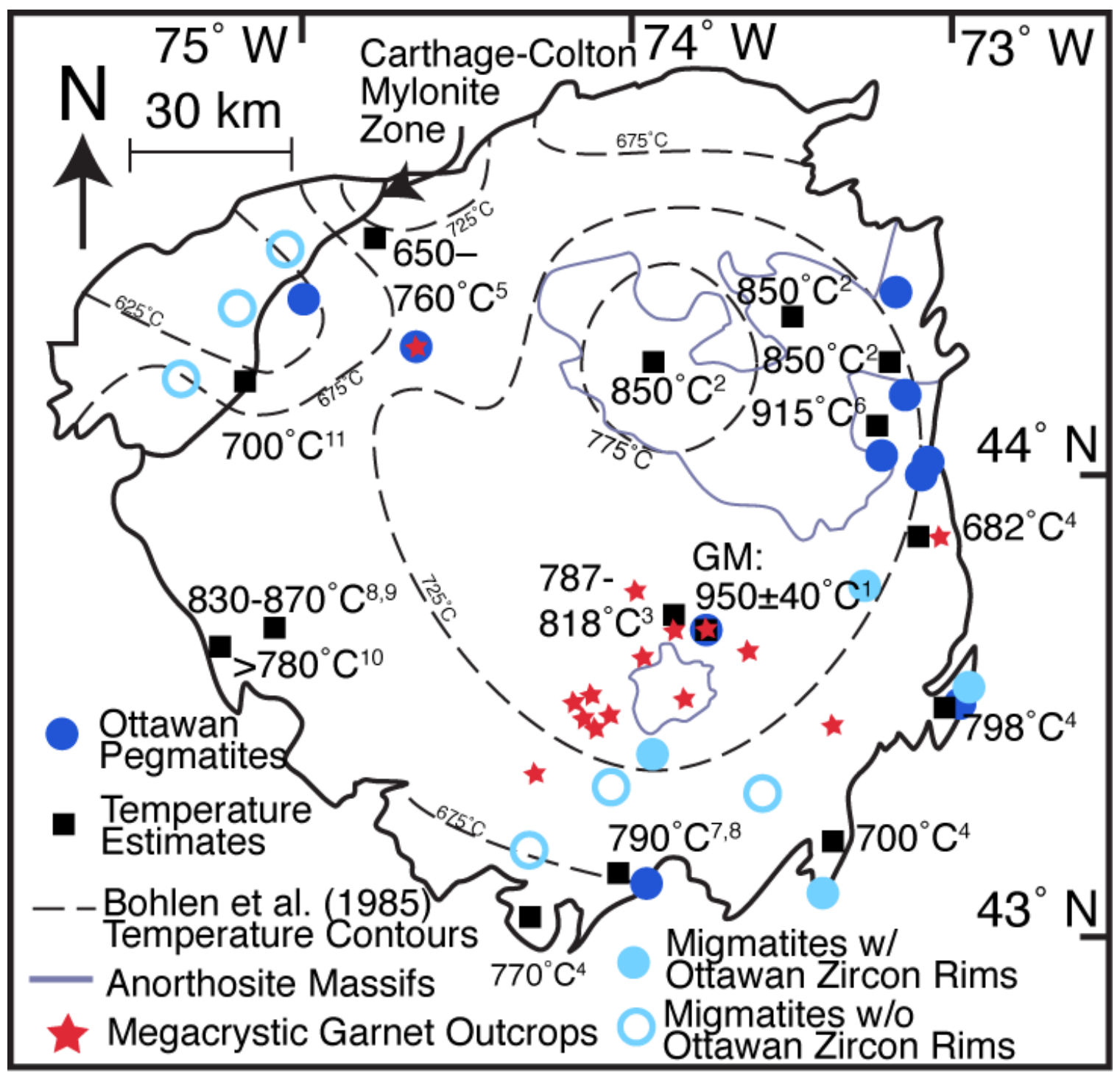

Figure 2.20: Thermobarometry in the Adirondack Highlands from the following methods. 1: This study, 2: two pyroxene thermobarometry (Spear and Markussen, 1997), 3: Zr-in-Titanite thermometry (Chiarenzelli et al., 2011), 4: Quartz-garnet isotope thermometry (Peck and Valley, 2004), 5: Two-feldspar thermometry (Edwards and Essene, 1988), 6: Al-in-Hornblende thermometry, ternary feldspar thermometry, and estimates of metagabbro anatectic conditions (Alcock et al., 2004), 7: Garnet-biotite and GASP thermobarometry with garnet diffusion modelling (Storm and Spear, 2005), 8: Tiin-Quartz thermometry (Storm and Spear, 2009), 9: orthopyroxene-garnet thermobarometry (Darling et al., 2004), 10: Estimates from melt inclusions (Florence et al., 1995; Darling, 2013), 11: titanite oxygen isotope diffusion (Bonamici et al., 2015). Metapelitic migmatite age locations from Bickford et al. (2008). Ottawan pegmatite locations and ages from Lupulescu et al., (2011), McLelland and Selleck, (2011), and Wong et al., (2012). Garnet megacrystic outcrop locations from McLelland and Selleck, (2011). Dashed contours are from Bohlen et al. (1985). Carbon isotope thermometry (Kitchen and Valley, 1995) is well represented by the dashed contours as they calibrated their thermometers off of Bohlen et al. (1985). 


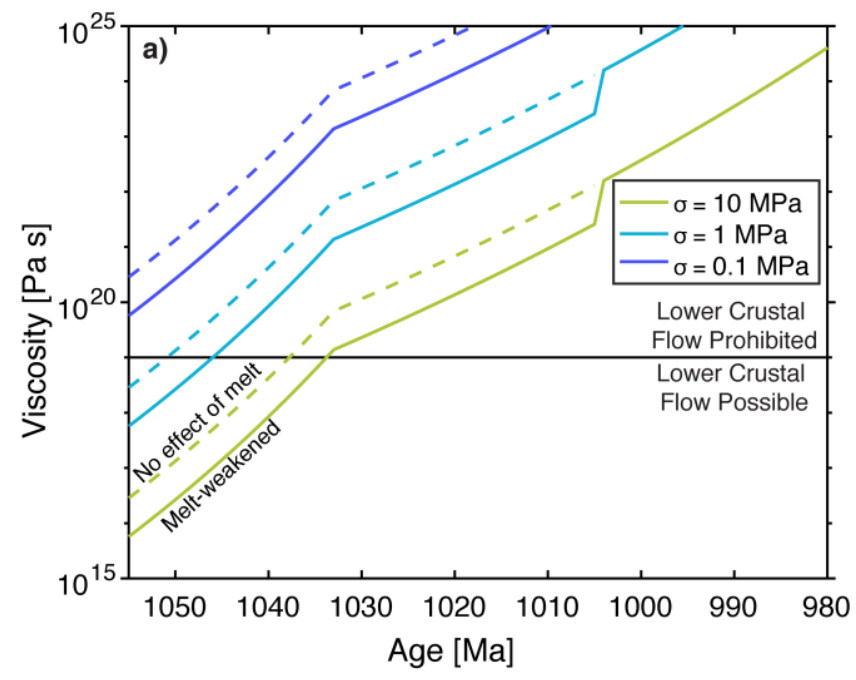

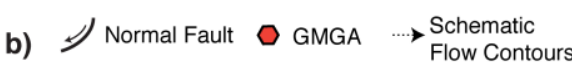

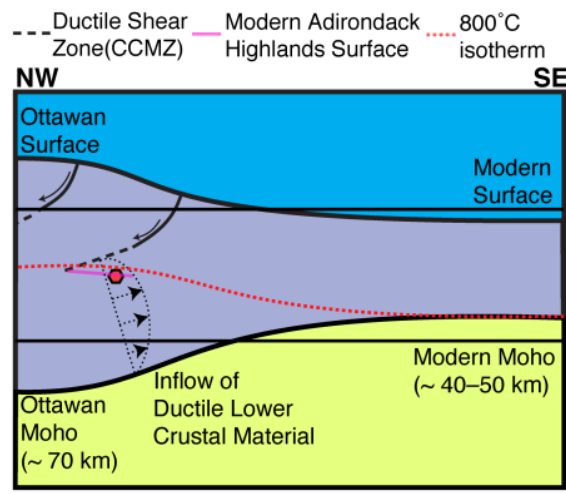

Figure 2.21: (a) Predicted viscosities for the Adirondack Highlands using the diffusion model cooling history (Figure 17) and anorthite wet dislocation creep flow law with $\mathrm{a}_{\mathrm{H} 2 \mathrm{O}}=0.1, \mathrm{P}=10 \mathrm{kbar}$, and deviatoric stress second invariants ranging from $0.1-10 \mathrm{MPa}$. A factor of 5 weakening is plotted to show the possible rheological effect of $\leq 12$ vol. $\%$ at temperatures above the wet granite minimum (Dimanov et al., 1998). Viscosities below the black line $\left(10^{19} \mathrm{~Pa} \mathrm{~s}\right)$ allow topography-driven lower crustal flow. (b) Schematic diagram depicting the formation of the Adirondacks Highlands as a metamorphic core complex due to the inflow of lower crustal ductile material caused by orogenic collapse. $\sigma_{1}$ denotes that the largest compressive stress is vertical during orogenic collapse. Modern Adirondacks Moho from Li et al. (2018). 


\section{Tables}

\begin{tabular}{|c|c|c|c|c|c|}
\hline Sample & Rock Description & Source & Latitude & Longitude & Garnet \\
\hline $\begin{array}{l}15-\mathrm{ADK}- \\
11\end{array}$ & $\begin{array}{l}\text { Lineated Gabbroic } \\
\text { Anorthosite }\end{array}$ & $\begin{array}{l}\text { This } \\
\text { Study }\end{array}$ & $\begin{array}{l}43^{\circ} 40^{\prime} 58.8^{\prime \prime} \\
\mathrm{N}\end{array}$ & $74^{\circ} 2^{\prime} 40.09^{\prime \prime} \mathrm{W}$ & 12 \\
\hline $\begin{array}{l}15-A D K- \\
14\end{array}$ & Gabbroic Anorthosite & $\begin{array}{l}\text { This } \\
\text { Study }\end{array}$ & $\begin{array}{l}43^{\circ} 40^{\prime} 56.4^{\prime \prime} \\
\mathrm{N}\end{array}$ & $74^{\circ} 03^{\prime} 15.1^{\prime \prime} \mathrm{W}$ & 0 \\
\hline $\begin{array}{l}17-A D K- \\
07\end{array}$ & Spinel-clouded Metagabbro & $\begin{array}{l}\text { This } \\
\text { Study }\end{array}$ & $\begin{array}{l}43^{\circ} 41^{\prime} 7.5^{\prime \prime} \\
\mathrm{N}\end{array}$ & $74^{\circ} 2^{\prime} 47.5^{\prime \prime} \mathrm{W}$ & 20 \\
\hline $\begin{array}{l}\text { 17-ADK- } \\
08\end{array}$ & Spinel-clouded Metagabbro & $\begin{array}{l}\text { This } \\
\text { Study }\end{array}$ & $\begin{array}{l}43^{\circ} 40^{\prime} 56.4^{\prime \prime} \\
\mathrm{N}\end{array}$ & $74^{\circ} 2^{\prime} 54.8^{\prime \prime} \mathrm{W}$ & 23 \\
\hline $\begin{array}{l}\text { 15-ADK- } \\
02\end{array}$ & Recrystallized Metagabbro & $\begin{array}{l}\text { This } \\
\text { Study }\end{array}$ & $\begin{array}{l}43^{\circ} 40^{\prime} 56.3^{\prime \prime} \\
\mathrm{N}\end{array}$ & $74^{\circ} 2^{\prime} 55.5^{\prime \prime} \mathrm{W}$ & 15.5 \\
\hline $\begin{array}{l}\text { 17-ADK- } \\
10\end{array}$ & Recrystallized Metagabbro & $\begin{array}{l}\text { This } \\
\text { Study }\end{array}$ & $\begin{array}{l}43^{\circ} 40^{\prime} 56.7^{\prime \prime} \\
\mathrm{N}\end{array}$ & $74^{\circ} 02^{\prime} 53.3^{\prime \prime} \mathrm{W}$ & 12 \\
\hline $\begin{array}{l}17-\mathrm{ADK}- \\
12\end{array}$ & Recrystallized Metagabbro & $\begin{array}{l}\text { This } \\
\text { Study }\end{array}$ & $\begin{array}{l}43^{\circ} 40^{\prime} 51.5^{\prime \prime} \\
\mathrm{N}\end{array}$ & $74^{\circ} 3^{\prime} 17.4^{\prime \prime} \mathrm{W}$ & 19 \\
\hline $\begin{array}{l}15-A D K- \\
12\end{array}$ & $\begin{array}{l}\text { Megacrystic Garnet } \\
\text { Amphibolite }\end{array}$ & $\begin{array}{l}\text { This } \\
\text { Study }\end{array}$ & $\begin{array}{l}43^{\circ} 40^{\prime} 55.8^{\prime \prime} \\
\mathrm{N}\end{array}$ & $74^{\circ} 2^{\prime} 56.2^{\prime \prime} \mathrm{W}$ & 24 \\
\hline $\begin{array}{l}15-A D K- \\
5 \mathrm{~A}\end{array}$ & $\begin{array}{l}\text { Megacrystic Garnet } \\
\text { Amphibolite }\end{array}$ & $\begin{array}{l}\text { This } \\
\text { Study }\end{array}$ & $\begin{array}{l}43^{\circ} 40^{\prime} 54.9^{\prime \prime} \\
\mathrm{N}\end{array}$ & $74^{\circ} 2^{\prime} 56.5^{\prime \prime} \mathrm{W}$ & $15-24$ \\
\hline $\begin{array}{l}15-\mathrm{ADK}- \\
9 \mathrm{~A}\end{array}$ & $\begin{array}{l}\text { Megacrystic Garnet } \\
\text { Amphibolite }\end{array}$ & $\begin{array}{l}\text { This } \\
\text { Study }\end{array}$ & $\begin{array}{l}43^{\circ} 40^{\prime} 55.9^{\prime \prime} \\
\mathrm{N}\end{array}$ & $74^{\circ} 2^{\prime} 56.2^{\prime \prime} \mathrm{W}$ & $15-24$ \\
\hline $\begin{array}{l}15-\mathrm{ADK}- \\
13\end{array}$ & $\begin{array}{l}\text { Megacrystic Garnet } \\
\text { Amphibolite }\end{array}$ & $\begin{array}{l}\text { This } \\
\text { Study }\end{array}$ & $\begin{array}{l}43^{\circ} 40^{\prime} 56.3^{\prime \prime} \\
\mathrm{N}\end{array}$ & $74^{\circ} 2^{\prime} 52.5^{\prime \prime} \mathrm{W}$ & $15-24$ \\
\hline $\begin{array}{l}\text { 17-ADK- } \\
\text { 09G,M }\end{array}$ & $\begin{array}{l}\text { Megacrystic Garnet } \\
\text { Amphibolite }\end{array}$ & $\begin{array}{l}\text { This } \\
\text { Study }\end{array}$ & $\begin{array}{l}43^{\circ} 40^{\prime} 56.1^{\prime \prime} \\
\mathrm{N}\end{array}$ & $74^{\circ} 2^{\prime} 52.2^{\prime \prime} \mathrm{W}$ & $15-24$ \\
\hline $\begin{array}{l}\text { 17-ADK- } \\
11\end{array}$ & $\begin{array}{l}\text { Megacrystic Garnet } \\
\text { Amphibolite }\end{array}$ & $\begin{array}{l}\text { This } \\
\text { Study }\end{array}$ & $\begin{array}{l}43^{\circ} 40^{\prime} 56.0^{\prime \prime} \\
\mathrm{N}\end{array}$ & $74^{\circ} 2^{\prime} 52.2^{\prime \prime} \mathrm{W}$ & $15-24$ \\
\hline $\begin{array}{l}\text { 17-ADK- } \\
03\end{array}$ & Garnet Hornblendite & $\begin{array}{l}\text { This } \\
\text { Study }\end{array}$ & $\begin{array}{l}43^{\circ} 40^{\prime} 55.5^{\prime \prime} \\
\mathrm{N}\end{array}$ & $74^{\circ} 2^{\prime} 52.2^{\prime \prime} \mathrm{W}$ & 24 \\
\hline $\begin{array}{l}\text { 15-ADK- } \\
07\end{array}$ & Garnet Hornblendite & $\begin{array}{l}\text { This } \\
\text { Study }\end{array}$ & $\begin{array}{l}43^{\circ} 40^{\prime} 55.6^{\prime \prime} \\
\mathrm{N}\end{array}$ & $74^{\circ} 2^{\prime} 55.1^{\prime \prime} \mathrm{W}$ & 3 \\
\hline & Gabbroic Anorthosite & \multicolumn{2}{|c|}{ Luther (1976) } & & 5 \\
\hline & Average Syenitic Granulite & \multicolumn{2}{|c|}{ Luther (1976) } & & $\operatorname{tr}$ \\
\hline & Olivine Metagabbro & \multicolumn{2}{|c|}{ Luther (1976) } & & 13 \\
\hline & Lineated Olivine Metagabbro & \multicolumn{2}{|c|}{ Sharga (1986) } & & 20 \\
\hline
\end{tabular}




\begin{tabular}{|c|c|c|c|c|c|c|c|c|}
\hline $\begin{array}{l}\text { Plagioc } \\
\text { lase }\end{array}$ & $\begin{array}{l}\text { Clinopyro } \\
\text { xene }\end{array}$ & $\begin{array}{l}\text { Orthopyro } \\
\text { xene }\end{array}$ & $\begin{array}{l}\text { Amphi } \\
\text { bole }\end{array}$ & $\begin{array}{l}\text { Biot } \\
\text { ite }\end{array}$ & $\begin{array}{l}\text { Microc } \\
\text { line }\end{array}$ & $\begin{array}{l}\text { Qua } \\
\text { rtz }\end{array}$ & $\begin{array}{l}\text { Olivi } \\
\text { ne }\end{array}$ & Accessory Minerals \\
\hline 74 & 0 & 1 & 5 & 8 & 0 & 0 & 0 & \\
\hline 85 & 1 & 5 & 7 & 1 & 0 & 1 & 0 & apatite \\
\hline 37 & 21 & 6 & 8 & 8 & 0 & 0 & $\operatorname{tr}$ & hercynite, iron sulfides \\
\hline 29 & 26 & 9.5 & 6.5 & 5.5 & 0 & 0 & 0.5 & $\begin{array}{l}\text { hercynite, magnetite, } \\
\text { iron sulfides }\end{array}$ \\
\hline 38 & 4 & 2.5 & 39 & 1 & 0 & 0 & 0 & $\begin{array}{l}\text { apatite, iron sulfides, } \\
\text { magnetite }\end{array}$ \\
\hline 48 & 5.5 & 1.5 & 27 & 6 & 0 & 0 & 0 & \\
\hline 30.5 & 13 & 4.5 & 27 & 6 & 0 & 0 & 0 & \\
\hline 23 & 0 & 6 & 44 & 3 & 0 & 0 & 0 & \\
\hline $0-29$ & 0 & $0-3$ & $46-68$ & $0-2$ & 0 & $\operatorname{tr}$ & 0 & $\begin{array}{l}\text { ilmenite, rutile, zircon, } \\
\text { apatite, magnetite, } \\
\text { quartz, iron sulfides }\end{array}$ \\
\hline $0-29$ & 0 & $0-3$ & $46-68$ & $0-2$ & 0 & $\operatorname{tr}$ & 0 & $\begin{array}{l}\text { ilmenite, rutile, zircon, } \\
\text { apatite, magnetite, } \\
\text { quartz, iron sulfides }\end{array}$ \\
\hline $0-29$ & 0 & $0-3$ & $46-68$ & $0-2$ & 0 & $\operatorname{tr}$ & 0 & $\begin{array}{l}\text { ilmenite, rutile, zircon, } \\
\text { apatite, magnetite, } \\
\text { chlorite, quartz, iron } \\
\text { sulfides }\end{array}$ \\
\hline $0-29$ & 0 & $0-3$ & $46-68$ & $0-2$ & 0 & 0 & 0 & \\
\hline $0-29$ & 0 & $0-3$ & $46-68$ & $0-2$ & 0 & $\operatorname{tr}$ & 0 & $\begin{array}{l}\text { ilmenite, rutile, zircon, } \\
\text { apatite, magnetite, } \\
\text { quartz, iron sulfides }\end{array}$ \\
\hline 2 & 0 & 19 & 61 & 4 & 0 & 0 & 0 & $\begin{array}{l}\text { ilmenite, rutile, zircon, } \\
\text { apatite, iron sulfides }\end{array}$ \\
\hline 0 & 0 & 10 & 79 & 8 & 0 & 0 & 0 & \\
\hline 83 & $0-6$ & $0-6$ & 5 & 1 & 0 & 0 & 0 & $\begin{array}{l}\text { ilmenite, magnetite, } \\
\text { zircon, apatite }\end{array}$ \\
\hline 23 & 3.5 & 2 & 4 & 0 & 55 & 11 & 0 & apatite, garnet, oxides \\
\hline 42 & 31 & 2 & 4 & 1 & 0 & 0 & 5 & magnetite, spinel \\
\hline 49 & 10.5 & 2 & 10 & 3 & 0 & 0 & 5 & magnetite, spinel \\
\hline
\end{tabular}

Table 2.1: Sample names, locations, and modal proportions (vol. \%). 


\begin{tabular}{|llllll|}
\hline $\begin{array}{l}\text { Measureme } \\
\text { nt Type }\end{array}$ & $\begin{array}{l}\text { Age } \\
{[\mathrm{Ma}]}\end{array}$ & Reference & $\begin{array}{l}\text { Temper } \\
\text { ature } \\
{\left[{ }^{\circ} \mathrm{C}\right]}\end{array}$ & Reference & $\begin{array}{l}\text { Distance from } \\
\text { Gore Mountain } \\
{[\mathrm{km}]}\end{array}$ \\
\hline $\begin{array}{l}\text { Titanite (U- } \\
\text { Pb) }\end{array}$ & $\begin{array}{l}1033 \\
\pm 4\end{array}$ & 1 & $750 \pm 25$ & 2 & 20 \\
\hline $\begin{array}{l}\text { Monazite } \\
\text { (U-Pb) }\end{array}$ & $\begin{array}{l}1033 \\
\pm 1\end{array}$ & 1 & $725 \pm 25$ & 3 & 25 \\
\hline $\begin{array}{l}\text { Pegmatite } \\
\text { (Zircon U- }\end{array}$ & $\begin{array}{l}1008 \\
\text { Pb) }\end{array}$ & 4 & 675 & 5 & 0 \\
\hline $\begin{array}{l}\text { Hornblend } \\
\text { e (Ar-Ar) }\end{array}$ & $\begin{array}{l}925 \pm \\
25\end{array}$ & 6 & & & 25 \\
\hline $\begin{array}{l}\text { Rutile (U- } \\
\text { Pb) }\end{array}$ & $911 \pm$ & 7 & $463 \pm 40$ & 6 & 25 \\
\hline $\begin{array}{l}\text { Biotite (Ar- } \\
\text { Ar) }\end{array}$ & $832 \pm$ & 6 & $420 \pm 30$ & 7 & 25 \\
\hline
\end{tabular}

Table 2.2: Measurement type, age, temperatures, and distance from Gore Mountain used to constrain the GMGA cooling history. 1:(Mezger et al., 1991), 2:(Spencer et al., 2013), 3:(Smith and Giletti, 1997), 4:(McLelland and Selleck, 2011), 5:(Luth et al., 1964), 6:(Onstott and Peacock, 1987), 7:(Mezger et al., 1989), 8:(Harrison et al., 1985). The pegmatites are not a closure temperature, instead requiring that the GMGA must have been below the wet granite minimum $\left(675^{\circ} \mathrm{C}\right)$ at $1008 \pm 10 \mathrm{Ma}$. 


\section{Chapter 3:}

\section{Causes of oceanic crustal thickness oscillations along a 74-Myr Mid-Atlantic Ridge flow line}

This chapter was originally published as: Shinevar, W. J., Mark, H. F., Clerc, F., Codillo, E. A., Gong, J., Olive, J. A., ... \& Behn, M. D. (2019). Causes of oceanic crustal thickness oscillations along a 74-M mid-atlantic ridge flow line. Geochemistry, Geophysics, Geosystems, 20(12), 6123-6139. https://doi.org/10.1029/2019GC008711. Used with permission as granted in the original copyright agreement. 


\begin{abstract}
Gravity, magnetic, and bathymetry data collected along a continuous 1400-km-long spreading-parallel flow line across the Mid-Atlantic Ridge indicate significant tectonic and magmatic fluctuations in the formation of oceanic crust over a range of timescales. The transect spans from $28 \mathrm{Ma}$ on the African Plate to $74 \mathrm{Ma}$ on the North American plate, crossing the Mid-Atlantic Ridge at $35.8^{\circ} \mathrm{N}$. Gravity-derived crustal thicknesses vary from 3-9 km with a standard deviation of $1 \mathrm{~km}$. Spectral analysis of bathymetry and residual mantle Bouguer anomaly (RMBA) show diffuse power at $>1$ Myr and concurrent peaks at 390, 550, and $950 \mathrm{kyr}$. Large-scale $(>10-\mathrm{km})$ mantle thermal and compositional heterogeneities, variations in upper mantle flow, and detachment faulting likely generate the $>1 \mathrm{Myr}$ diffuse power. The 550- and 950-kyr peaks may reflect the presence of magma solitons and/or regularly spaced $\sim 7.7$ and $13.3 \mathrm{~km}$ short-wavelength mantle compositional heterogeneities. The 390-kyr spectral peak corresponds to the characteristic spacing of faults along the flow line. Fault spacing also varies over longer periods (>10 Myr), which we interpret as reflecting long-lived changes in the fraction of tectonically- vs. magmatically- accommodated extensional strain. A newly discovered off-axis oceanic core complex (Kafka Dome) found at $8 \mathrm{Ma}$ on the African plate further suggests extended time periods of tectonically dominated plate separation. Fault spacing negatively correlates with gravity-derived crustal thickness, supporting a strong link between magma input and fault style at mid-ocean ridges.
\end{abstract}




\section{Introduction}

The oceanic lithosphere covers more than two-thirds of the Earth's surface and plays an essential role in plate tectonics. Oceanic lithosphere forms at mid-ocean ridges (MORs) through a combination of magmatic and tectonic activity (Macdonald et al., 1996; Searle, 2013). Variability in the magma supply associated with differences in spreading rate, axial thermal structure, and/or mantle melting processes has been linked to first-order differences in ridge morphology (e.g., Chen and Morgan, 1990a, 1990b; Ito and Behn, 2008; Roth et al., 2019), fault behavior (e.g., Buck et al., 2005; Behn and Ito, 2008; Tucholke et al., 2008), and the chemistry of mid-ocean ridge basalts (e.g., Bonatti et al., 2003; Behn and Grove, 2015).

Temporal variability in magmatic and tectonic forcing at mid-ocean ridges has been hypothesized and/or observed on timescales from millions to thousands of years. For example, Bonatti et al. (2003) found a long-term increase in gravity-derived crustal thickness along the Vema Transform Fault (Guinea Fracture Zone) in the Atlantic, which they hypothesized to result from a long-term ( $>20 \mathrm{Myr}$ ) increase in mantle potential temperature. Previous studies in the Mid-Atlantic also found 2-4 Myr period variations in gravity-derived crustal thickness, which were interpreted as representing changes in mantle upwelling and flow (Pariso et al., 1995; Bonatti et al., 2003) or as reflecting alternating phases of dominantly magmatic and amagmatic extension (Tucholke et al., 1997). Further, Minshull et al. (2006) attributed seismically derived crustal thickness variations with periods of $\sim 3 \mathrm{Myr}$ near the ultraslow-spreading Southwest Indian Ridge to be the result of episodic melt flow and tectonic extension during amagmatic periods.

On slightly shorter time-scales, Canales et al., (2000) reported seismically-derived crustal thickness variations with periods of $\sim 0.5-1$ Myr near the axis of the Mid-Atlantic Ridge close to the Kane fracture zone, which they attributed to temporal variability in magma supply. Measured cross sections of the Oman ophiolite also depict thickness variations over 5-10 km scale attributed to accretion above mantle diapirs (Nicolas et al., 1996). Assuming a half spreading rate between 25 and $50 \mathrm{~mm} \mathrm{yr}^{-1}$ for the crust formed in the Oman ophiolite, the 5-10 km scale thickness variations correspond to variations with a periodicity of 100-400 kyr. High-resolution sampling across the intermediate-spreading Juan de Fuca Ridge (Ferguson et al., 2017) revealed a rapid change ( $<10 \mathrm{kyr})$ in basalt 
geochemistry coincident with 1-km increase in crustal thickness (Carbotte et al., 2008), demonstrating that changes in magma supply can also occur on very short time scales.

Some short period ( $<100 \mathrm{kyr}$ ) variations in crustal production have been proposed to result from external forcing on the MOR magmatic system. Crowley et al. (2015) hypothesized that fluctuations in sea level caused by Milanković cycles (23, 41, and 100 kyr) could modulate the amount of magma produced by adiabatic decompression melting below MORs by modulating mantle pressure. Tolstoy (2015) also suggested that orbital forcing affects crustal stresses and thus the dynamics of melt extraction on Milanković time scales, particularly at fast-spreading ridges.

One challenge in deciphering temporal changes in the structure and evolution of oceanic lithosphere is that most previous studies have focused on the formation of young lithosphere at or near the ridge axis. For example, to understand the magmatic input to mid-ocean ridges, studies have focused on variations in the chemistry of mid-ocean ridge basalts (e.g., Langmuir et al., 1992; Gale et al., 2013), near-axis seismic and gravity measurements of crustal thickness (e.g., Kuo and Forsyth, 1988; Detrick et al., 1995; Hooft et al., 2000), and the physical dynamics of magma chambers and their eruptions (e.g., Rubin and Pollard, 1988; Sinton and Detrick, 1992; Tan et al., 2016). Near-axis geophysical observables, such as gravity, bathymetry, and fault style, have also been analyzed to understand the way magmatism and tectonics interact to shape the ridge axis (e.g., Kuo and Forsyth, 1988; Detrick et al., 1995; Hooft et al., 2000; Buck et al., 2005; Howell et al., 2016, 2019). By contrast, relatively few studies have investigated off-axis oceanic lithosphere (e.g., Morris et al., 1993; Tucholke et al., 1997; Lizarralde et al., 2004) where mass wasting and sedimentation restrict sampling and complicate the bathymetric record of faulting. Thus, temporal variability has typically been inferred from very short across-axis studies (e.g., Canales et al., 2000; Crowley et al., 2015), as well as comparison of spatial variations between different ridge segments of similar spreading rates (e.g. Purdy et al., 1992).

To better quantify the temporal variability in magma supply and fault style in oceanic lithosphere over timescales of $10^{4}-10^{7}$ years, we acquired a $1400-\mathrm{km}$-long geophysical transect collecting bathymetry, gravity, and magnetic data during the SCARF cruise (Student-led Cruise Along a Ridge Flow Line) (\#AR023-02) aboard the R/V Neil 
Armstrong in October 2017. The cruise track followed a single, spreading-parallel flow line between $30^{\circ}$ and $45^{\circ} \mathrm{W}$ crossing the Mid-Atlantic Ridge (MAR) at $35.8^{\circ} \mathrm{N}, \sim 100 \mathrm{~km}$ north of the Oceanographer Fracture Zone (Figure 1). The cruise yielded one of the longest geophysical surveys along a single ridge flow line and covered $\sim 28 \mathrm{Ma}$ lithosphere on the African plate to $74 \mathrm{Ma}$ lithosphere on the North American plate. Our analysis of this flow line allows us to estimate key properties of the oceanic lithosphere, including crustal thickness, effective elastic plate thickness, and fault characteristics to provide constraints on the tectonic and magmatic processes that control temporal variation of crustal formation at the same mid-ocean ridge segment.

\section{Geologic Setting}

The Central Atlantic Ocean, the portion of the Atlantic Ocean south of the Azores plateau and north of Guinean Fracture Zone, began spreading at 190 Ma (Labails et al., 2010), likely triggered by the 203 and 193 Ma surges of Central Atlantic magmatic province volcanism (Jourdan et al., 2009). Early accretion in the Central Atlantic Ocean was highly asymmetric, adding significantly more material to the North American plate. The Central Atlantic Ocean originally accreted slowly (half spreading rate of $4 \mathrm{~mm} \mathrm{yr}^{-1}$ ) until $170 \mathrm{Ma}$, when the spreading direction shifted from northwest-southeast to east-west and spreading rate doubled. Afterwards, the half spreading rate remained around $10 \mathrm{~mm}$ $\mathrm{yr}^{-1}$ with periods of faster rates up to $30 \mathrm{~mm} \mathrm{yr}^{-1}$ (Labails et al., 2010; Seton et al., 2012).

The Mid-Atlantic Ridge north of the Oceanographer Fracture Zone and south of the Tydeman Fracture Zone consists of 20-45 km long segments separated by nontransform offsets. The SCARF cruise track followed a flow line that crossed the ridge axis near the center of the third segment north of the Oceanographer Fracture Zone at $35.8^{\circ} \mathrm{N}, 34.2^{\circ} \mathrm{W}$. The crossing point lies approximately $90 \mathrm{~km}$ north of the Oceanographer Fracture Zone and $260 \mathrm{~km}$ south of Tydeman Fracture Zone. This segment has been named previously as the South Alvin Mid-Atlantic Ridge (S. AMAR) (e.g., Detrick et al., 1995)and AMARR91 by Gale et al. (2013). The S. AMAR segment is 40-km long and has a continuous, hourglass-shaped axial rift valley (Paulatto et al., 2015; Eason et al., 2016).

The surrounding near-axis region of the Mid-Atlantic Ridge has been well studied. The Rainbow Hydrothermal Vent Field (German et al., 1996) is situated 
approximately $50 \mathrm{~km}$ northeast of the S. AMAR segment, and the French-American MidOcean Undersea Study (Project FAMOUS) (Ballard et al., 1975)investigation area was located two segments further to the north. The axial rift valley is shallow where it intersects the SCARF cruise track, approximately $2580 \mathrm{~m}$ deep and $8 \mathrm{~km}$ wide. The segment currently has a slightly asymmetric ridge-perpendicular half spreading rate of 14

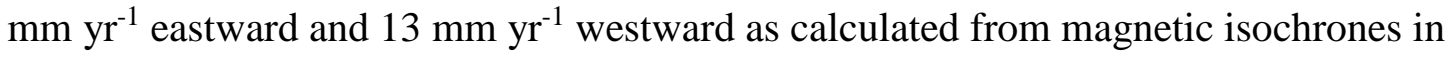
this study (see Section 3.1). Rare-earth element and isotopic chemistry of dredged MORB samples for this segment, as well as other nearby segments show heterogeneity, suggesting at least three mantle components, one of which comes from the Azores plume (White and Schilling, 1978; Shirey et al., 1987; Bougault et al., 1988).

\section{Observations: Underway Geophysical Data Collection}

\subsection{Magnetics}

We used sea surface total magnetic field data to constrain seafloor age along the SCARF cruise track. The data were acquired using a SeaSPY Overhauser magnetometer towed at an offset of 300 meters behind the ship. The raw sea surface total magnetic field data was corrected for (1) navigation offset from ship-to-magnetometer layback, (2) outlying data points, (3) the international geomagnetic reference field (IGRF-11 model, Finlay et al., 2010), and (4) diurnal field variations (relative to Fredericksburg, Virginia, USA, (FRD)). Sea surface crustal magnetic anomalies were obtained by correcting the total field data for the paleo-inclinations $\left(30.5^{\circ}-35.2^{\circ}\right)$ and -declinations $\left(49.7^{\circ}-54.63^{\circ}\right)$ estimated for the Atlantic using the method of (Schettino, 2014) and the paleopoles of (Schettino and Scotese, 2005). The resulting magnetic anomalies along the SCARF transect are in good agreement with the EMAG2v3 (version 3) global magnetic anomaly grid (Meyer et al., 2016) when smoothed (Figure A1) and with magnetic anomaly measurements from nearby or crossing ship paths from NCEI's Marine Trackline Geophysical database (https://www.ngdc.noaa.gov/mgg/geodas/trackline.html) (Figure 1b).

We estimated the ages represented by the magnetic anomalies along the SCARF transect by matching the observed anomalies to a calculated synthetic magnetic anomaly profile. The synthetic model assumes a magnetization square wave based on a magnetized layer at a constant depth of $3.5 \mathrm{~km}$. The layer is $1 \mathrm{~km}$ thick and has a 
magnetization of $\pm 5 \mathrm{~A} / \mathrm{m}$ with polarities based on the Müller et al. (2008) ocean age database and the Wei (1995) Geomagnetic Polarity Time Scale. We filtered this synthetic magnetization profile with a $2-\mathrm{km}$ Gaussian window to account for emplacement effects, following the approach of Tivey and Tucholke (1998). The synthetic magnetization was converted to a synthetic magnetic anomaly profile using the Parker (1972) Fourier summation approach.

To assign isochron numbers and ages to magnetic anomalies along the SCARF cruise track, we visually correlated the synthetic magnetic anomaly profile with the measured magnetic anomalies (Figure 2). We defined the ridge axis as the midpoint of the axial valley and set its age to $0 \mathrm{Ma}$. Spreading rates were predicted on the basis of the correlated magnetic anomalies and agree well with those calculated along the SCARF transect using the global seafloor age model of Müller et al. (2008) (Figure 3d).

\subsection{Bathymetry and Fault Identification}

Bathymetry data (Figure 3a) were collected using a Kongsberg EM122 12-kHz multibeam echosounder. This multibeam echosounder has $0.2 \%$ error directly below the ship with a maximal $0.6 \%$ error at $60-70^{\circ}$. Center beam bathymetry was collected at $1 \mathrm{~Hz}$ and multi-beam bathymetry was collected at $0.33 \mathrm{~Hz}$. The data were cleaned for outlying data points and gridded with the MB-System software (Caress and Chayes, 2017). Figure A2.1-18 shows images of all the trackline multi-beam bathymetry (bathymetry data available through Marine Geoscience Data System). The swath width is $\sim 6$ times the water depth. We identified individual faults manually using a combination of the center beam and multibeam bathymetry. We identified axis-facing fault scarps as changes in topographic gradient observed in the center beam bathymetry data that correspond to linear features in the multibeam bathymetry. Abyssal hills may not be entirely faultcontrolled, and some may be relict volcanic ridges. Volcanic ridges should manifest as symmetric ridges, displaying both inward- and outward-facing slopes within a few $\mathrm{km}$ of one another. Although common at fast spreading rates, volcanic ridges are typically not preserved at slower spreading rates (Carbotte and Macdonald, 1994), and such morphological features were not seen along the transect. Here we interpret all fault scarp picks as abyssal hill-bounding faults. We estimate the throw (vertical offset) and heave (horizontal offset) of each fault by picking the shallowest depth of the fault in the center 
beam bathymetry as the scarp top and the deepest depth of the fault as the scarp bottom. We only picked faults that have an identifiable throw of greater than $10 \mathrm{~m}$. Using this approach, we identified 415 fault scarps along the SCARF transect (red dots in Figure 3a). Individual fault statistics are available in Supplementary Table 1. We find most fault slopes have less than $30^{\circ}$ angles, likely due to gravitational mass wasting of the fault scarps (Cannat et al., 2013) (Figure A3). We calculated fault spacing (bin length divided by the number of picked faults in a bin, Figure 3b) and total fault heave in overlapping $100 \mathrm{~km}$ bins every $25 \mathrm{~km}$ along the flow line. There are 12 or more faults in each bin. The resulting bin spacing precludes analysis of short-period $(<2 \mathrm{Myr})$ variations in fault spacing.

We validated our fault picks by examining the frequency distribution of fault throws (Figure 4). Natural fault populations are predicted to display an exponential frequency distribution for faults having lengths comparable to or greater than the brittle layer thickness (Cowie et al., 1993; Carbotte and Macdonald, 1994) and exponential distributions in scarp heights and fault spacing have been observed at the East Pacific Rise and Chile Ridge (Bohnenstiehl and Kleinrock, 1999; Bohnenstiehl and Carbotte, 2001; Howell et al., 2016). Consistent with these results, we observe that scarp frequency decays exponentially with scarp throw for our picks, suggesting that our scarp database is sampling the true fault population. The exponential decay of fault population fades at large throw $(>0.7 \mathrm{~km})$; we only find three faults with throw greater than $0.7 \mathrm{~km}$.

A major difference between previous fault population studies and ours is that most previous studies analyzed only near axis faults along multiple ridge segments, while most of our picked faults are located far from the ridge axis in $>10 \mathrm{Ma}$ lithosphere. For instance, the furthest off axis fault analyzed by Howell et al. (2016)is $100 \mathrm{~km}$ away from the ridge axis, corresponding to $\sim 3$ Ma lithosphere. To check the validity of our off-axis fault picks, we compared the distributions of fault throw for (1) all faults within $200 \mathrm{~km}$ of the ridge, (2) all faults within $400 \mathrm{~km}$ of the ridge, and (3) the entire transect. We find no change of slope in the cumulative throw distributions between those calculated for 200 and $400 \mathrm{~km}$ cut-offs below a throw of $\sim 0.6 \mathrm{~km}$. The change in slope for throw $>0.6 \mathrm{~km}$ is likely due to the low number of high throw faults found within $400 \mathrm{~km}$ of the ridge axis along our transect, making it difficult for a meaningful comparison. Beyond $400 \mathrm{~km}$ off- 
axis, we identify no faults with throw $>0.5 \mathrm{~km}$. In terms of total fault occurrence, we find 138 faults (33\% of the total faults found along the transect) at distances $>400 \mathrm{~km}$ offaxis ( $45 \%$ of our track line). The lack of identified faults off-axis is likely due to sedimentation and mass wasting reworking seafloor topography. This interpretation is supported by the observation that at higher sediment thicknesses $(>400 \mathrm{~m})$ there is an apparent increase in fault spacing, while for lower sediment thicknesses $(<\sim 300 \mathrm{~m})$ nearer to the ridge axis ( $<400 \mathrm{~km}$ away), fault spacing does not correlate with sediment thickness (Figure 3b). Thus, we limit our analyses of fault statistics on this transect to within $400 \mathrm{~km}$ of the ridge and interpret fault spacing variations within this distance to reflect changes in tectonic behavior.

We calculated the fraction of spreading accommodated by magmatic accretion, $M$ (0 for purely tectonic spreading and 1 for purely magmatic spreading; Buck et al., 2005) in each 100-km bin by subtracting the cumulative heave from the bin length and dividing by the bin length. $M$ values calculated in this manner are maxima, as apparent fault heave recorded by scarp morphology is reduced through sedimentation and mass wasting. In general, these effects should become more significant in older lithosphere farther offaxis. Focusing on bins within $400 \mathrm{~km}$ of the ridge axis, where we have the best estimates of fault statistics, we find that $M$ varies from $0.6-0.85$ and is smallest near the ridge (Figure 3c). Farther off-axis, variations in fault spacing are likely to be better proxies for variations in tectonic behavior, as spacing will only be affected by mass wasting and sedimentation if an existing fault is degraded or buried such that it can no longer be identified in the center beam data.

\subsection{Gravity}

Shipboard gravity data was collected at a $1 \mathrm{~Hz}$ sampling rate along the SCARF transect using a Bell BGM-3 gravimeter. Corrections were applied for (1) instrument calibration, (2) instrument drift, (3) latitude variations, and (4) the Eötvös effect. We filtered the corrected gravity data with a 2-pole low-pass Butterworth filter with corner frequency 0.004 per sample and removed outlying data points. The free-air anomaly (FAA) was calculated by subtracting the reference gravity along the GRS80 ellipsoid (Moritz, 1980) from the observed gravity. Our data is in excellent agreement with the 1arcminute satellite-derived marine FAA version 24 (Sandwell et al., 2014) (Figure 1c). 
The mantle Bouguer anomaly (MBA) was calculated by subtracting the water-sediment, sediment-crust, and crust-mantle density interfaces from the FAA following the spectral method of Parker (1972). We assume a 6-km thick crustal layer. Sediment thickness (Figure 3b) was taken from Divins (2003), which interpolated sediment thickness from compiled isopach maps, ocean drilling records, and seismic reflection data. To reduce edge effects in the calculation of the MBA, we added $500 \mathrm{~km}$ of satellite-derived data (Sandwell et al., 2014)to each end of the SCARF transect. Densities used to calculate density contrasts for water, sediment, crust, and mantle were assumed to be 1000, 2100, 2800, and $3300 \mathrm{~kg} \mathrm{~m}^{-3}$, respectively, with the sediment density taken from (Hamilton, 1978). To obtain the residual mantle Bouguer anomaly (RMBA) (Figure 3e), we further corrected the MBA for thermal contraction of the oceanic lithosphere assuming a halfspace cooling model (Turcotte and Schubert, 2014) with the magnetically derived ages

(Figure 2), $T_{\text {mantle }}=1350{ }^{\circ} \mathrm{C}, T_{\text {surface }}=0{ }^{\circ} \mathrm{C}$, thermal expansivity $\alpha=5 \times 10^{-5}{ }^{\circ} \mathrm{C}^{-1}$, and thermal diffusivity $\kappa=10^{-6} \mathrm{~m}^{2} \mathrm{~s}^{-1}$.

\subsection{Gravity-Derived Crustal Thickness}

The RMBA can be used to estimate relative variations in crustal thickness assuming a constant crustal density. Relative variations in crustal thickness derived from this approach have been shown to compare well to constraints from co-located seismic studies (e.g., Tolstoy et al., 1993; Hooft et al., 2000; Wang et al., 2011). Here we calculated relative crustal thickness variations by downward continuing the de-meaned RMBA to a constant depth of $10 \mathrm{~km}$ below the sea surface (Kuo and Forsyth, 1988; Wang et al., 2011). To remove short-wavelength noise, we filtered the RMBA before downward continuation, using a cosine taper designed such that signals with wavelengths less than $25 \mathrm{~km}$ were filtered out and signals with wavelengths greater than $45 \mathrm{~km}$ were fully retained. Because the average half spreading rate along the SCARF transect is $~ 14$ $\mathrm{km} \mathrm{Myr}^{-1}$, this removes crustal thickness variations occurring at wavelengths less than $\sim 2$ Myr. We then calculated crustal thickness variations with respect to a $6 \mathrm{~km}$ crust (Figure 3f), corresponding to the average crustal thickness obtained at a nearby ridge segment using seismic refraction data (Hooft et al., 2000). Our results agree well with the regional estimates of gravity-derived crustal thickness calculated by Wang et al. (2011).

\subsection{Kafka Dome}


Along our transect, we observed a dome-shaped bathymetric high at $35^{\circ} 34^{\prime} \mathrm{N}$, $32^{\circ} 54^{\prime}$ W (Figure 5), which we name Kafka Dome. Kafka Dome was identified as an oceanic core complex based on its dome morphology with a topographic prominence of $\sim 1 \mathrm{~km}$ and $\mathrm{a} \sim 7 \mathrm{~km}$ length widening away from the axis into an elongated ridge. This morphology is consistent with the breakaway ridge geometry observed at well-developed oceanic core complexes at $13^{\circ} 20^{\prime} \mathrm{N}$ and $13^{\circ} 30^{\prime} \mathrm{N}$ on the MAR (Figure 5c, Escartín et al., 2017) and Mt. Dent on the Mid-Cayman spreading center (Hayman et al., 2011). The measured size and topographic height of the dome are likely minimal estimates of the original dome structure due to off-axis sedimentation and mass wasting. We also observe a local $\sim 8 \mathrm{mGal}$ increase in the RMBA skewed towards the ridge axis (Figure $5 \mathrm{~b}$ ). Similar RMBA increases at other oceanic core complexes are commonly interpreted as positive mass anomalies caused by thinner crust in the fault footwall (Tucholke et al., 1998, 2008). We do not observe corrugations as seen at many near ridge core complexes (e.g., Cann et al., 1997), likely due to off-axis sedimentation. Taken together, these observations point toward Kafka Dome as a rare example of an inactive off-axis oceanic core complex.

The discovery of a fossil core complex indicates that within the last $10 \mathrm{Ma}$, faulting style at the S. AMAR segment has changed from an oceanic core complex regime to a regularly spaced abyssal hill regime characteristic of presently accreting seafloor in the vicinity of the Oceanographer Fracture Zone (Escartín et al., 2008). The Rainbow Massif and Pot of Gold Massif are the closest known large-offset detachment faults (Paulatto et al., 2015; Eason et al., 2016). The coincidence of Kafka Dome with the region of larger fault spacing located at 8-22 Myr on both sides of the ridge axis (shaded bars in Figure 3) suggests that this interval may be characteristic of a long-lived oceanic core complex regime.

\section{Time-Series Analysis}

Using the magnetically derived ages and our shipboard geophysical datasets, we apply spectral analysis to decompose the bathymetry and gravity data in space and time and determine what frequency range(s) hold the most power in our data. Because various tectonic and magmatic processes act on different timescales, the spectral power density can distinguish the relative importance of these processes. We also calculate the 
coherence and admittance between the gravity and simultaneously-observed center beam bathymetry data, which we use to estimate the elastic plate thickness, $T_{e}$, along the flow line.

\subsection{Spectral Analysis}

Time-domain spectral analysis on the bathymetry and RMBA (Figure 6) was performed using the multitaper method (Percival and Walden, 1993) with seven tapers. We used ages defined by linear interpolation of our magnetic isochron picks. We investigate spectral power in the time domain such that spreading rate changes do not produce spurious spectral peaks. We first de-trended the bathymetry and gravity data in the time domain. To help identify spectral peaks for bathymetry, the spectra were calculated on the time-derivative of the bathymetry, which amounts to pre-whitening the data (Percival and Walden, 1993). We limited all spectral analysis to wavelengths that occur five or more times in the analyzed section of the geophysical transect (e.g., <5.6 Myr for the two 0-28 Myr regions adjacent to the ridge axis) and were not filtered out via preprocessing (<300 kyr for gravity and <10 kyr for bathymetry). We define a spectral peak as a region that has a higher value than the $95^{\text {th }}$ percentile confidence interval of the background spectra.

We separated the transect into three sections for analysis: the entire eastern flank (0-28 Ma), the corresponding near ridge western flank (0-28 Ma), and the older, off-axis lithosphere (28-51 Ma) on the western flank. The window of the east flank (blue portion of Figure 6) is set by the length of our transect. The window of the near-axis west flank (red portion of Figure 6) is set equal to the eastern flank for comparison purposes. Further west, the cruise encountered stormy weather that added high frequency noise to our gravity data that the Butterworth filter was unable to remove, so we omit these from the subsequent analysis. Setting these boundaries allows us to employ a standard multi-taper method and intuitively present the analysis and confidence intervals. We find that the two near-axis sections (red and blue, Figure 6) display similar bathymetry and RMBA power spectra. The off-axis section (orange, Figure 6) lacks the same peaks in the bathymetry and has weaker power overall, likely due to mass wasting and sedimentation.

For the North American (western) 0-28 Ma bathymetry power spectra, broad peaks appear at 300-, 390-, 550-, and 950-kyr periods (dashed vertical black lines in 
Figure 6b). For the African (eastern) bathymetry power spectra, broad peaks appear at 270-, 340-, 550-, and 950-kyr periods. The near-axis RMBA power spectra show peaks at 390-, 550-, and 950-kyr periods on both the North American and African plates. Power is diffuse as spectral densities lack peaks but remain high at longer periods (> $1 \mathrm{Myr}$ ) for both the bathymetry and RMBA. The off-axis North American 28-51 Ma RMBA spectral density (orange in Figure 6d) shows a strong peak at $390 \mathrm{kyr}$ and a diffuse peak at $650 \mathrm{kyr}$ (dash-dotted line in Figure 6d).

The shortest period peaks in both the RMBA and bathymetry likely reflect abyssal hill spacing. The typical spacing of abyssal hill-bounding faults along the transect is $2-6$ $\mathrm{km}$ (Figure 3b). For a half spreading rate of $\sim 14 \mathrm{~mm} \mathrm{yr}^{-1}$, this implies that faulting should add power to the bathymetry spectra between $140-420 \mathrm{kyr}$. This is consistent with the spectral power in the bathymetry between $250-400 \mathrm{kyr}$, as well as the 390-kyr spectral peaks in the RMBA, suggesting that faulting modifies the crustal thickness at these periods.

The 550- and 950-kyr peaks in the RMBA of the near-axis sections and the 650kyr diffuse peak in the off-axis section do not correlate with the abyssal hill fabric and may instead reflect processes that result in variations in crustal thickness (see discussion in Section 5). The change in RMBA spectral peaks between the younger, near-axis (0$28 \mathrm{Ma}$ ) and the older, off-axis (28-51 Ma) suggests a change in the tectono-magmatic processes causing these peaks. There may also be power at longer wavelengths (e.g., 10$20 \mathrm{Myr}$ ) as seen by the periodicity in the raw RMBA data (Figure 3e); however, the section length limits us to interpreting periods in the power spectra less than 5.6 Myr.

There are no significant peaks in the bathymetry power spectrum at any of the Milanković cycle periods (100 kyr, $41 \mathrm{kyr}$, and $23 \mathrm{kyr}$ ) as reported by Crowley et al., (2015), supporting the idea that ocean floor bathymetry formed at slow-spreading MORs is not sensitive to fluctuations in melt supply triggered by sea level change (Goff, 2015; Olive et al., 2015, 2016; Goff et al., 2018).

\subsection{Admittance \& Coherence}

Elastic plate thickness, $T_{e}$, provides an estimate for the thickness of a rigid elastic plate (overlying an inviscid half-space) that best fits the observed patterns of lithospheric flexure. It is therefore a useful proxy for the integrated strength of the plate, and a direct 
control on the morphology of the seafloor (Watts, 2001). To estimate $T_{e}$, we calculated the admittance and coherence of the topography and MBA along the entire SCARF transect following the approach of (Forsyth, 1985) (Figure 7). Admittance is defined as the transfer function between topography and MBA. The highest value of admittance is reached through isostatic compensation, which produces topography in response to local thickening of the crust. Short-wavelength oscillations in crustal thickness, however, tend to be flexurally compensated, suppressing strong topographic signals. Thus, admittance is usually low in the short-wavelength limit. Thinner elastic plates will have a larger amplitude admittance at shorter wavelengths because they can isostatically compensate shorter wavelength topography.

Coherence is a statistic that characterizes the strength of the association between two spectra at different wavelengths. For an elastic plate, long wavelength topographic variations will be isostatically compensated, and thus bathymetry and the MBA will have a coherence of 1 . On the other hand, short wavelength topography that is not isostatically compensated will have a coherence of 0 . For the calculation of admittance and coherence, the bathymetry and MBA data were not pre-whitened and the densities of the crust and mantle were assumed to be 2800 and $3300 \mathrm{~kg} \mathrm{~m}^{-3}$, respectively. For comparison, we also calculated theoretical coherence and admittance curves for an idealized elastic plate model of a given $T_{e}$, assuming a Young's modulus of $100 \mathrm{GPa}$, Poisson's ratio of 0.25 , a crustal thickness of $6 \mathrm{~km}$, and equal loading on the surface and base of the plate. Estimates of $T_{e}$ from coherence are relatively insensitive to changing the assumed ratio of loading on the surface and base of the plate and to reasonable oceanic crustal thickness variations (4-8 km) (Forsyth, 1985). Coherence and admittance estimates of $T_{e}$ are also insensitive to the inclusion or exclusion of the off-axis (28-74 Ma) data.

An elastic plate thickness $\left(T_{e}\right)$ of 6-12 km best fits both the admittance and coherence (Figure 7). $T_{e}$ calculated from the admittance and coherence analyses reflects the strength of the plate at the time of loading. Our results are in the range found for $T_{e}$ in the Atlantic based on applying elastic flexure theory to off-axis volcanoes emplaced on young (<10 Ma) oceanic crust (Calmant and Cazenave, 1987). Smith et al. (2008) found evidence of highly-rotated low offset faults in the Central Atlantic which would 
suggest $T_{e}<1 \mathrm{~km}$ at ages $<1 \mathrm{Myr}$. Thus, because our admittance and coherence analyses for the entire SCARF transect predicts a $T_{e}$ in agreement with young lithosphere, we interpret that the loading was applied near, but not on the ridge axes, most likely during tectono-magmatic processes associated with the creation of the oceanic lithosphere.

\section{Discussion}

\subsection{Variations in Crustal Thickness}

Gravity-derived crustal thickness varies between 3 and $9 \mathrm{~km}$ with a standard deviation of $1.0 \mathrm{~km}$ assuming a mean of $6 \mathrm{~km}$ along the SCARF transect (Figure $3 \mathrm{f}$ ). These fluctuations are consistent with the range of crustal thicknesses observed in seismic studies in Atlantic crust away from hotspots (Canales et al., 2000b, 2000a; Hooft et al., 2000; Lizarralde et al., 2004) as well as previous gravity-derived crustal thickness analyses for the Atlantic Ocean (Lin et al., 1990; Detrick et al., 1995; Wang et al., 2011). We observe spectral peaks in the near-axis RMBA data at 390-, 550-, and 950-kyr periods and diffuse power at periods longer than 1 Myr. These observations are consistent with seismic imaging of oceanic crust, which find crustal thickness variations on timescales of 0.5-1 Myr in the Atlantic (e.g., near the Kane fracture zone: Canales et al., 2000a).

Variations in RMBA-derived crustal thickness could be caused by any one of the following tectonic and magmatic processes: variations at slow to ultra-slow spreading rates, along-segment thickness variations, faults offsetting the Moho, changes in ridge geometry and upper mantle flow, magma solitons, or thermal and chemical variations in the mantle source region (Figure 8). Below we discuss these different processes and their potential influence on the observed crustal thickness variations along the SCARF transect.

Spreading rate is not a dominant cause of crustal thickness variation. Our data show no significant correlation between spreading rate and crustal thickness (Figure A4). This agrees with observations and geodynamic melting models that show crustal thickness is not sensitive to spreading rate for spreading rates greater than $10 \mathrm{~mm} \mathrm{yr}^{-1}$ (Parmentier and Morgan, 1990; Chen, 1992; Behn and Grove, 2015).

Second, the inferred crustal thickness variations could be due to our transect wandering slightly off the flow line, either closer to the middle or edge of the ridge 
segment. Indeed, crustal thickness variations between 3 and $9 \mathrm{~km}$ have been observed on single ridge segments in the North Atlantic (Cannat, 1996; Hooft et al., 2000). Thus, if the transect was not always perfectly aligned with the segment center, this could explain some of the variability in our observations. This variation should not have a clear expression in the frequency domain due to its stochastic nature, and thus we do not consider it to be the primary source of crustal thickness variations along the SCARF transect.

Variations in ridge segment geometry and upper mantle flow have also been theorized to affect crustal thickness on both segment and regional scale (e.g., Detrick et al., 1995; Hooft et al., 2000; Bonatti et al., 2003). Rearrangement and/or changes in the length of segments could therefore bias our one-dimensional transect of crustal thickness observations. The timescales for such changes is typically on the order of millions of years (Schouten and Klitgord, 1982; Caress et al., 1988; Tucholke et al., 1997). Segment reorientation is observed through changes in the ridge-parallel magnetic lineation. For example, a lineation-perpendicular offset formed by the growth of a fracture zone or the rotation of the ridge-parallel magnetic lineations due to ridge rotation or rift propagation (e.g., Kleinrock et al., 1997). Global magnetic data (Meyer et al., 2016) along our trackline show no alteration in ridge-parallel magnetic lineations. Thus, there is no evidence of ridge segment length variability on either side of the ridge axis based on global magnetic data. Furthermore, ridge segment rearrangement is not periodic, so if it did occur, it would not be expected to manifest as discrete spatial peaks.

Normal faulting can locally alter crustal thickness by offsetting the base of the crust. Previous seismic oceanic crustal thickness studies have shown faulting to be a major driver of observed cross-axis crustal thickness variations because crustal thickness anomalies are often found with fault scarps directly above them (e.g., Canales et al., 2000a; Seher et al., 2010). As shown in Figure 3b, fault spacing within $400 \mathrm{~km}$ of the ridge axis ranges from 2-6 km along the SCARF transect. For an average half spreading rate of $\sim 14 \mathrm{~km} \mathrm{Myr}^{-1}$, the spectral power associated with such faulting should lie in periods of 140-420 kyr, coincident with spectral peaks in the bathymetry data between 250-400 kyr and the RMBA spectrogram peak at $390 \mathrm{kyr}$. However, the observed faulting periods do not coincide with the additional spectral peaks at 550 and $950 \mathrm{kyr}$. In 
the most extreme case, large-offset $(>5 \mathrm{~km})$ detachment faults can cause observable crustal thickness variations up to 1-3 km lasting for 1-3 Myr (Tucholke et al., 1998; Parnell-Turner et al., 2018). Detachment faults create strong asymmetry in crustal thickness, exposing deep crustal units in the footwall of the fault, while the hanging wall can experience emplacement of a complete crustal section (Olive et al., 2010). Because we interpret Kafka Dome as an oceanic core complex in 8 Ma crust east of the ridge axis (see Section 3.6), detachment faulting is a potential factor driving crustal thickness variations. However, the impact of a detachment fault on crustal thickness should be local. In our dataset, this would most likely add diffuse power at periods similar to their lifespan (1-3 Myr) instead of generating clear spectral peaks.

Magma solitons are buoyantly ascending porosity waves of high melt fraction that occur in porous two-phase flow such as the mantle-melting column beneath a mid-ocean ridge (Scott and Stevenson, 1984). These solitons could result in periodic crustal thickness variations if they carry sufficient melt to the ridge axis. Compaction and ascent timescales for basaltic melt in the sub-ridge mantle depend on the melting column height, the melt density contrast, the melt viscosity, the melt fraction, the grain size, and the permeability-porosity relationship (McKenzie, 1985). Depending on the choice of parameters, this timescale can range from $10^{4}-10^{7}$ years. These timescales reflect the time necessary to extract melt via compaction once, and provide no requirement that the melt extraction process is periodic. More recent two-phase flow models (Sim et al., $2018)$ at intermediate spreading rates $\left(3.5 \mathrm{~cm} \mathrm{yr}^{-1}\right.$ half spreading rate) produce stable and persistent porosity waves that produce changes in crustal thickness with an amplitude of $\sim 0.5 \mathrm{~km}$ and recurrence time scales on the order of 100s of kyrs. Further two-phase flow modelling is necessary in order to ascertain whether this periodicity exists at slower spreading rates and over which range of parameter values.

Source region heterogeneities, chemical and thermal, have also been invoked to explain observed variations in oceanic crustal thickness. Mantle compositional heterogeneity can cause variations in crustal production by enriching or depleting the mantle source, which modulates the melting fraction below the ridge (Katz and Weatherley, 2012). Thermal heterogeneities associated with mantle hotspots change the melt flux of the upwelling mantle. Bonatti et al. (2003)interpreted a combination of 
gravity and geochemical data collected along the Vema fracture zone as indicating an increase in mantle potential temperature in this region of the Central Atlantic Ocean over the last $20 \mathrm{Myr}$, causing an increase in crustal thickness on the timescale of the temperature variations (>10 Myr). However, regional gravity-derived crustal thickness calculations (Wang et al., 2011) suggest more complicated trends in this region.

Plume thermal pulsing has been interpreted to create regional crustal thickness variations that are reflected in the V-shaped ridges near the Azores. However, these Vshaped ridges do not extend south to the S. AMAR segment and Escartín et al. (2001)argue that the melt flux anomaly from the Azores plume stops at approximately $36^{\circ} \mathrm{N}, \sim 30 \mathrm{~km}$ north of the SCARF transect. Thus, while thermal pulsing can affect crustal thickness, there is no strong evidence for thermal source heterogeneities along the SCARF transect.

Trace element and isotopic data in dredged gabbros suggest chemical heterogeneities near the SCARF transect caused by influence from the Azores plume or patches of former sub-continental mantle lithosphere (Shirey et al., 1987; Bougault et al., 1988). To cause temporal variations of crustal thickness, these source heterogeneities would have to pass through the melting column entirely; thus the timescales of variation would depend on their size and spacing given a constant mantle upwelling velocity. For instance, in order for the 550- and 950-kyr spectral peaks to correspond to melting anomalies associated with mantle source heterogeneities upwelling at a rate of $\sim 14 \mathrm{~km} \mathrm{Myr}^{-1}$, these heterogeneities would need to have a characteristic size and/or spacing of 7.7 and 13.3 $\mathrm{km}$. Larger heterogeneities would cause longer period crustal thickness variations. Because we do not have a long time-series chemical dataset near this ridge-segment, we lack the ability to determine how much of the crustal thickness variations are due to chemical source heterogeneities.

In summary, diffuse power at longer periods ( $>1 \mathrm{Myr}$ ) along the SCARF transect is most likely due to a combination of detachment faulting, mantle source heterogeneities (thermal and/or compositional), and/or magma solitons. The lack of peaks at long periods is likely due to the lack of periodicity and the temporal independence of these processes, allowing the expression of their signals in crustal thickness to constructively or destructively interfere. Faulting is most likely the cause for spectral power in bathymetry 
and RMBA between 250-400 kyr because this time scale matches the characteristic spacing of fault-bounded abyssal hills. By contrast, only regularly spaced chemical source heterogeneities and/or magma solitons can explain the spectral peaks at 550 and 950 kyr. Further numerical studies are necessary to help estimate the relative importance and plausibility of the different factors contributing to the 550- and 950-kyr periods. The change in RMBA spectral peaks from 550 and $950 \mathrm{kyr}$ in the younger, near-axis sections (0-28 Ma) to a diffuse 650-kyr peak in the older, off-axis section (28-51 Ma) could be caused by a change in these tectono-magmatic processes.

\subsection{Variations of Faulting Style and Relation to Magma Supply Variations}

Geophysical modeling shows that the main control on fault spacing is the fraction of spreading accommodated by magmatic accretion, $M$ (Buck et al., 2005; Behn and Ito, 2008; Ito and Behn, 2008; Tucholke et al., 2008; Olive et al., 2015; Liu and Buck, 2018; Howell et al., 2019). Co-located analyses of ocean floor bathymetry and basalt geochemistry have validated the importance of magma supply on abyssal hill morphology (Roth et al., 2019). With higher $M$, faults are advected off axis into thicker lithosphere more rapidly. This makes continued slip on the existing fault energetically less favorable (Forsyth, 1992; Buck, 1993), resulting in the formation of a new fault near the ridge axis, and an overall decrease in fault spacing and fault offset (Behn and Ito, 2008). A special case occurs when $M$ approaches 0.5 , such that spreading on one side of

the ridge is accommodated purely by magma intrusion, while extension on the conjugate side is entirely accommodated by slip on a long-lived detachment fault whose footwall forms an oceanic core complex (Buck et al., 2005). These models predict an inverse relationship between fault spacing and crustal thickness.

These model predictions imply that if Kafka Dome is indeed the footwall of a detachment fault, the minimum $M$ observed should be close to 0.5 (e.g., MacLeod et al., 2009; Schouten et al., 2010)). The maximum $M$ calculated through fault heave analysis is 0.85 (Figure 3c). This range is in agreement with the overall range in $M$ values $(0.45-$ 0.75) that has been calculated in young lithosphere along the MAR (Ito and Behn, 2008; Paulatto et al., 2015).

The geophysical data collected along the SCARF transect allows us to further quantify the relationship between magma supply and fault spacing. The Spearman rank 
correlation coefficient (Spearman, 1904), $r$, detects any type of monotonic correlation rather than only a specific functional correlation and is less sensitive to outliers. Values of $r$ range from -1 to 1 , with larger absolute values indicating that the two variables more strongly co-vary according to a monotonically increasing (positive) or decreasing (negative) relationship. The corresponding $p$-value indicates the probability that the relationship is due to randomness. We find a strong and significant negative correlation $(r$ $=-0.64, p=2.2 \mathrm{e}-4)$ between average crustal thickness and fault spacing within $400 \mathrm{~km}$ of the ridge (Figure 9a). This agrees with previous findings in the Atlantic Ocean of fault spacing increasing at the edge of ridge segments where the crust is thinner (Shaw, 1992; Shaw and Jian Lin, 1993). Thus, we interpret the variations in fault spacing along the flow line (Figure 3b) to reflect variability in magmatic input into the brittle crust of the MAR over time. We find no significant correlation between the calculated $M$ value and crustal thickness over the same bins $(r=-0.254, p=0.19)$ (Figure 9b). This lack of a significant correlation could be due to the coarse resolution of our calculated $M$ values, inaccuracies in our heave measurements due to off-axis sedimentation and mass wasting, or that $M$ is independent of crustal thickness as observed by Howell et al., (2016). Olive et al. (2010) modeled extensional faulting at mid-ocean ridges with separated melt accretion rates in the ductile and brittle layers of oceanic crust and showed that faulting is only sensitive to the $M$ value in the brittle lithosphere. Thus, varying amounts of magma intrusion in the asthenosphere does not affect faulting style and could result in a decoupling of fault style and crustal thickness variations.

Finally, we note that $r$ statistics can be sensitive to outliers. For example, removing the two data points with high $M$ and high crustal thickness results in a nonintuitive negative correlation $(r=-0.495, \mathrm{p}=0.01)$, illustrating the weakness of the correlation between $M$ and crustal thickness. Thus, while a correlation between $M$ and crustal thickness is expected on a global scale — as both are known to increase with increasing spreading rate (Dick et al., 2003; Olive et al., 2015) - it is possible that our transect did not encounter strong enough fluctuations in magma supply to be clearly reflected in both crustal thickness and tectonic fabric. 


\section{Conclusion}

We conducted one of the longest continuous geophysical surveys along a 1400$\mathrm{km}$ spreading-parallel flow line across the Mid-Atlantic Ridge from $28 \mathrm{Ma}$ on the African Plate to $74 \mathrm{Ma}$ on the North American plate. The transect was analyzed to study covariability in bathymetry, gravity, and fault statistics in order to elucidate tectonomagmatic variability through time at a single slow-spreading ridge segment. Gravityderived crustal thickness varies from 3-9 $\mathrm{km}$ along the transect with a standard deviation of $1.0 \mathrm{~km}$ assuming a mean crustal thickness of $6 \mathrm{~km}$. Admittance and coherence of gravity and bathymetry predict the effective elastic thickness of the lithosphere, $T_{e}$, to be 6-12 km, consistent with other estimates for young oceanic lithosphere and indicating that most lithospheric loading that produced relief occurred near, but not on the ridge axis.

Bathymetry and RMBA spectral densities show concurrent peaks on both the eastern and western flanks (0-28 Ma) at 390-, 550-, and 950-kyr periods, with diffuse power at longer periods ( $>1 \mathrm{Myr}$ ). We interpret the diffuse power along the transect as due to a combination of detachment faulting, mantle source heterogeneities (thermal and/or compositional), and variations in upper mantle flow. The 390-kyr spectral peak corresponds to the characteristic spacing of abyssal hill-bounding faults. By contrast, the 550- and 950-kyr peaks are more likely explained by short-wavelength mantle source heterogeneities and/or magma solitons. Further off-axis (28-51 Ma), RMBA spectral density shows a diffuse peak at $650 \mathrm{kyr}$ instead of 550 and $950 \mathrm{kyr}$ could be caused by a change in these tectono-magmatic processes over $>10 \mathrm{Myr}$ time periods. Further modelling and analysis are necessary to better quantify the characteristic time scales of these processes and their parameter dependence.

Finally, fault statistics and the identification of a newly observed, off-axis oceanic core complex suggest $M$ values ranging from $0.5-0.85$ along flow line. We find a significant negative correlation between fault spacing and gravity-derived crustal thickness, indicating the variations in fault spacing along the flow line reflect variability in magmatic input into the brittle crust of the MAR over time. This implies that future statistical analyses of fault populations have the potential to identify variations in mantle melting and melt transport at mid-ocean ridges. In particular, further studies that jointly 
analyze faulting characteristics and crustal thickness have the potential to elucidate past variations in magma production.

\section{Acknowledgements}

Data and supplemental materials are available at the Woods Hole Open Access Server (doi.org/10.26025/1912/24796). We would like to thank the Woods Hole Oceanographic Institution, National Science Foundation, Naval Oceanographic Office, and the captain and crew of R/V Neil Armstrong for making the SCARF cruise possible. We would also like to thank Eboné Pierce for her help during the cruise. We thank Meghan Jones for advice using MBSystem. We also thank Maurice Tivey, John Greene, and Masako Tominaga for advice on processing the magnetic datasets. We would like to thank Peter Huybers for sharing his spectral analysis codes. We would like to thank Rob Sohn for his help on interpreting spectral analysis. We would like to thank Del Bohnenstiel, Milena Marjanović, one anonymous reviewer, and Editor Thorsten Becker for their very helpful comments that improved this manuscript. Funding was provided for this research by NSF OCE-14-58201. 


\section{Figures}
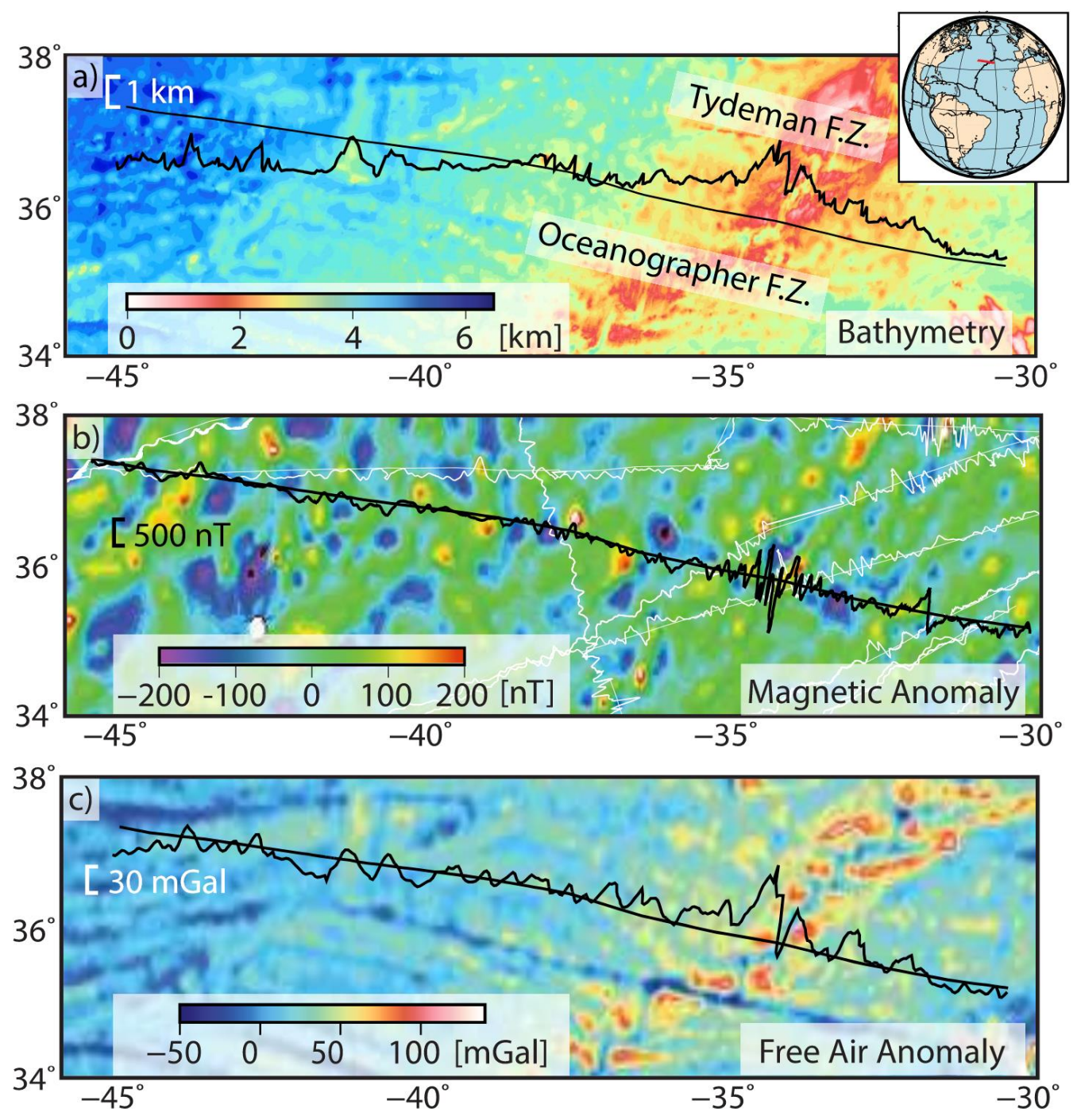

Figure 3.1: Comparison of shipboard and regional data sets along the SCARF cruise track. a) Track line bathymetry (scale in $\mathrm{km}$ is shown by white bar) plotted along the track line (straight black line) over satellite-derived bathymetry (Weatherall et al., 2015) for the region. The inset shows global plate boundaries (black lines) and our track line (red line). b) Shipboard magnetic anomaly (scale in $\mathrm{nT}$ is shown by white bar) plotted 
along the track line over global magnetic anomaly grid EMAG2v3 (Meyer et al., 2016). White lines are other shipboard magnetic anomaly tracks from NCEI's Marine Trackline Geophysical database (https://www.ngdc.noaa.gov/mgg/geodas/trackline.html). c) Shipboard free air gravity anomaly (scale in $\mathrm{mGal}$ is shown by white bar) plotted along the track line against 1 arcminute satellite-derived global free air anomaly version 24 (Sandwell et al., 2014). 


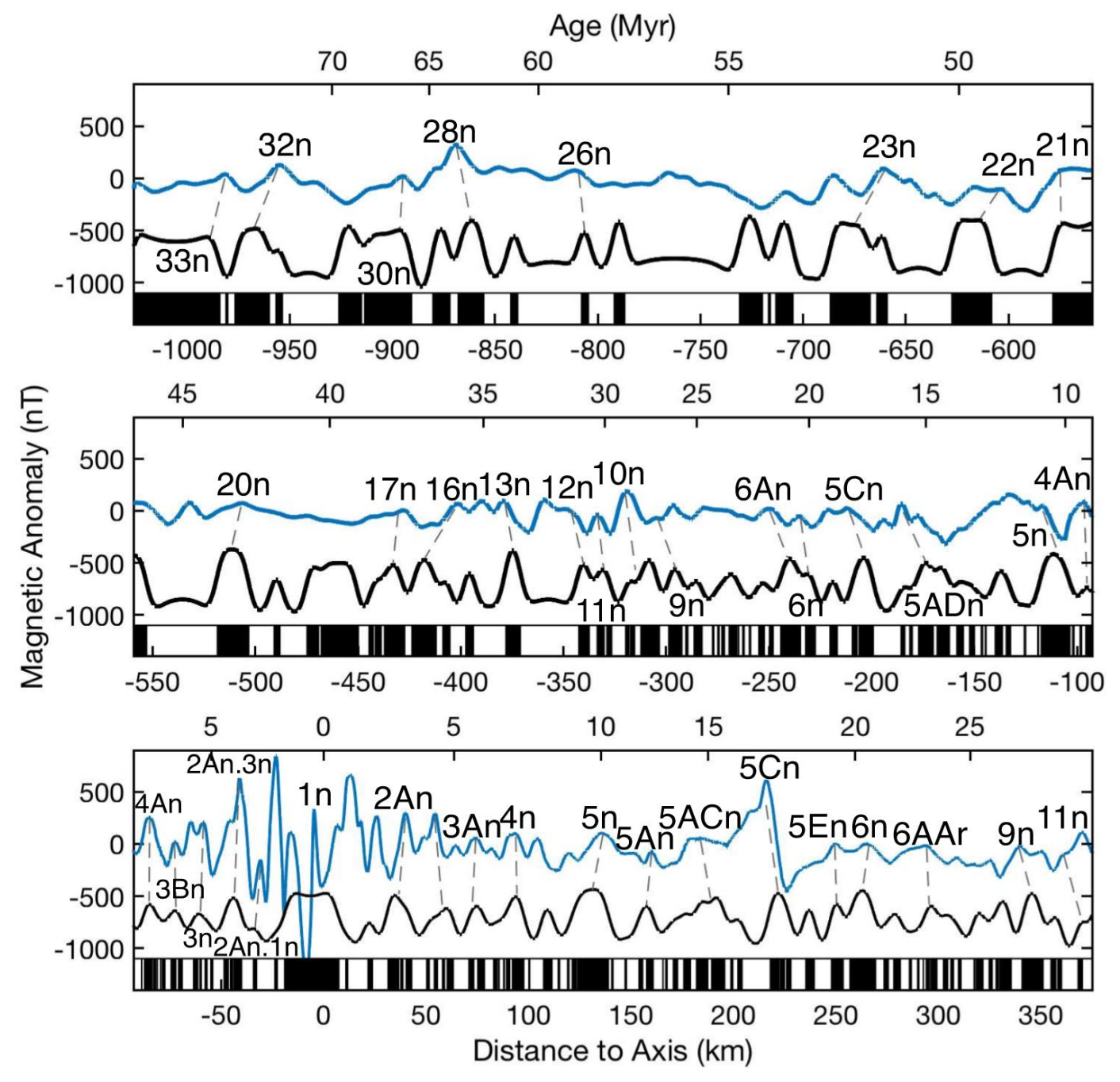

Figure 3.2: Comparison of the observed magnetic anomaly along the SCARF transect (blue line) and synthetic magnetic anomaly (black line) calculated from the magnetostratigraphic scale plotted on the bottom. See section 3.1 for synthetic calculation method. Synthetic profile is vertically translated by $-700 \mathrm{nT}$ for illustration purposes. Isochron picks are labeled and represented as dashed grey lines. 


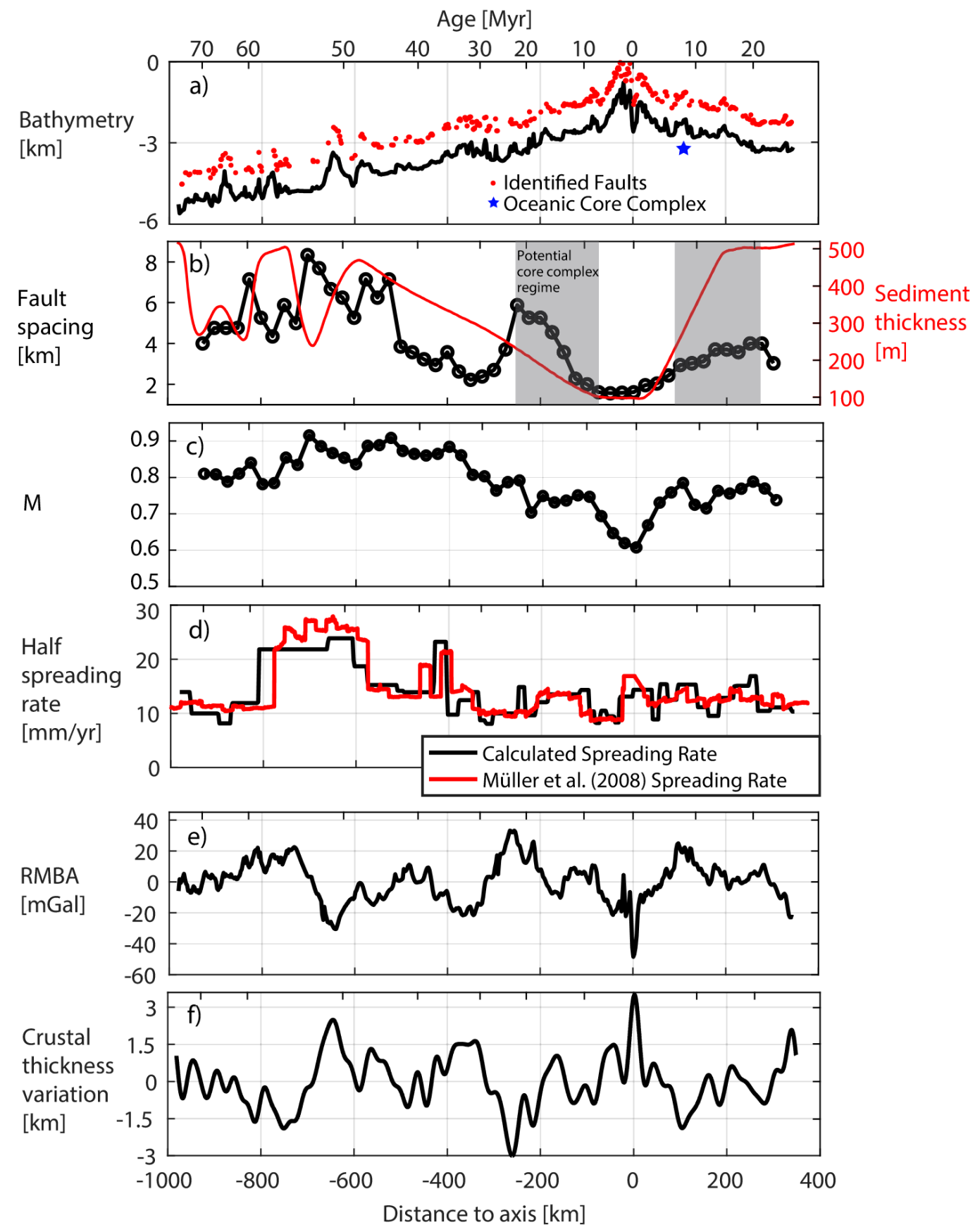

Figure 3.3: Shipboard geophysical datasets and derived geophysical parameters along the SCARF transect. a) Track line bathymetry (black) with picked fault locations (red dots, displayed $1 \mathrm{~km}$ shallower than picked location). The location of the observed oceanic core complex, Kafka Dome is marked by the blue star, displayed $0.7 \mathrm{~km}$ deeper than the picked location. b) Binned fault spacing (open circles) and interpolated sediment thickness from compiled isopach maps, ocean drilling records, and seismic 
reflection data (red line; Divins, 2003). Grey regions denote potential oceanic core complex regimes located symmetrically across the ridge axis. c) $M$ (circles) calculated as described in Section 3.2. d) Half spreading rates calculated from our magnetic anomaly derived ages (black line) and from an interpolated global age grid (Müller et al., 2008). e) Calculated residual mantle Bouguer anomaly (RMBA). f) Downward continued crustal thickness variations calculated from the RMBA assuming an average crustal thickness of $6 \mathrm{~km}$. 


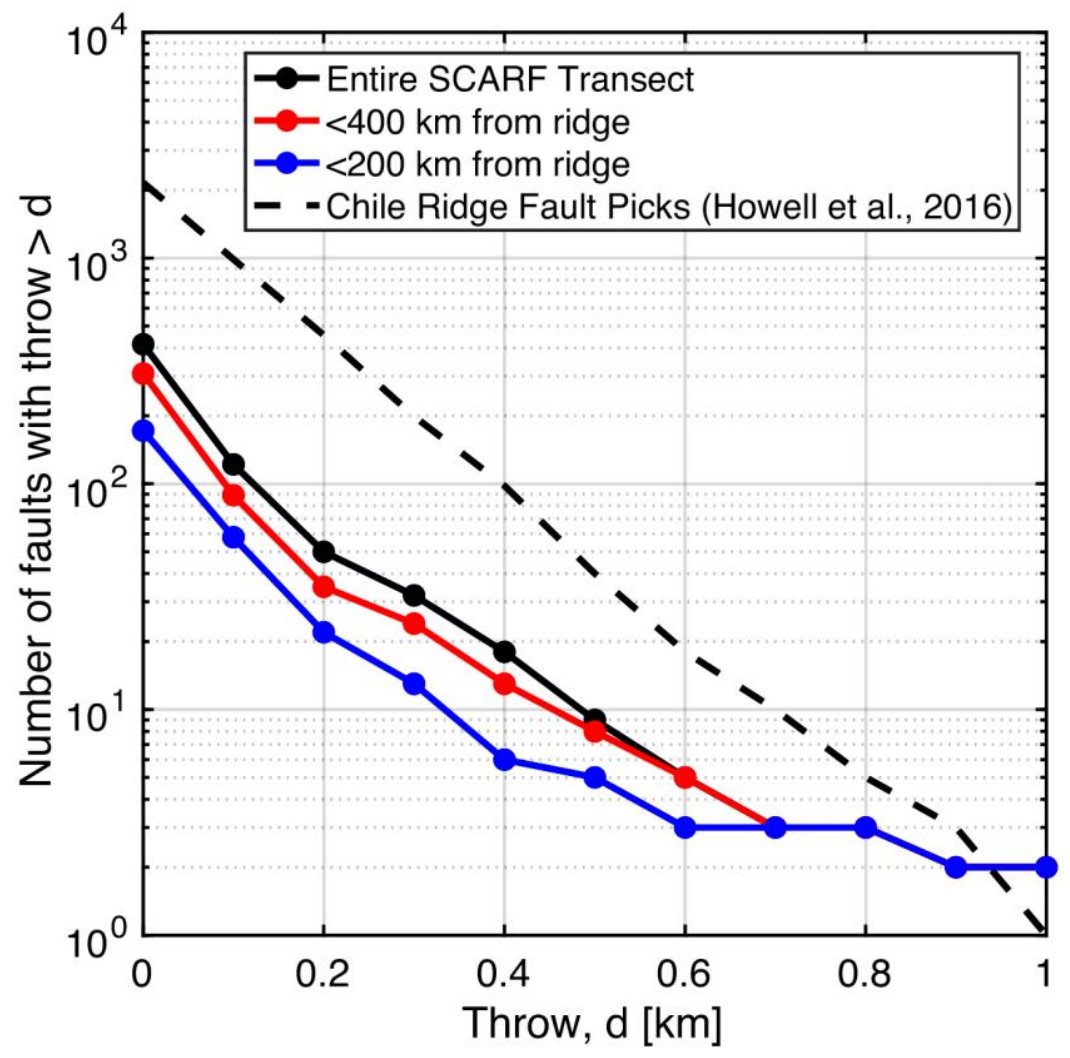

Figure 3.4: Cumulative frequency distribution of fault throw for the entire SCARF transect (solid black line), as well as for only those faults within $200 \mathrm{~km}$ (blue) and 400 $\mathrm{km}$ (red) of the ridge axis. The throw distribution from near-ridge picked faults on the Chile Ridge (dashed black line) is shown for comparison. Straight lines in this plot indicate an exponential fault distribution, which is predicted for natural normal fault populations (see Section 3.2). We interpret the difference in the fault population between those located within $400 \mathrm{~km}$ of the ridge to that calculated for the entire transect to be due to the increasing effects of sedimentation and mass wasting. Thus, we limit our interpretations to fault statistics within $400 \mathrm{~km}$. The change in slope of the fault 
distributions for throws $>0.6 \mathrm{~km}$ is likely due to the low number of observed high throw faults in our dataset. 

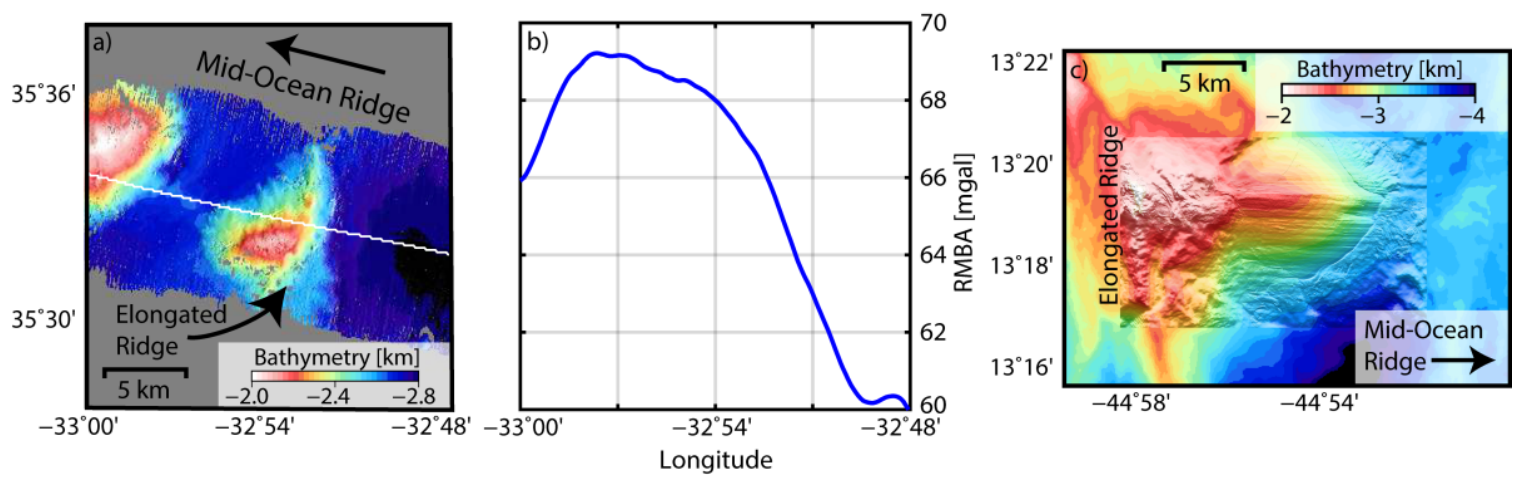

Figure 3.5: a) Shaded bathymetry for our observed oceanic core complex, Kafka Dome. White line denotes the ship track. b) Calculated RMBA along the track line showing an 8 $\mathrm{mGal}$ local increase over the Kafka Dome, characteristic of many oceanic core complexes. c) Bathymetry from oceanic core complex 13²0' N (Escartín et al., 2017) for comparison. The horizontal scale is the same in both a) and c). 

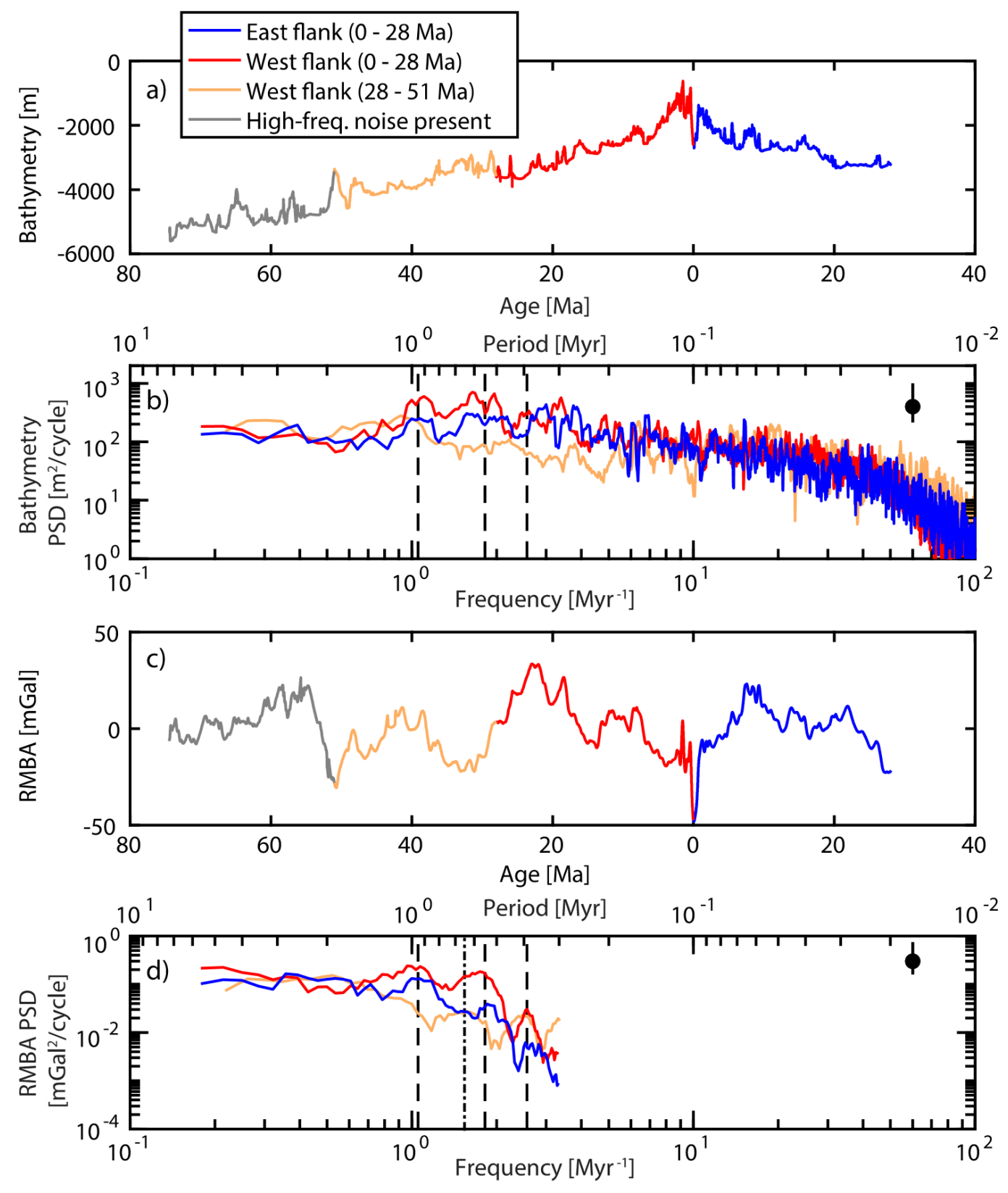

Figure 3.6: a) Track line bathymetry separated into four sections. b) Power spectral density of pre-whitened bathymetry for the three colored sections. c) Calculated residual mantle Bouguer anomaly (RMBA) separated into the same sections. d) Power spectral density of pre-whitened RMBA. The approximate $5^{\text {th }}$ to $95^{\text {th }}$ percentile confidence interval from the spectral method is indicated by the bottom and top of the black bar in the upper right corner of $b$ ) and d) relative to a given value (circle). Vertical dashed lines 
show interpreted concurrent peaks between the east (red) and the near-axis west (blue) at 390-, 550-, and 950-kyr periods. Dash-dotted line in d) shows the interpreted diffuse peak at $650 \mathrm{kyr}$ for the 28-51 Ma west flank RMBA. Off-axis data shows a different RMBA and bathymetry spectrum compared to the near ridge data. 

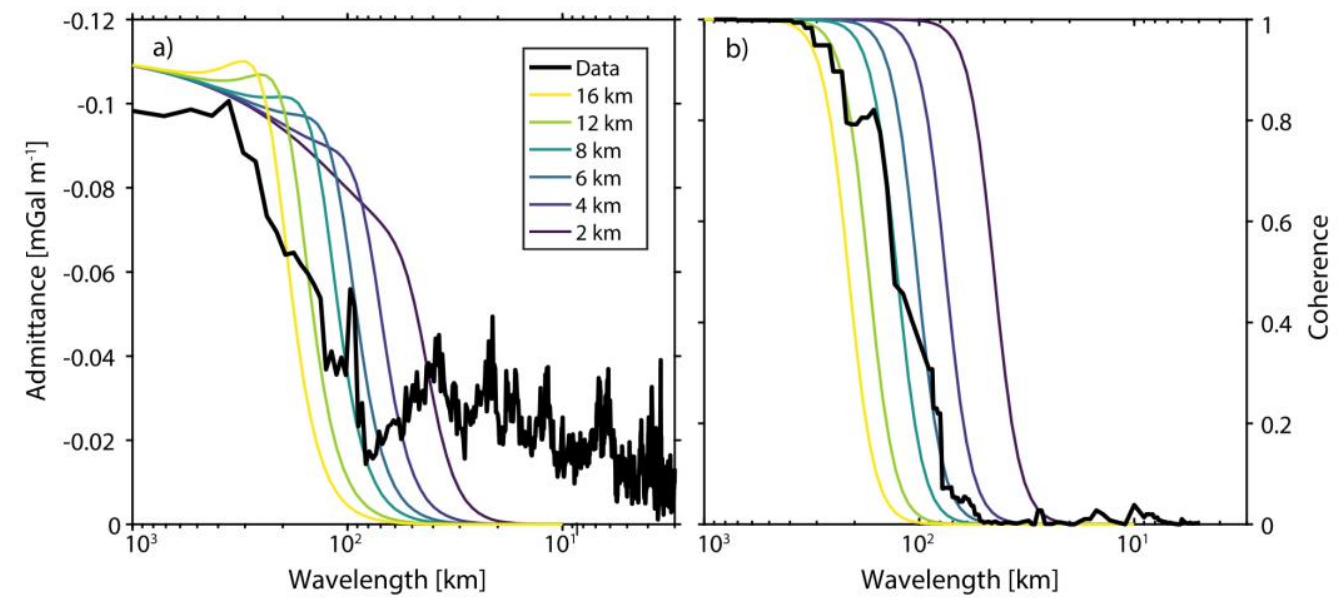

Figure 3.7: a) Calculated admittance (black line) plotted alongside theoretical admittance curves for different values of effective elastic thickness, $T_{e}$. b) Calculated coherence (black line) plotted alongside theoretical coherence curves for various values of $T_{e}$. Both models predict $T_{e}$ values between $6-12 \mathrm{~km}$. 


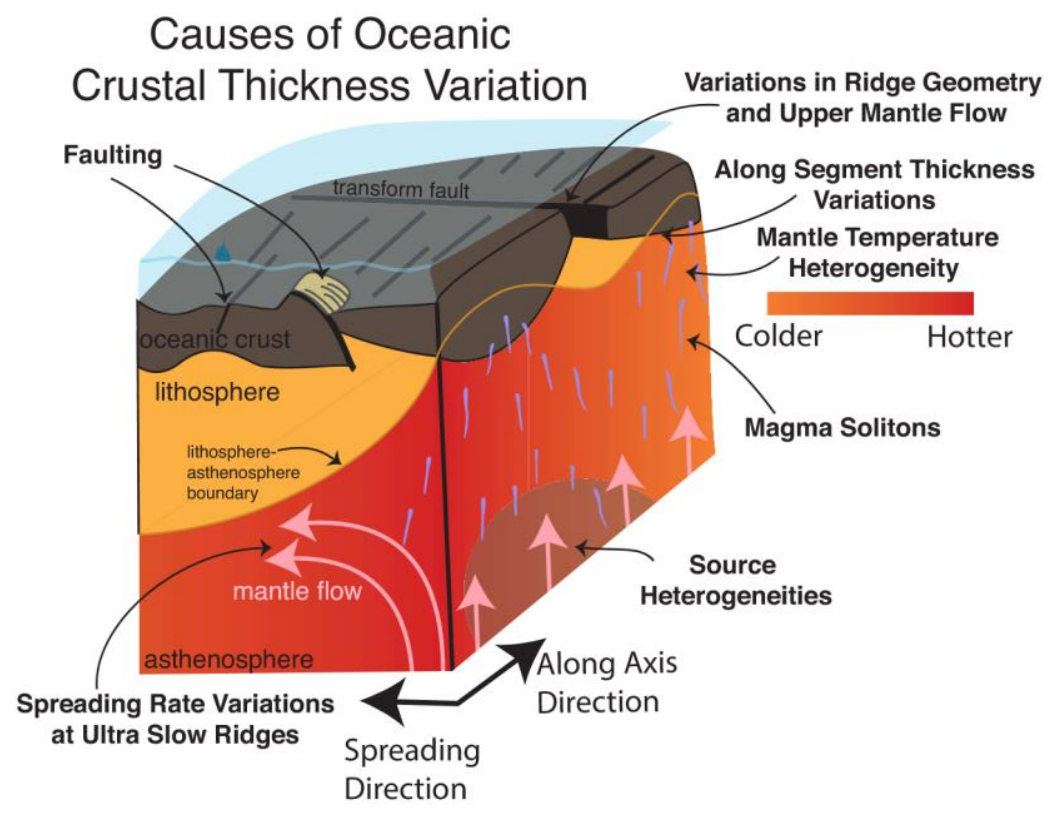

Figure 3.8: Schematic diagram depicting potential causes for oceanic crustal thickness variation discussed in Section 5.1. 

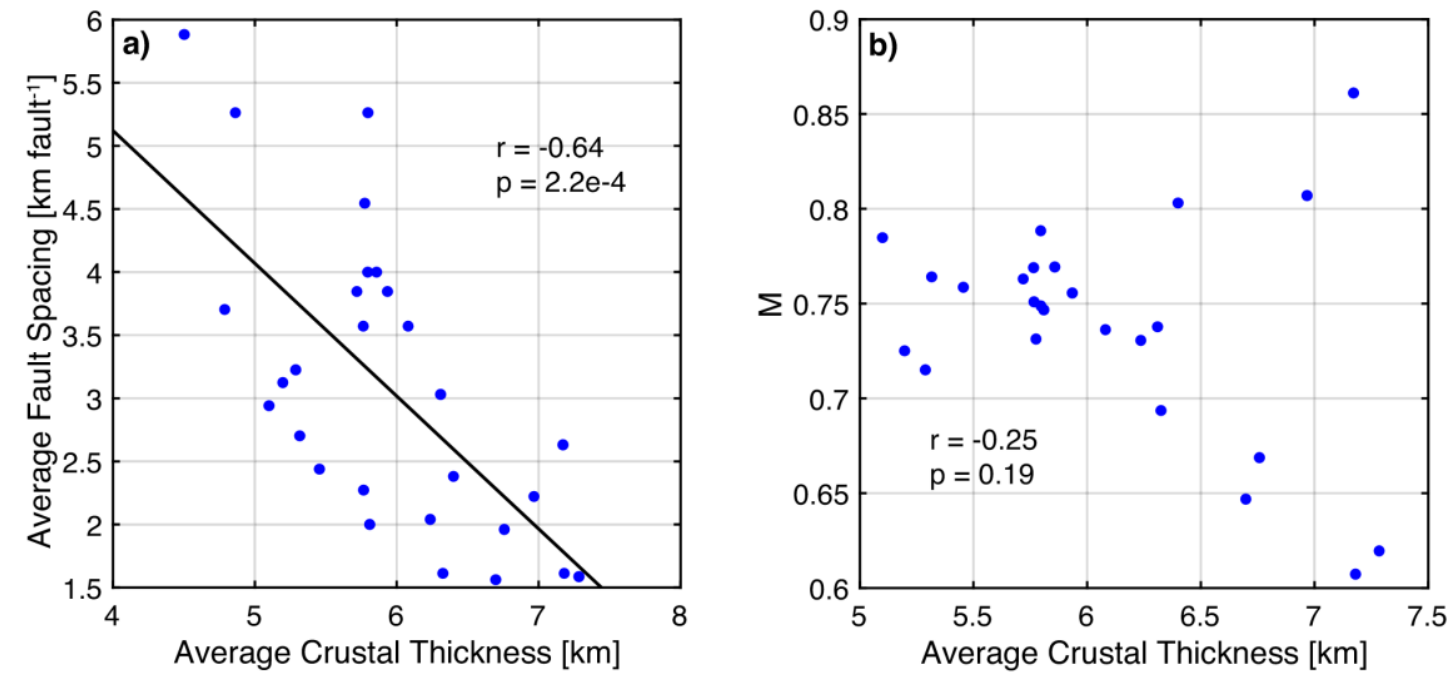

Figure 3.9: a) Binned fault spacing versus binned crustal thickness for all bins less than $400 \mathrm{~km}$ from the ridge. b) Binned crustal thickness against $M$ for all bins within $400 \mathrm{~km}$ of the ridge. Overlapping bins are $100 \mathrm{~km}$ wide every $25 \mathrm{~km}$. 


\section{Chapter 4:}

WISTFUL: Whole-Rock Interpretative Seismic Toolbox for Ultramafic Lithologies 


\begin{abstract}
Seismic tomography is the highest-resolution, deepest-reaching geophysical measurement of the Earth's mantle. Unfortunately, the interpretation of seismic wave speeds is not always unique. One approach to quantify the range of temperatures and compositions that are consistent with a given seismic wave speed at a given depth involves forward modelling wave speeds from bulk compositions using thermodynamic calculations. Here, we introduce the Whole-Rock Interpretative Seismic Toolbox for Ultramafic Lithologies (WISTFUL), a new toolbox to convert mantle seismic wave speeds into best-fit temperature, density, and composition. WISTFUL consists of a database of 4333 peridotites and 481 pyroxenites, their elastic moduli, mineral modes, and seismic wave speeds, and a set of MATLAB ${ }^{\circledR}$ functions to aid in interpreting mantle seismic wave speeds. WISTFUL includes functions to correct the elastic seismic wave speeds for anelastic effects and to invert seismic wave speed in terms of temperature and composition. In addition, WISTFUL contains three general user interfaces, one which plots relationships between calculated parameters, one which calculates seismic wave speeds along different geotherms, and one that inverts for best-fit temperature and properties using the inversion functions. We utilize Perple_X, a Gibbs free energy minimization routine, to calculate the mineral assemblages and elastic seismic wave speeds from ultramafic bulk compositions. Two dominant sources of uncertainty exist: (1) uncertainty in the elastic property measurements and mixing equations to determine the bulk properties, and (2) uncertainty in the predicted mineral assemblage and composition. Regarding the first source of uncertainty, we show experimental seismic wave speed measurements on ultramafic lithologies are reproducible with updated mineral endmember moduli and mixing methodologies. To constrain the second source of uncertainty, we compare predicted mineral assemblages and seismic wave speeds for 130 well-studied peridotite and pyroxenite xenoliths using five sets of solution models to the observed modal assemblages and estimated seismic wave speeds at the last-equilibrated temperature and pressure. We find that the Jennings \& Holland (2015) solution model best reproduces xenolith assemblages and predicted wave speeds $(0.5 \%$ root-mean squared error in $V_{p}$ and $V_{s}$ ).
\end{abstract}




\section{Introduction}

Mantle dynamics are dominantly controlled by variations in mantle density (McKenzie, 1969; Hager and O'Connell, 1981; Grand et al., 1997). For example, the negative buoyancy of cold, dense oceanic lithosphere is a primary driving force of plate tectonics on Earth (Forsyth and Uyeda, 1975; Becker and O'Connell, 2001; Conrad and Lithgow-Bertelloni, 2002). In the upper mantle, it is thought that density variations are mainly controlled by temperature and to a lesser degree by composition (Lee, 2003; Mooney and Kaban, 2010). Temperature is also the strongest control on mantle rheology (Karato and Wu, 1993; Hirth and Kohlstedt, 2003; Bürgmann and Dresen, 2008). Thus, quantitative constraints on temperature and compositional variations in the Earth's mantle are essential to improving our understanding of the large-scale structure and dynamics of the upper mantle.

The speed with which seismic waves travel through rocks is controlled by the stable mineral assemblage, as well as the presence or absence of fluids and/or melt (Fowler, 2004). The elastic moduli and the stable mineral assemblage change with pressure $(\mathrm{P})$, temperature $(\mathrm{T})$, bulk composition, as well as oxygen fugacity (Green and Ringwood, 1970; Stixrude and Lithgow-Bertelloni, 2011; Holland et al., 2018). Additionally, at high temperatures $\left(>800{ }^{\circ} \mathrm{C}\right)$, anelastic reduction in shear modulus becomes important and is controlled by mantle temperature, pressure, grain size, wave frequency, and oxidation state (Karato, 1993; Faul and Jackson, 2015; Cline et al., 2018). Recent improvements to instrumentation, instrument coverage density, computing power, and algorithms have led to a unprecedented increase in the resolution and certainty of regional, as well as global, seismic tomographic models (e.g., Kárason and van der Hilst, 2000; Romanowicz, 2003; Rawlinson et al., 2010; Ho et al., 2016; Shen and Ritzwoller, 2016; Golos et al., 2020).

Our goal is to make a validated, thermodynamically-consistent tool (WISTFUL, Whole-rock Interpretative Seismic Toolbox for Ultramafic Lithologies) to quantitatively convert mantle seismic wave speeds into best-fit temperature, composition, and density. WISTFUL calculates anharmonic seismic wave speeds for a database of 4877 ultramafic lithologies at variable $\mathrm{P}, \mathrm{T}$ conditions using an updated database of elastic moduli and thermodynamic modelling to determine the mineral assemblages. Users can choose one 
of two implementations of anelasticity. WISTFUL utilizes a set of MATLAB $®$ functions to compare input mantle seismic wave speeds with the database of calculated seismic wave speeds in order to find the best-fit temperature, composition, and density given pressure and choice of anelasticity. Along with companion functions, WISTFUL contains three MATLAB® general user interfaces (GUIs). The first plots relationships between parameters like elastic moduli, composition, and density. The second plots seismic wave speeds along various geotherms. The third visualizes the inversion process best-fit temperature and properties using the inversion functions.

The first part of this chapter describes previous work on the interpretation of seismic wave speed in terms of composition and temperature. The second part constrains the error inherent to the forward calculation of seismic wave speeds from bulk compositions in order to show the robustness of our methodology. The final part of the chapter describes the dataset behind WISTFUL and its MATLAB® functions and GUIs. This toolbox is provided via a supplement, and future versions will be update online (github.com/wshinevar/WISTFUL).

\section{Previous Work}

There are two general approaches to interpret seismic wave speeds: (1) comparison with laboratory measurements of seismic wave speed for different compositions, and (2) comparison with seismic wave speeds calculated using mineral assemblages and elastic properties. Early work focused on the first of these approaches, interpreting mantle seismic wave speeds focused on understanding what potential rock types produced similar wave speeds to the observations (Birch, 1960; Christensen, 1966). More recent studies focused on compiling rock types and/or regional samples to link wave speeds directly to composition (Miller and Christensen, 1994; Kelemen and Holbrook, 1995; Kern et al., 1996). Studies have analyzed mantle wave speeds using elastic parameters estimated from experiments to determine mantle temperatures (Goes et al., 2000; Goes and van der Lee, 2002). A limitation of these approaches is that interpretations are restricted by the existing laboratory measurements of seismic wave speed, which are limited and do not cover all known rock compositions. In addition, laboratory measurements of seismic wave speed for rock samples can be hampered by 
secondary alteration that may not be present in the lower crust and mantle (Rudnick and Fountain, 1995; Gao et al., 2000).

The alternative approach is to calculate seismic wave speeds by averaging the elastic moduli of individual minerals that constitute a rock in appropriate proportions. Jordan (1979) calculated modal assemblages and elastic properties of ultramafic rocks using major-element compositions of garnet lherzolites assuming mineral norms, mineral partition coefficients, and mineral elastic properties to investigate the relationship of density and elastic properties with mantle fertility. Combining these approaches, Fountain and Christensen (1989) compiled measurements of minerals and rocks, xenolith observations, and seismic wave speeds to improve interpretations crustal and mantle composition beneath the continental United States. More recent studies compiled laboratory mineral elastic moduli measurements to aid the calculations of seismic wave speeds for an input mineral assemblages (Hacker et al., 2003a; Hacker and Abers, 2004; Abers and Hacker, 2016). Other studies have calculated the physical properties of xenoliths and/or ultramafic rocks to better understand compositional effects on elastic properties (Lee, 2003; Schutt and Lesher, 2006, 2010; Afonso et al., 2010) and mantle anisotropy (Tommasi et al., 2004, 2008; Baptiste et al., 2012). A limitation to this mineral averaging methodology is that the estimated mineral assemblages are not necessarily in thermodynamic equilibrium, potentially leading to misinterpretation of seismic wave speeds.

A solution to this limitation uses thermodynamic modelling to predict the equilibrium mineral assemblages for a given bulk rock composition over a range of pressure-temperature conditions. The seismic wave speed is then calculated for each specific mineral assemblage, accounting for wave speed variations due to mineral compositional variations and phase transitions (Helffrich et al., 1989; Sobolev and Babeyko, 1989, 1994). Sobolev et al. (1996, 1997) built upon this methodology by incorporating the effects of anelasticity and partial melt to the interpret of mantle seismic wave speeds beneath the Massif Central (France). The combination of thermodynamic modelling in conjunction with laboratory-constrained mineral elastic moduli and densities have been used to interpret the continental lower crust (Sammon et al., 2020), the stability of arc lower crust (Behn and Kelemen, 2006; Jagoutz and Behn, 2013), the 
mantle wedge at subduction zones (Hacker et al., 2003a, 2003b), cratonic lithospheric mantle (Begg et al., 2009), and continental Moho temperatures (Schutt et al., 2018). To address the potential influence of sampling bias in compositional-wave speed relations, Behn and Kelemen (2003) applied thermodynamic modelling and compiled elastic moduli for a synthetic composition database of anhydrous igneous and meta-igneous rocks.

With increasing computational resources, recent work has incorporated other geophysical measurements, e.g., topography and gravity, to better constrain the composition and/or density of the mantle during seismic inversions (Perry et al., 2003; Simmons et al., 2009, 2010; Kaban et al., 2014; Tesauro et al., 2014). Other authors have utilized thermodynamic calculations of mantle compositions in the seismic tomographic inversion to estimate mantle compositions (Khan et al., 2011; Zunino et al., 2016). Similarly, Afonso et al. (2013a, 2013b, 2016) utilized probabilistic joint inversions built on the forward-modeling of LitMOD (Afonso et al., 2008; Fullea et al., 2009; Kumar et $a l ., 2020$ ), integrating seismic delay times, gravity data, geoid height, topography, and heat flow to decipher the most likely compositional and thermal state of the mantle. Further work has added long wavelength resistivity measurements to inversions in order to estimate the water content throughout the mantle (Khan et al., 2015; Khan, 2016).

A detriment of these joint-inversions is that the addition of gravity data does not necessarily increase the accuracy of the inversion due to the non-uniqueness of gravity solutions (Blom et al., 2017). Another possible problem is the requirement of regional thermal models, which often contain high uncertainty from error in surface heat flow measurements, as well as uncertainty of heat production in the continental crust (Pollack and Chapman, 1977; Chapman, 1986; Jaupart and Mareschal, 2007). Furthermore, the uncertainties in many thermodynamic models are often unconstrained, and few studies have investigated how these uncertainties propagate into geophysical parameters (e.g., Afonso et al., 2013a; Connolly and Khan, 2016). Also, as thermodynamic models and geophysical parameters like elastic moduli or density are further constrained, the entire inversion methodology must be repeated.

To improve on these previous studies and methodologies, WISTFUL aims to investigate the uncertainty present in the forward calculations of ultramafic seismic wave 
speeds in order to create a post-inversion methodology for quantitatively converting mantle seismic wave speeds into best-fit temperature, composition, and density.

\section{Uncertainty in Seismic Wave Speed Forward Calculations}

Here we discuss the uncertainty inherent to the methodology of calculating seismic wave speeds from bulk compositions using thermodynamic models. Two sources of error are discussed here: 1) the error in the elastic property measurements and mixing equations, and 2) error in the predicted mineral assemblage and composition. We examine at the error in elastic property measurements and mixing equations by comparing measured seismic wave speeds of ultramafic samples with wave speeds calculated using mixing equations and elastic moduli used in our approach. We then estimate error in predicted mineral assemblages and predicted seismic wave speeds by comparing calculated mineral assemblages and wave speeds from our thermodynamic calculations to a compilation of xenoliths with wave speeds calculated directly from the reported mineral assemblage and compositions.

All thermodynamic calculations were conducted in the Gibbs-free-energy minimization program Perple_X version 6.9.1 (Connolly, 2009) downloaded on April $15^{\text {th }}, 2021$. Perple_X calculates stable mineral assemblages and compositions using a set of chosen thermodynamic solution models for an input bulk composition. From these calculated mineral assemblages, aggregate elastic moduli are calculated in Perple_X in one of two ways. The first calculates the bulk modulus of each mineral endmember present from the Gibbs energy equation. Shear moduli is then calculated from the bulk moduli assuming a Poisson's ratio. Mineral moduli are then mixed together to calculate the aggregate elastic moduli. The second way Perple_X calculates the elastic moduli using the input elastic moduli from experimental observations and then mixing them to calculate aggregate moduli. Seismic wave speed is then calculated using the aggregate elastic moduli and density. One benefit of Perple_X is that a variety of thermodynamic databases and mineral solution models can be used. Another benefit is that the elastic moduli data in the thermodynamic database can be edited to incorporate new measurements. The integration of thermodynamic calculations and moduli estimation in a single program of thermodynamic calculations allows for a simple, integrated workflow.

\section{Calculating Seismic Wave Speeds}


To calculate the elastic moduli of a mineral, Perple_X uses a Reuss average (Reuss, 1928) weighted by molar volume:

$$
G^{\text {mineral }}=\left(\left[\frac{1}{V^{\text {mineral }}}\right] \sum \frac{X^{\text {endmember }} V^{\text {endmember }}}{G^{\text {endmember }}}\right)^{-1},
$$

where $V^{\text {endmember }}$ is the endmember molar volume, $X^{\text {endmember }}$ is the endmember molar fraction, $V^{\text {mineral }}$ is the molar volume for the mineral solid solution, and $G$ is the adiabatic shear modulus for the written superscript. Bulk rock elastic moduli are calculated using a Voigt-Reuss-Hill average (Hill, 1952):

$$
G^{\text {rock }}=\frac{1}{2}\left(\sum F^{\text {mineral }} G^{\text {mineral }}+\frac{1}{\sum F^{\text {mineral }} / G^{\text {mineral }}}\right),
$$

where $F^{\text {mineral }}$ is the volume fraction of each mineral. Both averages are equivalent for the adiabatic bulk modulus $(K)$ by replacing the mineral and endmember shear moduli with bulk moduli. Seismic wave speed is calculated as

$$
\begin{gathered}
V_{s}=\sqrt{\frac{G^{\text {rock }}}{\rho^{\text {rock }}}}, \\
V_{p}=\sqrt{\frac{K^{\text {rock }}+\frac{4}{3} G^{\text {rock }}}{\rho^{\text {rock }}}}
\end{gathered}
$$

where $V_{S}$ is the shear wave speed, $V_{p}$ is the primary wave speed, $\rho^{\text {rock }}$ is the bulk rock density, and $K^{\text {rock }}$ is the adiabatic bulk moduli for the bulk rock.

For seismic wave speed calculations in WISTFUL, we utilize elastic moduli from the literature where available (compiled by Abers and Hacker, 2016) along with updated literature data for mineral endmembers used in either the solution models or calibration calculations not included in previous compilations (Table 1). Unlike Abers and Hacker (2016), Perple_X uses linear moduli derivatives with respect to temperature and pressure when using experimental bulk moduli. Thus, linear elastic moduli temperature derivatives for mineral endmembers taken from Abers and Hacker (2016) were fit to data between 25 and $600{ }^{\circ} \mathrm{C}$ at $1 \mathrm{GPa}$. When no experimental observations exist, the bulk modulus and the bulk modulus pressure and temperature derivatives are calculated from the Gibbs free energy (c.f. Bina and Helffrich, 1992) over a range of 200-1400 ${ }^{\circ} \mathrm{C}$ and $0.1-6 \mathrm{GPa}$ using the Perple_X program frendly and then fit to an explicit linear form. One exception to 
this was the garnet endmember knorringite $\left(\mathrm{Mg}_{3} \mathrm{Cr}_{2}\left(\mathrm{SiO}_{4}\right)_{3}\right)$, as no elasticity data existed, so we approximated it as the same bulk and shear modulus as garnet endmember uvarovite $\left(\mathrm{Ca}_{3} \mathrm{Cr}_{2}\left(\mathrm{SiO}_{4}\right)_{3}\right)$ (Table 1). For mineral endmember for which an experimental measurement of the bulk modulus at room pressure and temperature exists, but no data exists on pressure and/or temperature derivative, we utilize the ambient experimental bulk modulus along with derivatives fit as described above.

Shear moduli cannot be thermodynamically derived. If no shear moduli data are input to Perple_X, the program calculates the bulk shear modulus assuming a constant Poisson's ratio for all minerals. Poisson ratios for mantle mineral endmembers can vary from 0.20 to 0.35 at room temperature and pressure and can change up to $\sim 8 \%$ between ambient conditions and $800^{\circ} \mathrm{C}$ at $1 \mathrm{GPa}$. Thus, the assumption of constant Poisson's ratio to calculate shear modulus for all minerals increases the uncertainty on these calculations. To minimize this error, we utilize all available experimental shear modulus and derivatives. If shear modulus data at ambient condition exists without pressure and/or temperature derivatives, we estimate the pressure and/or temperature shear modulus derivatives from the bulk modulus derivatives to maintain the ambient conditions Poisson's ratio. If no shear modulus data exists for an endmember composition, we utilize the shear modulus data of the closest ionic endmember (Table 1). This approach gives each mineral endmember our best estimate of that mineral's Poisson's ratio.

Figure 2 shows the deviation of bulk moduli from experimental observations and the bulk moduli calculated using the Holland and Powell (2011) thermodynamic database at $700^{\circ} \mathrm{C}$ and $1 \mathrm{GPa}$ for relevant mantle mineral endmembers. While there is generally good agreement (root mean squared error (RMSE) on bulk moduli of $13.3 \mathrm{GPa}$ for mantle minerals), certain moduli can be drastically overpredicted like $\mathrm{Mg}$-tschermak by $60 \mathrm{GPa}$ or underpredicted like almandine by $26 \mathrm{GPa}$. Most thermodynamically calculated bulk moduli underpredict the experimental observations. This error has a large impact on seismic wave speed, making it vital to use all available experimental moduli for endmembers to minimize the error in calculating seismic wave speeds.

To validate the aforementioned mixing calculations and moduli for ultramafic minerals, we compiled multi-directional seismic wave speed measurements for a variety of ultramafic rocks with reported modal assemblages (Birch, 1960, 1961; Simmons, 
1964; Christensen, 1966, 1974, 1978; Mao et al., 1970; Christensen and

Ramananantoandro, 1971; Babuška, 1972; Kroenke et al., 1976; Peselnick and Nicolas, 1978; O’Reilly et al., 1990; Miller and Christensen, 1994; Kono et al., 2004, 2009;

Prelicz, 2005). For a reported mineral composition, we decompose the minerals into the mineral endmembers following the Jennings \& Holland (2015) solution models and calculate the seismic wave speed following the same approach as Perple_X (described above). In some studies, orthopyroxene and/or clinopyroxene are present in the measurement samples but no mineral chemical compositions are provided. When orthopyroxene is reported without mineral composition, we calculate orthopyroxene composition from the olivine composition assuming orthopyroxene is purely enstatiteferrosillite and an olivine-orthopyroxene partition coefficient $K_{D}^{O l-O p x}=\frac{Y_{M g}^{O p x} Y_{F e}^{O l}}{Y_{M g}^{O l} Y_{F e}^{O p x}}=1.15$ based on experimental studies (von Seckendorff and O’Neill, 1993). $Y_{M g}$ or $Y_{F e}$ are the molar fraction of $\mathrm{Mg}$ or $\mathrm{Fe}$ in the respective superscript. When clinopyroxene is reported without mineral composition, we calculate clinopyroxene composition from the olivine or orthopyroxene compositions assuming clinopyroxene is purely diopside-hedenbergite and an orthopyroxene-clinopyroxene partition coefficient $K_{D}^{C p x-O p x}=\frac{Y_{M g}^{O p x} Y_{F e}^{C p x}}{Y_{M g}^{C p x} Y_{F e}^{O p x}}=1$ in line with experiments and field observations with equilibration temperatures $1000-1200^{\circ} \mathrm{C}$ (Mori and Green, 1978; Kretz, 1982). We compare the highest-pressure measurements (often $1 \mathrm{GPa}$ ) to minimize the effects of cracks or porosity on the measurements with the calculated wave speed. Triaxial measurements were averaged to obtain the isotropic wave speeds.

Overall, there is good agreement between the laboratory-derived wave speed data and wave speeds calculated using reported mineral assemblage and mineral endmember moduli, with a root-mean squared error (RMSE) of $0.11 \mathrm{~km} / \mathrm{s}$ (Figure 3 ). This error could be due to miscounting of mineral modes, experimental error for the seismic wave speed measurements due to remnant porosity, uncertainty within the elastic moduli for each endmember, and uncertainty on the exact compositions of each mineral for measurements that only report olivine composition. Altogether, we interpret this low error $(\sim 1.3 \%)$ as 
justification for our choice of the elastic moduli mixing approach described above and moduli data for ultramafic assemblages.

\section{Thermodynamic Solution Model Error Validation}

In addition to the error discussed above, the other error in the forward calculation of seismic wave speeds from bulk composition is the error in correctly predicting the mineral assemblage, composition, and the effect of these uncertainties on predicting seismic wave speed. A previously used methodology to validate thermodynamic solution models, utilized by Afonso et al. (2013a), compared predicted modes using Stixrude and Lithgow-Bertelloni (2011) to point-counted estimates of ten garnet peridotite xenoliths (6 lherzolites, 4 harzburgites). They found that the thermodynamic calculations at the pressure-temperature conditions predicted by mineral thermobarometers mostly reproduced the modal proportions within counting error derived for the thin section estimates. Afonso et al., (2013a) found that this error did not greatly affect the predicted wave speeds or densities. A previously noted limitation of comparing thermodynamic models with xenoliths is the small dataset of samples that have detailed laboratory measurements (e.g., modal assemblage and pressure-temperature (P-T) estimates). Another limitation is that there is no spinel peridotite mineral barometer, so previous xenolith-thermodynamic model comparisons were limited to the garnet stability field and contained no spinel bearing peridotites. Furthermore, no constraints on pyroxenites were made. The benefits of comparing thermodynamically predicted mineral assemblages with xenoliths rather than modal assemblages of petrologic experiments is that most experimental results are used as constraints to formulate thermodynamic models. Therefore, any thermodynamic model validation obtained through comparison to petrologic experiments is circular if the experiments were used to calibrate the model.

Fortunately, with advances of electron-backscatter diffraction (EBSD), more peridotite and pyroxenite xenoliths have been studied in detail with modal assemblage estimates. We improve and expand upon this approach by: 1) expanding the xenolith database to compare with a larger composition and pressure-temperature range, including spinel-garnet peridotites, spinel peridotites with geotherm-based barometry, and pyroxenites, and 2) exploring multiple different solution models and oxygen states when the solution models utilize $\mathrm{Fe}_{2} \mathrm{O}_{3}$ in order to find the most reliable solution model. 
We compiled 130 xenoliths with the following attributes: 1) a pressuretemperature estimate, 2) less than 1 vol. \% hydrous phase (e.g., phlogopite or amphibole), 3) measured compositions for all minerals, 4) major-element bulk composition that are either measured or calculated from mineral composition and mode, and 5) a mineral modal assemblage that is either measured via electron-backscatter diffraction (EBSD) or calculated by least-squares regression from bulk composition and mineral compositions to minimize the modal assemblage error. Sample data were compiled from (Lee and Rudnick, 1999; Falus et al., 2008; Ionov et al., 2010; Baptiste et al., 2012; Tommasi and Ishikawa, 2014; Demouchy et al., 2015). If a bulk composition was calculated from mineral mode and composition, we used the following densities to convert vol. \% to wt. $\%$ for the major minerals based on Abers and Hacker (2016): olivine $3340 \mathrm{~kg} \mathrm{~m}^{-3}$, orthopyroxene $3280 \mathrm{~kg} \mathrm{~m}^{-3}$, clinopyroxene $3310 \mathrm{~kg} \mathrm{~m}^{-3}$, spinel $3850 \mathrm{~kg} \mathrm{~m}^{-3}$, and garnet $3800 \mathrm{~kg} \mathrm{~m}^{-3}$. Ninety-nine $(76 \%)$ of these xenoliths are peridotites (>40 vol. \% olivine normalized to olivine-orthopyroxene-clinopyroxene); the remaining $31(24 \%)$ are pyroxenites (<40 vol. \% olivine). We note that none of these peridotites contain plagioclase, therefore providing no test in the shallowest part of the mantle $(\sim 20 \mathrm{~km}$ depth, Borghini et al., 2010). Most of these xenoliths come from continental regimes with the exception of oceanic and plume influenced mantle xenoliths from the Ontong Java plateau (Tommasi and Ishikawa, 2014). P-T estimates for these xenoliths cover pressures from 1.2-6.8 $\mathrm{GPa}$ and temperatures of $656-1414{ }^{\circ} \mathrm{C}$.

Solution models for olivine, orthopyroxene, clinopyroxene, plagioclase, spinel and garnet were investigated (Table 2). Melt solution models were excluded from the comparison calculations. Oxidation state is important for mantle xenoliths, as more oxidized mantle will further stabilize ferric iron bearing phases like pyroxene, spinel, and garnet. Direct measurements on primitive peridotites suggests mantle $\mathrm{Fe}^{3+} / \Sigma \mathrm{Fe}$ of 3.5 mol. \%, but can vary between 1 and 6 mol. \% (Canil et al., 1994, grey box Figure 4) and varies with the relative depletion of the peridotite. This estimate $(>3 \mathrm{~mol} . \%)$ is supported by measurements of $\mathrm{Fe}^{3+} / \Sigma \mathrm{Fe}$ contents in primary MORB (Cottrell and Kelley, 2011). Mineral assemblages and elastic seismic wave speeds were calculated for each xenolith at its P-T estimate for each set of solution models over a range of oxidation states $(0-10$ mol. $\% \mathrm{Fe}^{3+} / \Sigma \mathrm{Fe}$, colored lines, Figure 4$)$ in addition to a set of calculations where the 
mol. $\% \mathrm{Fe}^{3+} / \sum \mathrm{Fe}$ was constrained for each sample by the observationally derived equation (Canil et al., 1994):

$$
\frac{\mathrm{Fe}^{3+}}{\sum \mathrm{Fe}}=14.7-0.3 \mathrm{MgO},
$$

where $\mathrm{MgO}$ is the bulk rock $\mathrm{MgO}$ content in wt. \% (triangles, Figure 4). The Stixrude and Lithgow-Bertelloni (2011) (SLB, green square, Figure 4) solution models do not incorporate ferric iron in their calculations.

To identify which set of solution models best match the observed mineral assemblage, a root-mean-square error (RMSE) was calculated for each mineral mode (olivine, orthopyroxene, clinopyroxene, garnet, and spinel) and summed for each composition. This phase RMSE was averaged over all xenoliths to estimate phase error (Figure 4a). The SLB solution models provides the lowest phase RMSE (11.8\%), followed by the Jennings and Holland (2015) (JH, orange line and triangle, Figure 4) solution models at variable $\mathrm{Fe}^{3+} / \sum \mathrm{Fe}$ and 6-7 mol. \% $\mathrm{Fe}^{3+} / \sum \mathrm{Fe}(12.3 \%)$. Although the SLB database produces slightly lower phase RMSE, the SLB models simplify certain phase transitions like the garnet-spinel transition due to the lack of $\mathrm{Fe}_{2} \mathrm{O}_{3}$ and $\mathrm{Cr}_{2} \mathrm{O}_{3}$, which allow for higher-pressure spinel stability as well as spinel-garnet co-stability (Klemme, 2004). This simplification may cause misinterpretation at shallow mantle conditions.

On average, the mineral assemblage is well-predicted well by the for Jennings and Holland using variable $\mathrm{Fe}^{3+} / \Sigma \mathrm{Fe}$ (Figure 5). The JH solution models predict olivine well but tend to overpredict garnet and underpredict clinopyroxene and orthopyroxene in pyroxenites. Due to the small volume amount of spinel stable in peridotites, spinel error does not strongly contribute to the phase RMSE. The JH solution models often underpredicts the spinel mode for spinel bearing peridotites, predicting no spinel stable for 30 spinel-bearing samples. 20 of these 30 samples also have no observed garnet, and thus have estimated pressures based on geotherms and geothermometers. Thus, this modal error for all solution models could be due to over-estimation of equilibration pressure. The JH solution models also predict spinel to be stable in 5 xenoliths where none was observed. Only 3 of these samples have garnet present, so this mismatch could also be due to error in the pressure estimates. 
Equally important to correctly predicting the phases is correctly predicting the elastic wave speeds. Because mineral composition and mineral mode both affect elastic moduli and density (and therefore seismic wave speed), we also compared seismic wave speeds calculated by Perple_X for each solution model with seismic wave speeds calculated using mineral compositions in each xenolith at the equilibrium P-T conditions. To calculate wave speeds from mineral compositions and modes, minerals were decomposed into endmembers by normalizing the mineral compositions in wt. \% into molar formula, after which the formula were decomposed into mineral endmembers following Wood and Banno (1973) and Holland et al. (2018). All Ni and Mn endmembers were considered to have the same elastic moduli as the Mg endmembers for these calculations when $\mathrm{Ni}$ and $\mathrm{Mn}$ were measured in the xenoliths with the exception of spessartine. Elastic parameters and densities were taken at the specified P-T conditions for each endmember mineral and then averaged following the methodology used in Perple_X (see Calculating Seismic Wavespeeds). Using this expected $V_{p}$ and $V_{s}$ for each xenolith and one produced by Perple_X for the bulk composition, we calculated an RMSE for both elastic wave speeds to estimate the deviation caused by both the phase error as well as the mineral composition error (Figures $4 b, c)$.

The variable $\mathrm{Fe}^{3+} / \Sigma \mathrm{Fe} \mathrm{JH}$ models provide the lowest $V_{p} \mathrm{RMSE}(0.04 \mathrm{~km} / \mathrm{s}$, Figure $4 \mathrm{~b})$ and $V_{s}$ RMSE $(0.02 \mathrm{~km} / \mathrm{s}$, Figure $4 \mathrm{c})$, both roughly $0.5 \%$ assuming a mantle $V_{p}$ and $V_{s}$ of $8.0 \mathrm{~km} / \mathrm{s}$ and $4.5 \mathrm{~km} / \mathrm{s}$, respectively (Figure 6). This uncertainty in the forward calculation of seismic wave speed is similar to the uncertainty in recent seismic models. For instance, bootstrapping analyses of a recent continental scale seismic model MIT20_PS (Golos et al., 2020) suggest average errors of approximately $0.1 \%$ in $V_{p}$ and $0.2 \%$ in $V_{s}$, with error for both $V_{p}$ and $V_{s}$ rarely exceeding $0.5 \%$ and similar uncertainties in $V_{s}$ were calculated for EMC-US.2016 (Shen and Ritzwoller, 2016). The lowest error is the Holland et al. (2018) model does similarly well with $\mathrm{V}_{\mathrm{s}}(0.02 \mathrm{~km} / \mathrm{s}, 0.5 \%)$, but significantly worse with $V_{p}(0.10 \mathrm{~km} / \mathrm{s}, 1.25 \%)$. The SLB models produce a $0.06 \mathrm{~km} / \mathrm{s}$ error in both $V_{p}$ and $V_{s}(0.75$ and $1.33 \%$, respectively).

Overall, we prefer the JH solution models at either variable or constant 6 mol. \% $\mathrm{Fe}^{3+} / \Sigma \mathrm{Fe}$ to minimize the seismic and phase RMSE. These two options minimize the 
errors in the wave speeds and modal assemblages, and agree with available constraints on mantle oxidation state.

There are other possible sources of error in this comparison besides errors in the thermodynamic solution models: error in the xenolith P-T estimates, errors in the mineral modes estimates, errors in bulk composition, error in mineral composition, and errors in oxidation state. Most thermobarometric estimates report $2 \sigma$ errors of $4-6 \mathrm{kbar}$ and $100^{\circ} \mathrm{C}$ (Nickel and Green, 1985; Brey and Köhler, 1990). Furthermore, the xenolith assemblages may not record the same equilibration conditions as the mineral thermobarometry. While errors should be minimal in point counting, the mineral assemblage in a thin section may not represent the entire equilibrium system. Similarly measured bulk compositions may not reflect the equilibrium bulk composition for the sample. Conversely, if the bulk composition and/or modal assemblage is calculated from the mineral compositions, variability in the mineral compositions will produce errors, especially for lower concentration elements like $\mathrm{Cr}_{2} \mathrm{O}_{3}$. Further analysis is needed to constrain the effects of these errors on our validation.

\section{WISTFUL}

With the methods, errors, and assumptions associated with calculating seismic wave speed using thermodynamic calculations and elastic moduli in mind, we now describe WISTFUL (Whole-Rock Interpretative Seismic Toolbox for Ultramafic Lithologies), discuss the composition database used for our seismic wave speed calculations, as well as how to use the associated functions and GUIs. All database files, functions, and MATLAB® GUIs are listed in Table 1 and available in a compressed folder in the supplement. The most recent up-to-date version is hosted on (https://github.com/wshinevar/WISTFUL). To use the functions and GUIs, place the directory containing all .m code files and mat database files on your MATLAB® search path or in your current directory. The codes were tested using MATLAB® 2021a.

\section{Compositional Database}

Major element compositions for ultramafic rocks were compiled by downloading all rocks labeled as peridotite, dunite, lherzolite, harzburgite, xenolith peridotite, pyroxenite, and wehrlite from the EarthChem (http://portal.earthchem.org/) and GEOROC (http://georoc.mpch-mainz.gwdg.de/georoc/) databases on January $24^{\text {th }} 2019$. 
Duplicate compositions were removed. We added the whole-rock compositions from Beni Bousera Massif from (Gysi et al., 2011). We filtered the downloaded compositions for samples for which $\mathrm{Al}_{2} \mathrm{O}_{3}+\mathrm{CaO}+\mathrm{K}_{2} \mathrm{O}+\mathrm{MgO}+\mathrm{MnO}+\mathrm{Na}_{2} \mathrm{O}+\mathrm{SiO}_{2}+\mathrm{TiO}_{2}+\mathrm{FeO}^{\mathrm{T}}$ summed to $98.5-101.5 \mathrm{wt} \%$. Figure 7 shows single-oxide histograms for the entire database. Before thermodynamic calculations, the compositional data was renormalized to 100 $\mathrm{wt} \%$ into the NCFMASOCr system for the JH solution models. If a composition was missing a measurement, that value was assumed to be zero for the sum. No equilibration temperature cutoff was used for the thermodynamic calculations. Each composition has seismic wave speed calculated from $200-1600{ }^{\circ} \mathrm{C}$ and $0.5-6$ GPa over a $157 \times 157$ grid.

\section{Database Files}

1) WISTFUL_compositions_clean.mat,

This file contains the oxide composition for each rock in the database in wt. \% along with calculated $\mathrm{Mg} \#$ and location data when available.

2) WISTFUL_densities_clean.mat

This file contains the densities $\left[\mathrm{kg} \mathrm{m}^{-3}\right]$ for all samples over the investigated range of pressure and temperature.

\section{3) WISTFUL_parsed_modes_clean.mat}

This file contains the parsed modal assemblage (olivine, orthopyroxene, clinopyroxene, garnet, spinel, other) [vol. \%] for all samples over the investigated range of pressure and temperature.

4) WISTFUL_rockType.mat

This contains the rock-type defined by the renormalized olivine-orthopyroxeneclinopyroxene ternary using the calculated modes at $800^{\circ} \mathrm{C}$ and $2 \mathrm{GPa}$ (Figure 8), resulting in 4333 peridotite compositions and 481 pyroxenite compositions. Number interpretations of the rock type can be found in the readme.md file.

5) WISTFUL_speeds_moduli_clean.mat.

This contains the anharmonic shear and bulk modulus [Pa] as well as the $V_{p}$ and $V_{s}$

$\left[\mathrm{km} \mathrm{s}^{-1}\right]$ for each rock in the database over the pressure [bars] and temperature $[\mathrm{K}]$ range.

\section{MATLAB function files}

\section{1. fitClosestX.m}


One way to invert for temperature from a given seismic wave speed is to find the temperature at which the seismic misfit of the closest $\mathrm{X}$ samples is minimized. A misfit value, $Y$, is determined at an input pressure for every temperature and every WISTFUL peridotite between the seismic wave speed input (one or two of $V_{S}, V_{p}$, and $\left(V_{p} / V_{s}\right)$ ) and those predicted for each composition in the WISTFUL database $\left(V_{S_{\text {WISTFUL }}}, V_{p_{\text {WISTFUL }}}\right.$, $\left.\left(V_{p} / V_{S}\right)_{\text {WISTFUL }}\right)$ by the data normalized distance. For example, if $V_{S}$ and $\left(V_{p} / V_{s}\right)$ are given, then

$$
Y=\sqrt{\left(\frac{V_{s}-V_{S_{\text {WISTFUL }}}}{V_{S_{\text {MITPS }}}}\right)^{2}+\left(\frac{\left(V_{p} / V_{S}\right)-\left(V_{p} / V_{S}\right)_{W I S T F U L}}{\left(V_{p} / V_{s}\right)}\right)^{2}}
$$

At each temperature, an average misfit $\left(\bar{Y}_{X}\right)$ is calculated as the mean of the $\mathrm{X}$ smallest misfits. The best-fit temperature $\left(T_{B}\right)$ is defined as the temperature with the minimum $\bar{Y}_{X}$. We define the uncertainty of $T_{B}$ to be half of the range of all temperatures that fit the criteria

$$
\bar{Y}_{X}^{T}<\bar{Y}_{X}^{T_{B}}+\sigma_{Y_{X}^{T_{B}}},
$$

where the superscript $\mathrm{T}$ denotes the temperature for $\bar{Y}_{X}$, and $\sigma_{Y_{X}^{T_{B}}}$ is the standard deviation of the $\mathrm{X}$ smallest misfits at $T_{B}$.

\section{2. fitPropertyClosestX.m}

Along with finding the best-fit temperature, one can also find the best-fit of a given property. For instance, the best-fit density, $\rho_{B}, \mathrm{Mg} \#\left(M g \#_{B}\right)$, or other compositional parameter desired, is then calculated as the average of the that parameter from the $\mathrm{X}$ closest samples weighted by the reciprocal of the misfit of those samples at the best-fit temperature. For instance, $M g \#_{B}$ would be calculated as:

$$
M g_{B}=\frac{\sum_{i} M g \#_{i} Y_{i}^{-1}}{\sum_{i} Y_{i}^{-1}}
$$

where subscript $i$ denotes one of the closest X samples. We estimate the uncertainty for $M g \#_{B}$ as the average of the standard deviation of $\mathrm{Mg} \#$ weighted by $\bar{Y}_{X}^{T}$. These uncertainty estimates account for the distribution of wave speed misfit between the 
seismic and WISTFUL models, as well as the coarseness of the temperature values of the grid search.

\section{3. numWithinError.m}

Another routine to invert temperature from seismic wave speeds is to see how many samples at are within a specified error for a given seismic wave speed within a given pressure and temperature range. This function calculates the number of WISTFUL samples that fit within error bounds for a given seismic wave speed at each temperature. It then calculates the best-fit temperature with uncertainty from the mean and standard deviation of a Gaussian distribution fit to the number of samples within the given error bounds.

\section{4. fitPropertyNumWithin.m}

This function returns a weighted average and standard deviation of an input property, e.g., $\mathrm{Mg} \#$, for all samples within error of a searched seismic wave speed at a given pressure and temperature. The mean and standard deviation is weighted by the inverse of the misfit as described above in fitPropertyClosestX.m.

In addition to these functions, we provide two MATLAB® scripts to as examples to use the above functions from command line with the correct results to ensure the database files are loaded properly.

1) exampleClosestX.m

This script shows an example use of the fitClosestX.m and fitPropertyClosetsX.m along with the expected outputs to ensure the database files are loaded correctly.

\section{2) exampleNumWithin.m}

This script shows an example use of the numWithinError.m and fitPropertyNumWithin.m along with the expected outputs to ensure the database files are loaded correctly.

\section{Anelastic Corrections}

Olivine behaves anelastically at high temperature $\left(>900^{\circ} \mathrm{C}\right)$ (Faul and Jackson, 2005, 2015; Jackson and Faul, 2010). Here, we assume that anelasticity only affects the shear modulus and that anelasticity calibrated on olivine samples can be applied to all ultramafic rocks. For our databases, we allow users to choose between the extendedBurgers model fit of (Jackson and Faul, 2010) which combines a Maxwell element as 
well as a background element. This combination has been found to best fit laboratory data as well as fit well attenuation estimates from geodetic and seismic measurements (Lau and Faul, 2019). This Jackson and Faul (2010) anelasticity excludes the effects of water, supported by (Cline et al., 2018), but in contrast to previous experiments (Aizawa et al., 2008). Comparisons of measured and predicted quality factors prefer the inclusion of a water dependence to predict the G discontinuity (Behn et al., 2009; Karato and Park, 2018; Ma et al., 2020; Mark et al., 2021). Thus, we also allow the user to use the powerlaw fit of Behn et al. (2009) which incorporates a water dependence. We note the powerlaw anelasticity fails to fit experimental observations at low quality factors $\left(\mathrm{Q}^{-1}>0.1\right)$ (Jackson and Faul, 2010). Further experiments are necessary to fully quantify the effects of water. Observed increase of anelasticity (Cline et al., 2018) due to oxidation is also not considered here due to the slight variation present in the database. Seismic wave speed for all database compositions is available in uncorrected format along with the following MATLAB ${ }^{\circledR}$ functions and live script to calculate anelastic corrections:

\section{1. behn2009shear.m, creep10.m, J1anel.m, J1p.m, J2anel.m, J2p.m}

These functions calculate the anelastic effects on the shear moduli described in the next section. The latter five functions are shared courtesy of Ulrich Faul.

2. calculateWaveSpeedFiles.mlx

This live script loads in the uncorrected moduli in order to apply the user's choice of anelastic correction. It then saves the corrected database as a new .mat file (Figure 9).

\section{General User Interfaces}

In addition to these functions, we create three GUI's to help further investigate the compositional database and WISTFUL designed with the MATLAB® App Designer.

\section{Relations}

WISTFUL_relations.mlapp launches a GUI which allows the user to investigate the distribution or relationship of two parameters at a given pressure and temperature (Figure 10). By default, the GUI loads the elastic seismic moduli. If one wishes to apply an anelastic correction, one must create a corrected wave speed file (see calculateWaveSpeedFiles.mlx) and load it into the GUI using the load button in the top left corner. Once loaded, the text under the load button will display the name of the loaded file. 
Two different plots can be made with this GUI. 1) One can plot a histogram to see the distribution of a given parameter at a chosen temperature and pressure. 2) One can plot a relationship between two parameters. The plotted parameters are chosen in the drop down menus on the left side. Plotted samples can be restricted by rock type or by a single compositional constraint using the rock type and additional constraints check boxes. The figure only updates when you hit the "Plot!" button, at which point the text to the left of the figure will state how many samples are plotted. The only exception to this is to the change axes interface in the bottom right hand portion. The "Export data to workspace" button allows for further investigation of the plotted datasets outside of the GUI. The steps required to reproduce the image seen in Figure 10 are detailed in caption.

\section{Geotherm Profiler}

WISTFUL_profiles.mlapp launches a GUI which allows the user to investigate the seismic property of any given subset of rocks along a range of geotherms (Figure 11). By default, this GUI loads the elastic seismic moduli. As described above, if one wishes to apply an anelastic correction, one must create a corrected wavespeed file using calculateWaveSpeedFiles.mlx and use the load button in the top left corner. Regularly used geotherms such as a half-space cooling geotherm, a plate model geotherm, a continental geotherm with a constant heat production value are precoded into the GUI with the flexibility for users to specify parameters including ocean age, surface heat flux, or crustal heat productivity. Further input is allowed through the loading of a usergenerated geotherm. For this functionality, the user must load a mat file with vector files for depth [km], pressure [bars], and temperature $\left[{ }^{\circ} \mathrm{C}\right]$ named as $\mathrm{z}, \mathrm{p}$, and $\mathrm{t}$ (casesensitive). The loaded geotherm will be saved in the GUI until closed or another geotherm is loaded. The user can choose what rock types to plot, what property to plot, and what uncertainty to plot (mean only, range, mean with one or two standard deviations) using the drop-down menus on the left. The user can also further select which rocks to plot by adding a single compositional constraint if desired. The "Plot!" button plots the input request. The axes can be changed by the max depth plotted, as well as the "Set Axes" functionality in the bottom right. The "Export data to workspace" button allows for further investigation of the plotted data outside of the GUI. The steps required to reproduce the image seen in Figure 11 are detailed in caption. 


\section{Inversion}

WISTFUL_profiles.mlapp launches a GUI which allows the user to invert for

best-fit temperature and property using either of the fitting functions described above (Figure 12). Similar to the other GUI's, the user can load their choice of anelastic corrections and choose the rock type or compositional constraints for this inversion. For the inversion, the user can choose to fit to $V_{p}, V_{s}$, or some combination. The user can also choose the temperature range to look over as well as the extra property to fit. Once the options are chosen, the "Fit!" button plots the average RMSE using closest X or the number of samples within error using the number within $\mathrm{X}$ in the top middle figure. The bottom plot depicts the best fit composition for each temperature. A text box on the lefthand side states how many samples are being used in the inversion due to the constraints given. The best-fit temperature and property value along with uncertainty are displayed beneath the middle figures. Furthermore, the user can plot the histogram of the data at any single temperature using the "Plot Histogram!" button under the rightmost figure for any chosen temperature. After hitting the "Fit!" button, the "Temperature for Histogram" edit box will default to the best-fit temperature from the inversion. The "Export data to workspace" button allows for further investigation of the plotted data outside of the GUI. The steps required to reproduce the image seen in Figure 12 are detailed in caption.

\section{Summary}

With recent increases in tomographic resolution and inversion methodologies, a challenge for geoscientists is interpret these new models in terms of temperature and composition. In order to constrain the temperatures and compositions that are consistent with a given seismic wave speed involves forward modelling wave speeds from bulk compositions. To calculate seismic wave speeds from bulk composition, we here use the Gibbs free-energy minimization program Perple_X (Connolly, 2009). We updated the Perple_X moduli database to include up-to-date bulk and shear moduli (Table 1).

To constrain error present in these forward calculations, we investigate the two dominant sources of uncertainty: 1) uncertainty in the elastic property measurements and mixing equations to determine the bulk properties, and 2) uncertainty in the predicted mineral assemblage and composition. Regarding the first, we found experimental seismic wave speed measurements on ultramafic samples are reproducible with the updated 
mineral endmember moduli and mixing methodologies within laboratory measurement error. To constrain the second uncertainty, we compare predicted mineral assemblages and seismic wave speeds for 130 well-studied peridotite and pyroxenite xenoliths using five sets of solution models to the observed modal assemblages and estimated seismic wave speeds at the last-equilibrated temperature and pressure. We tested five sets of solution models against well-studied xenoliths with bulk and mineral compositions, as well as modal assemblages, and find that the Jennings and Holland (2015) solution model database best reproduces ultramafic phase assemblages and elastic seismic wave speeds $\left(\sim 0.5 \%\right.$ in $V_{p}$ and $\left.V_{s}\right)$.

With these errors in mind, we present WISTFUL (Whole-rock Interpretative Seismic Toolbox for Ultramafic Lithologies). Using the Jennings and Holland (2015) solution models with either constant or oxygen fugacity based on the $\mathrm{MgO}$ content of the composition, we calculate the anharmonic elastic seismic wave speeds for a compiled database of 4877 ultramafic whole-rock compositions. To correct for the calculated seismic wave speeds for anelastic effects, we include a live script to apply corrections from Jackson and Faul (2010) and Behn et al. (2009). WISTFUL includes a set of functions that invert for best-fit temperature and property by investigating either the closest $\mathrm{X}$ samples or the temperature at which the most samples are within error of a given wave speed. Lastly, three easy-to-use GUIs (relationships, geotherm profiles, and inversion) can be utilized as educational classroom tools in undergraduate and graduatelevel classrooms. 
Figures

\section{WISTFUL Workflow:}

Literature + implicit elastic moduli incorporating anelasticity

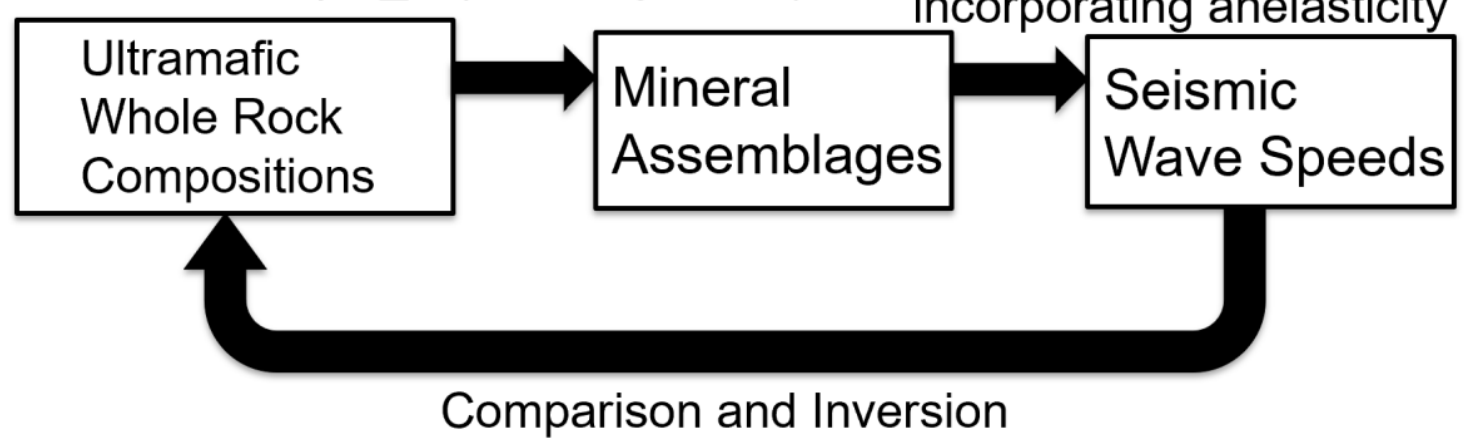

Figure 4.1: Workflow for WISTFUL. 


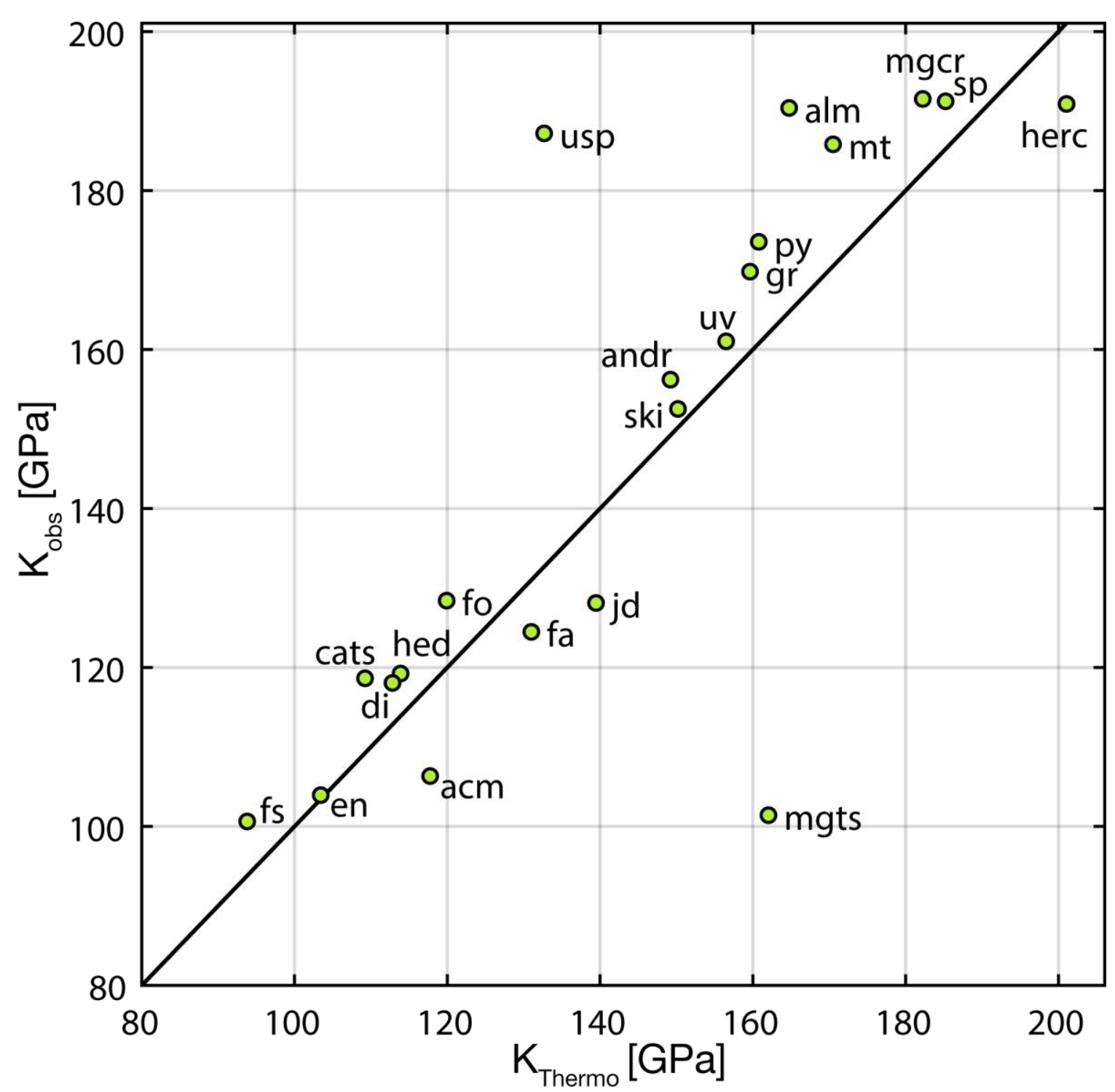

Figure 4.2: Experimental bulk moduli $\left(K_{o b s}\right)$ plotted against thermodynamically derived bulk moduli $\left(K_{\text {Thermo }}\right)$ for mantle mineral phase endmembers with experimental data at $500^{\circ} \mathrm{C}$ and $1 \mathrm{GPa}$ using the (Holland and Powell, 2011) database. Abbreviations: acm, acmite; alm, almandine; andr, andradite; cats, Ca-tschermak; di, diopside; en, enstatite; fa, fayalite; fo, forsterite; gr, grossular; hed, hedenbergite; herc, hercynite; jd, jadeite; mgcr, magnesiochromite; mgts, magnesium-tschermak; mt, magnetite; py, pyrope; ski, skiagite; sp, spinel; usp, ulvospinel; uv, uvarovite. 


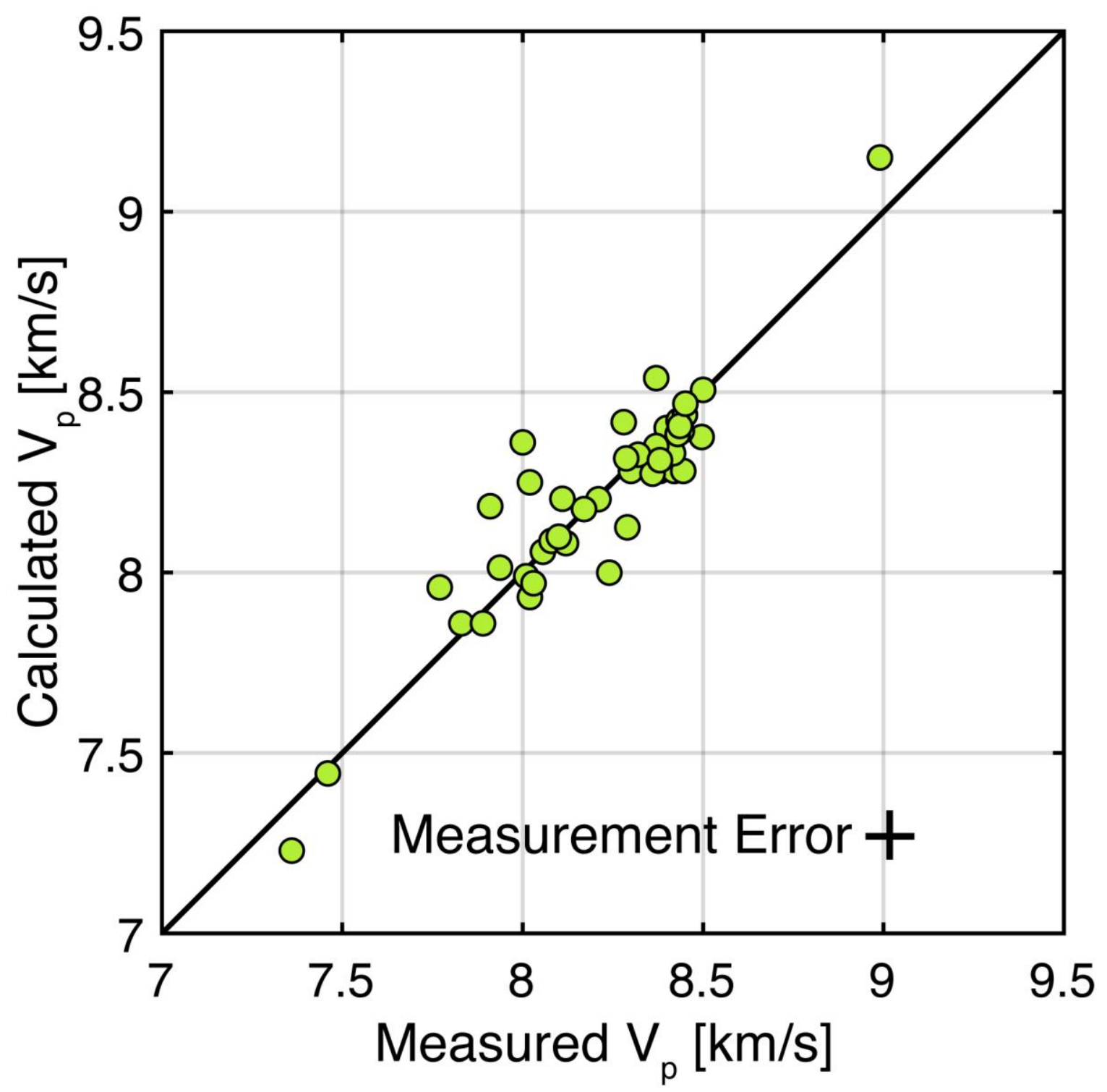

Figure 4.3: $V_{p}$ calculated for ultramafic rocks from modal assemblage, modal composition, and predicted mineral moduli versus laboratory measured $V_{p}$. See Section 2 for details. Estimated error in both directions shown in bottom right. 


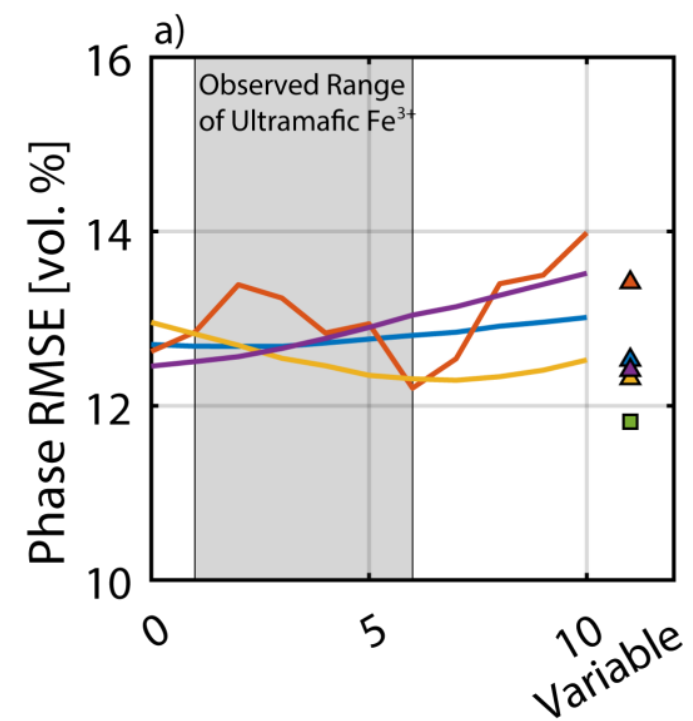

Constant $\mathrm{Fe}^{3+} \quad$ Variable $\mathrm{Fe}^{3+}$

- Cr Holland \& Powell (1998) $\quad \Delta$

- Holland et al. (2018)

$-\quad$ Jennings \& Holland (2015)
$-\quad$ Holland \& Powell (1998)

- Stixrude \& Lithgow-Bertelloni (2011)

$\mathrm{Fe} 3+/ \Sigma \mathrm{Fe}$ [mol. \%]

b)

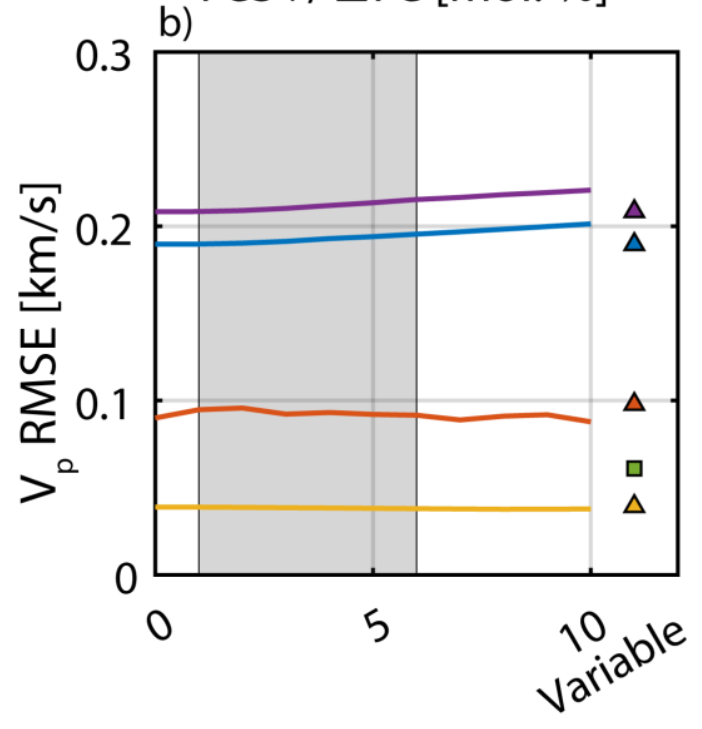

$\mathrm{Fe} 3+/ \Sigma \mathrm{Fe}$ [mol. \%]

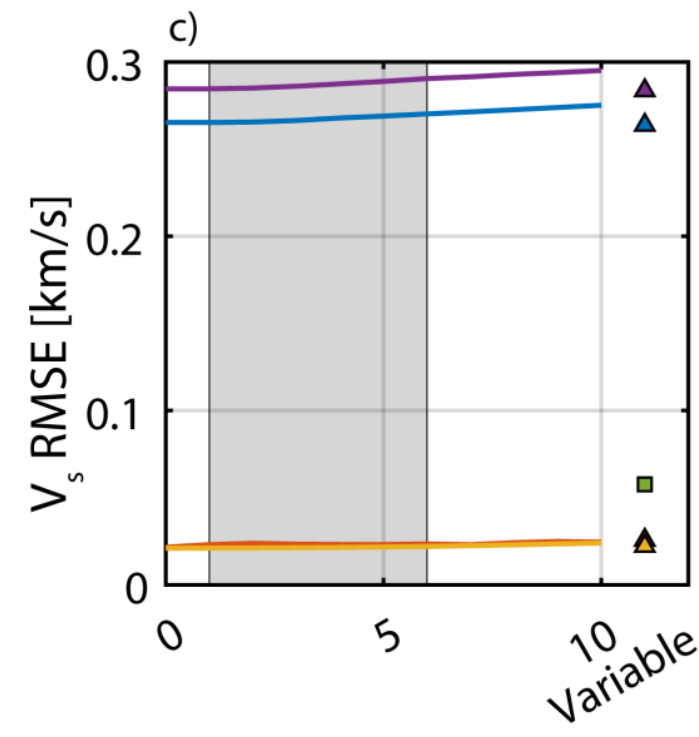

$\mathrm{Fe} 3+/ \Sigma \mathrm{Fe}$ [mol. \%]

Figure 4.4: Root-mean squared error (RMSE) for phase and seismic wave speed for all the solution models as a function of $\mathrm{Fe}^{3+} / \sum \mathrm{Fe}$. Grey box shows the range of observed $\mathrm{Fe}^{3+} / \sum \mathrm{Fe}$ in ultramafic rocks (Canil et al., 1994). Stixrude \& Lithgow-Bertelloni (2011) is constant since it does not include $\mathrm{Fe}_{2} \mathrm{O}_{3}$ in its solution model. 

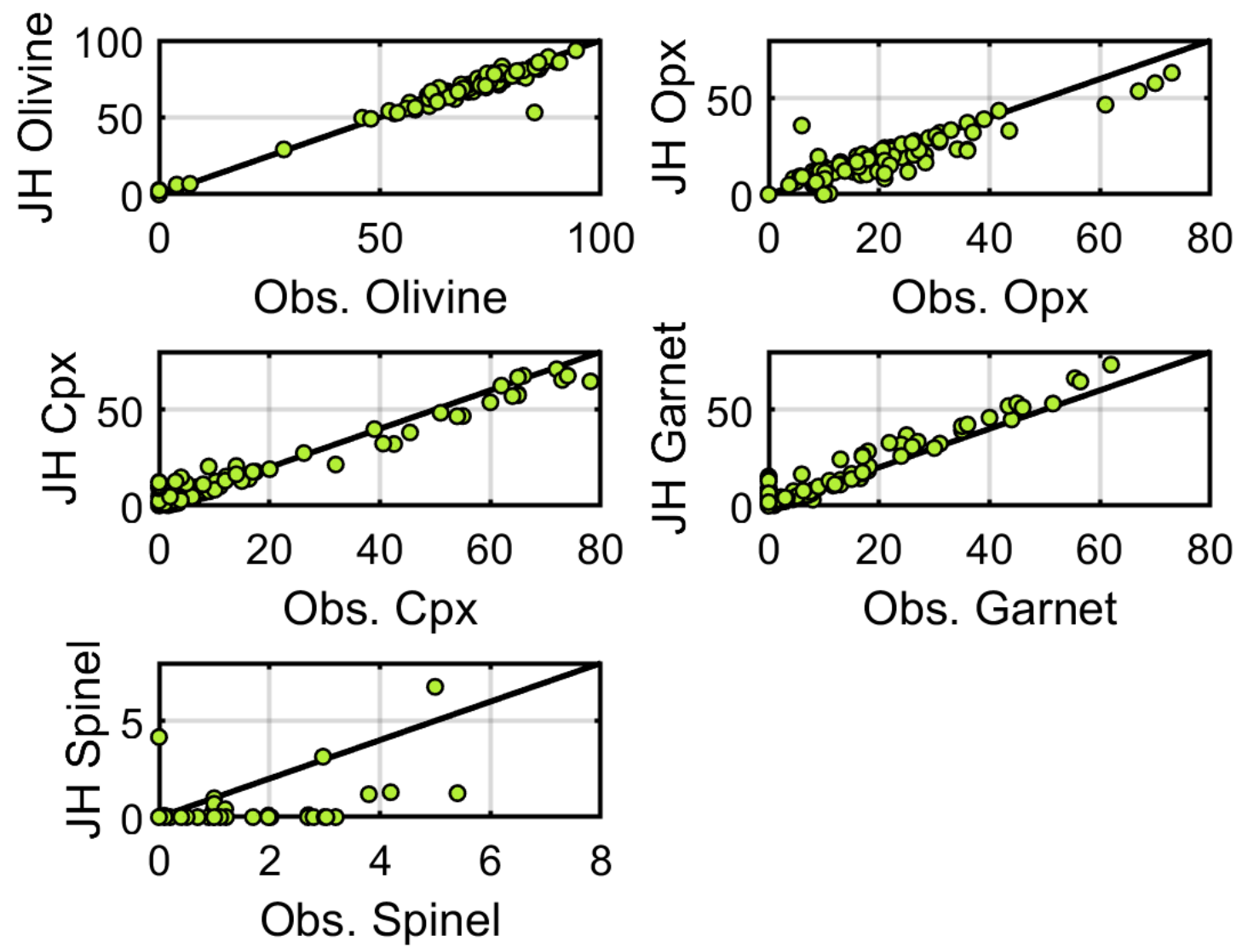

Figure 4.5: Mineral proportions for all xenoliths at their equilibrium conditions calculated using the Jennings \& Holland (2015) solution models and variable $\mathrm{Fe}_{2} \mathrm{O}_{3} / \mathrm{FeO}^{\mathrm{T}}$ plotted against the observed volume proportions. All amounts are in vol. \%. 

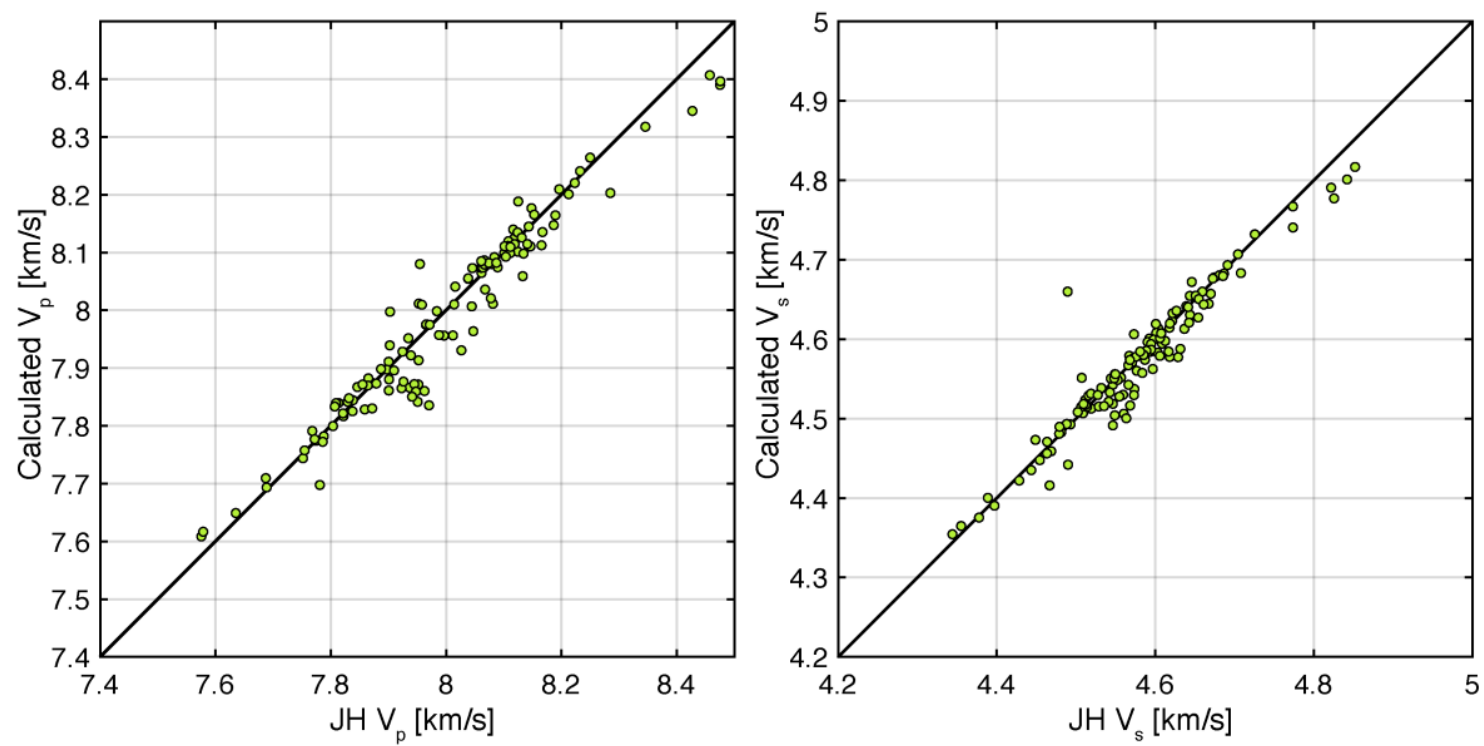

Figure 4.6: Seismic wavespeeds for all xenoliths at their equilibrium conditions calculated using the Jennings \& Holland (2015) solution models variable $\mathrm{Fe}^{3+} / \Sigma \mathrm{Fe}$ plotted against the seismic wavespeeds calculated from the observed mineral modes and compositions. 

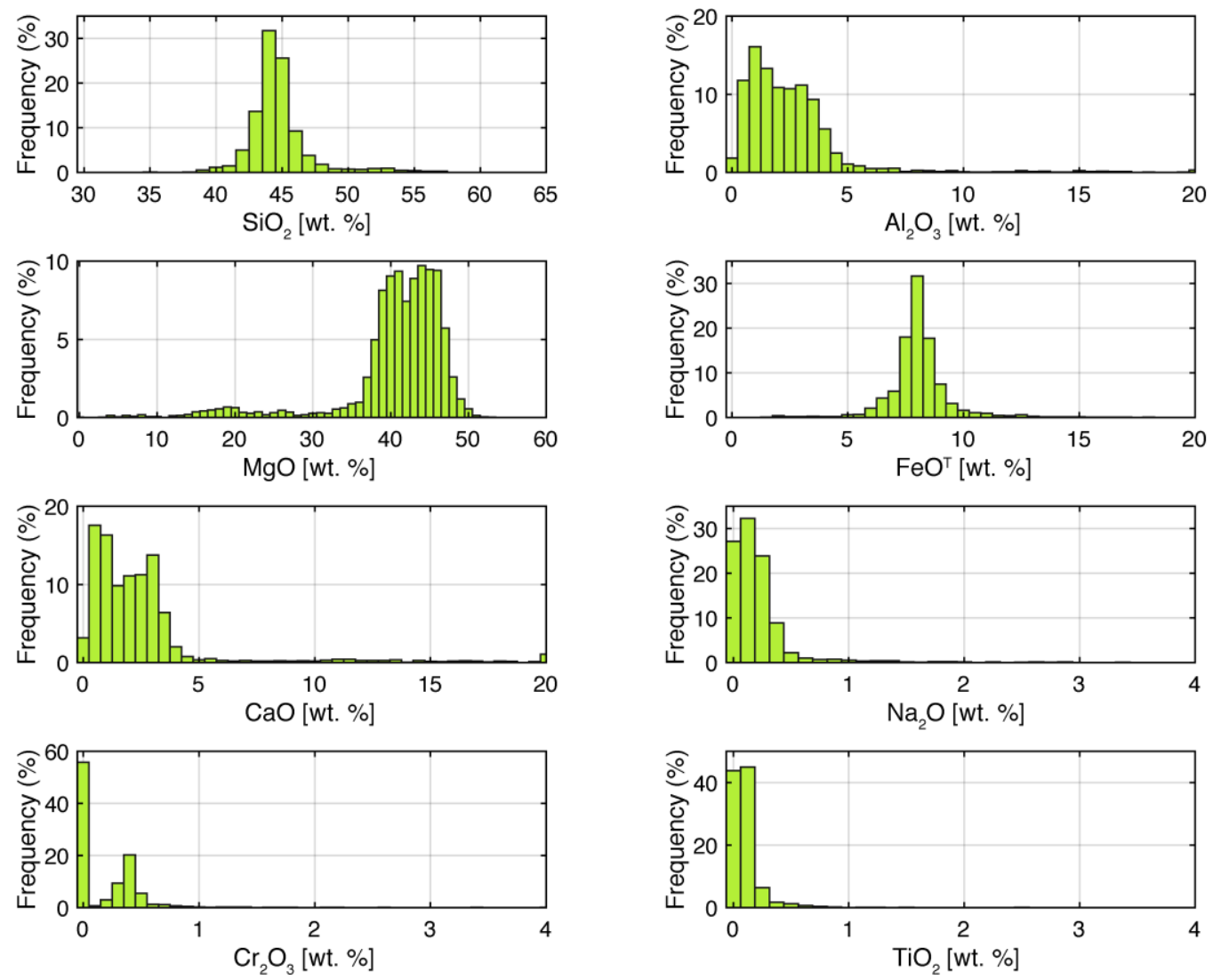

Figure 4.7: Compositional histograms for the ultramafic database. 


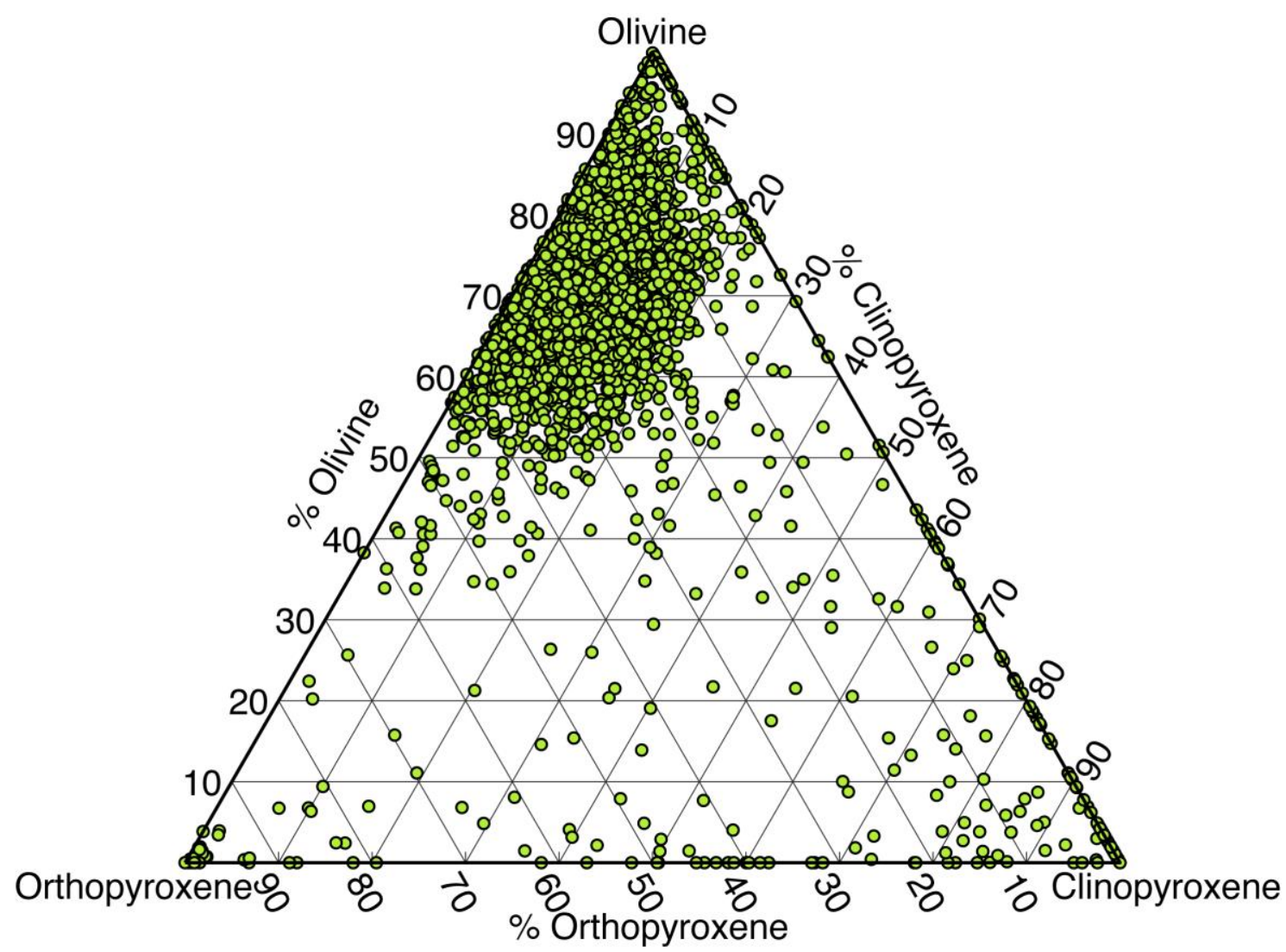

Figure 4.8: The ultramafic database plotted in the renormalized in the olivineorthopyroxene-clinopyroxene ternary. Modes calculated at $800{ }^{\circ} \mathrm{C}$ and $2 \mathrm{GPa}$. 


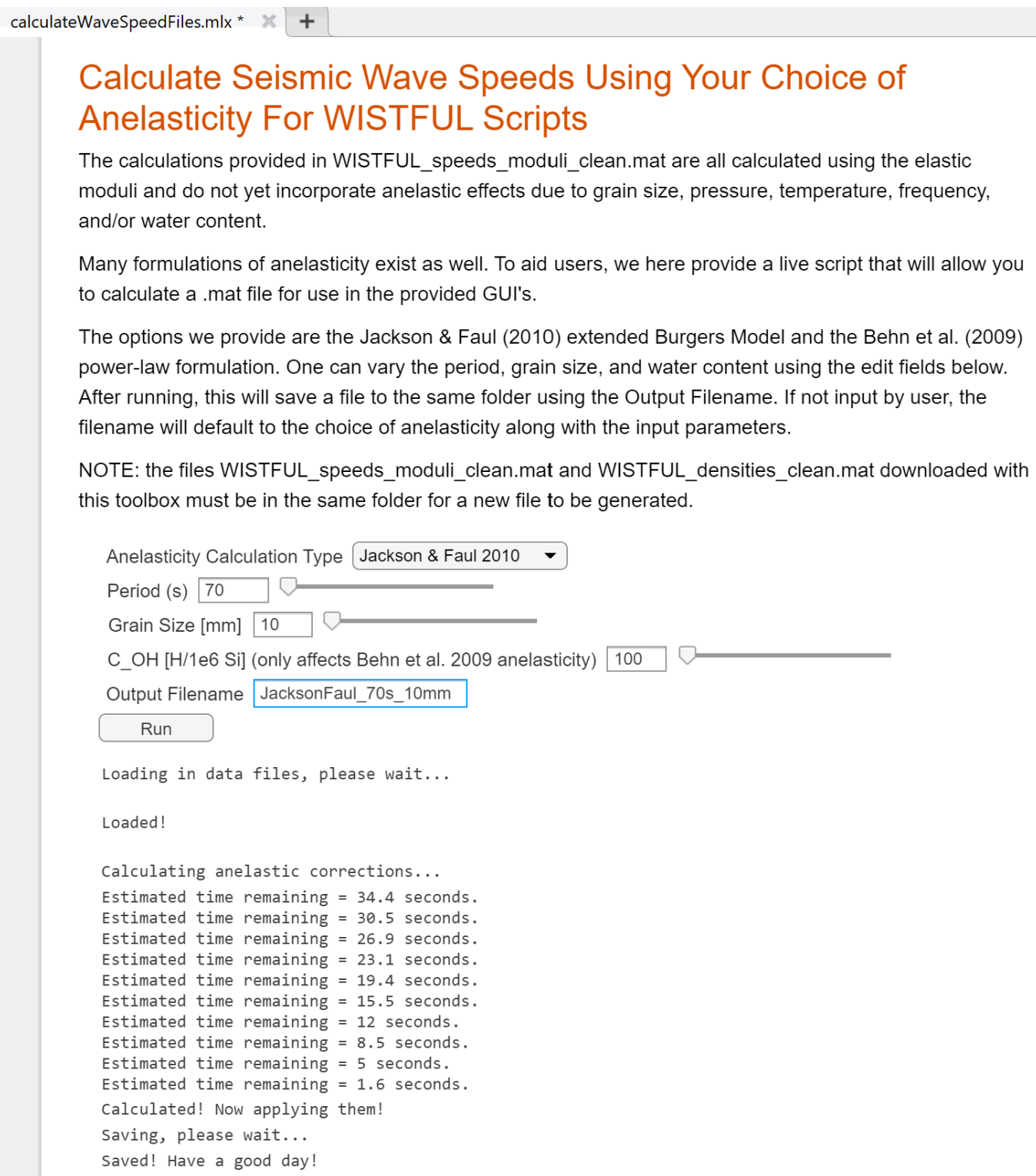

Many formulations of anelasticity exist as well. To aid users, we here provide a live script that will allow you to calculate a .mat file for use in the provided GUI's.

The options we provide are the Jackson \& Faul (2010) extended Burgers Model and the Behn et al. (2009) power-law formulation. One can vary the period, grain size, and water content using the edit fields below. After running, this will save a file to the same folder using the Output Filename. If not input by user, the filename will default to the choice of anelasticity along with the input parameters.

NOTE: the files WISTFUL_speeds_moduli_clean.mat and WISTFUL_densities_clean.mat downloaded with this toolbox must be in the same folder for a new file to be generated.

Figure 4.9: Snapshot of calculateWaveSpeedFiles.mlx. 


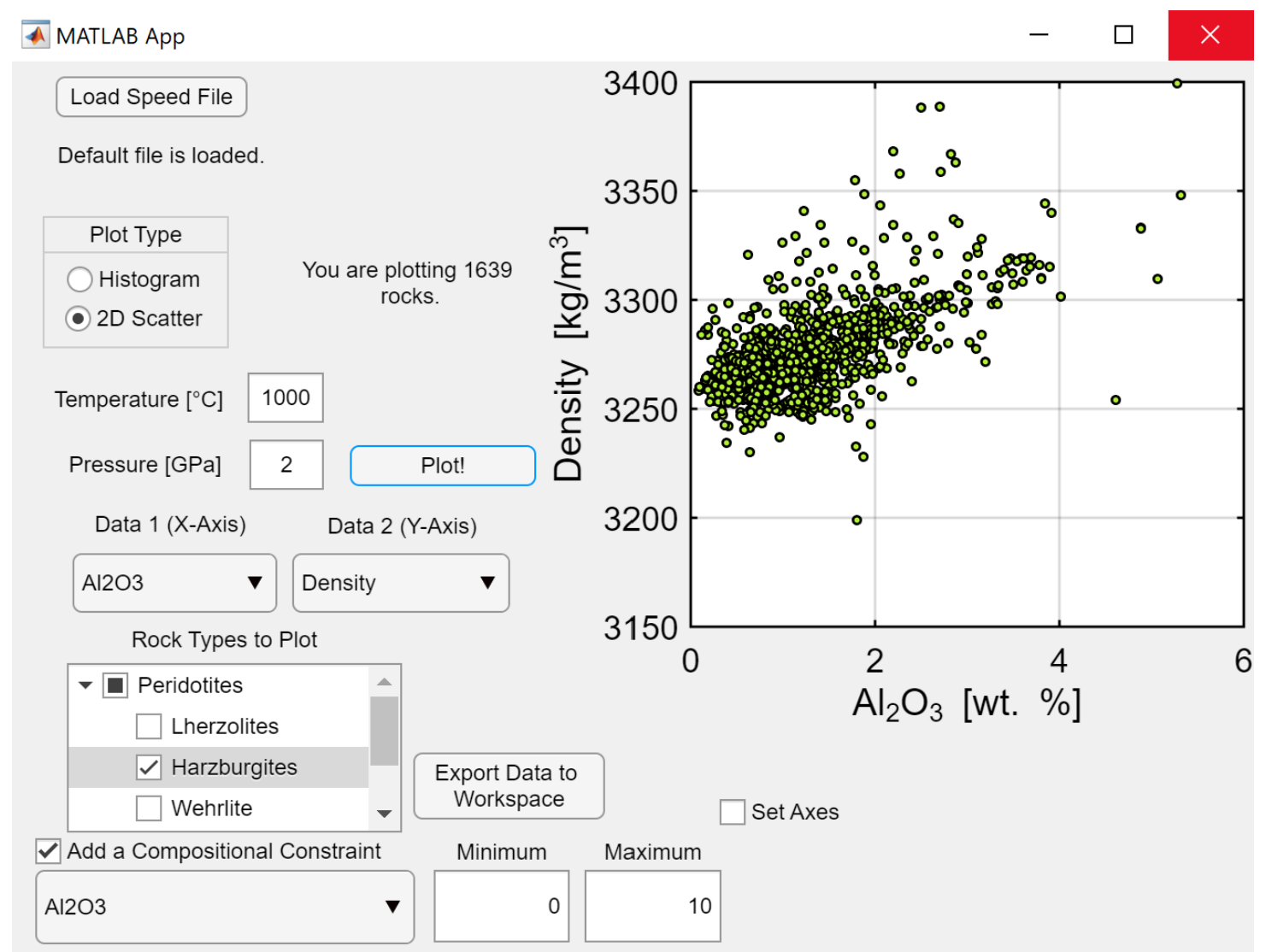

Figure 4.10: Snapshot of relationships GUI plotting a scatter plot of harzburgites density against $\mathrm{Al}_{2} \mathrm{O}_{3}$ at $1000{ }^{\circ} \mathrm{C}$ and $2 \mathrm{GPa}$. To reproduce this figure, load

WISTFUL_relationships.mlapp. Choose the axes data, temperature, and pressure as shown. Limit the rock types plotted to only harzburgites. Click the add a compositional constraint button and then select the drop-down menu, minimum, and maximum below as shown. Finally, hit the Plot! button. 


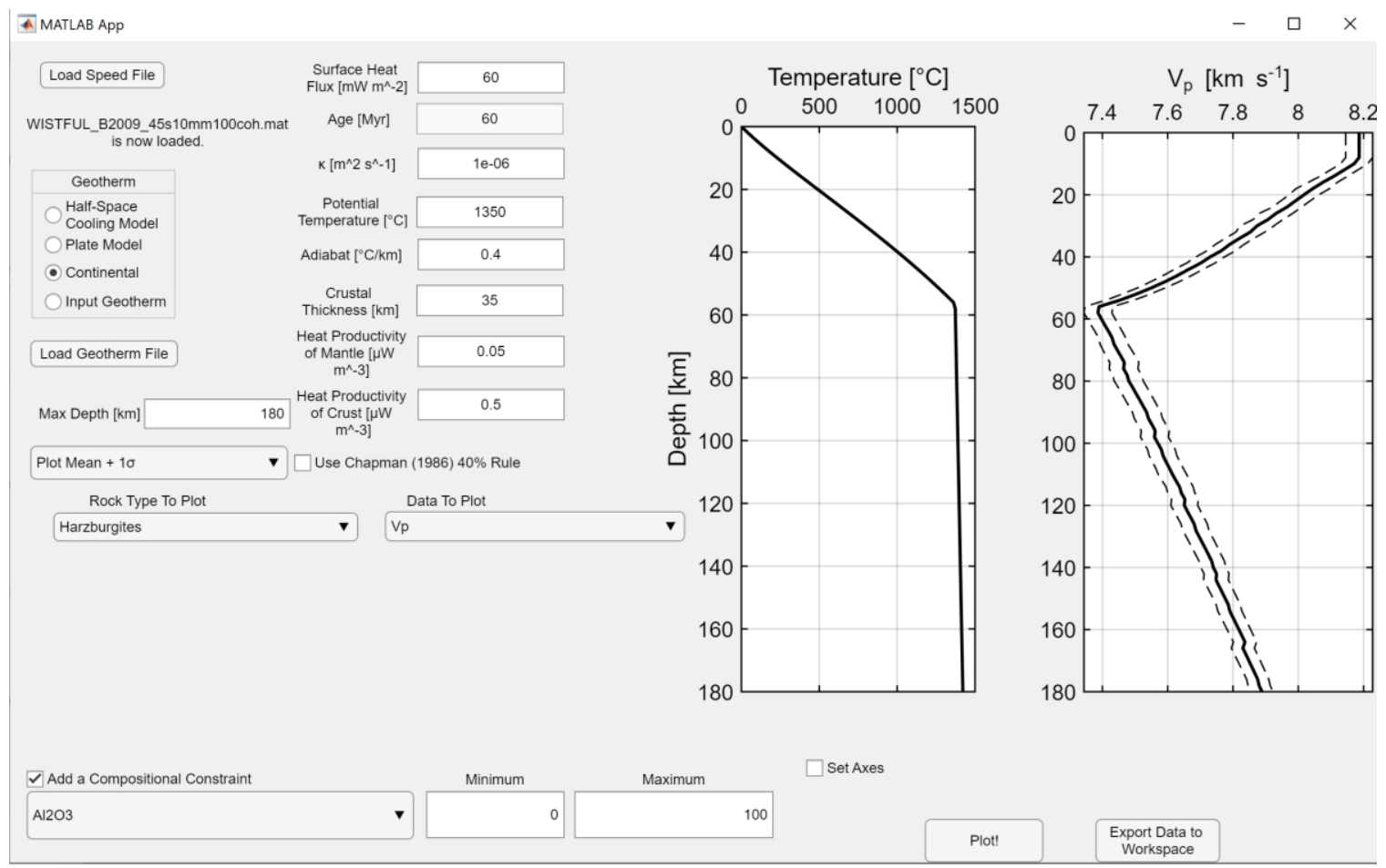

Figure 4.11: Snapshot of geotherm profiles GUI. To reproduce this figure, first create a wave speed file using calculateWaveSpeedFiles. $m l x$ corrected for $10 \mathrm{~mm}$ grainsize, 100 ppm $\mathrm{C}_{\mathrm{OH}}$, and $45 \mathrm{~s}$ period using the Behn et al. (2009) anelasticity. Afterwards open WISTFUL_profiles.mlapp. Using the Load Speed File button, load in the corrected speed file described above. Then, set the text boxes and drop downs to be as shown. Finally, hit the Plot! button. 


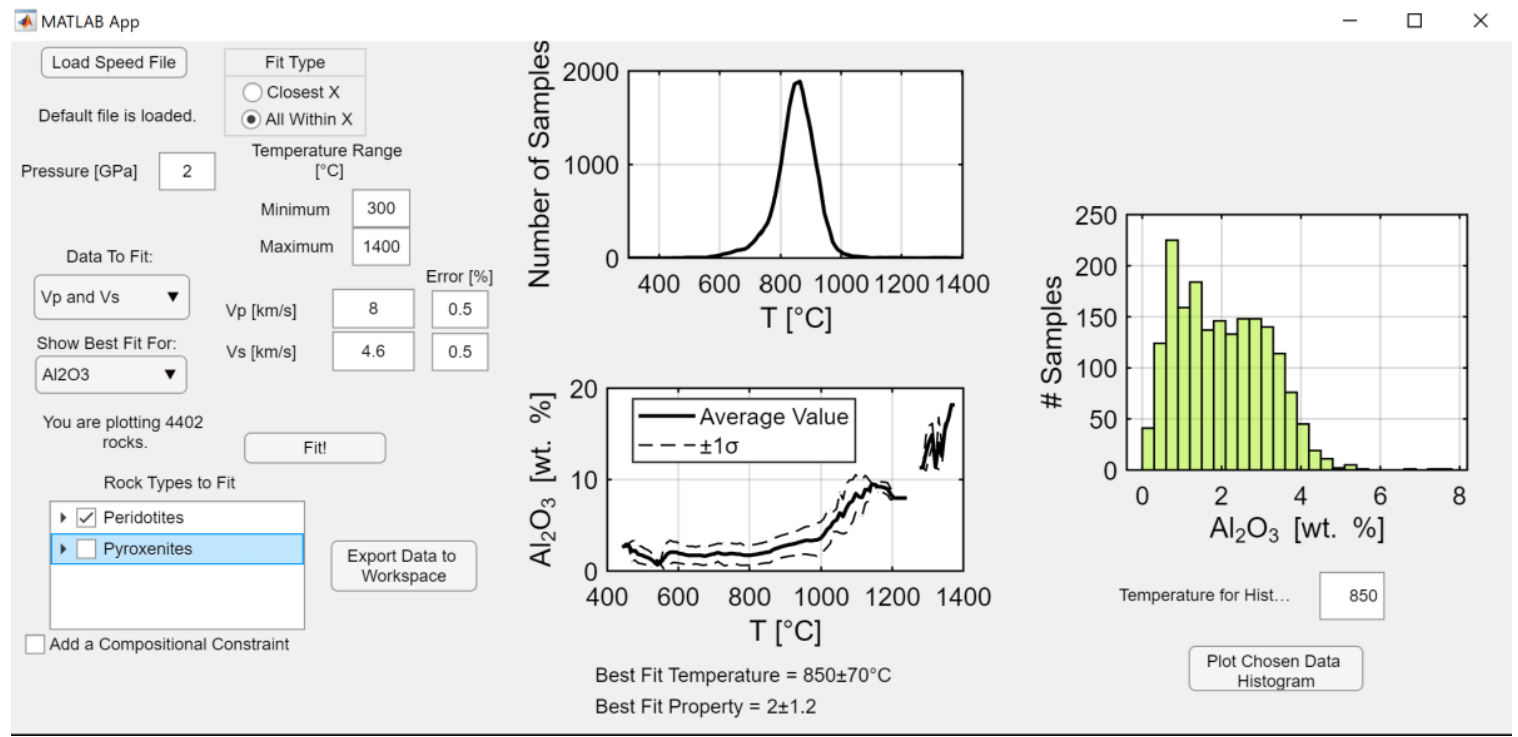

Figure 4.12: Snapshot of inversion GUI. To reproduce this figure, first open

WISTFUL_inversion.mlapp. Set the text and check boxes to be as seen to the left of the figures, with all types of peridotites checked. Then, set the text boxes and drop downs to be as shown. Afterwards, hit the Plot! button to plot the middle figures. Once plotted the Temperature for Histogram box will be automatically updated to the best-fit temperature. Finally, press the Plot Chosen Data Histogram button to plot the right-most figure. 


\section{Tables}

\begin{tabular}{|c|c|c|c|c|c|c|c|}
\hline $\begin{array}{l}\text { Mine } \\
\text { ral } \\
\text { Endm } \\
\text { embe } \\
\mathrm{r}\end{array}$ & $\begin{array}{l}\text { Che } \\
\text { mica } \\
1 \\
\text { For } \\
\text { mula }\end{array}$ & $\begin{array}{l}\text { Ambient } \\
\text { Bulk } \\
\text { Moduli, } \\
\text { K [GPa] }\end{array}$ & $\begin{array}{l}\text { Bulk } \\
\text { Pressur } \\
\text { e } \\
\text { Derivati } \\
\text { ve, K' }\end{array}$ & $\begin{array}{l}\text { Bulk } \\
\text { Temperatur } \\
\text { e } \\
\text { Derivative, } \\
\mathrm{K}_{\mathrm{T}}[\mathrm{GPa} / \mathrm{K}]\end{array}$ & $\begin{array}{l}\text { Ambient } \\
\text { Shear } \\
\text { Moduli, } \\
\text { G [GPa] }\end{array}$ & $\begin{array}{l}\text { Shear } \\
\text { Pressure } \\
\text { Derivati } \\
\text { ve, G' }\end{array}$ & $\begin{array}{l}\text { Shear } \\
\text { Temperatur } \\
\text { e } \\
\text { Derivative, } \\
\mathrm{G}_{\mathrm{T}}[\mathrm{GPa} / \mathrm{K}]\end{array}$ \\
\hline $\begin{array}{l}\text { Mont } \\
\text { icellit } \\
\mathrm{e} \\
\end{array}$ & $\begin{array}{l}\mathrm{CaM} \\
\mathrm{gSiO} \\
4\end{array}$ & $113^{4}$ & $4^{4}$ & $-0.01^{1}$ & $55.2^{5}$ & $1.954^{3}$ & $-0.0049^{3}$ \\
\hline $\begin{array}{l}\text { Spess } \\
\text { artine }\end{array}$ & $\begin{array}{l}\mathrm{Mn}_{3} \\
\mathrm{Al}_{2} \mathrm{~S} \\
\mathrm{i}_{3} \mathrm{O}_{12}\end{array}$ & $189^{6}$ & $4.2^{6}$ & $-0.0255^{1}$ & $96.3^{7}$ & $2.2^{3}$ & $-0.013^{3}$ \\
\hline $\begin{array}{l}\text { Andr } \\
\text { adite }\end{array}$ & $\begin{array}{l}\mathrm{Ca}_{3} \mathrm{~F} \\
\mathrm{e}_{2} \mathrm{Si}_{3} \\
\mathrm{O}_{12}\end{array}$ & $154.5^{8}$ & $4.71^{8}$ & $-0.02^{9}$ & $89.7^{8}$ & $1.25^{8}$ & $-0.011^{3}$ \\
\hline $\begin{array}{l}\text { Skiag } \\
\text { ite }\end{array}$ & $\begin{array}{l}\mathrm{Fe}_{5} \mathrm{~S} \\
\mathrm{i}_{3} \mathrm{O}_{12}\end{array}$ & $157.4^{10}$ & $6.7^{10}$ & $-0.0278^{1}$ & $76.4^{11}$ & $3.27^{3}$ & $-0.0135^{3}$ \\
\hline $\begin{array}{l}\text { Uvar } \\
\text { ovite }\end{array}$ & $\begin{array}{l}\mathrm{Ca}_{3} \mathrm{C} \\
\mathrm{r}_{2} \mathrm{Si}_{3} \\
\mathrm{O}_{12}\end{array}$ & $161^{12}$ & $4.5^{12}$ & $-0.018^{12}$ & $89.9^{13}$ & $1.8^{13}$ & $-0.01^{3}$ \\
\hline $\begin{array}{l}\text { Knorr } \\
\text { ingite }\end{array}$ & $\begin{array}{l}\mathrm{Mg}_{3} \\
\mathrm{Cr}_{2} \mathrm{~S} \\
\mathrm{i}_{3} \mathrm{O}_{12} \\
\end{array}$ & $161^{2}$ & $4.5^{2}$ & $-0.018^{2}$ & $89.9^{2}$ & $1.8^{2}$ & $-0.01^{2}$ \\
\hline $\begin{array}{l}\text { K- } \\
\text { jadeit } \\
\text { e } \\
\end{array}$ & $\begin{array}{l}\mathrm{KAl} \\
\mathrm{Si}_{2} \mathrm{O} \\
6 \\
\end{array}$ & $147.4^{1}$ & $4.9^{1}$ & $-0.0171^{1}$ & $85^{2}$ & $1.9^{2}$ & $-0.0059^{2}$ \\
\hline $\begin{array}{l}\text { Acmi } \\
\text { te }\end{array}$ & $\begin{array}{l}\mathrm{NaF} \\
\mathrm{eSi}_{2} \\
\mathrm{O}_{6} \\
\end{array}$ & $118^{20}$ & $4.2^{20}$ & $-0.0089^{1}$ & $85^{2}$ & $1.9^{2}$ & $-0.0059^{2}$ \\
\hline $\begin{array}{l}\text { Kosm } \\
\text { ochlo } \\
\mathrm{r} \\
\end{array}$ & $\begin{array}{l}\mathrm{NaC} \\
\mathrm{rSi}_{2} \\
\mathrm{O}_{6}\end{array}$ & $123^{19}$ & $3.6^{19}$ & $-0.0065^{1}$ & $85^{2}$ & $1.9^{2}$ & $-0.0059^{2}$ \\
\hline $\begin{array}{l}\text { Pericl } \\
\text { ase }\end{array}$ & $\mathrm{MgO}$ & $162.8^{14}$ & $3.94^{14}$ & $-0.025^{14}$ & $130.3^{14}$ & $2.17^{14}$ & $-.02^{14}$ \\
\hline $\begin{array}{l}\text { Ulvos } \\
\text { pinel }\end{array}$ & $\begin{array}{l}\mathrm{TiO} \\
\mathrm{Fe}_{2} \mathrm{O} \\
5\end{array}$ & $147^{15}$ & $4^{15}$ & $-0.0366^{1}$ & $26^{16}$ & $0.522^{3}$ & $-0.0064^{3}$ \\
\hline $\begin{array}{l}\text { Magn } \\
\text { esioc } \\
\text { hromi } \\
\text { te }\end{array}$ & $\begin{array}{l}\mathrm{MgC} \\
\mathrm{r}_{2} \mathrm{O}_{4}\end{array}$ & $182.5^{17}$ & $5.8^{17}$ & $-.0121^{1}$ & $130^{18}$ & $2.85^{3}$ & $-.0086^{3}$ \\
\hline
\end{tabular}

Table 4.1: Newly input elastic moduli and derivatives used in the seismic wave speed calculations. Notes and references: 1) Derived from thermodynamic properties, 2) Taken from nearest endmember, 3) Fit to maintain ambient pressure-temperature Poisson's ratio, 4) Sharp et al. (1987), 5) Peercy and Bass (1990), 6) Zhang et al. (1999) 7) Bass (1989), 8) Jiang et al. (2004), 9) Pavese et al. (2001), 10) Woodland et al. (1999), 11) 
Vasiukov et al. (2018), 12) Gréaux and Yamada (2019), 13) Wang and Ji (2001), 14) Fan et al. (2019), 15) Xiong et al. (2015) 16) Syono et al. (1971) 17) Nestola et al. (2014) 18) estimated in Matsukage et al. (2010), 19) Posner et al. (2014), 20) Xu et al. (2017). 


\begin{tabular}{|c|c|c|c|c|c|}
\hline $\begin{array}{l}\text { Solution } \\
\text { Model } \\
\text { Set }\end{array}$ & $\begin{array}{l}\text { Holland and Powell } \\
\text { (1998) }\end{array}$ & $\begin{array}{l}\text { Cr Holland \& } \\
\text { Powell }\end{array}$ & $\begin{array}{l}\text { Stixrude } \\
\text { and } \\
\text { Lithgow- } \\
\text { Bertelloni } \\
(2011)\end{array}$ & $\begin{array}{l}\text { Jennings } \\
\text { and } \\
\text { Holland } \\
(2015)\end{array}$ & $\begin{array}{l}\text { Holland } \\
\text { et al. } \\
(2018)\end{array}$ \\
\hline $\begin{array}{l}\text { Element } \\
\text { al } \\
\text { System: }\end{array}$ & 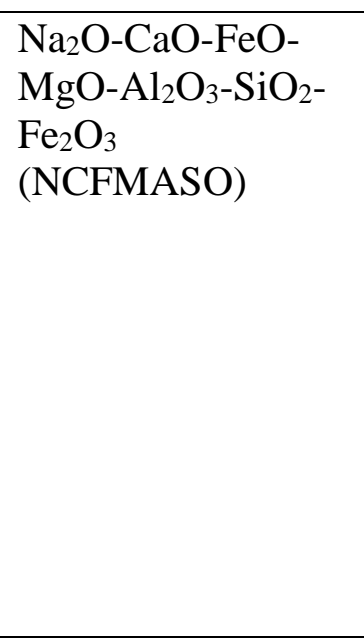 & $\begin{array}{l}\mathrm{Na}_{2} \mathrm{O}-\mathrm{CaO}-\mathrm{FeO}- \\
{\mathrm{MgO}-\mathrm{Al}_{2} \mathrm{O}_{3-}}^{\mathrm{SiO}_{2}-\mathrm{Fe}_{2} \mathrm{O}_{3}-\mathrm{Cr}_{2} \mathrm{O}_{3}} \\
\text { (NCFMASOCr) }\end{array}$ & $\begin{array}{l}\mathrm{Na}_{2} \mathrm{O}-\mathrm{CaO}- \\
\mathrm{FeO}-\mathrm{MgO}- \\
\mathrm{Al}_{2} \mathrm{O}_{3}-\mathrm{SiO}_{2} \\
\text { (NCFMAS } \\
\text { ) }\end{array}$ & $\begin{array}{l}\mathrm{Na}_{2} \mathrm{O}- \\
\mathrm{CaO}- \\
\mathrm{FeO}- \\
\mathrm{MgO}- \\
\mathrm{Al}_{2} \mathrm{O}_{3-} \\
\mathrm{SiO}_{2-} \\
\mathrm{Fe}_{2} \mathrm{O}_{3-} \\
\mathrm{Cr}_{2} \mathrm{O}_{3} \\
\text { (NCFM } \\
\text { ASOCr) }\end{array}$ & $\begin{array}{l}\mathrm{K}_{2} \mathrm{O}- \\
\mathrm{Na} 2 \mathrm{O}- \\
\mathrm{CaO}- \\
\mathrm{FeO}- \\
\mathrm{MgO}- \\
\mathrm{Al}_{2} \mathrm{O}_{3-}- \\
\mathrm{SiO}_{2-} \\
\mathrm{H}_{2} \mathrm{O}_{-} \\
\mathrm{TiO}_{2-} \\
\mathrm{Fe}_{2} \mathrm{O}_{3-}- \\
\mathrm{Cr}_{2} \mathrm{O}_{3} \\
\text { (KNCFM } \\
\text { ASTOCr) } \\
\end{array}$ \\
\hline Olivine & $\mathrm{O}(\mathrm{HP})$ & $\begin{array}{l}\mathrm{O}(\mathrm{HP}) \text { (Holland } \\
\text { and Powell, 1998) }\end{array}$ & $\mathrm{O}$ & $\mathrm{O}(\mathrm{JH})$ & \begin{tabular}{|l|}
$\mathrm{O}(\mathrm{HGP})$ \\
\end{tabular} \\
\hline $\begin{array}{l}\text { Orthopyr } \\
\text { oxene }\end{array}$ & $\begin{array}{l}\text { Opx(HP) (Powell } \\
\text { and Holland, 1999) }\end{array}$ & $\begin{array}{l}\text { CrOpx(HP) } \\
\text { (Powell and } \\
\text { Holland, 1999) }\end{array}$ & Opx & $\mathrm{Opx}(\mathrm{JH})$ & $\begin{array}{l}\mathrm{Opx}(\mathrm{HG} \\
\mathrm{P})\end{array}$ \\
\hline $\begin{array}{l}\text { Clinopyr } \\
\text { oxene }\end{array}$ & $\begin{array}{l}\text { Cpx(HP)(Holland } \\
\text { and Powell, 1996) }\end{array}$ & $\begin{array}{l}\text { Cpx }(H P) \\
\text { (Holland and } \\
\text { Powell, 1996) }\end{array}$ & Cpx & $\mathrm{Cpx}(\mathrm{JH})$ & $\begin{array}{l}\text { Cpx(HGP } \\
\text { ) }\end{array}$ \\
\hline Garnet & $\mathrm{Gt}(\mathrm{HP})$ & $\begin{array}{l}\text { CrGt } \\
\text { (Malaspina et al., } \\
\text { 2009; Ziberna et } \\
\text { al., 2013) }\end{array}$ & Gt_maj & $\operatorname{Grt}(\mathrm{JH})$ & \begin{tabular}{|l|}
$\mathrm{Gt}(\mathrm{HGP})$ \\
\end{tabular} \\
\hline Spinel & $\mathrm{Sp}(\mathrm{HP})$ & $\begin{array}{l}\text { CrSp (Klemme et } \\
\text { al., 2009) }\end{array}$ & $\mathrm{Sp}$ & $\mathrm{Sp}(\mathrm{JH})$ & $\mathrm{Sp}(\mathrm{HGP})$ \\
\hline $\begin{array}{l}\text { Plagiocl } \\
\text { ase }\end{array}$ & $\begin{array}{l}\mathrm{Pl}(\mathrm{I} 1, \mathrm{HP})(\text { Holland } \\
\text { and Powell, 2003) }\end{array}$ & $\begin{array}{l}\mathrm{Pl}(\mathrm{I} 1, \mathrm{HP}) \\
\text { (Holland and } \\
\text { Powell, 2003) }\end{array}$ & $\mathrm{Pl}$ & $\mathrm{Pl}(\mathrm{JH})$ & $\begin{array}{l}\text { Pl(I1,HP) } \\
\text { (Holland } \\
\text { and } \\
\text { Powell, } \\
\text { 2003) }\end{array}$ \\
\hline
\end{tabular}

Table 4.2: List of solution models sets used for xenolith comparisons. References are given for the solution models not taken from the set reference. The Holland and Powell (2011) thermodynamic database was used for all the calculations with the exception of the Stixrude and Lithgow-Bertelloni (2011). We used 0 wt. \% $\mathrm{H}_{2} \mathrm{O}$ for our calculations using Holland et al. (2018). 


\begin{tabular}{|c|c|}
\hline Filename & Purpose \\
\hline behn2009Shear.m & $\begin{array}{l}\text { Function to calculate Behn et al. (2009) } \\
\text { anelasticity. }\end{array}$ \\
\hline calculateWaveSpeedFiles.mlx & $\begin{array}{l}\text { Live function to apply anelastic } \\
\text { corrections to the database. }\end{array}$ \\
\hline $\begin{array}{l}\text { creep10.m, Jlanel.m, J1p.m, J2anel.m, } \\
\text { J2p.m }\end{array}$ & $\begin{array}{l}\text { Functions to calculate Jackson and Faul, } \\
\text { (2010) anelasticity written by Uli Faul. }\end{array}$ \\
\hline findClosestX.m & $\begin{array}{l}\text { Function to find the closest } X \text { samples to a } \\
\text { input seismic wave speed at a pressure } \\
\text { and temperature range. }\end{array}$ \\
\hline fitPropertyClosestX.m & $\begin{array}{l}\text { Function to find best fit property with } \\
\text { output from findClosestX.m. }\end{array}$ \\
\hline fitPropertyNumWithin.m & $\begin{array}{l}\text { Function to find best fit property with } \\
\text { output from numWithinError.m. }\end{array}$ \\
\hline numWithinError.m & $\begin{array}{l}\text { Function to find the number of samples } \\
\text { within error from seismic data at a given } \\
\text { pressure and temperature range. }\end{array}$ \\
\hline README.txt & $\begin{array}{l}\text { A readme file with units and descriptions } \\
\text { of all files in WISTFUL. }\end{array}$ \\
\hline WISTFUL_compositions_clean.mat & $\begin{array}{l}\text { Compositional database with latitude and } \\
\text { longitude of samples. }\end{array}$ \\
\hline WISTFUL_densities_clean.mat & Database with densities. \\
\hline WISTFUL_inversion.mlapp & Inversion GUI. \\
\hline
\end{tabular}




\begin{tabular}{|l|l|}
\hline WISTFUL_parsed_modes_clean.mat & Database with modes. \\
\hline WISTFUL_profiles.mlapp & Geotherm Profile GUI. \\
\hline WISTFUL_relations.mlapp & Relations GUI. \\
\hline WISTFUL_rockType.mat & Database file with rock type information. \\
\hline WISTFUL_speeds_moduli_clean.mat & Database with moduli and wave speeds. \\
\hline exampleNumWithin.m, & Example scripts. \\
exampleClosestX.m & \\
\end{tabular}

Table 4.3: Functions, files, and databases. 


\section{Chapter 5:}

Mantle Thermochemical Variations beneath the Continental United States Through Petrologic Interpretation of Seismic Tomography 


\begin{abstract}
Constraining the thermomechanical state of the mantle beneath the continental United States is vital to understand the density stability of the mantle lithosphere. Recent studies have shown the potential of combining high-resolution seismic inversions with petrologically informed forward-calculations of seismic wave speed to better constrain the thermomechanical state of the mantle. Here we apply the Whole-rock Interpretive Seismic Toolbox For Ultramafic Lithologies (WISTFUL, Chapter 4) to analyze MITPS_20 (Golos et al., 2020), a joint body and surface wave tomographic inversion for $V_{p}$ and $V_{s}$ with high resolution in the shallow mantle. We evaluate MITPS_20 to constrain temperature and compositional variations at 60 and $80 \mathrm{~km}$ depth in the mantle lithosphere using two different anelastic corrections. We infer temperature variations beneath the continental United States up to $800-900^{\circ} \mathrm{C}$ at $60 \mathrm{~km}$ and $80 \mathrm{~km}$. East of the Rocky Mountains, the mantle lithosphere is generally cold $\left(350-850^{\circ} \mathrm{C}, 60 \mathrm{~km}\right)$, with higher temperatures (up to $1000^{\circ} \mathrm{C}, 60 \mathrm{~km}$ ) on the Atlantic coastal margin. Longwavelength thermal variations are present in these regions, some correlated with surface expressions of rifting events. By contrast, the mantle lithosphere west of the Rocky Mountains is hot (often $>1000{ }^{\circ} \mathrm{C}$ at $60 \mathrm{~km}$ and $>1200{ }^{\circ} \mathrm{C}$ at $80 \mathrm{~km}$ ), with highest temperatures found under Holocene volcanoes. We find our temperature and composition estimates agree well with constraints from recently $(<10 \mathrm{Ma})$ erupted mantle xenoliths in the southwestern US. The two anelasticity corrections predict significantly colder mantle temperatures at $60 \mathrm{~km}$ depth than does primary magma thermobarometry. This discrepancy is most likely due to the differences in sampling resolution between seismic and geochemical methodologies, as well as errors in the anelastic formulations. In agreement with previous work, we find that the chemical depletion predicted by our model does not fully compensate the density difference due to temperature between the eastern and western United States. Using Rayleigh-Taylor instability analysis, we estimate the timescales for lithospheric delamination. While the shallow North American cratonic lithosphere is currently density unstable, it is too cold to delaminate in reasonable timescales as long as there exists pervasive lithospheric compositional buoyancy.
\end{abstract}




\section{Introduction}

The North American continent consists of an amalgamation of continental and arc fragments originating over the course of Earth's history (Hoffman, 1988; Whitmeyer and Karlstrom, 2007). To first order, geologic and geophysical observations divide the continental United States in two geologic provinces (or regions): the tectonically active western region and the stable eastern region, broadly separated by the Rocky Mountain Front. Surface strain rate is only detectable in the west (Kreemer et al., 2014), in line with the dominant western locations of historically recorded high magnitude (>6.0) seismic activity (Stover and Coffman, 1993; Petersen et al., 2020). Heat flow is highest in the west, with lowest values in the Archean cratons in the east (Morgan and Gosnold, 1989; Williams and Deangelo, 2011), and Holocene volcanism occurs exclusively in the west of the continental United States (Venzke, 2013). The west is dominated by high relief with long-wavelength negative Bouguer gravity anomalies, in contrast to the low relief and short-wavelength positive Bouguer gravity anomalies in the east (Woollard, 1965; Kane and Godson, 1989; Phillips et al., 1993; Danielson and Gesch, 2011). Coherence between Bouguer gravity anomalies and topography predict thin elastic thicknesses in the west and thick elastic thicknesses in the east (Bechtel et al., 1990; Audet and Bürgmann, 2011). In addition, mantle seismic wave speeds drastically differ between the two regions, with slow seismic wave speeds in the west and fast seismic wave speeds in the east (Schmandt and Lin, 2014; Shen and Ritzwoller, 2016; Golos et al., 2020). Similarly, the depth at which mantle seismic anisotropy aligns with absolute plate motion is significantly shallower in the west compared to the east (Yuan and Romanowicz, 2010; Yuan et al., 2011).

Temperature exerts the dominant control on rheology (Karato and $\mathrm{Wu}, 1993$; Hirth and Kohlstedt, 2003), density (Afonso et al., 2005; Abers and Hacker, 2016), and mantle seismic wave speed (Cammarano et al., 2003; Abers and Hacker, 2016). Thus, taken together, these observations point toward elevated shallow mantle temperatures in the western US compared to colder temperatures in the east (Pakiser, 1963; Humphreys and Dueker, 1994; Goes and van der Lee, 2002; Mooney and Kaban, 2010). This variation in mantle temperature has been related to the age of the lithosphere as the 
shallow mantle cools with time (Pollack and Chapman, 1977; Chapman, 1986; Goes et al., 2020).

Re-Os dating, as well as isotopic measurements, suggest that the shallow cratonic mantle is as old as the surface rocks (Lee, 2006). In order for cratonic mantle to remain buoyant and persist over billions of years, the density increase due to cooling has been hypothesized to be balanced by a density decrease due to the depletion of the mantle through melting (Jordan, 1975, 1979; Oxburgh and Parmentier, 1978; Griffin et al., 2003). The density structure associated with the combined effects of composition and temperature is therefore vital to the force balance within the North American lithosphere (Zoback and Mooney, 2003; Flament et al., 2013; Becker et al., 2014). Some petrologic studies have supported this isopycnic hypothesis through density estimates from Kaapvaal xenolith compositions along modern calculated geotherms (Kelly et al., 2003). Other studies from various fields have argued that the density increase due to cooling is not fully compensated by composition in other cratons (Forte et al., 1995; Shapiro et al., 1999a; Kaban et al., 2003; Schutt and Lesher, 2006; Eaton and Claire Perry, 2013).

The goal of this chapter is to interpret the MITPS_20 seismic tomographic model (Golos et al., 2020) in terms of temperature, composition, and density using WISTFUL (Whole-Rock Interpretive Seismic Toolbox For Ultramafic Lithologies) (Chapter 4). MITPS_20 incorporates both body and surface wave data from the USArray, giving improved vertical and lateral resolution within the crust and upper mantle for both $V_{p}$ and $V_{s}$. WISTFUL is a set of seismic wave speeds calculated over a pressure-temperature (PT) grid for a large database of more than 4800 ultramafic bulk compositions. WISTFUL incorporates an up-to-date integration of laboratory measurements of elastic moduli, new thermodynamic solution models and databases chosen to best-fit the mineral modes of well-studied mantle xenoliths, and two different experimental calibrations of olivine anelasticity. In this chapter, we first discuss the methodology of the seismic model and WISTFUL. Based on the two anelastic formulations, we report temperature, composition, and density for the continental United States and eastern Canada. We then compare the thermochemical results at 60 and $80 \mathrm{~km}$ with surface geologic regions and features. Using our calculated density, composition, and temperatures, we investigate the relative chemical and thermal buoyancy of cratonic lithosphere. To corroborate our model 
interpretation, we compare our results with chemistry and thermobarometry from xenoliths as well as magmatic temperatures. Lastly, we calculate the compositional buoyancy of the shallow mantle beneath the cratonic United States and discuss the stability of continental cratonic mantle.

\section{Geological setting and previous study results}

Geologic mapping and geochronology show the west of the Rocky Mountains experienced recent orogenesis (Laramide Orogeny, 75-35 Ma, English and Johnston, 2004; Amato et al., 2017) and is an active plate boundary, while the east last experienced internal deformation during the Neoproterozoic due to the Mid-Continental Rift (1100 Ma, Van Schmus and Hinke, 1985) and Grenville Orogeny (ca. 1300-980, McLelland et $a l ., 2010)$. More recent eastern tectonism has occurred on the eastern margin of North America, including the Acadian Orogeny (375-335 Ma, Murphy and Keppie, 2005), Alleghenian Orogeny (325-260 Ma, Dallmeyer et al., 1986; Secor et al., 1986), rifting related to the opening of the central Atlantic Ocean with the intrusion of the Central Atlantic Magmatic Province ( 200 Ma, Labails et al., 2010; Marzoli et al., 2018), and the opening of the Gulf of Mexico ( 200 Ma, Bird et al., 2005).

Recent improvements in seismometer coverage, seismic tomographic inversion methodology, as well as methods for wave speed interpretation over the last few decades, have led to many new studies of the thermochemical state of the mantle lithosphere beneath the United States. For instance, some authors have interpreted the temperature of the mantle beneath the continental United States assuming a single composition, finding a $500^{\circ} \mathrm{C}$ variation in Moho temperature (Schutt et al., 2018) or mantle temperature in the shallow mantle (Goes and van der Lee, 2002). Perry et al. (2003) utilized a topographygravity inversion to derive a three-dimensional scaling relationship between seismic wave speed and density, which was subsequently applied to seismic models to estimate the temperature and chemical depletion beneath the cratonic United States. They found a maximum temperature perturbation of $\sim 500^{\circ} \mathrm{C}$ and maximum $\mathrm{Mg} \#(100 \times \mathrm{mol} . \mathrm{Mg} /(\mathrm{mol}$. $\mathrm{Mg}+$ mol. Fe)) variation of 2 at $150 \mathrm{~km}$ depth. Simmons et al. $(2009,2010)$ incorporated mineral properties and geodynamical observations to better constrain global mantle density structure by allowing their seismic inversion to use a three-dimensional 
scaling relationship between density and wave speed, and found a $\sim 600^{\circ} \mathrm{C}$ variation beneath North America at 100-175 km.

More recent work has taken an iterative, probabilistic approach to inverting seismic wave speed and composition using other geophysical data, e.g., topography and gravity (Kaban et al., 2014; Tesauro et al., 2014), finding even larger, $800^{\circ} \mathrm{C}$ maximum temperature differences at $100 \mathrm{~km}$ depth. Other authors have utilized thermodynamic calculations of mantle compositions to jointly invert for composition, making the entire inversion thermodynamic consistent (Khan et al., 2011), and resulting in a significantly lower $200^{\circ} \mathrm{C}$ maximum temperature variation at $100 \mathrm{~km}$. Similarly, Afonso et al. (2013a, 2013b, 2016) utilized probabilistic joint inversions to investigate the mantle thermochemical state in the western-central United States based on the forward-modeling of LitMOD (Afonso et al., 2008; Fullea et al., 2009). These studies integrated seismic delay times, gravity data, geoid height, topography, and heat flow and found a $>500^{\circ} \mathrm{C}$ difference at $55 \mathrm{~km}$ depth between the Rio Grande Rift and Proterozoic provinces east of the Rocky Mountain Front.

\section{Methodology}

Here we apply WISTFUL to the 60 and $80 \mathrm{~km}$ depth slices of MITPS_20 (Golos et al., 2020) (Figure 1). The MITPS_20 tomographic model is generated from a joint inversion of $\mathrm{P}, \mathrm{P}_{\mathrm{n}}$, and $\mathrm{S}$ body wave travel times as well as Rayleigh wave phase velocities at periods ranging from 5-290 s. Incorporating both body and surface wave data affords good vertical and lateral resolution within the crust and upper mantle for $V_{p}$ and $V_{s}$ (Golos et al., 2020). Combining $V_{p}$ and $V_{s}$ drastically improves the interpretation constraints of thermal and compositional variation compared to $V_{p}$ or $V_{s}$ alone (Lee, 2003; Afonso et al., 2013a). This improved vertical and horizontal resolution and the availability of jointly constrained $V_{p}$ and $V_{s}$ make MITPS_20 a prime model to utilize in order to investigate the compositional and thermal variations beneath the continental United States.

Checkerboard tests provide a qualitative diagnostic value of horizontal resolution, especially where resolution is poor (Lévěque et al., 1993; van der Hilst et al., 1993). We only interpret MITPS_20 in regions that recover recognizable structure in checkerboard tests, thus removing western Canada. We limit our investigation to the 60 and $80 \mathrm{~km}$ 
model depth slices, as they are the best resolved depths in the mantle (Golos et al., 2020). As MITPS_20 recovers $1.5^{\circ} \times 1.5^{\circ}$ checkerboards at 60 and $80 \mathrm{~km}$, we aim to interpret anomalies at least that size. Depth slices estimate wave speeds over thicknesses of $\pm \sim 10$ $\mathrm{km}$.

MITPS_20 solves for the relative variations in $V_{p}$ and $V_{s}\left(\delta V_{p}, \delta V_{s}\right)$. From synthetic data inversions, scaling parameters $\left(\alpha_{p}\right.$ and $\left.\alpha_{s}\right)$ are derived to compensate for the effects of inversion regularization to find the scaled relative variations in $V_{p}$ and $V_{s}$ :

$$
\begin{aligned}
& \delta V_{s_{\text {scaled }}}=\delta V_{s} \alpha_{s}, \\
& \delta V_{p_{\text {scaled }}}=\delta V_{p} \alpha_{p} .
\end{aligned}
$$

After scaling, the relative variations are converted to absolute $V_{S_{M I T P S}}$ and $\left(V_{p} / V_{S}\right)_{M I T P S}$ (Figure 9a, b) using

$$
\begin{gathered}
V_{s_{\text {MITPS }}}=\left(1+\delta V_{s_{\text {scaled }}}\right) V_{s_{\text {ref }}} \\
\left(V_{p} / V_{s}\right)_{\text {MITPS }}=\left(1+\frac{\delta V_{p_{\text {scaled }}}^{2}}{V_{s_{\text {ref }}}}-\frac{\delta V_{s_{\text {scaled }}^{2}}^{2} V_{p_{\text {ref }}}}{V_{s_{\text {ref }}^{2}}^{2}}\right)\left(V_{p} / V_{s}\right)_{\text {ref }},
\end{gathered}
$$

where $V_{p_{\text {ref }}}$ and $V_{s_{\text {ref }}}$ are from a modified version of the AK135 reference model (Kennett et al., 1995). As $V_{p_{\text {ref }}} / V_{s_{r e f}}$ for AK135 is greater than interpretable values obtained from WISTFUL (1.793 at $60 \mathrm{~km}$ compared to 1.73-1.77, Figure 2), we choose independent reference values, $\left(V_{p} / V_{s}\right)_{\text {ref }}(1.752$ at $60 \mathrm{~km}$ and 1.753 at $80 \mathrm{~km})$, constraining the absolute $V_{p} / V_{s}$ to fall within interpretable values.

To interpret these seismic wave speeds in terms of temperature, density, and composition, we utilize the "number within error" approach from WISTFUL. In this approach, pressure is calculated at each point in the depth slice assuming a crustal thickness from (Schmandt et al., 2015) with an average density of $2800 \mathrm{~kg} \mathrm{~m}^{-3}$ and an average mantle density of $3300 \mathrm{~kg} \mathrm{~m}^{-3}$. Using the calculated pressure at each grid point, we calculate the number of peridotites with $\mathrm{Mg} \#>85$ within $0.5 \%$ distance of the $V_{s}$ and $0.5 \%$ distance of $V_{p} / V_{s}$ for temperatures between 300 and $1600^{\circ} \mathrm{C} . \mathrm{Mg} \#$ (molar $\mathrm{Mg} /(\mathrm{Mg}+\mathrm{Fe}))$ is an estimate for the depletion of the mantle with more depleted samples having higher $\mathrm{Mg}$ \# due to the preference of $\mathrm{FeO}$ to partition into the melt (Hess, 1989). Peridotite xenolith compositions ranging from Mg\# 86-95 (Pearson et al., 2003), and most primitive mantle estimates range from Mg\# 89-90 (Jagoutz et al., 1979; 
McDonough and Sun, 1995; Workman and Hart, 2005). There is a correlation in Mg \# and $V_{p} / V_{s}$ of peridotites in the garnet-stability field where more depleted peridotites have a lower $V_{p} / V_{s}$ (Lee, 2003; Afonso et al., 2010). This correlation is weaker in the spinelstability field and at high temperatures due to the pronounced effect of anelasticity (Afonso et al., 2010). Another compositional sign of depletion or fertility is $\mathrm{Al}_{2} \mathrm{O}_{3}$ content in peridotite because melt extraction results in the depletion of $\mathrm{Al}_{2} \mathrm{O}_{3}$-rich phases like clinopyroxene, spinel, and garnet, leaving behind orthopyroxene and olivine (Kushiro, 2001; Lee et al., 2011). Unlike Mg\#, which has a strong effect on the shear modulus of all mantle minerals, changing the aluminum content of a peridotite has less determinate effect on its seismic wave speed, and thus A12O3 contents have larger uncertainty (and thereby relative error) in the WISTFUL fits. We utilize the calculated $0.5 \%$ root-mean square error for forward calculations in WISTFUL, as our uncertainty constraint because it is larger than the average uncertainty from MITPS_20 $\left(\sim 0.2 \%\right.$ in $V_{p}$ and $V_{s}$ based on bootstrapping analyses (Golos et al., 2020)).

The best-fit temperature and uncertainty are defined as the mean and standard deviation of a Gaussian distribution fit to the temperature-samples within error distribution. The best-fit composition or density and its uncertainty is defined as the mean and standard deviation at the best-fit temperature of all the peridotites, weighted by the inverse of the total misfit, $X$

$$
X=\sqrt{\left(\frac{\left.V_{S_{M I T P S}}-V_{S_{W I S T F U L}}\right)^{2}+\left(\frac{\left(V_{p} / V_{S}\right)_{M I T P S}-\left(V_{p} / V_{S}\right)_{W I S T F U L}}{V_{S_{M I T P S}}}\right)^{2}}{\left(V_{p} / V_{S}\right)_{M I T P S}}\right.}
$$

where $\left(V_{S_{M I T P S}},\left(V_{p} / V_{S}\right)_{M I T P S}\right)$ and $\left(V_{S_{\text {WISTFUL }}},\left(V_{p} / V_{S}\right)_{\text {WISTFUL }}\right)$ are the seismic wave speeds and ratios for MITPS_20 and the WISTFUL peridotites respectively.

Temperature, density, and composition estimates are only calculated for wave speeds that have at least 20 peridotite wave speeds within error. This procedure is repeated for every point in the seismic model, and in this way equivalent "temperature tomography" and "composition tomography" maps are generated. As WISTFUL weights compositional estimates by the inverse of the misfit for each composition averaged, a lower $V_{p} / V_{s}$ given the same $V_{s}$ will generally predict a more depleted composition (Figure 2). The magnitude of this effect varies depending on the temperature and absolute seismic wave speeds. 
In order to interpret mantle seismic wave speeds, one must correct for the anelastic behavior of olivine at high temperatures (Faul and Jackson, 2015). We choose to investigate two anelasticity models: the extended-Burgers model of Jackson and Faul (2010) hereafter referred to as JF2010 and the power-law formulation of Behn et al. (2009) hereafter referred to as B2009. (See Chapter Four for discussion concerning these anelasticities). We assume that olivine anelasticity applies to all minerals present. For anelastic corrections, we correct the dominant seismic period calculated from MITPS_20 (45 s for $60 \mathrm{~km}, 70 \mathrm{~s}$ for $80 \mathrm{~km}$ ). We choose a grain size of $1 \mathrm{~cm}$, in line with grain sizes for hot, annealed mantle (Van der Wal et al., 1993), old cratonic xenoliths (Baptiste and Tommasi, 2014; Pokhilenko et al., 2014), and Cenozoic xenoliths from the western United States (Li et al., 2008b). For the B2009 formulation, we choose an olivine water content of $50 \mathrm{H} / 10^{6} \mathrm{Si}\left(\sim 7 \mathrm{ppm} \mathrm{H}_{2} \mathrm{O}\right)$ to approximate dry mantle peridotite, in line with average olivine water contents observed in mantle xenoliths from the western continental United States (Grant et al., 2007; Li et al., 2008b) and globally (Demouchy and BolfanCasanova, 2016). At low-temperatures $\left(<800^{\circ} \mathrm{C}\right)$ where no anelasticity is predicted, both models produce the same results (Figure 2). The B2009 anelastic corrections changes the wave speed at $>900^{\circ} \mathrm{C}$ and results in an exponential $V_{s}-V_{p} / V_{s}$ slope as a function of temperature. The JF2010 anelasticity changes the predicted wave speeds at $\sim 800^{\circ} \mathrm{C}$, and results in a gentler, more linear slope in $V_{s}-V_{p} / V_{s}$ as a function of temperature. In all following figures, results with the B2009 anelasticity will be plotted on the left, while the JF2010 anelasticity will be plotted on the right.

\section{Results}

In this section, we will first discuss the model results of temperature and model uncertainty (Figure 3,4). We will then briefly discuss composition in terms of best-fit $\mathrm{Mg}$ \# (Figure 5) and $\mathrm{Al}_{2} \mathrm{O}_{3}$ content (Figure 6) as well as their respective uncertainties. We will lastly discuss best-fit density and uncertainty (Figure 7).

\section{Temperature}

As expected, we find the mantle beneath the Northern Cordillera United States to be hot relative to the cold, central and eastern United States (Figure 3). At $60 \mathrm{~km}$, temperatures range from $350-1300^{\circ} \mathrm{C}$ using B2009 and $350-1200^{\circ} \mathrm{C}$ for JF2010 (Figure 4 top). Mean $1 \sigma$ temperature uncertainty is $61^{\circ} \mathrm{C}$ for B2009 and $48^{\circ} \mathrm{C}$ for JF2010. At 80 
$\mathrm{km}$, temperatures range from $500-1400^{\circ} \mathrm{C}$ for $\mathrm{B} 2009$ and $500-1350^{\circ} \mathrm{C}$ for $\mathrm{JF} 2010$

(Figure 4 bottom). Mean $1 \sigma$ temperature uncertainty is $\sim 55^{\circ} \mathrm{C}$ for $\mathrm{B} 2009$ and $\sim 40^{\circ} \mathrm{C}$ for JF2010. At temperatures for which the anelasticities differ $\left(\mathrm{T}>800{ }^{\circ} \mathrm{C}\right)$, B2009 predicts on average $90^{\circ} \mathrm{C}$ hotter temperatures at $60 \mathrm{~km}$ and $100^{\circ} \mathrm{C}$ at $80 \mathrm{~km}$ compared to JF2010. The maximum predicted temperature difference is $150^{\circ} \mathrm{C}$ when $\mathrm{B} 2009$ predicts $1200^{\circ} \mathrm{C}$ and JF2010 predicts $1050^{\circ} \mathrm{C}$. Despite these differences, the structure of the temperature field is similar between the two models. High temperature anomalies tend to align with locations of Holocene volcanism in the western United States (triangles, Figure 3, orange bars, Figure 4, Venzke, 2013) and with alkaline and carbonatite rocks younger than $1 \mathrm{Gyr}$ (circles, Figure 3). This is expected as alkaline and carbonatite rocks derive from highpressure and/or volatile-rich mantle melting (Takahashi and Kushiro, 1983; Hess, 1989), often associated with intraplate volcanism due to rifting or plumes.

The cratonic United States west of the Grenville Front is cold, but not heterogeneous in its temperature structure $\left(350-850^{\circ} \mathrm{C}\right.$ at $60 \mathrm{~km}, 500-1000^{\circ} \mathrm{C}$ at $80 \mathrm{~km}$ based on B2009). The coldest temperatures at both 60 and $80 \mathrm{~km}$ depth are found in the Archean Superior Province $\left(350^{\circ} \mathrm{C}\right.$ at $60 \mathrm{~km}, 500{ }^{\circ} \mathrm{C}$ at $\left.80 \mathrm{~km}\right)$. The hottest predicted temperatures in the eastern interior correlate to regions with surface expressions of continental rifts like the Proterozoic Mid-Continent Rift (1,000 Ma, MCR, Van Schmus and Hinke, 1985; Van Schmus, 1992). More recent surface expressions of mid-to-late Cambrian rifting (550-500 Ma), such as the Oklahoma aulacogen (Lambert et al., 1988; Hanson et al., 2013; Brueseke et al., 2016), Rome Trough (Thomas, 2006), and Reelfoot Rift (Ervin and McGinnis, 1975), are also correlated with increased temperature anomalies, though the Reelfoot Rift anomaly may be related to more recent tectonism and hotspot volcanism associated with the Bermuda hotspot (Chu et al., 2013; Pollitz and Mooney, 2014).

The eastern United States south and west of the Grenville Front is uniformly hotter than the cratonic regions at $80 \mathrm{~km}\left(700-1200{ }^{\circ} \mathrm{C}, \mathrm{B} 2009\right)$. At $60 \mathrm{~km}$, the Atlantic coastal margin is hotter in three large $\left(>2^{\circ} \times 2^{\circ}\right)$ regions previously interpreted to have abnormal temperatures for the eastern United States ( $>900^{\circ} \mathrm{C}$, B2009): (1) the Central Appalachian Anomaly (CAA) below Virginia and West Virginia, (2) the North Appalachian Anomaly (NAA) below New York and New England, and (3) the 
Mississippi Embayment (ME). B2009 predicts temperatures for the Central Appalachian Anomaly up to $1000 \pm 100^{\circ} \mathrm{C}$ at $60 \mathrm{~km}$ and $1200 \pm 60^{\circ} \mathrm{C}$ at $80 \mathrm{~km}$ depth. This high temperature is supported by Eocene-aged ( 48 Ma) basaltic dike swarms in Virginia and West Virginia, which record P-T conditions of $1412 \pm 25^{\circ} \mathrm{C}, 2.32 \pm 0.31 \mathrm{GPa}, \sim 80 \mathrm{~km}$ depth (Mazza et al., 2014). The Central Appalachian Anomaly and the associated temperature anomaly have been hypothesized to result from asthenospheric upwelling driven by delamination (Mazza et al., 2014), edge-driven convection (Carrero Mustelier and Menke, 2021), or thermal remnants of Atlantic rifting and the Central Atlantic Magmatic Province (Marzoli et al., 2018).

Similarly, B2009 predicts temperatures for the North Appalachian Anomaly up to $950^{\circ} \mathrm{C}$ at $60 \mathrm{~km}$ and $1250^{\circ} \mathrm{C}$ at $80 \mathrm{~km}$ depth. The anomaly is significantly larger at 80 km. The North Appalachian Anomaly has been interpreted by to be the result of an upwelling mantle due to the slow wave speeds and a decrease in the strength of mantle anisotropy (Levin et al., 2018; Yang and Gao, 2018). The upwelling should be relatively young due to the lack of observed surface volcanism (Levin et al., 2018), but could explain the $1 \mathrm{~mm} \mathrm{yr}^{-1}$ uplift of the Adirondack Mountains (Isachsen, 1975; Yang and Gao, 2018). Yang and Gao (2018) hypothesized the source of this anomaly is related to or caused by the Great Meteor Hotspot, which traversed from Southeastern Canada to New England (Sleep, 1990), formed the White Mountains in New Hampshire ( 130-100 Ma, Heaman and Kjarsgaard, 2000), and more recently formed the New England Sea Mounts (100-80 Ma, Duncan, 1984).

Lastly, the Mississippi Embayment is a large region of subsidence beginning the late Cretaceous (ca. 90 Ma, Cushing et al., 1964; Cox and Van Arsdale, 2002). The mantle beneath this region shows distinctly hotter temperatures at $80 \mathrm{~km}$ depth $\left(\sim 1100^{\circ} \mathrm{C}\right.$, B2009) than the rest of the eastern United States. Highest temperatures in the Mississippi Embayment are located below Louisiana (up to $1200^{\circ} \mathrm{C}$, B2009). Surprisingly, at $60 \mathrm{~km}$ depth, the temperatures are similar to the cratonic interior $\left(500-800^{\circ} \mathrm{C}, \mathrm{B} 2009\right)$ with the exception of the southern fringe of Texas and Florida. Some authors explain the subsidence as renewed extension related to the opening of the Gulf of Mexico (e.g., Braile et al., 1984), but recent work has hypothesized that the embayment could have been related to an increased heat flux from the Bermuda hotspot below Mississippi at the 
beginning of the subsidence (Morgan, 1983; Cox and Van Arsdale, 2002; Chu et al., 2013). This increased flux along with the beginning of seafloor spreading in the Gulf of Mexico ( 150 Ma, Burke, 1988) could explain these high temperatures.

To the west of the Rocky Mountain Front, the temperature is significantly increased compared to the eastern United States (mostly $>1000^{\circ} \mathrm{C}$ at $60 \mathrm{~km}$ and $>1200^{\circ} \mathrm{C}$ at $80 \mathrm{~km}, \mathrm{~B} 2009)$. The B2009 estimates of $>1200^{\circ} \mathrm{C}$ temperatures in the western United States at $80 \mathrm{~km}$ agree with lithosphere-asthenosphere $<80 \mathrm{~km}$ boundary depths in the western continental United States interpreted from receiver function and global seismic tomographic studies (Yuan and Romanowicz, 2010; Hopper and Fischer, 2018; Liu and Gao, 2018; Steinberger and Becker, 2018).

The cold regions $\left(<700^{\circ} \mathrm{C}\right)$ in the west include the mantle beneath the eastern Wyoming Craton, the Isabella Anomaly in California, and southeastern Washington and Idaho. At $80 \mathrm{~km}$, the mantle below the eastern Wyoming Craton retains a colder temperature unlike the western, likely due to the western portion having been modified by the Yellowstone hostpot and the Laramide orogeny (Wu et al., 2014; Dave and Li, 2016). The cold temperatures beneath the Sierra Nevadas could be explained by either an overthickened or delaminating eclogitic lower arc crustal root (Ducea and Saleeby, 1998) or a remnant, unsubducted portion of the Farallon slab (Wang et al., 2013). The higher than regional $V_{s}$ and lower $V_{p} / V_{s}$ in southeastern Washington and Idaho, which result in lower temperatures, has been hypothesized to be a remnant slab (Schmandt and Humphreys, 2011). The lower temperatures could also be similar to the colder anomaly under the Wyoming craton, relatively unaffected shallow mantle as there is no recent volcanism in that region (Figure 3).

Conversely, the regions that are predicted to be hottest $\left(>1200{ }^{\circ} \mathrm{C}\right.$ at $\left.60 \mathrm{~km}\right)$ are associated with recent volcanism or rifting like the Rio Grande Rift (Olsen et al., 1987), Yellowstone/the Snake River Plain, the Cascades Range and related backarcs, including Oregon's High Lava Plains. The Basin and Range is colder at $60 \mathrm{~km}$ depth than areas with Holocene volcanism, but has similar temperatures at $80 \mathrm{~km}$ depth $\left(900-1000^{\circ} \mathrm{C}\right.$ at $60 \mathrm{~km}, \sim 1200^{\circ} \mathrm{C}$ at $80 \mathrm{~km}, \mathrm{~B} 2009$ ) in line with the absence of Holocene volcanism.

\section{Composition and Density}


Along with predicting temperature, WISTFUL also predicts the composition and density. Best-fit Mg \# ranges from 87.5-92.3 for B2009 (Figure 5) at $60 \mathrm{~km}$ with a mean of 90.3 and a mean $1 \sigma$ uncertainty of 1 . At $80 \mathrm{~km}, \mathrm{~B} 2009$ predicts a $\mathrm{Mg} \#$ range 87.692.5 with a mean of 90.3 and a mean $1 \sigma$ uncertainty of 0.9 . JF2010 tends to predict slightly more depleted compositions, most notably in the western region. At both 60 and $80 \mathrm{~km}, \mathrm{~J} 2010$ predicts a range of 88.6-92.5 with a mean of 90.6 and a mean $1 \sigma$ uncertainty of 0.9 . Both models predict the most depleted values at the core of cratonic regions. The mantle beneath the Mid-Continent Rift shows slightly enriched values relative to the cratonic cores, potentially due to trapped melt refertilizing the mantle lithosphere in line with a heavily underplated lower crust (Hutchinson et al., 1990).

Similar compositional trends are observed in $\mathrm{Al}_{2} \mathrm{O}_{3}$ (Figure 6). Best-fit $\mathrm{Al}_{2} \mathrm{O}_{3}$ ranges from 0.7-2.8 wt. \% for B2009 (Figure 5) at $60 \mathrm{~km}$ with a mean of $1.9 \mathrm{wt}$ \% and a mean $1 \sigma$ uncertainty of 1.1 wt. $\%$. At $80 \mathrm{~km}, \mathrm{Al}_{2} \mathrm{O}_{3}$ ranges $1.1-3.0$ wt. \% with a mean of $2.0 \mathrm{wt} . \%$ and a mean $1 \sigma$ uncertainty of $1.1 \mathrm{wt} . \%$. JF2010 tends to predict slightly more depleted compositions, most notably in the western region. At $60 \mathrm{~km}, \mathrm{~J} 2010$ predicts a range of 1-2.8 wt. \% with a mean of $1.87 \mathrm{wt}$ \% and a mean $1 \sigma$ uncertainty of $1.0 \mathrm{wt} . \%$. At $80 \mathrm{~km}, \mathrm{Al}_{2} \mathrm{O}_{3}$ ranges $1.1-2.9$ wt. $\%$ with a mean of 1.8 wt. $\%$ and a mean $1 \sigma$ uncertainty of 1.1 wt. \%. Regions with the most enriched compositions in $\mathrm{Mg} \#(<88.5)$, most depleted in $\mathrm{Al}_{2} \mathrm{O}_{3}(<1 \mathrm{wt} . \%)$, and high uncertainty at $60 \mathrm{~km}$ could be due to the presence of melt, as WISTFUL does not account for in its forward calculations of seismic wave speed and fits are often based on fewer, more anomalous compositions (see Discussion).

At $60 \mathrm{~km}$, density ranges from $3230 \mathrm{~kg} \mathrm{~m}^{-3}$ in the western United States to 3340 $\mathrm{kg} \mathrm{m}^{-3}$ in the eastern United States with a mean of $3310 \mathrm{~kg} \mathrm{~m}^{-3}$ and a mean $1 \sigma$ uncertainty of $20 \mathrm{~kg} \mathrm{~m}^{-3}$ for both anelasticity models (Figure 7). At $80 \mathrm{~km}$, the lower bound changes to $3240 \mathrm{~kg} \mathrm{~m}^{-3}$ for B2009 and $3250 \mathrm{~kg} \mathrm{~m}^{-3}$ for JF2010, with the other numbers remaining the same. The ranges and averages are similar since B2009 predicts both hotter temperatures and more enriched compositions, the effects of which counteract each other.

\section{Model Validation}

We compare the model results with estimates of temperature and composition from xenoliths, as well as melting P-T estimates calculated from primary magmas, to 
validate our methodology and choice of anelastic correction. The benefit of comparison to well-studied young ( $<10 \mathrm{Ma})$ xenoliths is that we can constrain both temperature and composition. Another avenue for validation would be to compare our model results with surface heat flow, but because surface heat flow is controlled more by crustal heat production and upper crustal hydrothermal processes than variations in mantle heat flux (Chapman, 1986; Mareschal and Jaupart, 2013), related uncertainties are too large for any validation purposes.

We compiled 14 xenolith localities that have erupted within the last $10 \mathrm{Myr}$ (black squares, Figures 5,6), each with at least 4 xenolith bulk compositions that have $\mathrm{Mg} \#>0.85$ and $<2$ wt $\% \mathrm{H}_{2} \mathrm{O}$ to avoid averaging xenoliths that have been heavily refertilized or altered before/during eruptive processes (Kudo et al., 1972; Smith and Levy, 1976; Frey and Prinz, 1978; Smith, 1979, 2000; Ehrenberg, 1979; Aoki, 1981; Wilshire et al., 1988; Riter and Smith, 1996; Smith and Alexis Riter, 1997; Smith et al., 1999; Porreca et al., 2006; Li et al., 2008b; Luffi et al., 2009; Byerly and Lassiter, 2012; Chin et al., 2012; Marshall et al., 2017, 2018). We take the average xenolith composition to reflect the mantle composition beneath that xenolith locality and the related uncertainty to be the standard deviation. To compare these observations with our model results, we average the best-fit compositions of all model results within $0.5^{\circ}$ arc-distance from the locality. We estimate the uncertainty in the model to be the maximum of the average uncertainty or the standard deviation of the averaged values. Spinel xenolith compositions are compared with the estimated 60-km composition (blue squares, Figure 8), while deeper garnet xenoliths are compared with the 80-km composition (green square, Figure 8). B2009 predicts mantle Mg \# well, while JF2010 tends to predict slightly more depleted compositions in $\mathrm{Mg} \#$, though most localities are within error (9 of 14 localities). $\mathrm{Al}_{2} \mathrm{O}_{3}$ predicted by both anelasticity models agrees within error, though this is caused by the combination of the large $\mathrm{Al}_{2} \mathrm{O}_{3}$ uncertainties from WISTFUL, as well as the large $\mathrm{Al}_{2} \mathrm{O}_{3}$ variability measured at the xenolith localities.

In addition to composition, geochemical estimates of mantle temperature are commonly calculated in the western United States based on: (1) xenolith thermobarometry (squares, Figure 9) and (2) primary magma thermobarometry (triangles, Figure 9). Mantle xenolith thermobarometry (e.g., Brey and Köhler, 1990) relies on using 
the relative mineral composition to calculate the $\mathrm{P}-\mathrm{T}$ conditions at which those mineral compositions are in equilibrium. We compiled 13 localities with at least one temperature (or P-T) estimate (Kil and Wendlandt, 2004; Porreca et al., 2006; Li et al., 2008b; Byerly and Lassiter, 2012; Chin et al., 2012; Marshall et al., 2018). Because no reliable spinel barometer exists, most spinel thermometry is calculated at $1.5 \mathrm{GPa}$ as spinel-bearing xenoliths could vary anywhere in the spinel stability field ( 0.7-2 GPa). Here, we compare all spinel thermometers with our $60-\mathrm{km}$ estimate $(\sim 1.7 \mathrm{GPa})$ and acknowledge that our model results should be equal or exceed this thermometry as the spinel xenoliths could be sampling a shallower mantle. More reliable garnet field barometers exist, and we compare all temperatures garnet field thermometry within $0.3 \mathrm{GPa}$ of the $80 \mathrm{~km}$ pressure ( 2.4 GPa). To compare these temperatures with our model results, we average the best-fit temperatures from all model points within $0.5^{\circ}$ arc-distance from the locality. We consider the temperature error to be the maximum between the average temperature uncertainty and the standard deviation of averaged temperatures. We consider the temperature error in a xenolith locality to be the maximum of the standard deviation of the calculated temperatures and published thermometer uncertainty.

B2009 agrees within error for 4 out of 11 spinel xenolith localities, overpredicting temperature by $\sim 125^{\circ} \mathrm{C}$ for 5 xenolith localities (blue squares, Figure 9 left). JF2010 fits xenolith thermobarometry slightly better, fitting 5 out of 11 xenolith locality temperatures (blue squares, Figure 9 right). For two spinel-bearing xenolith localities and one garnet bearing xenolith locality, JF2010 predicts $100-200^{\circ} \mathrm{C}$ colder temperatures than recorded by the xenoliths. Green Knobs in New Mexico and Vulcan's Throne in Arizona predict temperatures much lower $\left(750-775^{\circ} \mathrm{C}\right)$ than either model predicts using either both anelasticities at $60 \mathrm{~km}$. These are anomalously low temperatures for the region as well; there is recent ( $<1 \mathrm{Myr}$ ) magmatism in the Rio Grande Rift as well as the nearby presence of granulite facies lower crustal xenoliths (Cipar et al., 2020). Likely these spinel xenoliths are sampled from significantly shallower mantle near the regional Moho $(\sim 30$ $\mathrm{km})$.

B2009 agrees within error of 1 out of the 2 garnet xenolith localities, while JF2010 predicts neither within error. The most anomalous garnet-bearing xenolith locality (Big Creek, Sierra Nevadas, California) predicts cold temperatures for $80 \mathrm{~km}$ 
$\left(\sim 750^{\circ} \mathrm{C}\right)$, in stark disagreement with both models. It is unlikely that these xenoliths were not in equilibrium at high temperatures $\left(\sim 750^{\circ} \mathrm{C}\right)$. Instead, the xenoliths may record a previous thermochemical state given that they erupted in an $8 \mathrm{Myr}$ old diatreme (Chin et $a l .$, 2012). Thus, this temperature discrepancy could be interpreted as a change in shallow mantle temperature since the diatreme eruption. These potential changes in mantle thermal state might also reflect changes in the chemical state if melt was advected and reacted with the mantle. Only in the most recent eruptions should there be a strong correlation between model results and xenolith thermochemical state.

Another temperature comparison for the two anelasticities is primary magma thermobarometry, which uses compositions of primary magmas and primary melt inclusions to calculate the pressure and temperature at which a melt was last in equilibrium with the mantle (c.f. Till, 2017). Here we use temperatures estimated from different thermometers that incorporate both tholeiitic and alkaline samples (Leeman $e t$ al., 2005; Ruscitto et al., 2010; Till et al., 2013; Plank and Forsyth, 2016; Till, 2017). We also include recalculated temperature estimates from high-Mg andesites from Mt. Shasta (Baker et al., 1994; Grove et al., 2002) using the thermometer of Mitchell and Grove (2015) at $1.5 \mathrm{GPa}$ (Shasta, triangle, Figure 9). Due to the importance of measuring $\mathrm{H}_{2} \mathrm{O}$ and $\mathrm{CO}_{2}$ on the liquidus temperature and pressure, we only use estimates made with measured $\mathrm{H}_{2} \mathrm{O}$ based on melt inclusions. As volatiles rapidly diffuse from melt inclusions (Gaetani et al., 2012; Bucholz et al., 2013), the temperature estimates for hydrous melting using these water contents are an upper bound (Till, 2017), but generally agree with estimates from regional tholeiitic primary magmas. To compare regions with different numbers of estimates, we binned magmatic temperature estimates into $0.5^{\circ} \mathrm{x} 0.5^{\circ}$ regions for pressure estimates within $0.3 \mathrm{GPa}$ of the regional pressures at 60 and $80 \mathrm{~km}$. We take the uncertainty in the magmatic estimates to be the maximum between the reported uncertainty or the standard deviation of averaged estimates. This binned temperature estimate is compared with the mean temperature of all WISTFUL predictions at either 60 and $80 \mathrm{~km}$ within $0.5^{\circ}$ arc-distance. We consider the model temperature error to be the maximum between the average temperature uncertainty and the standard deviation of averaged temperatures. 
Both anelasticities models significantly underpredict magmatic temperatures estimates (triangles, Figure 9). On average, B2009 underpredict magmatic temperatures by $230^{\circ} \mathrm{C}$ at $60 \mathrm{~km}$ and $75^{\circ} \mathrm{C}$ at $80 \mathrm{~km}$ (triangles, Figure 9 left). JF2010 underpredicts temperatures by $360^{\circ} \mathrm{C}$ at $60 \mathrm{~km}$ and $170^{\circ} \mathrm{C}$ at $80 \mathrm{~km}$ (triangles, Figure 9 right). There are multiple hypotheses for this stark disagreement: (1) scale of the temperature estimates, (2) error in the anelastic correction of seismic wave speeds, (3) error in the magmatic thermobarometers, or (4) error in the forward calculation of mantle seismic wave speeds, potentially due to the exclusion of melt or hydrous phases. The following paragraphs discuss these possibilities.

The first reason for the systematic difference in model temperature and magmatic temperature is the scale difference between the temperature estimates. Magmatic temperature estimates sample the temperature at which the melt was in equilibrium with the mantle and may only represent small regions of the mantle, especially if melt is focused (e.g., Kelemen and Dick, 1995) or escapes the mantle on short ( 10 kyr) timescales (Feineman and DePaolo, 2003). Conversely, seismic tomographic inversions such as MITPS_20 are limited to resolving seismic anomalies greater than roughly $1.5^{\circ} \times 1.5^{\circ}$ with vertical resolution on the order of $10 \mathrm{~km}$ (Golos et al., 2020). Thus, smallscale seismic anomalies due to thermal upwellings or melt, but that is not pervasive throughout a grid cell, can be smeared or not sensed. Furthermore, seismic inversions smooth their wave speeds in order to stabilize the inversion, though MITPS_20 corrects for some of this effect (see Methodology). Subduction zones will be especially difficult to image due to any smearing of the colder subducting lithosphere, which will increase seismic wave speed, decreasing the temperature estimate. The fact that the both $80-\mathrm{km}$ temperatures agree better with magmatic estimates may suggest that at lithospheric depths, vertical smearing decreases seismic wave speeds as it samples from starkly colder mantle from shallower depths along a steep geotherm. Regional, high-resolution seismic studies using multiple methodologies are necessary to understand these effects. Comparison between these results and WISTFUL forward predictions could highlight previously unseen strengths and weaknesses of each methodology.

A second reason for the temperature discrepancy could be error in anelastic corrections of seismic wave speed. Anelasticity experiments are difficult with different 
models and experiments giving different results and sensitivities (Faul and Jackson, 2015; Karato and Park, 2018). Although B2009 produces better fits with compositions and temperatures, the power-law formulation of anelasticity does not fit experimental data well at low quality factors (high temperatures or melt present) (Jackson and Faul, 2010). Certain parameters in the both anelasticities are relatively unconstrained, like the activation volume (Jackson and Faul, 2010; Faul and Jackson, 2015). Other comparisons of high-quality seismic experiments and forward calculations of peridotite seismic wave speeds require altering the relaxation peak frequencies (Ma et al., 2020). Furthermore, the effect of water content on anelasticity is currently under debate (Aizawa et al., 2008; Cline et al., 2018; Karato and Park, 2018). Regardless, as we assumed relatively dry water contents for B2009, increasing the water content further decreases $V_{s}$, thus shifting all forward calculations for B2009 above $900^{\circ} \mathrm{C}$ to the left in Figure 2. Thus, assuming an increased water content would have our methodology predict colder temperatures for the same model. Similarly, while grain size is an important parameter for anelasticities as well, especially at high temperatures (Faul and Jackson, 2005; Behn et al., 2009), we have assumed a reasonable grain size near the upper bound observed in xenoliths. Any grain size reduction increases anelastic effects, thus reducing the modelled temperature. Therefore, variable grain size and its effect on anelasticity cannot help the temperature discrepancy discussed here. Oxidation has been found to increase dissipation (Cline et $a l ., 2018)$. We do not incorporate this effect, which would reduce our temperatures in arc settings as arc mantle is more oxidized (Kelley and Cottrell, 2012). On the other hand, as long as melt and fluids are focused, the oxidation would not decrease large-scale seismic wave speed as only a small portion of the mantle would become oxidized. Finally, we utilize the assumption that anelasticities calculated from experiments on pure olivine apply to polymineralic peridotite assemblages. While experiments with similar results have been conducted on a harzburgitic assemblage (olivine+orthopyroxene) (Sundberg and Cooper, 2010), more experiments are necessary to understand whether differences in mineral assemblage change the anelastic effect at different temperatures, pressures, and seismic periods.

The uncertainties in the pressure or temperature predicted by the magmatic thermobarometers cannot explain the observed temperature discrepancy. While water 
content can drastically reduce the peridotite solidus, tholeiitic magmas are observed in the western United States. Melting experiments on dry peridotite compositions require temperatures $>1300{ }^{\circ} \mathrm{C}$ at $60 \mathrm{~km}$ depth, temperatures even the B2009 anelasticity rarely predicts within uncertainty (Hirschmann, 2000). Given the existence of Holocene age tholeiitic magmas, the reported uncertainty in magmatic thermobarometry $\left(11-43^{\circ} \mathrm{C}\right.$, 0.1-0.4 GPa) cannot explain the temperature discrepancy present at $60 \mathrm{~km}$.

Miscalculation in the forward calculation of seismic wave speeds in WISTFUL is also unlikely to explain the temperature estimate discrepancy. As we incorporate expected non-systematic uncertainty from our forward calculations into the error allowed for fitting and utilize current experimental moduli for most mineral endmembers, the only systematic error from this could be due to a difference in mixing assumptions, e.g. anisotropy. WISTFUL calculates the isotropic wave speeds, so comparing with the fast direction wave speeds would produce colder than realistic temperature estimates. As MITPS_20 inverts isotropic wave speed from combination of teleseismic body waves and surface wave arrival times, we believe a systematic increase in recovered wave speed due to anisotropy beneath all regions with magmatic temperature estimates unlikely.

Compositionally, we do not include the effect of melt and hydrous phases. The addition of melt and/or hydrous phases in the forward calculation of seismic wave speeds would decrease the predicted temperature. Melt strongly reduces $V_{s}$ (e.g., Hammond and Humphreys, 2000), but the exact wave speed reduction is heavily dependent on the melt content and the melt connectivity (Zhu et al., 2011). Similarly, pargasitic amphibole, $\left(\mathrm{NaCa}_{2}\left(\mathrm{Mg}_{4} \mathrm{Al}\right)\left(\mathrm{Si}_{6} \mathrm{Al}_{2}\right) \mathrm{O}_{22}(\mathrm{OH})_{2}\right)$, the most common hydrous phase predicted for the shallow mantle (Dawson and Smith, 1982), has a $V_{s}$ of $3.85 \mathrm{~km} \mathrm{~s}^{-1}$ and a $V_{p} / V_{s}$ of 1.83 at $60 \mathrm{~km}$ pressure and $1200{ }^{\circ} \mathrm{C}$ using B2009 and moduli from Abers and Hacker (2016). At the same conditions, diopside has a $V_{s}$ of $4.35 \mathrm{~km} \mathrm{~s}^{-1}$ and a $V_{p} / V_{s}$ of 1.78 . Replacing any clinopyroxene at the same temperature with pargasite would decrease $V_{s}$ and increase $V_{p} / V_{s}$ in forward calculations (shifting all forward calculations to the upper left in Figure 2 ). Therefore, the addition of melt and/or hydrous phases would decrease the predicted temperature for the same seismic wave speed. Despite amphibole dikes and peridotites being hypothesized as a significant source of volatiles for alkaline and ocean-island basalts (Harry and Leeman, 1995; Pilet et al., 2011), the volume required to have a 
geochemical impact is unlikely to make a seismically noticeable fraction of the shallow mantle.

In summary, we find that the xenolith compositional agreements with B2009, its prediction of greater or equal temperature to spinel-bearing xenoliths, and better fitting temperatures compared to magmatic estimates supports that the B2009 anelastic predictions over those from JF2010. The systematic difference between our best-fit temperature estimates with magmatic temperature estimates can only be explained by a difference in the scale of the estimates and/or errors in anelastic corrections. Further experimental work on anelasticity is required to better interpret high temperature mantle regions like the western United States.

\section{Density and Stability of Cratonic Roots}

Based on the temperature and density predicted by our model, we have the unique opportunity to investigate the relative importance of compositional and thermal buoyancy. For this goal, we use a dimensionless parameter, B

$$
B=\frac{\Delta \rho_{c}}{\rho \alpha \Delta T}
$$

where $\Delta \rho_{c}$ is the density variation attributed to compositional heterogeneity, $\rho$ is the reference density of the mantle at the same pressure, $\alpha$ is the coefficient of a thermal expansivity (Shapiro et al., 1999b) assumed to be $3.5 \times 10^{-5} \mathrm{~K}^{-1}$ (Afonso et al., 2005). Negative B values imply negative compositional buoyancy. A B value near 0 implies that no compositional buoyancy exists. A B value of 1 implies that the compositional and thermal effects are equal, allowing perpetual lithospheric stability. A B value much greater than 1 implies that the compositional buoyancy is greater than thermal effects.

We calculate this parameter by parsing the compositional effect of densities through comparison of best-fit temperatures and densities for the mantle beneath the United States. We take $\Delta T$ to be difference of the best-fit observed temperature and the average observed temperature of the Basin and Range for the anelastic model and depth. We use the average Basin and Range as a reference point for this calculation as it is a warm, but mostly amagmatic region that is likely be in isostatic equilibrium at these depths. We only calculate $\mathrm{B}$ for points at least $100^{\circ} \mathrm{C}$ colder than the average observed temperature for that anelasticity and depth to avoid the denominator being too small. 
Because our methodology fits both temperature and density, we can calculate $\Delta \rho_{c}$ as the difference in best-fit densities corrected for the thermal difference:

$$
\Delta \rho_{c}=\rho_{B R}(1-\alpha \Delta T)-\rho_{o b s}
$$

where $\rho_{B R}$ is the average density of the Basin and Range for each model and depth and $\rho_{o b s}$ is the best-fit observed density value at each grid point.

B values range from $-2.1-1.6$ at $60 \mathrm{~km}$, with a non-negative mean of 0.15 at 60 km (Figure 10). Green regions in Figure 10 represent areas that have no or negative compositional buoyancy. Relative to $60 \mathrm{~km}$, compositional buoyancy increases at $80 \mathrm{~km}$ due to the more depleted composition, resulting in B values from $-1.36-0.62$ with a nonnegative mean of 0.28 . For JF2010, B values range from $-2.4-1.2$, with a nonnegative mean of 0.14 at $60 \mathrm{~km}$, and B values from $-0.8-0.94$ with a nonnegative mean of 0.22 at $80 \mathrm{~km}$. The cratons in the eastern United States are always less than 1 at both 60 and $80 \mathrm{~km}$, showing that the density increase due to cooling is not fully counteracted by chemical depletion. This result agrees with previous estimates from seismology (Forte et al., 1995), long-wavelength geoid (Shapiro et al., 1999a), gravity (Kaban et al., 2003), geochemical density estimates (Schutt and Lesher, 2006), and numerical thermal models (Eaton and Claire Perry, 2013) that B for cratonic roots is typically a positive value less than 1 . Under the cratonic regions at $80 \mathrm{~km}, \mathrm{~B} 2009$ predicts $\Delta \rho_{c} \approx 20 \mathrm{~kg} \mathrm{~m}^{-3}$.

Foundering of unstable lithosphere, or delamination, can occur in two ways: (1) basal tractions due to horizontal density gradients, and (2) Rayleigh-Taylor-type instabilities due to perturbation of the lithosphere-asthenosphere boundary. Basal tractions are likely high in the mantle beneath the Rocky Mountain front, where density gradients by our methodology are predicted to be high (Figure 7). To investigate the effect of these basal tractions on the edge of cratons, models are necessary. Shapiro et al., (1999b) found that the deep lithosphere was stable to basal tractions as long as there existed compositional buoyancy and high mantle activation energies ( $500 \mathrm{~kJ} / \mathrm{mol})$ similar to those predicted for dry olivine and dislocation creep (Hirth and Kohlstedt, 2003). Further models are necessary to better constrain the model space for lithospheric 
stability as results are also dependent on the buoyancy of the lithosphere, model boundary conditions, and model geometry.

Rayleigh-Taylor-type instability can be investigated analytically. Houseman and Molnar (1997) derived the time, $t$, for a Rayleigh-Taylor instability to form from an initial perturbation for a non-Newtonian fluid is:

$$
t=\frac{\left(\frac{D}{g \Delta \rho h}\right)^{n}\left(\frac{n}{C}\right)^{n}\left(\frac{Z_{0}}{h}\right)^{1-n}}{n-1}
$$

where $n$ is the stress exponent of the material, $\Delta \rho$ is the density difference between the layers, $g$ is the gravitational acceleration $\left(9.8 \mathrm{~m} \mathrm{~s}^{-2}\right), \mathrm{C}$ is the growth rate (numerically found to be maximally $\sim 1$ ), $h$ is the layer thickness, $Z_{0}$ is the initial perturbation thickness, and $D$ is a rheologic coefficient. We assume that

$$
\Delta \rho=\rho_{0}\left(1-\alpha T_{p o t}\right),-\left(\rho_{0}-\Delta \rho_{c}\right)(1-\alpha T)
$$

where we $T_{p o t}$ is the mantle potential temperature $\left(1350^{\circ} \mathrm{C}\right), \rho_{0}$ is the ambient temperature mantle density $\left(3440 \mathrm{~kg} \mathrm{~m}^{-3}\right) . D$ is calculated from the flow-law parameters as

$$
D=\frac{A^{-\frac{1}{n}} \exp \frac{Q+P V}{n R T}}{2}
$$

where $A$ is the flow-law prefactor, $Q$ is the activation energy, $V$ is the activation volume, $R$ is the gas constant $\left(8.314 \mathrm{~J} \mathrm{~mol}^{-1}\right), P$ is the pressure, and T the temperature in Kelvin. For all following calculations we take rheologic parameters for dry dislocation creep of olivine ( $n=3.5, Q=530 \mathrm{~kJ} / \mathrm{mol}, \mathrm{V}=10 \mathrm{~m}^{-3} \mathrm{~mol}^{-1}, A=1.1 \times 10^{16} \mathrm{~Pa}^{-3.5} \mathrm{~s}^{-1}$ ) (Hirth and Kohlstedt, 2003).

Instability times range from < 1 Myr to $>1$ Gyr depending on the layer thicknesses, average temperatures, compositional buoyancy, and initial perturbation ( 1 or 10\%) (Figure 11). The main factors that control the timescale at which lithospheric Rayleigh-Taylor instabilities form are: (1) the thickness of the layer, $h$, (2) the initial perturbation, $Z_{0}$, (3) the average lithospheric temperature, $T$, (4) the lithospheric compositional buoyancy, $\Delta \rho_{c}$. The first two are inverse proportional to the instability timescale. Warmer temperatures promote faster instability times due to the temperaturedependence of mantle viscosity. If the layer is too cold $\left(<800^{\circ} \mathrm{C}\right)$, no layer will be able to 
viscously delaminate in a geologically feasible time (>1 Gyr), no matter how dense or thick the layer is. Temperature also influences density, and layers will be density stable as temperature nears the mantle potential temperature, resulting in an upper bound on temperature that is allowable for instabilities to form. Compositional buoyancy reduces this upper bound (Figure 11b, d).

As the unstable layers must be hotter than $800^{\circ} \mathrm{C}$ on average to delaminate in a geologically reasonable time, the maximum unstable layer thickness is best calculated as the difference in depth between the $800^{\circ} \mathrm{C}$ isotherm and either the lithosphereasthenosphere boundary $\left(1350^{\circ} \mathrm{C}\right)$ or the temperature where negativity buoyancy begins $\left(\sim 1190^{\circ} \mathrm{C}\right.$ for $\left.\Delta \rho_{c}=20 \mathrm{~kg} \mathrm{~m}^{-3}\right)$. Moho temperatures at $\sim 30 \mathrm{~km}$ depth in the western US are often greater than $800^{\circ} \mathrm{C}$ (Schutt et al., 2018). B2009 finds the east to be $\sim 800^{\circ} \mathrm{C}$ at 80 $\mathrm{km}$ depth. The lithospheric-asthenosphere boundary from seismic and geophysical studies indicate $\sim 50-80 \mathrm{~km}$ in the west and $\sim 200-250 \mathrm{~km}$ in the east (Steinberger and Becker, 2018). Thus, the maximum unstable layer thicknesses range from $20-50 \mathrm{~km}$ thick for the west and be 120-170 km for the east), with an average layer temperature of 1000$1200^{\circ} \mathrm{C}$ (black boxes, Figure 11).

From this analysis, three conclusions arise. First, young, hot lithosphere that has no compositional buoyancy can delaminate on the order of 10-100 Myr as long as there exists initial thickness perturbations of $10 \%$ (Figure 11a). This suggests that the lithosphere quickly flattens after formation. Second, old, thick lithosphere must be relatively flat ( 1\% thickness perturbations), since even with pervasive compositional buoyancy, instability times can be on the order of $10 \mathrm{Myr}$ (Figure 11d). This may suggest that basal tractions between horizontal density gradients as those observed at the Rocky Mountain Front in our density predictions could be most important for lithospheric delamination. Lastly, deep cratonic lithosphere must be chemically buoyant to exist over billions of years, as layers with no chemical buoyancy and $1 \%$ thickness perturbations become can become unstable in less than 1 Gyr (Figure 11a).

To constrain the maximum lithospheric thickness that an unstable layer can achieve before foundering occurs, we equate the timescale for the initiation of a Rayleigh-Taylor type instability (Eq. 8) to the timescale to form that layer assuming a half-space cooling model (Turcotte and Schubert, 2014): 


$$
t=\frac{h^{2}}{4 \kappa}\left(\frac{1}{e r f^{-1}\left(T_{\text {bot }} / T_{\text {pot }}\right)-e r f^{-1}\left(T_{\text {top }} / T_{\text {pot }}\right)}\right)^{2},
$$

where $\kappa$ is the thermal diffusivity of $10^{-6} \mathrm{~m}^{2} \mathrm{~s}^{-1}, T_{p o t}$ is the mantle potential temperature $\left(1350^{\circ} \mathrm{C}\right), T_{b o t}$ is the temperature at which there exists $<2 \mathrm{~kg} \mathrm{~m}^{-3}$ buoyancy, and $T_{\text {top }}$ is the minimal layer temperature. We assume an initial perturbation $1 \%$ of the layer thickness. We assume that the rheology and density of the layer is equal to that calculated at its average temperature. Thicknesses are calculated for compositional buoyancies between 0 and $20 \mathrm{~kg} \mathrm{~m}^{-3}$ (the compositional buoyancy predicted at $80 \mathrm{~km}$ from B2009). Once a thickness is calculated, we then calculate how long the instabilities would take to form using Eq. 11 (numbers, Figure 12). For no compositional buoyancy, thicknesses range from $105-150 \mathrm{~km}$. The fastest forming instability occurs around $110 \mathrm{Myr}$ with a thickness of $\sim 130 \mathrm{~km}$. This is similar to the oldest ages of the oceanic lithosphere (Müller et al., 2008). For a compositional buoyancy of $10 \mathrm{~kg} \mathrm{~m}^{-3}$, thicknesses range from 135$225 \mathrm{~km}$. The fastest forming instability occurs around $\sim 500 \mathrm{Myr}$ with a thickness of $\sim 170$ $\mathrm{km}$. For a compositional buoyancy of $20 \mathrm{~kg} \mathrm{~m}^{-3}$, thicknesses range from 180-350 km. The fastest forming instability occurs around $\sim 2 \mathrm{Gyr}$ with a thickness of $\sim 250 \mathrm{~km}$. Thus, a pervasive $20 \mathrm{~kg} \mathrm{~m}^{-3}$ chemical buoyancy decreases the thickness of the warm, density unstable layer enough to persist throughout geologic time. Thus, cratons are likely still present due to the combination of lithospheric depletion and their cold, rigid temperature structure.

These analyses are simplified estimates to constrain the possibility of RayleighTaylor type instabilities beneath continental lithosphere. As such, we acknowledge these estimates are likely upper estimates due to the assumptions we used. Because the halfspace cooling model excludes the effect of heat production present in continental crust (Chapman, 1986), the shallow mantle temperatures would be warmer, and thus less viscous, decreasing instability times. We also exclude any effects of pressure or phase changes on density which have been shown numerically to slightly inhibit growth rates (Houseman and Molnar, 1997). Furthermore, this analysis excludes any effect of strainrate weakening (Houseman and Molnar, 1997). Any convergent lithospheric deformation would exacerbate initial lithospheric perturbations as well as increase the background strain-rate, further decreasing the instability times. Thus, future work should constrain the 
effects of these assumptions in order to better understand the thicknesses and times expected for lithospheric delamination.

\section{Conclusion}

Understanding the thermomechanical state of the mantle beneath the continental United States is vital to understand the current mantle flow and force balance, as density is the driving force in plate tectonics (Forsyth and Uyeda, 1975). To constrain this, we applied the forward-model calculations of WISTFUL (Chapter 4) to analyze MITPS_20 (Golos et al., 2020), a joint body and surface wave tomographic inversion for $V_{p}$ and $V_{s}$ with high resolution in the shallow mantle. We analyzed the results using two anelastic corrections: the power-law formulation of Behn et al. (2009) (B2009) and the extendedBurgers model of Jackson and Faul (2010) (JF2010). The east is significantly colder than the west. We interpret maximum temperature variations beneath the continental United States of $900^{\circ} \mathrm{C}$ using B2009 and $800^{\circ} \mathrm{C}$ using JF2010, in agreement with the higher predictions by more recent seismic interpretations (Kaban et al., 2014; Tesauro et al., 2014; Afonso et al., 2016).

Within the east, long-wavelength thermal anomalies are still present. Some are correlated with surface expressions of historic rifting events like the Oklahoma Aulacogen and Mid-Continent Rift, while other thermal anomalies are correlated with recent magmatism, predicted plumes, or hypothesized edge convection like the Northern and Central Appalachian Anomalies. The highest temperatures in the west are located under Holocene volcanism and the Rio Grande Rift. Both models predict that the eastern United States is depleted compared to the western United States, with B2009 at $80 \mathrm{~km}$ predicting the largest amounts of chemical depletion. Regional variations in mantle chemistry exist, with the mantle beneath the Mid-Continent Rift showing increased fertility relative to the cratonic cores.

Comparing our model results with xenolith compositions, xenolith thermobarometry, and primary magma thermobarometry, both B2009 and JF2010 produce acceptable results compared to the compositions of recently erupted xenoliths in the Southwestern United States, with B2009 better estimating Mg \#. B2009 produces temperatures always equal to or higher than temperature estimates for spinel xenolith, likely since xenoliths can sample significantly shallower mantle, while JF2010 predicts 
colder temperatures for two localities. Both anelasticities predict significantly colder temperatures compared to primary magma thermometry, potentially due to differences in seismic resolution and the scale at which the magmatic temperatures sample as well as errors in the anelastic formulations. As B2009 better predicts composition and temperature, we prefer this model's results.

Density plays a key role in the stability of cratonic mantle roots through Earth's history. We find that the chemical depletion predicted by our model does not fully compensate for the density difference due to temperature between the eastern and western United States, in agreement with recent geophysical and geochemical studies (Forte et al., 1995; Shapiro et al., 1999a; Kaban et al., 2003; Schutt and Lesher, 2006; Eaton and Claire Perry, 2013). Rayleigh-Taylor instability analysis suggests that the lithosphereasthenosphere boundary quickly ( 10 Myr) flattens and that there must be some pervasive chemical depletion under the North American Craton for it to persist over billions of years. Instead, cratons are still present due to the combination of some chemical depletion as well as their cold, rigid structure. Increased deformation, thermal weakening, or thermal blanketing by the continental crust would decrease cratonic stability, potentially causing cratonic lithosphere delamination. 


\section{Figures}
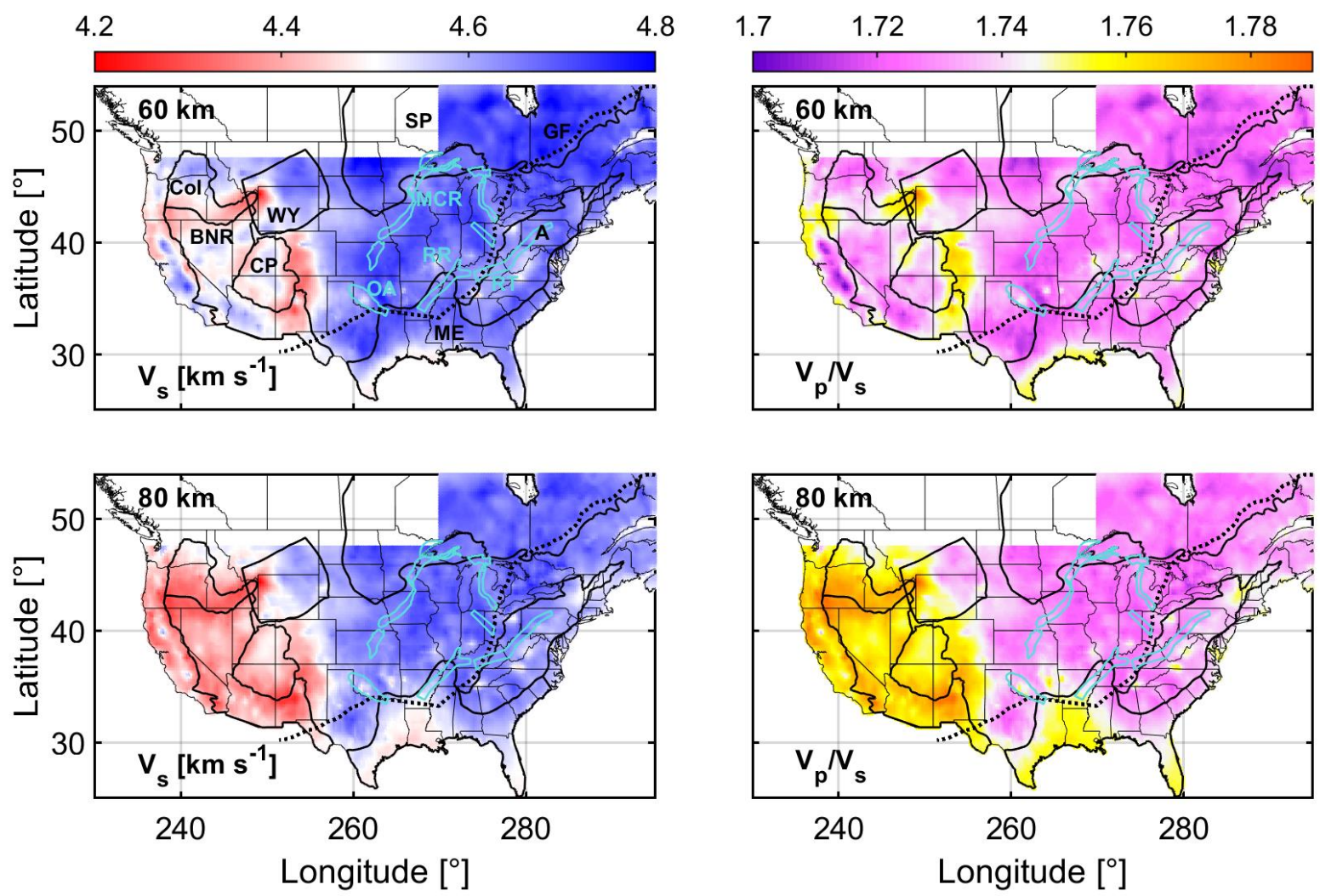

Figure 5.1: 60 and $80 \mathrm{~km}$ depth slices of $V_{s}$ and $V_{p} / V_{s}$ for seismic model MITPS. Black boundaries represent tectonic provinces (A: Appalachian Mountains, BNR: Basin and Range, Col: Columbia Plateau/Snake River Plain, CP: Colorado Plateau, SP: Superior Craton, WY: Wyoming Craton). Cyan boundaries represent surface exposures of continental rifting events (MCR: Mid-continent rift, OA: Oklahoma aulacogen, RR: Reelfoot Rift, RT: Rome Trough). The dotted line represents the Grenville Front (GF). All boundaries from Whitmeyer and Karlstrom (2007). 

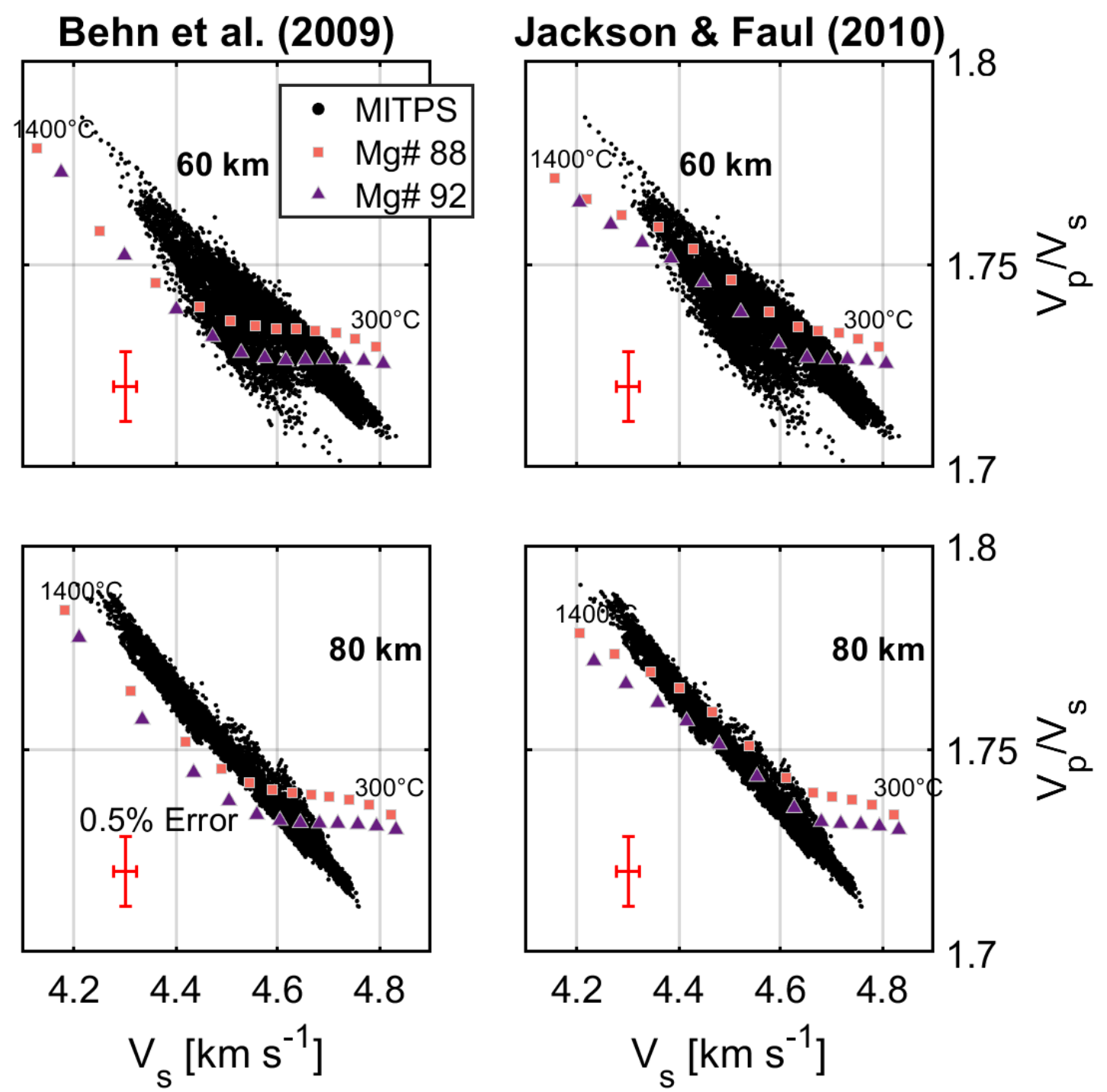

Figure 5.2: MITPS at 60 (top) and 80 (bottom) km depth plotted alongside average wave speeds for enriched ( $\mathrm{Mg} \#=88$, pink) and depleted $(\mathrm{Mg} \#=92$, purple) peridotites from 300 to $1300{ }^{\circ} \mathrm{C}$ plotted every $100{ }^{\circ} \mathrm{C}$ assuming the Behn et al. (2009) power-law anelasticity (left) and the Jackson and Faul (2010) extended-Burger's model anelasticity. Red error bars represent the $0.5 \%$ error for the WISTFUL forward calculations. 

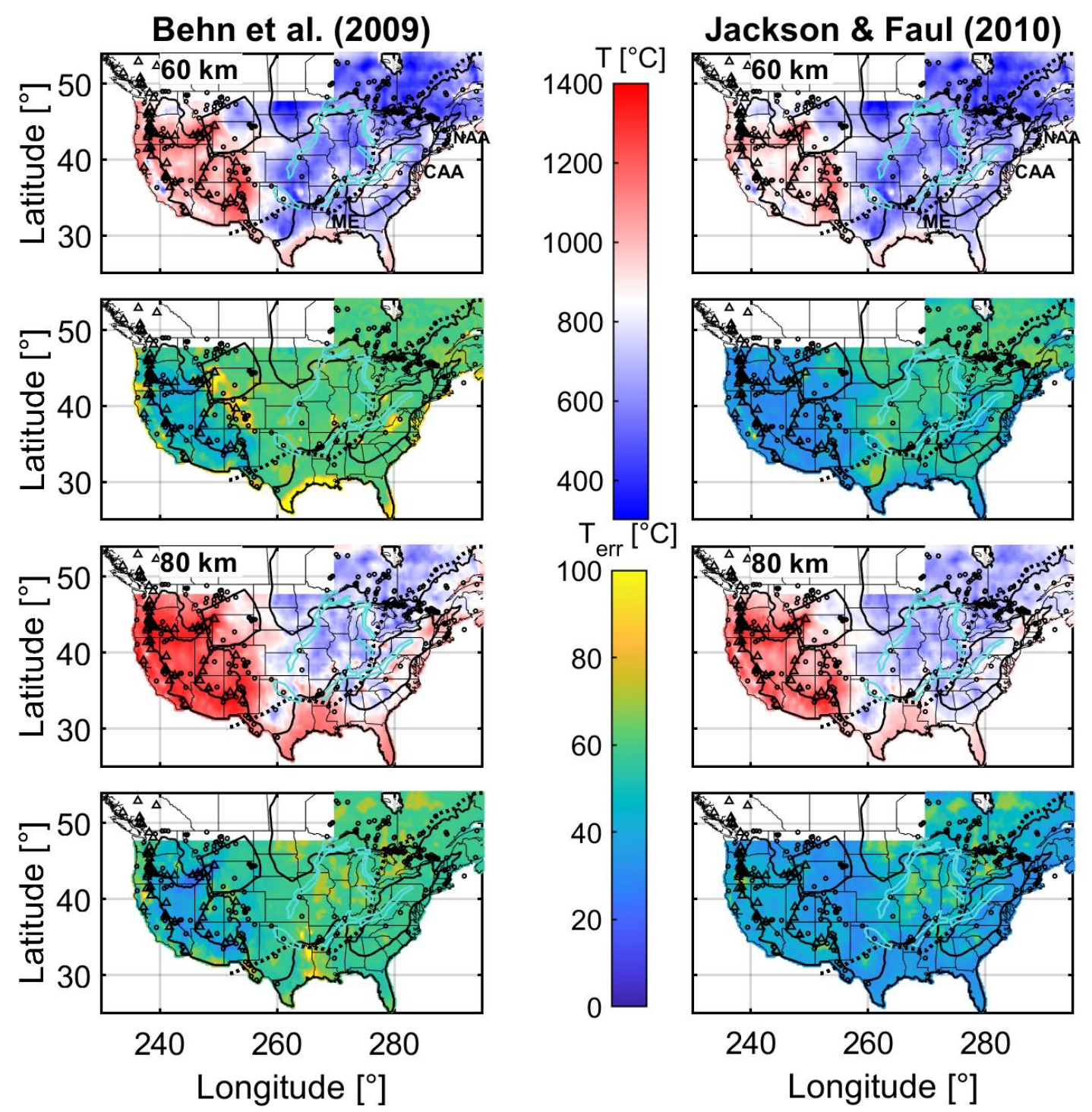

Figure 5.3: Best-fit temperature and uncertainty at 60 and $80 \mathrm{~km}$ Boundaries as in Figure 1. Circles represent surface outcrops of alkaline or carbonatite magmatism younger than $1 \mathrm{Ga}$ (http://alkcarb.myrocks.info/). Triangles represent locations of Holocene volcanism (Venzke, 2013). Acronyms as follows: NAA, North Appalachian Anomaly, CAA, Central Appalachian Anomaly, ME, Mississippi Embayment. CAA and NAA text plotted $7^{\circ}$ east of actual anomalies. 
Behn et al. (2009)
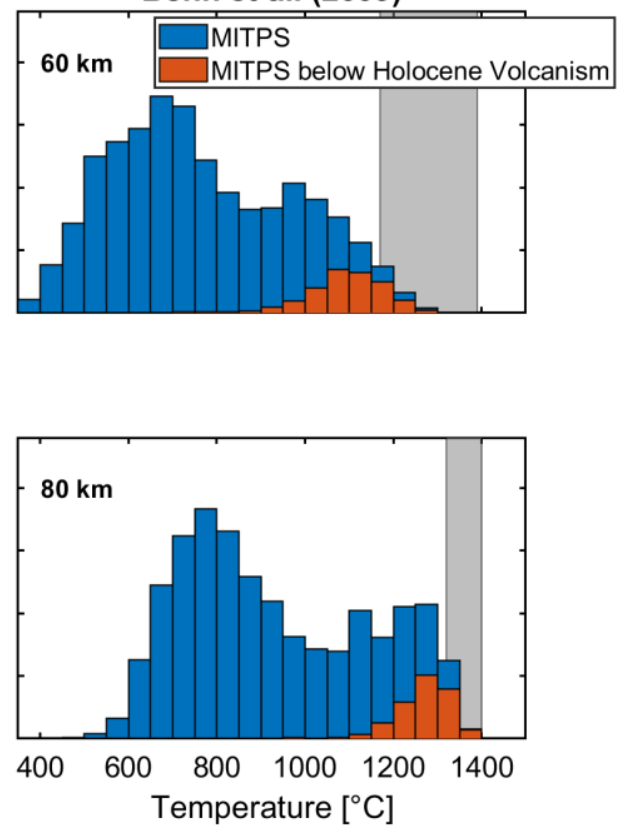

Jackson \& Faul (2010)
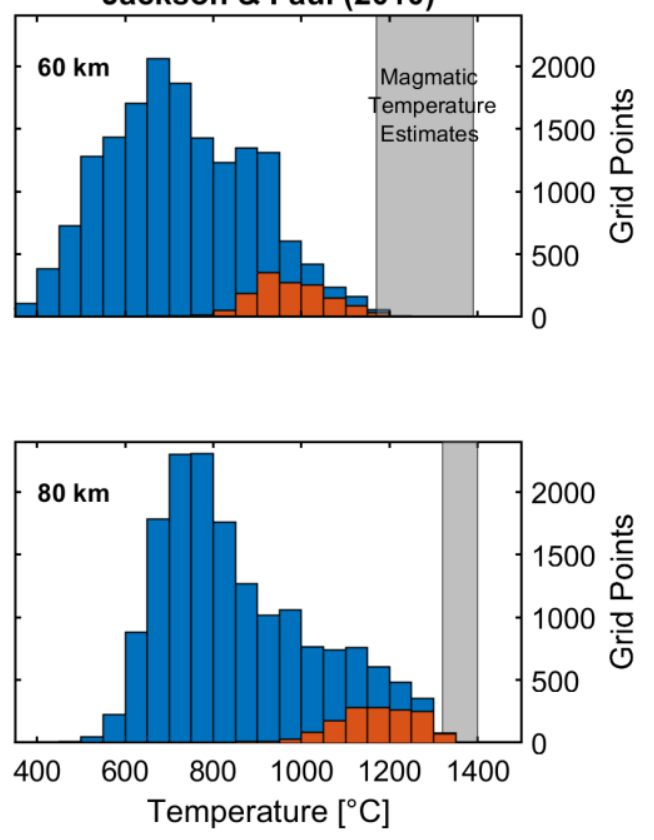

Figure 5.4: All temperature estimates for both anelasticities at 60 and $80 \mathrm{~km}$ depths (blue) plotted along with temperature estimates within $1^{\circ}$ arcdistance of locations for Holocene volcanism. Grey regions depict the range of magmatic temperature estimates (see text for discussion). 

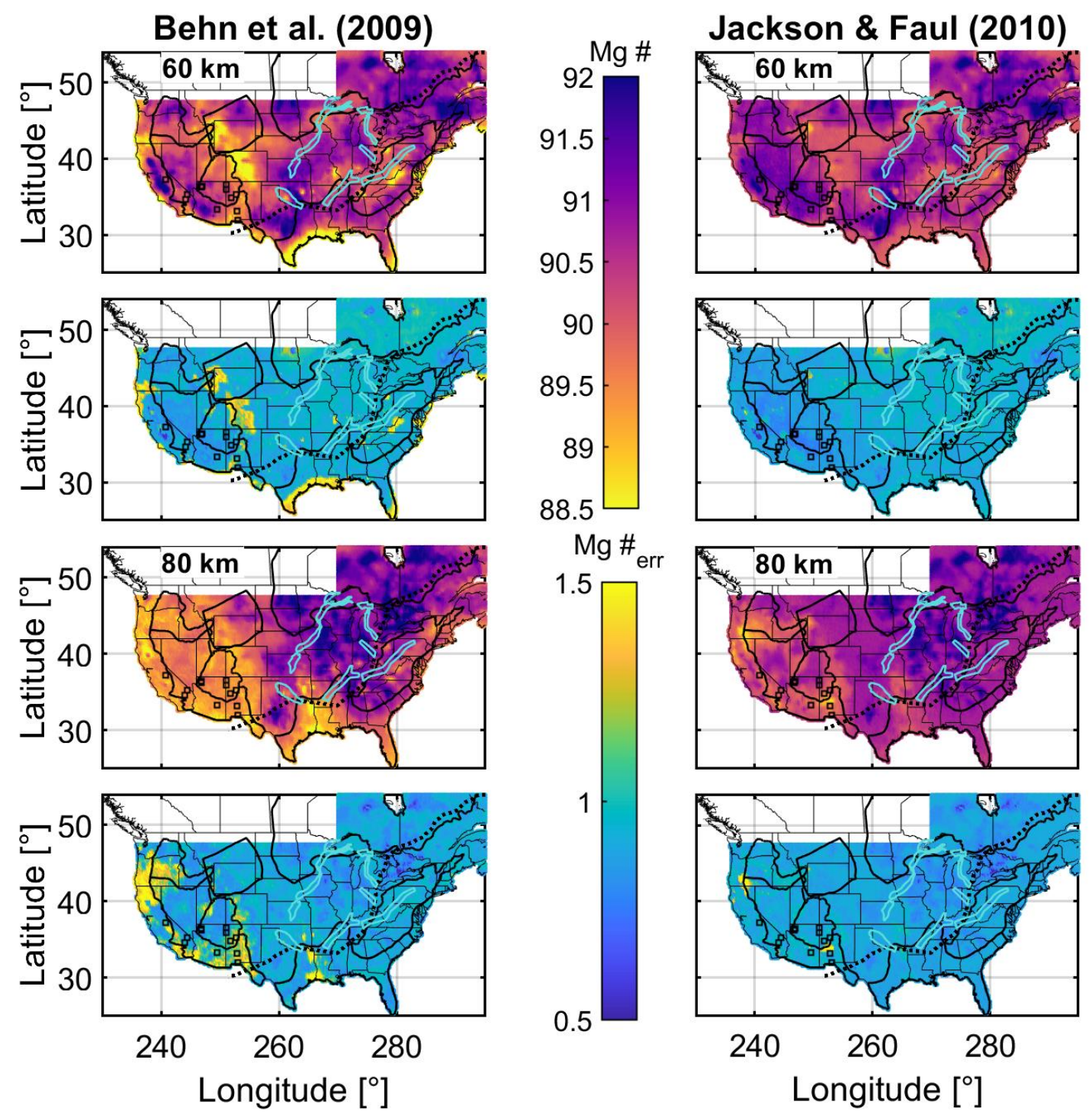

Figure 5.5: Best-fit $\mathrm{Mg} \#$ and uncertainty at 60 and $80 \mathrm{~km}$. Boundaries as in Figure 1. Squares depict xenolith localities younger than $10 \mathrm{Ma}$. 

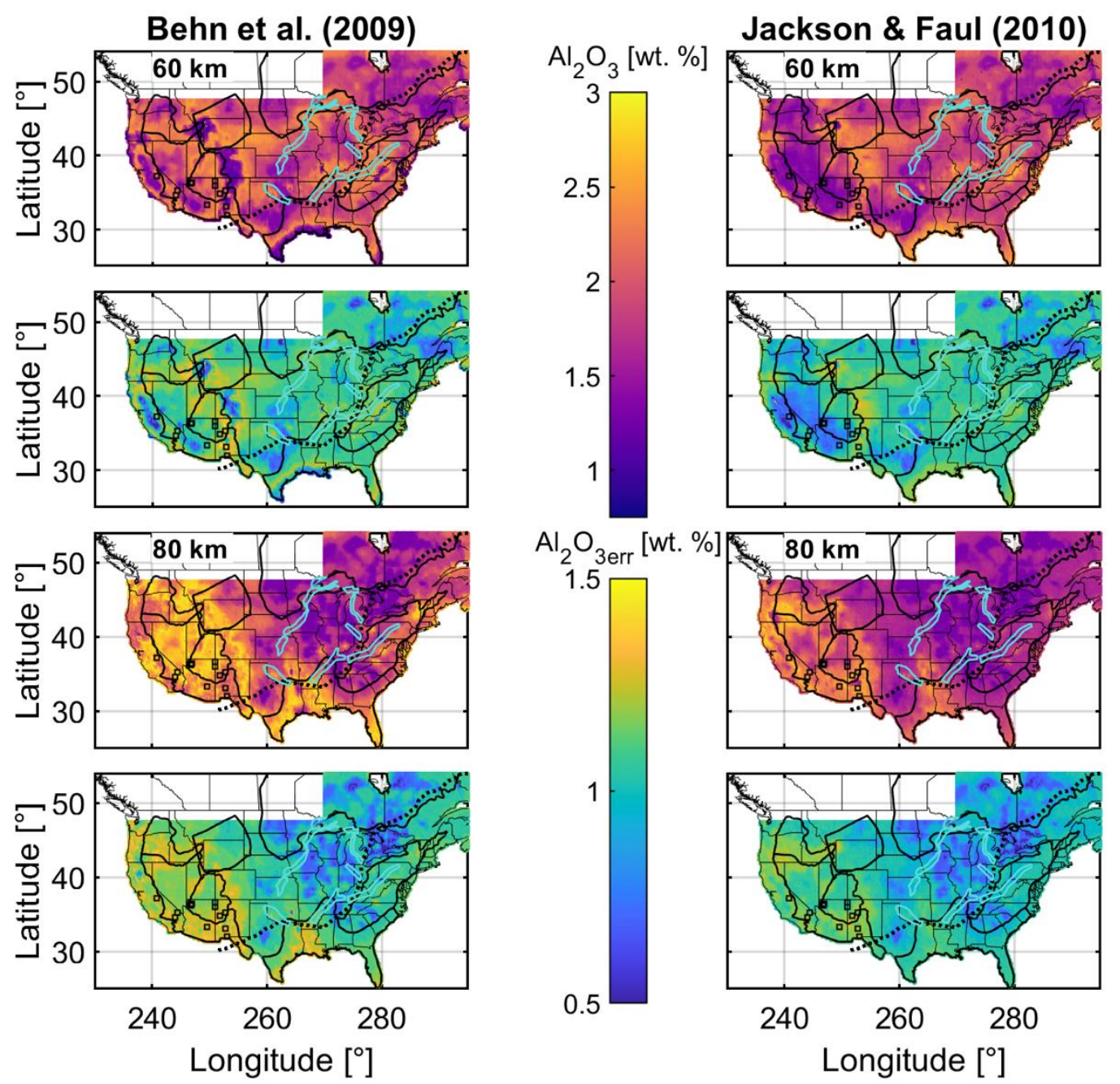

Figure 5.6: Best-fit $\mathrm{Al}_{2} \mathrm{O}_{3}$ content and uncertainty at 60 and $80 \mathrm{~km}$. Boundaries as in Figure 1. Squares depict xenolith localities younger than $10 \mathrm{Ma}$. 

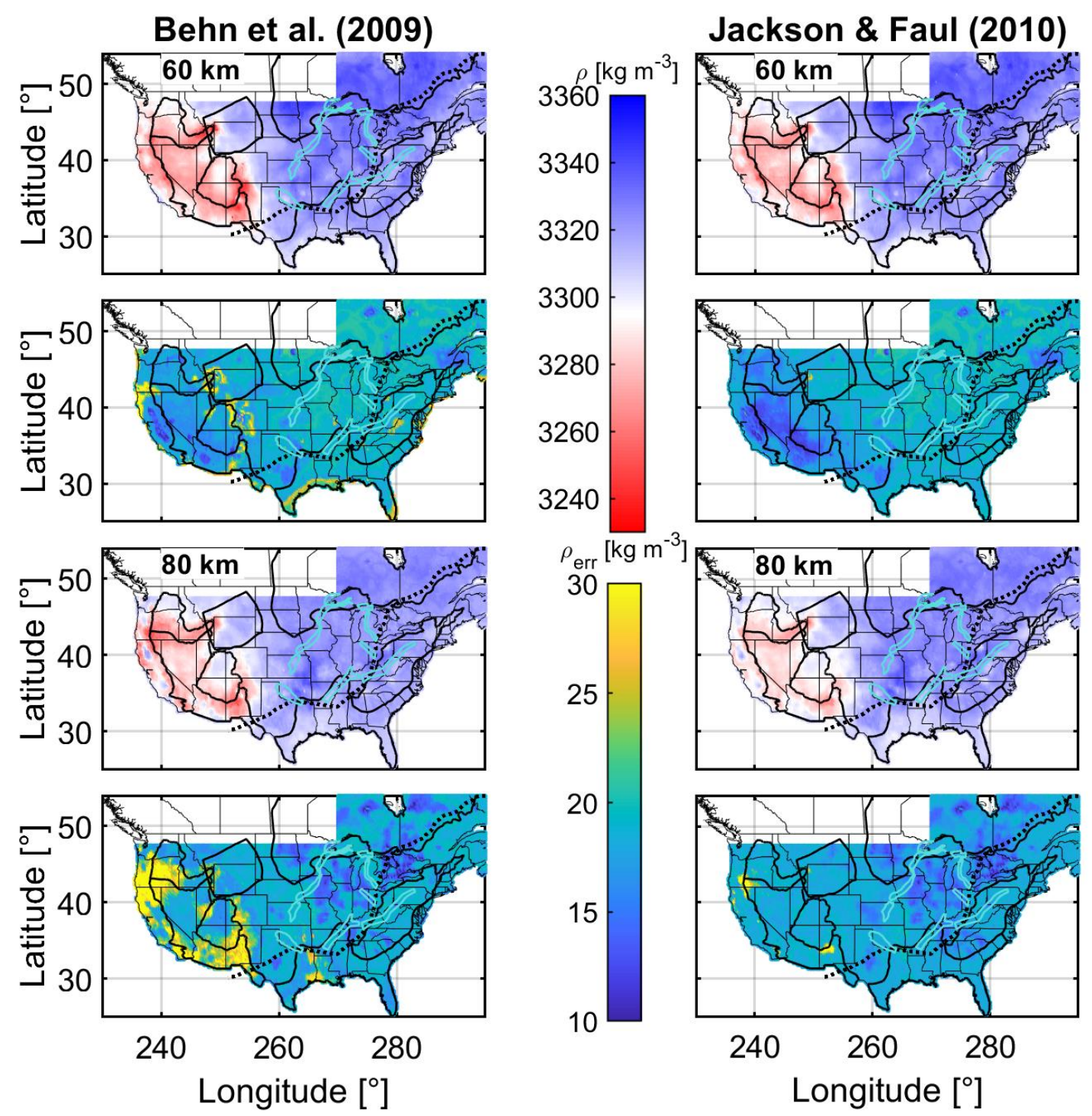

Figure 5.7: Best-fit density and uncertainty at 60 and $80 \mathrm{~km}$. Boundaries as in Figure 1. 

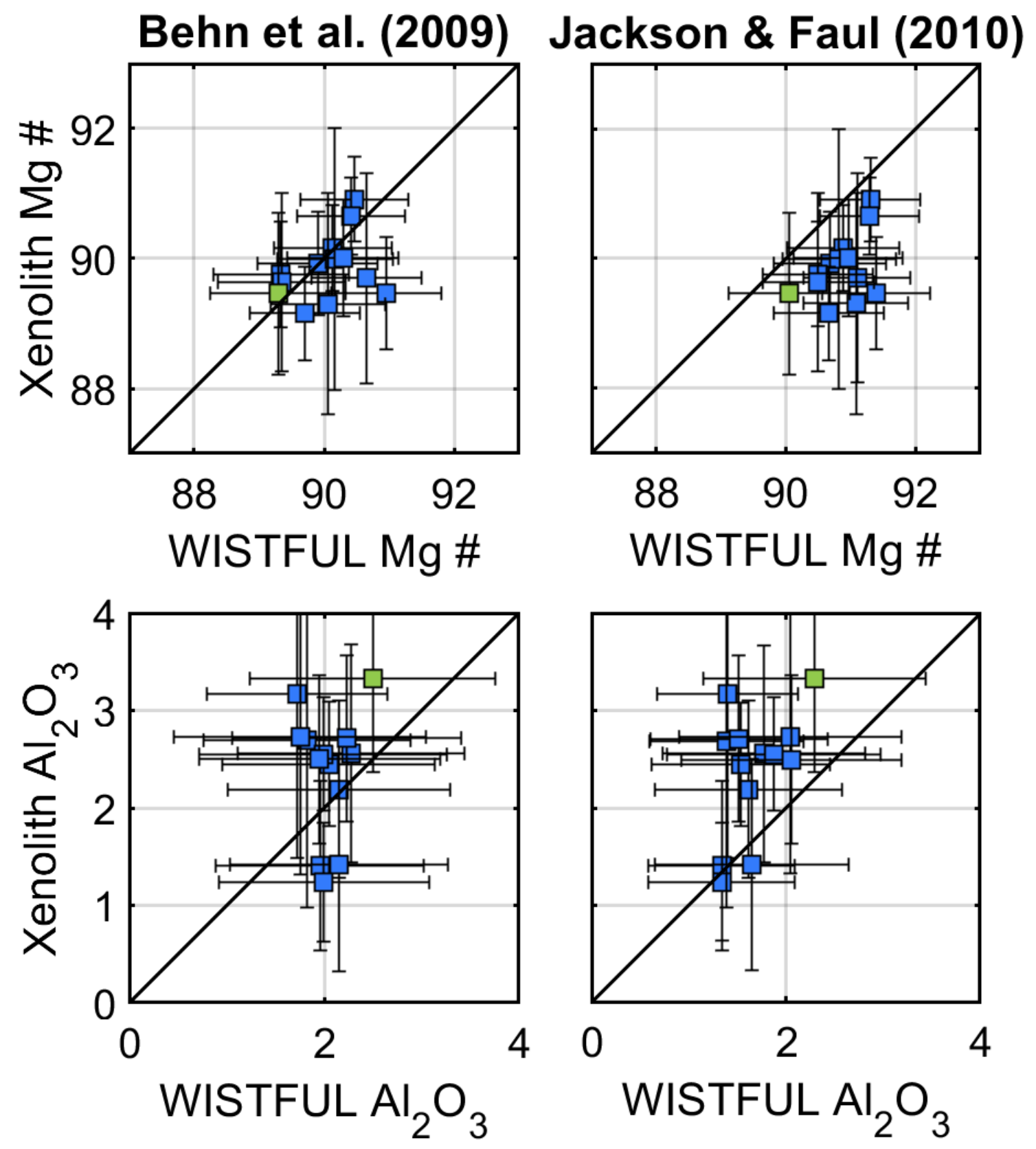

Figure 5.8: Comparison of average <10 Ma xenolith composition against average best-fit composition within $0.5^{\circ}$ arcdistance from the surface exposure. Error bars depict a 1sigma error. The blue squares represent spinel-bearing xenolith localities for which the 60 $\mathrm{km}$ depth slice was used; the green square signifies a garnet-bearing xenolith locality for which the $80 \mathrm{~km}$ slice was used. 

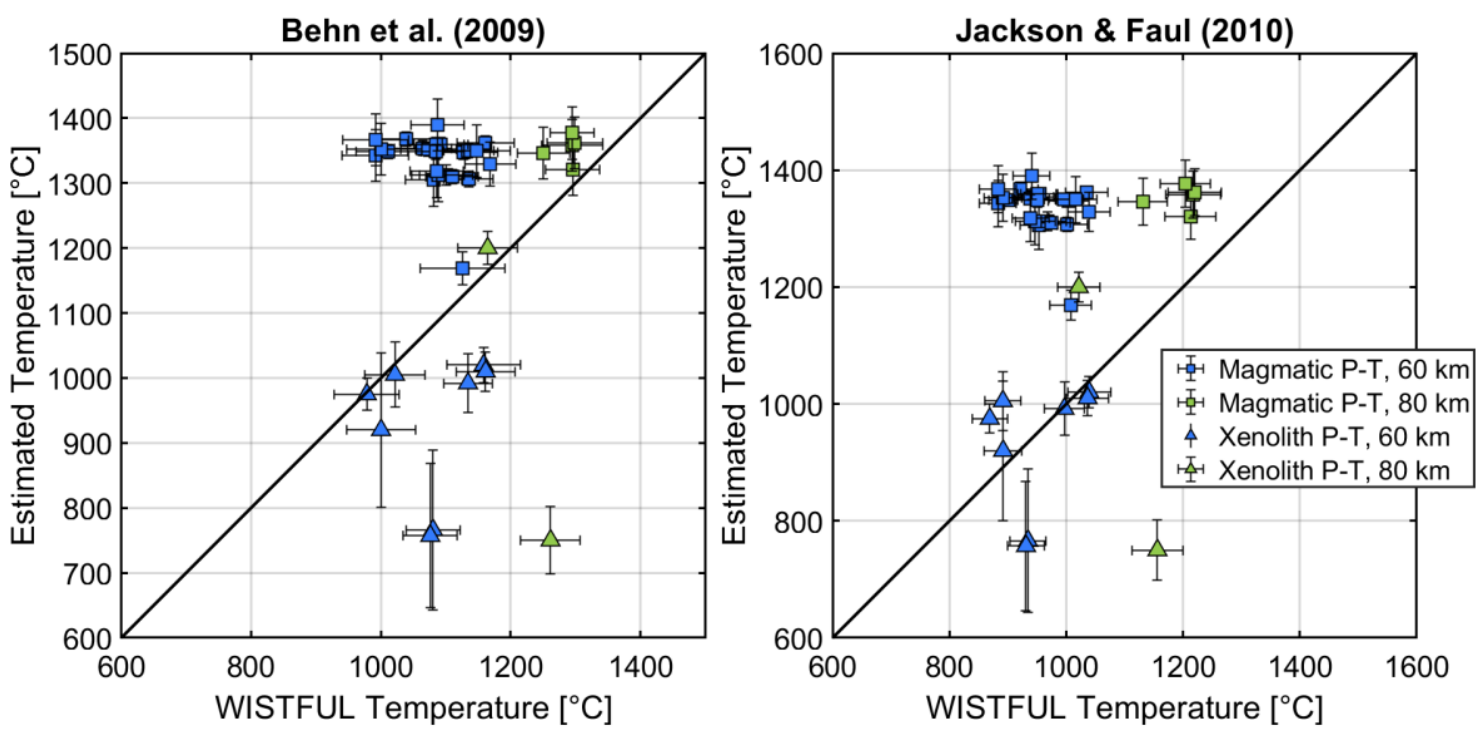

Figure 5.9: Temperature estimates from xenoliths (triangles) and magmatic temperature estimates (squares) against average WISTFUL temperature within $0.5^{\circ}$ arcdistance of the surface outcrop for 60 (blue) and $80 \mathrm{~km}$ (green). Error bars depict a 1-sigma error. 


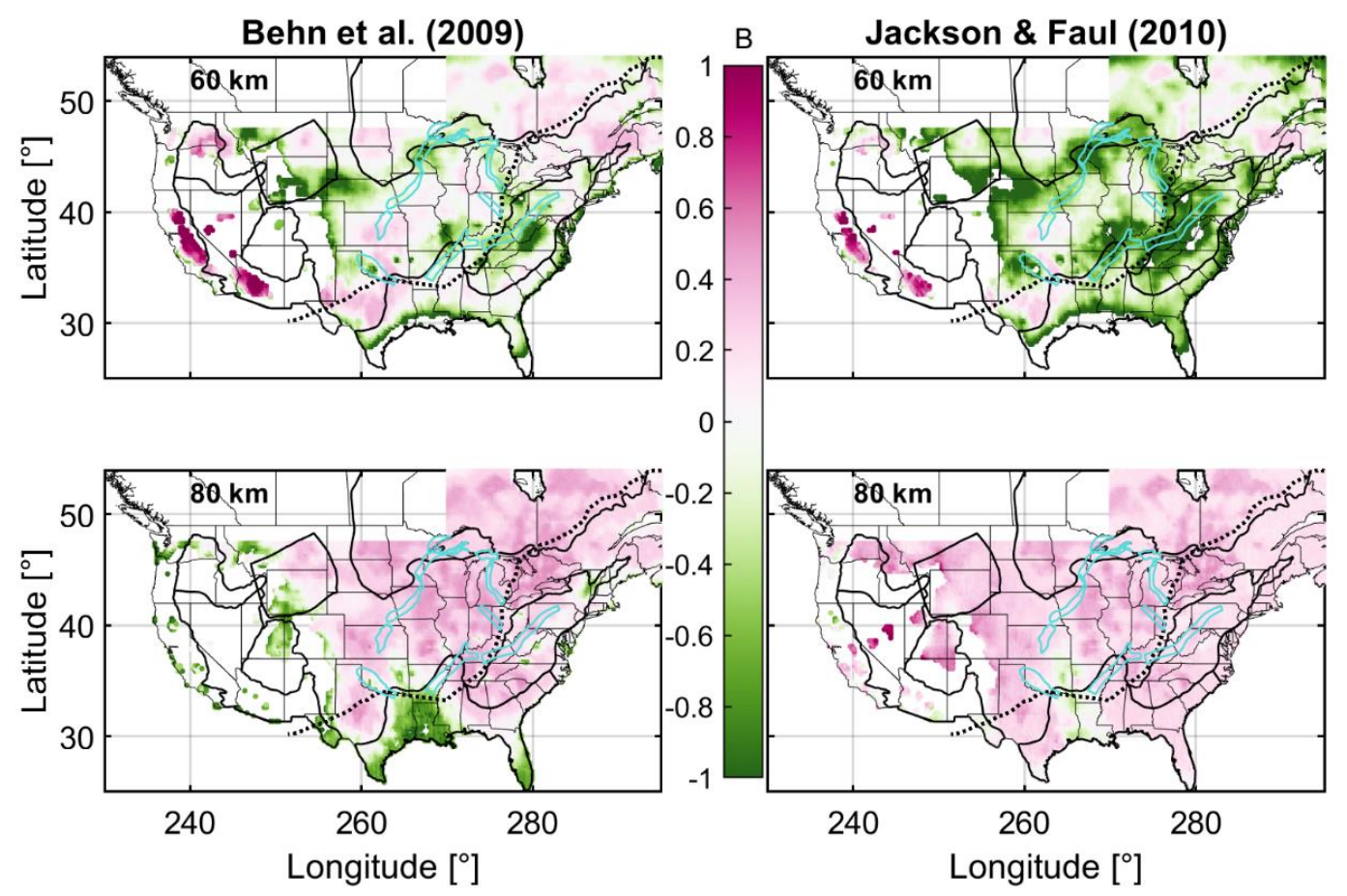

Figure 5.10: $B$ calculated from the best-fit temperature and density compared to the average density and temperature values in the Basin and Range. Boundaries as in Figure 1. See discussion for details on calculation. 


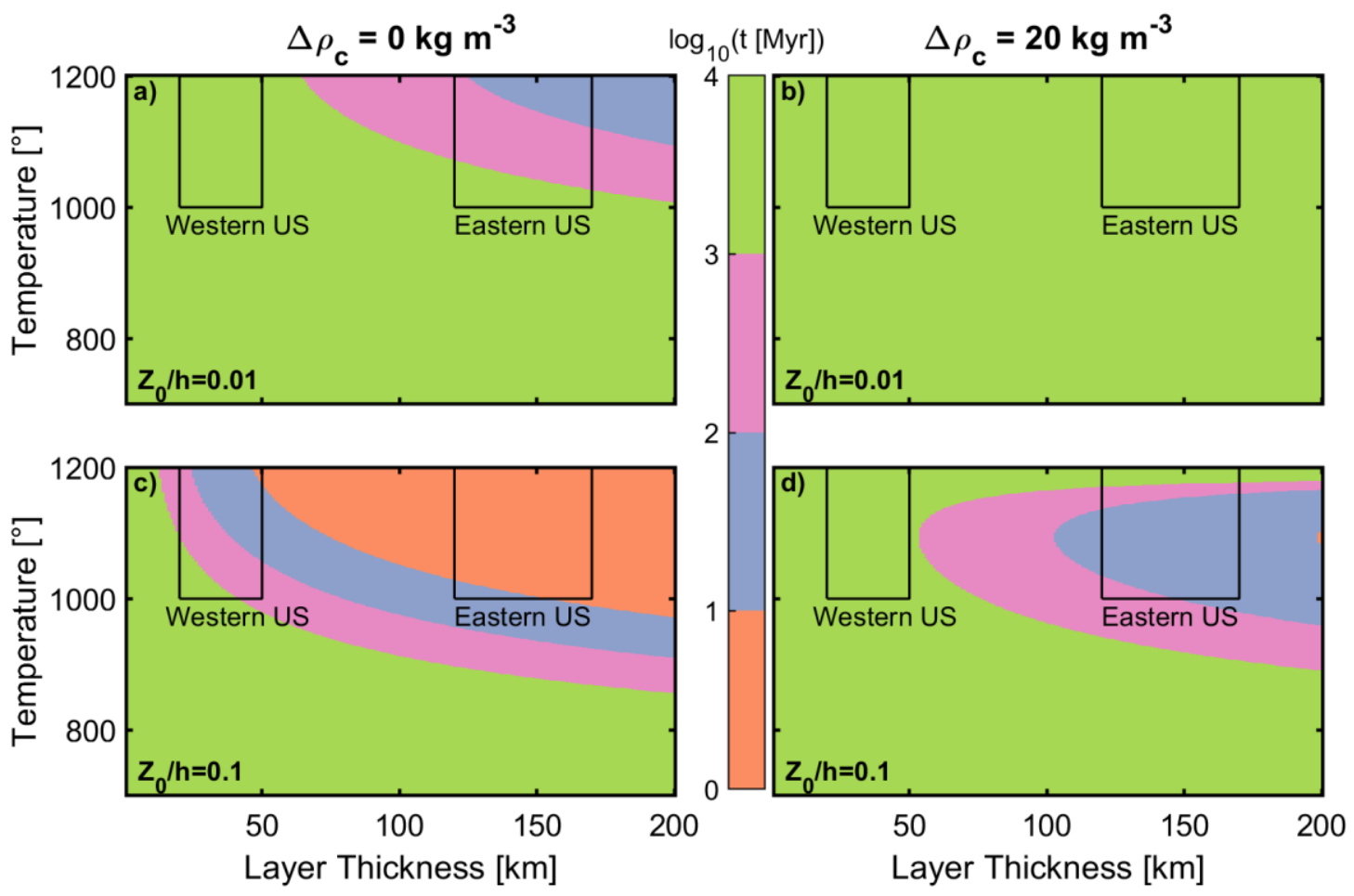

Figure 5.11: Instability time for a density unstable layer as a function of its thickness and average temperature, which controls the rheology and density variation. The top row (a, b) assumes $1 \%$ initial perturbations while the bottom row (c, d) assumes $10 \%$ initial perturbations. The left column (a, c) assumes no compositional buoyancy, while the right column (b, d) assumes a compositional buoyancy observed at $80 \mathrm{~km}$ in the North American Craton. Western and Eastern US boxes represent the lithospheric thicknesses of mantle layers with temperature $>800^{\circ} \mathrm{C}$. 


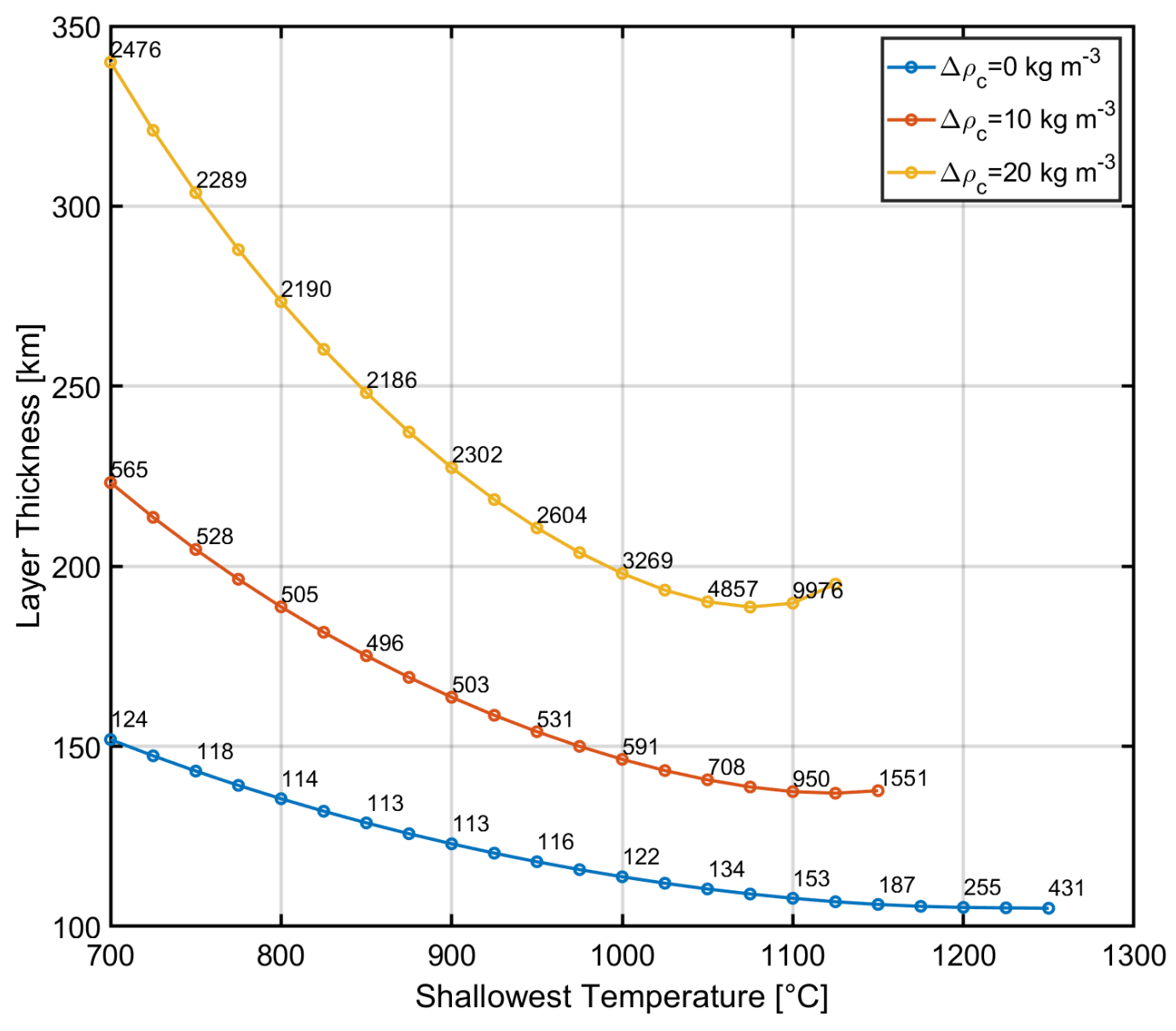

Figure 5.12: Unstable thicknesses calculated by equating the Rayleigh-Taylor instability time assuming $1 \%$ initial perturbations with the time it takes a half space cooling model to form a density unstable layer with assuming there is no lithospheric delamination above the shallowest temperature. The thickness is defined as the difference in depth between the shallowest temperature and the temperature at which the mantle density is buoyant by $2 \mathrm{~kg} \mathrm{~m}^{-3}$. Rheology and density difference are assumed to be their respective values assuming the average layer temperature. Numbers state the time [Myr] for the instability to form. 
Chapter 6:

Concluding Remarks 
The job of the geoscientist is to inspect the portion of Earth to which we have access, namely Earth's surface, in order to constrain past and present geophysical and geochemical processes. The lithosphere is the rigid plates of the Earth created by the slow cooling through the surface. These plates vary drastically in size, composition, and thermal structure between oceanic plates, continental plates, as well as within each plate. This thesis is unified in uncovering and interpreting new constraints on the thermal, chemical, and mechanical state of deeper lithosphere through the use of surface geoobservables. Chapters 1, 4, and 5 focused on the interpretation of seismic wave speed for the lower crust and upper mantle in order to constrain compositional variability. Chapter 2 focused on field and petrologic observations to constrain the metamorphic temperature and cooling rates of the lower crust during orogenic collapse. Chapter 3 focused on the interpretation of magnetic, gravity, and bathymetry data from a continuous $74 \mathrm{Myr}$ spreading-parallel flow line across the Mid-Atlantic Ridge. These results are then used to constrain the tectonic and geochemical processes that control lithospheric formation and evolution at depths that are difficult or impossible to directly sample.

\section{Future Directions}

Here I discuss a few possible future directions that directly follow from the research presented in this thesis, focusing primarily on the thesis chapters that use seismic wave speeds to infer internal properties of Earth's crust and mantle (Chapters 1, 4, and 5). Three major directions for future work include: (1) the addition of the effects of melt, mechanical mixing, anisotropy, and resistivity to WISTFUL, (2) the application of WISTFUL to available or future datasets, and (3) the creation of similar databases and error constraints for crustal rocks.

\section{1) Melt, Mechanical Mixing, Anisotropy, and Resistivity}

Seismic wave speed is dependent on the stable mineral assemblage, pressure, temperature, and presence of melt or hydration. Chapter 4 assumed the last two were negligible on a large scale, as the retained melt fraction is likely low in the mantle (McKenzie, 2000; Sims et al., 2002) and/or limited to melt channels that are volumetrically small compared to tomographic resolution (Zhu et al., 2011). The effect of the melt on the shear modulus can strongly vary dependent on the melt fraction retained as well as the interconnectivity on the retained melt (Hammond and Humphreys, 2000; 
Takei, 2017). Future work should incorporate various formulations for the effect of melt on shear modulus to quantify the potential uncertainties. Similarly, mantle hydration was ignored in the forward calculation of mineral assemblages. To investigate mantle metasomatism, as may be present in arc wedges, another set of thermodynamic models, like that of Holland et al. (2018) solution model, are required that incorporate $\mathrm{H}_{2} \mathrm{O}$.

The diversity of compositions present in exhumed mantle sections and ultramafic xenoliths likely indicate a variable composition mantle composition over small (on the order of 10 m) scales (e.g., Kelemen and Dick, 1995; Li et al., 2008; Baptiste and Tommasi, 2014). Due to the non-uniqueness of seismic wave speed interpretation, I only considered each seismic voxel as a single, ultramafic composition, excluding the possibility of a mechanical mixture of two or more compositions. With better geochemical constraints from xenoliths or recent magmatic eruptions, one could forward model the seismic wave speeds predicted for each and calculate allowable combinations along a geotherms. 1-20 vol. \% eclogite present in the upper mantle has been predicted from xenolith observations, seismic wave speeds, and gravity beneath continental cratons (James et al., 2004; Garber et al., 2018). Using wave speeds calculated for end member compositions, one could constrain the range of permittable compositional combinations for a given region.

In this thesis, I have calculated the mineral assemblage over a range of shallow mantle temperatures and pressures. I can also calculate other geophysical observables such as the possible anisotropy and the magnetic resistivity for each composition. Recent work has shown that the strength of anisotropy is correlated with the olivine content of mantle xenoliths (Bernard et al., 2021). Therefore, the strength of regional anisotropies could be used as an additional constraint on the mantle composition. Resistivity for each composition would be a useful estimate for temperature, water content, and melt using laboratory derived relations (Fullea et al., 2011). These forward calculations for the WISTFUL database would be most useful in regions of the United States which have higher resolution measurements from the USArray (Kelbert et al., 2019).

\section{2) WISTFUL applications}

In addition to interpreting the seismic wave speed of the continental mantle, the oceanic mantle holds great potential for interpreting seismic wave speed to understand 
thermochemical variation in the global mantle. Recent global surface-wave tomographic models (e.g., Kustowski et al., 2008; Ritsema et al., 2011; Auer et al., 2014; Ho et al., 2016), regional on-axis studies like Pi_LAB in the equatorial Atlantic (Rychert et al., 2020, 2021; Harmon et al., 2021; Saikia et al., 2021), and regional off-axis studies like NoMelt in the Pacific (Sarafian et al., 2015; Lin et al., 2016; Mark et al., 2019, 2021; Russell et al., 2019; Ma et al., 2020) provide seismic models that could be quantitively interpreted using WISTFUL to better constrain the compositional, and thermal evolution of the oceanic mantle lithosphere. These regional studies are especially useful as they incorporate detailed geophysical studies of resistivity and/or anisotropy.

For instance, fast spreading ridges between 50 and $200 \mathrm{~km}$ depth in recent global $V_{s}$ models are $0.05-0.1 \mathrm{~km} \mathrm{~s}^{-1}$ faster compared to slow-spreading ridges (Kustowski et al., 2008; Ritsema et al., 2011; Auer et al., 2014; Ho et al., 2016, Figure 1). This variation continues off-axis, leading Auer et al. (2015) to interpret this difference to be caused by potential temperature variations beneath the Pacific and Atlantic basins. However, the potential temperature variations required to produce such significant seismic wave speed difference $\left(>100^{\circ} \mathrm{C}\right)$ would produce drastically different oceanic crustal thicknesses (Behn and Grove, 2015) and melt compositions, which is not observed (Chen, 1992). Other important parameters that could explain the observed variation are mantle composition and water content (if it affects anelasticity), and/or grain size. Future research will test the importance of these parameters by combining the forward modelling abilities of WISTFUL with geodynamic models that incorporate grain-size evolution like Turner et al. $(2015,2017)$ (Figure 2).

\section{3) Crustal Seismic Wave Speeds}

Many scientists have used crustal seismic wave speeds to interpret the regional or average composition of the lower continental crust (e.g., Rudnick and Fountain, 1995; Christensen, 1996; Lowry and Pérez-Gussinyé, 2011; Schulte-Pelkum et al., 2017). This analysis can elucidate competing models for the formation and evolution of continental crust over time (Hacker et al., 2015). I have already created a crustal database including igneous, metamorphic, and sedimentary compositions in Chapter 1, but similar uncertainty analysis for ultramafic solution models presented in Chapter 4 is necessary 
for crustal rocks utilizing both well-studied intrusive igneous like exposed Talkeetna samples (e.g., Behn and Kelemen, 2006) as well low- and high-grade metamorphic rocks.

Furthermore, the database created in Chapter 1 includes only anhydrous compositions at a single oxygen fugacity. To interpret lower crustal seismic wave speeds, the entire range of water contents and oxygen fugacity must be considered. The lower continental crust typically contains $0-1$ wt. $\% \mathrm{H}_{2} \mathrm{O}$ (Huang et al., 2013), but could be locally fluid saturated (Manning, 2018). Oxygen fugacity in volcanic rocks can vary by more than three orders of magnitude relative to the quartz-fayalite-magnetite fugacity buffer (Cottrell et al., 2020). Thus, any complete crustal database has a significantly larger parameter space compared to Chapter 4 and must also include the potential effects of fluids on seismic wave speed.

Similar to mantle seismic wave speeds, anelasticity could play an important part deciphering the lower continental crust with high temperatures, definitely present throughout the western United States (Schutt et al., 2018). Studies of anelasticity on crustal compositions show that different anelastic corrections need to be applied on basaltic and granitic rocks (e.g., Kampfmann and Berckhemer, 1985). A homologous temperature formulation rederived from the available experimental data on anelasticity in crustal rocks would need to be created for this work.

Overall, this thesis shows the promise of carefully determining smaller-scale thermal and chemical heterogeneities in the mantle with the utilization of joint $V_{p}$ and $V_{s}$ tomographic models utilizing body and surface waves. The combination of geophysical observables with petrologic and field observations can elucidate the detailed and complex story of Earth's past and present. 


\section{Figures}

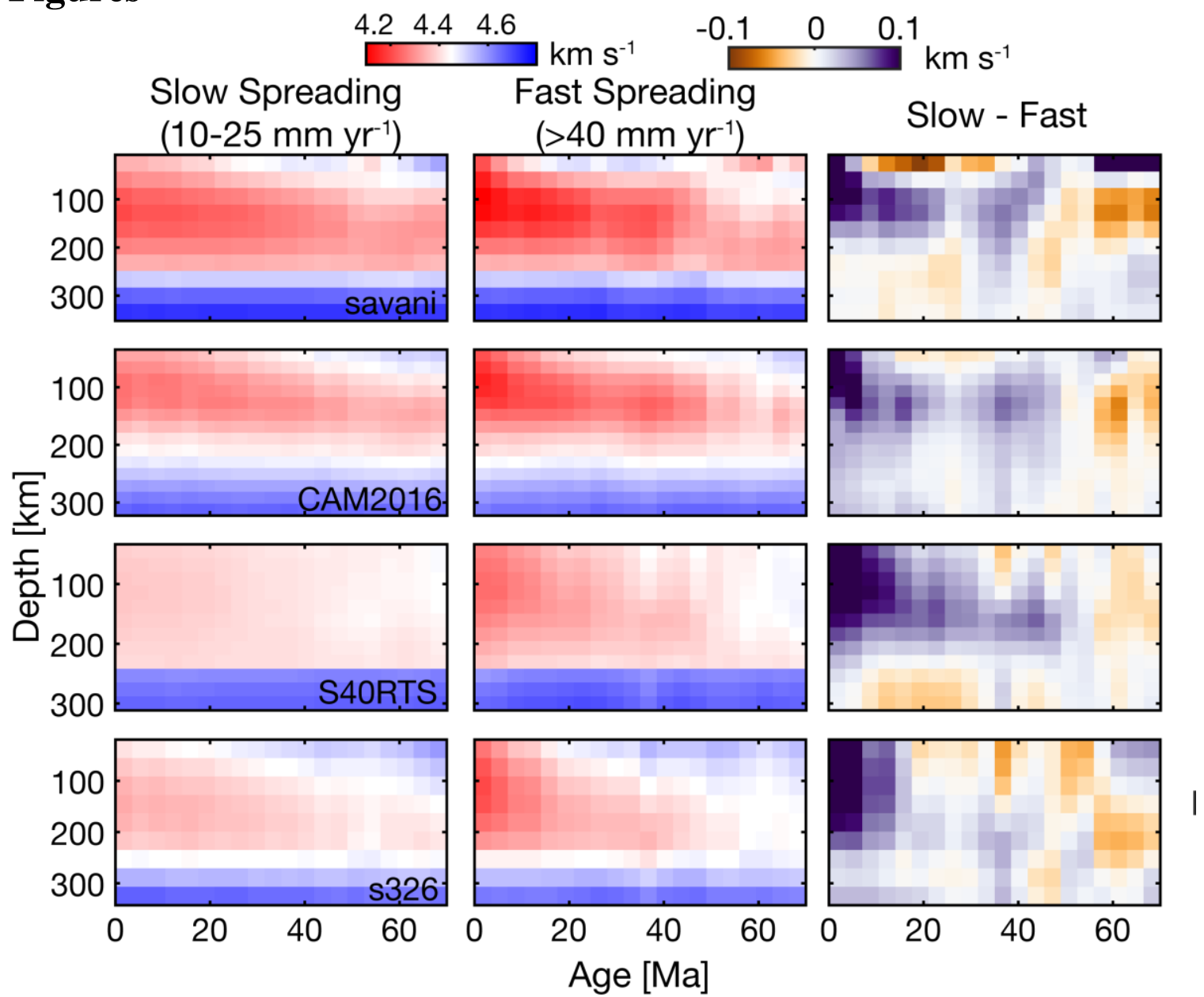

Figure 6.1: Average $V_{s}$ in absolute wave speed using $3 \mathrm{Myr}$ bins for slow and fast spreading rates using global age and spreading rates (Müller et al., 2008) for four recent global $V_{s}$ tomographic models: savani (Auer et al., 2014), CAM2016 (Ho et al., 2016), S40RTS (Ritsema et al., 2011), and s326 (Kustowski et al., 2008). $V_{s}$ is plotted at the cell centers for each model. Isotropic $V_{s}$ is plotted for each model with the exception of S40RTS which reports vertical $V_{s}$. The right column shows the difference between the slow and fast oceanic mantle for each model. 


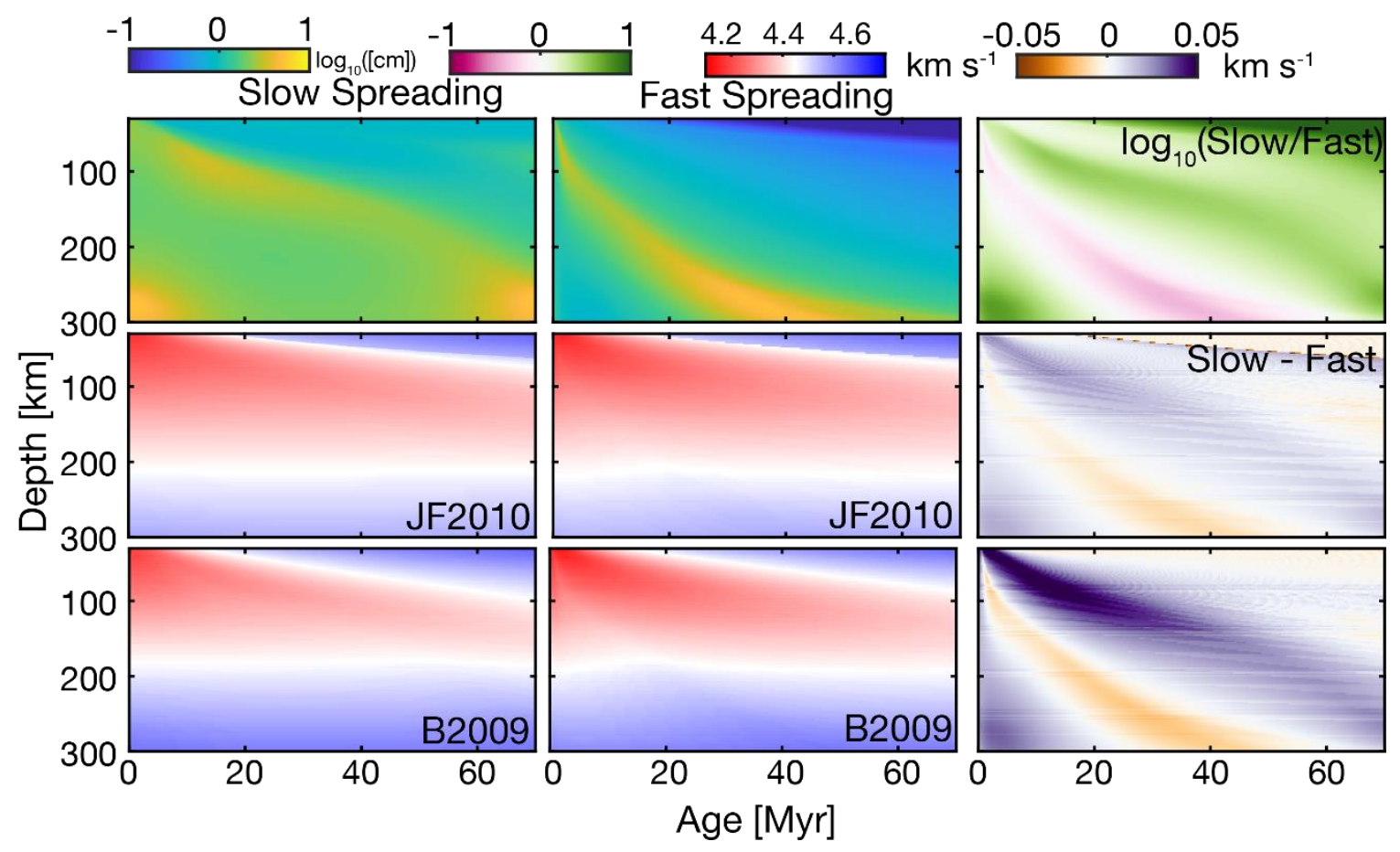

Figure 6.2: Top row: Predicted grainsize and $V_{s}$ age using the Turner et al. (2015) geodynamic model setup for a slow $\left(10 \mathrm{~mm} \mathrm{yr}^{-1}\right)$ and fast $\left(100 \mathrm{~mm} \mathrm{yr}^{-1}\right)$ full spreading rate using dry olivine flow laws (Hirth and Kohlstedt, 2003) and $T_{p}=1350{ }^{\circ} \mathrm{C}$. The rightmost figure shows the $\log _{10}$ ratio of the slow and fast grainsize models. Middle row: Predicted $V_{s}$ using the grainsize and the Jackson and Faul (2010) anelasticity. Bottom row: Predicted $V_{s}$ using Behn et al. (2009) anelasticity assuming olivine has 100 ppm $\mathrm{H} / \mathrm{Si}$. Rightmost figure shows the difference between the slow and fast models. 


\section{References}

Abers, G. A. \& Hacker, B. R. (2016). A MATLAB toolbox and Excel workbook for calculating the densities, seismic wave speeds, and major element composition of minerals and rocks at pressure and temperature. Geochemistry, Geophysics, Geosystems.

Afonso, J. C., Fernàndez, M., Ranalli, G., Griffin, W. L. \& Connolly, J. A. D. (2008). Integrated geophysical-petrological modeling of the lithosphere and sublithospheric upper mantle: Methodology and applications. Geochemistry, Geophysics, Geosystems 9.

Afonso, J. C., Fullea, J., Griffin, W. L., Yang, Y., Jones, A. G., Connolly, J. A. D. \& Reilly, S. Y. O. (2013a). 3-D multiobservable probabilistic inversion for the compositional and thermal structure of the lithosphere and upper mantle. I: A priori petrological information and geophysical observables. Journal of Geophysical Research: Solid Earth 118, 2586-2617.

Afonso, J. C., Fullea, J., Yang, Y., Connolly, J. A. D. \& Jones, A. G. (2013b). 3-D multiobservable probabilistic inversion for the compositional and thermal structure of the lithosphere and upper mantle. II: General methodology and resolution analysis. Journal of Geophysical Research: Solid Earth 118, 1650-1676.

Afonso, J. C., Ranalli, G. \& Fernàndez, M. (2005). Thermal expansivity and elastic properties of the lithospheric mantle: Results from mineral physics of composites. Physics of the Earth and Planetary Interiors 149, 279-306.

Afonso, J. C., Ranalli, G., Fernàndez, M., Griffin, W. L., O’Reilly, S. Y. \& Faul, U. (2010). On the Vp/Vs-Mg\# correlation in mantle peridotites: Implications for the identification of thermal and compositional anomalies in the upper mantle. Earth and Planetary Science Letters 289, 606-618.

Afonso, J. C., Rawlinson, N., Yang, Y., Schutt, D. L., Jones, A. G., Fullea, J. \& Griffin, W. L. (2016). 3-D multiobservable probabilistic inversion for the compositional and thermal structure of the lithosphere and upper mantle: III. Thermochemical tomography in the Western-Central U.S. Journal of Geophysical Research: Solid Earth 121, 7337-7370.

Ague, J. J., Eckert, J. O., Chu, X., Baxter, E. F. \& Chamberlain, C. P. (2013). Discovery of ultrahigh-temperature metamorphism in the Acadian orogen, Connecticut, USA. Geology 41, 271-274.

Aizawa, Y., Barnhoorn, A., Faul, U. H., Fitz Gerald, J. D., Jackson, I. \& Kovács, I. (2008). Seismic properties of Anita Bay dunite: An exploratory study of the influence of water. Journal of Petrology 49, 841-855.

Alcock, J., Isachsen, C., Livi, K. \& Muller, P. (2004). Unraveling growth history of zircon in anatectites from the northeast Adirondack Highlands, New York: Constraints on pressure-temperature-time paths. In: Tollo, R. P., McLelland, J., Corriveau, L. \& Bartholomew, M. J. (eds) Memoir 197: Proterozoic Tectonic Evolution of the Grenville Orogen in North America. Geological Society of America, 267-284.

Amato, J. M., Mack, G. H., Jonell, T. N., Seager, W. R. \& Upchurch, G. R. (2017). Onset of the Laramide orogeny and associated magmatism in southern New Mexico based on U-Pb geochronology. Bulletin of the Geological Society of America 129, 12091226. 
Anderson, D. L. \& Dziewonski, A. M. (1984). Seismic Tomography. IEE Colloquium (Digest) 251, 60-71.

Aoki, K. (1981). Major element geochemistry of chromian spinel peridotite xenoliths in the Green Knobs Kimberlite, New Mexico. Science Reports Tohoku University 15, 127-130.

Armbrustmacher, T. J. \& Banks, N. G. (1974). Clouded plagioclase in metadolerite dikes, Southeastern Bighorn Mountains, Wyoming. American Mineralogist 59, 656-665.

Armstrong, J. T. (1995). CITZAF - A package of correction programs for the quantitative electron microbeam X-ray analysis of thick polished materials, thin-films, and particles. Microbeam Analysis.

Ashwal, L. D. (1982). Mineralogy of mafic Fe-Ti oxide-rich differentiates of the Marcy anorthosite massif, Adirondacks, New York. American Mineralogist 67, 14-27.

Audet, P. \& Bürgmann, R. (2011). Dominant role of tectonic inheritance in supercontinent cycles. Nature Geoscience. Nature Publishing Group 4, 184-187.

Auer, L., Becker, T. W., Boschi, L. \& Schmerr, N. (2015). Thermal structure, radial anisotropy, and dynamics of oceanic boundary layers. Geophysical Research Letters 42, 9740-9749.

Auer, L., Boschi, L., Becker, T. W. \& Giardini, D. (2014). Savani : A variable resolution whole-mantle model of anisotropic shear velocity variations based. 3006-3034.

Austrheim, H. (1998). Influence of Fluid and Deformation on Metamorphism of the Deep Crust and Consequences for the Geodynamics of Collision Zones. , 297-323.

Axler, J. A. \& Ague, J. J. (2015). Oriented multiphase needles in garnet from ultrahightemperature granulites, Connecticut, U.S.A. American Mineralogist 100, 22542271.

Babuška, V. (1972). Elasticity and anisotropy of dunite and bronzitite. Journal of Geophysical Research 77, 6955-6965.

Baker, M. B., Grove, T. L. \& Price, R. (1994). Primitive basalts and andesites from the Mt. Shasta region, N. California: products of varying melt fraction and water content. Contributions to Mineralogy and Petrology 118, 111-129.

Ballard, R. D., Bryan, W. B., Heirtzler, J. R., Keller, G., Moore, J. G. \& Van Andel, T. (1975). Manned Submersible Observations in the FAMOUS Area: Mid-Atlantic Ridge. Science 190, 103-108.

Baptiste, V. \& Tommasi, A. (2014). Petrophysical constraints on the seismic properties of the Kaapvaal craton mantle root. Solid Earth 5, 45-63.

Baptiste, V., Tommasi, A. \& Demouchy, S. (2012). Deformation and hydration of the lithospheric mantle beneath the Kaapvaal craton, South Africa. Lithos. Elsevier B.V. 149, 31-50.

Bartholome, P. (1960). Genesis of the Gore Mountain Garnet Deposit, New York. Economic Geology 55, 255-277.

Bass, J. D. (1989). Elasticity of grossular and spessartite garnets by Brillouin spectroscopy. Journal of Geophysical Research 94, 7621-7628.

Basu, A., Faggart, B. \& Sharma, M. (1989). Implications of Nd-isotopic study of Proterozoic garnet amphibolites and wollastonite skarns from the Adirondack Mountains, New York. Proc. 28th Internat. Geol. Congr. Washington, DC.

Beaumont, C., Jamieson, R. A., Nguyen, M. H. \& Medvedev, S. (2004). Crustal channel flows: 1. Numerical models with applications to the tectonics of the Himalayan- 
Tibetan orogen. Journal of Geophysical Research: Solid Earth 109, 1-29.

Bechtel, T. D., Forsyth, D. W., Sharpton, V. L. \& Grieve, R. A. F. (1990). Variations in effective elastic thickness of the North American lithosphere. Nature 343, 636-638.

Becker, T. W., Faccenna, C., Humphreys, E. D., Lowry, A. R. \& Miller, M. S. (2014). Static and dynamic support of western United States topography. Earth and Planetary Science Letters. Elsevier B.V. 402, 234-246.

Becker, T. W. \& O’Connell, R. J. (2001). Predicting plate velocities with mantle circulation models. Geochemistry, Geophysics, Geosystems 2.

Beckman, V. \& Möller, C. (2018). Prograde metamorphic zircon formation in gabbroic rocks: The tale of microtextures. Journal of Metamorphic Geology 36, 1221-1236.

Beckman, V., Möller, C., Söderlund, U. \& Andersson, J. (2017). Zircon growth during progressive recrystallization of Gabbro to Garnet Amphibolite, Eastern Segment, Sveconorwegian orogen. Journal of Petrology 58, 167-188.

Begg, G. C. et al. (2009). The lithospheric architecture of Africa: Seismic tomography, mantle petrology, and tectonic evolution. Geosphere 5, 23-50.

Behn, M. D. \& Grove, T. L. (2015). Melting systematics in mid-ocean ridge basalts: Application of a plagioclase-spinel melting model to global variations in major element chemistry and crustal thickness. Journal of Geophysical Research: Solid Earth 120, 4863-4886.

Behn, M. D., Hirth, G. \& Elsenbeck, J. R. (2009). Implications of grain size evolution on the seismic structure of the oceanic upper mantle. Earth and Planetary Science Letters. Elsevier B.V. 282, 178-189.

Behn, M. D. \& Ito, G. (2008). Magmatic and tectonic extension at mid-ocean ridges: 1. Controls on fault characteristics. Geochemistry, Geophysics, Geosystems 9.

Behn, M. D. \& Kelemen, P. B. (2003). Relationship between seismic P-wave velocity and the composition of anhydrous igneous and meta-igneous rocks. Geochemistry, Geophysics, Geosystems 4, 1-57.

Behn, M. D. \& Kelemen, P. B. (2006). Stability of arc lower crust: Insights from the Talkeetna arc section, south central Alaska, and the seismic structure of modern arcs. Journal of Geophysical Research: Solid Earth 111, 1-20.

Behr, W. M. \& Hirth, G. (2014). Rheological properties of the mantle lid beneath the Mojave region in southern California. Earth and Planetary Science Letters. Elsevier B.V. 393, 60-72.

Behr, W. M. \& Platt, J. P. (2012). Kinematic and thermal evolution during two-stage exhumation of a Mediterranean subduction complex. Tectonics 31.

Bernard, R. E., Schulte-Pelkum, V. \& Behr, W. M. (2021). The competing effects of olivine and orthopyroxene CPO on seismic anisotropy. Tectonophysics. Tectonophysics 228954.

Bickford, M. E., McLelland, J. M., Selleck, B. W., Hill, B. M. \& Heumann, M. J. (2008). Timing of anatexis in the eastern Adirondack Highlands: Implications for tectonic evolution during ca. 1050 Ma Ottawan orogenesis. Bulletin of the Geological Society of America 120, 950-961.

Bina, C. R. \& Helffrich, G. R. (1992). Calculation of elastic properties from thermodynamic equation of state principles. Annual review of Earth and planetary sciences. Vol. 20 527-552.

Birch, F. (1960). The velocity of compressional waves in rocks to 10 kilobars: 1. Journal 
of Geophysical Research 65, 1083-1102.

Birch, F. (1961). The velocity of compressional waves in rocks to 10 kilobars: 2. Journal of Geophysical Research. Washington, D. C.: American Geophysical Union 66, 2199-2224.

Bird, D. E., Burke, K., Hall, S. A. \& Casey, J. F. (2005). Gulf of Mexico tectonic history: Hotspot tracks, crustal boundaries, and early salt distribution. AAPG Bulletin $\mathbf{8 9}$, 311-328.

Bird, P. (1991). Lateral extrusion of lower crust from under high topography, in the isostatic limit. Journal of Geophysical Research 96, 275-286.

Black, L. P. et al. (2004). Improved 206Pb/238U microprobe geochronology by the monitoring of a trace-element-related matrix effect; SHRIMP, ID-TIMS, ELAICP-MS and oxygen isotope documentation for a series of zircon standards. Chemical Geology 205, 115-140.

Black, L. P. \& Gulson, B. L. (1978). The age of the mud tank carbonatite, strangways range, northern territory. BMR Journal of Australian Geology and Geophysics $\mathbf{3}$, 227-232.

Blom, N., Boehm, C. \& Fichtner, A. (2017). Synthetic inversions for density using seismic and gravity data. Geophysical Journal International 209, 1204-1220.

Bohlen, S. R., Valley, J. W. \& Essene, E. J. (1985). Metamorphism in the adirondacks. I. petrology, pressure and temperature. Journal of Petrology 26, 971-992.

Bohnenstiehl, D. R. \& Kleinrock, M. C. (1999). Faulting and fault scaling on the median valley floor of the trans-Atlantic geotraverse (TAG) segment, $\sim 26^{\circ} \mathrm{N}$ on the MidAtlantic Ridge. Journal of Geophysical Research: Solid Earth 104, 29351-29364.

Bohnenstiehl, D. W. R. \& Carbotte, S. M. (2001). Faulting patterns near 19³0'S on the East Pacific Rise: Fault formation and growth at a superfast spreading center. Geochemistry, Geophysics, Geosystems 2.

Bonamici, C. E., Fanning, C. M., Kozdon, R., Fournelle, J. H. \& Valley, J. W. (2015). Combined oxygen-isotope and U-Pb zoning studies of titanite: New criteria for age preservation. Chemical Geology. Elsevier B.V. 398, 70-84.

Bonatti, E., Ligi, M., Brunelli, D., Cipriani, A., Fabretti, P., Ferrante, V., Gasperini, L. \& Ottolini, L. (2003). Mantle thermal pulses below the Mid-Atlantic Ridge and temporal variations in the formation of oceanic lithosphere. Nature 423, 499-505.

Borghini, G., Fumagalli, P. \& Rampone, E. (2010). The stability of plagioclase in the upper mantle: Subsolidus experiments on fertile and depleted lherzolite. Journal of Petrology 51, 229-254.

Bougault, H., Dmitriev, L., Schilling, J. G., Sobolev, A., Joron, J. L. \& Needham, H. D. (1988). Mantle heterogeneity from trace elements: MAR triple junction near $14^{\circ} \mathrm{N}$. Earth and Planetary Science Letters 88, 27-36.

Brady, R. J., Ducea, M. N., Kidder, S. B. \& Saleeby, J. B. (2006). The distribution of radiogenic heat production as a function of depth in the Sierra Nevada Batholith, California. Lithos 86, 229-244.

Braile, L. W., Hinze, W. J., Sexton, J. L., Keller, G. R. \& Lidiak, E. G. (1984). Tectonic development of the New Madrid seismic zone. US Geological Survey Open File Report 84, 204-233.

Brey, G. P. \& Köhler, T. (1990). Geothermobarometry in four-phase lherzolites II. new thermobarometers, and practical assessment of existing thermobarometers. Journal 
of Petrology 31, 1353-1378.

Brueseke, M. E., Hobbs, J. M., Bulen, C. L., Mertzman, S. A., Puckett, R. E., Walker, J. D. \& Feldman, J. (2016). Cambrian intermediate-mafic magmatism along the Laurentian margin: Evidence for flood basalt volcanism from well cuttings in the Southern Oklahoma Aulacogen (U.S.A.). Lithos. Elsevier B.V. 260, 164-177.

Bucholz, C. E., Gaetani, G. A., Behn, M. D. \& Shimizu, N. (2013). Post-entrapment modification of volatiles and oxygen fugacity in olivine-hosted melt inclusions. Earth and Planetary Science Letters. Elsevier 374, 145-155.

Buck, W. R. (1993). Effect of lithospheric thickness on the formation of high- and lowangle normal faults. Geology 21, 933-936.

Buck, W. R., Lavier, L. L. \& Poliakov, A. N. B. (2005). Modes of faulting at mid-ocean ridges. Nature 719-723.

Buddington, A. F. (1939). Adirondack igneous rocks and their metamorphism. Geological Society of America Memoir 7, 354.

Buddington, A. F. (1952). Chemical petrology of some metamorphosed Adirondack gabbroic, syenitic and quartz syenitic rocks. Jour. Sci., Bowen Vol 37-84.

Bürgmann, R. \& Dresen, G. (2008). Rheology of the Lower Crust and Upper Mantle: Evidence from Rock Mechanics, Geodesy, and Field Observations. Annual Review of Earth and Planetary Sciences 36, 531-567.

Burke, K. (1988). Tectonic evolution of the Caribbean. Annual Review of Earth and Planetary Sciences 16, 201-230.

Byerly, B. L. \& Lassiter, J. C. (2012). Evidence from mantle xenoliths for lithosphere removal beneath the central Rio Grande Rift. Earth and Planetary Science Letters. Elsevier 355-356, 82-93.

Calmant, S. \& Cazenave, A. (1987). The elastic thickness of the lithosphere in the Pacific Ocean. Earth and Planetary Science Letters 85, 277-288.

Cammarano, F., Goes, S., Vacher, P. \& Giardini, D. (2003). Inferring upper-mantle temperatures from seismic velocities. Physics of the Earth and Planetary Interiors 138, 197-222.

Canales, J. P., Collins, J. A., Escartín, J. \& Detrick, R. S. (2000a). Seismic structure across the rift valley of the Mid-Atlantic Ridge at $23^{\circ} 20^{\prime}$ (MARK area): Implications for crustal accretion processes at slow spreading ridges. Journal of Geophysical Research: Solid Earth 105, 28411-28425.

Canales, J. P., Detrick, R. S., Lin, J., Collins, J. A. \& Toomey, D. R. (2000b). Crustal and upper mantle seismic structure beneath the rift mountains and across a nontransform offset at the Mid-Atlantic Ridge $\left(35^{\circ} \mathrm{N}\right)$. Journal of Geophysical Research: Solid Earth 105, 2699-2719.

Canil, D., O’Neill, H. S. C., Pearson, D. G., Rudnick, R. L., McDonough, W. F. \& Carswell, D. A. (1994). Ferric iron in peridotites and mantle oxidation states. Earth and Planetary Science Letters 123, 205-220.

Cann, J. R., Blackman, D. K., Smith, D. K., McAllister, E., Janssen, B., Mello, S., Avgerinos, E., Pascoe, A. R. \& Escartin, J. (1997). Corrugated slip surfaces formed at ridge-transform intersections on the Mid-Atlantic Ridge. Nature 385, 329-332.

Cannat, M. (1996). How thick is the magmatic crust at slow spreading oceanic ridges ? Melt Migration in the Axial Lithosphere of Slow Spreading Ridges : Constraints from Ultramafic and Gabbroic Samples. Journal of Geophysical Research: Solid 
Earth 101, 2847-2857.

Cannat, M., Mangeney, A., Ondréas, H., Fouquet, Y. \& Normand, A. (2013). Highresolution bathymetry reveals contrasting landslide activity shaping the walls of the Mid-Atlantic Ridge axial valley. Geochemistry, Geophysics, Geosystems 14, 9961011.

Carbotte, S. M. \& Macdonald, K. C. (1994). Comparison of seafloor tectonic fabric at intermediate, fast, and super fast spreading ridges: Influence of spreading rate, plate motions, and ridge segmentation on fault patterns. Journal of Geophysical Research: Solid Earth 99, 13609-13631.

Carbotte, S. M., Nedimović, M. R., Canales, J. P., Kent, G. M., Harding, A. J. \& Marjanović, M. (2008). Variable crustal structure along the Juan de Fuca Ridge: Influence of on-axis hot spots and absolute plate motions. Geochemistry, Geophysics, Geosystems 9.

Caress, D. W. \& Chayes, D. N. (2017). MB-System: Mapping the Seafloor. .

Caress, D. W., Menard, H. W. \& Hey, R. N. (1988). Eocene reorganization of the PacificFarallon Spreading Center north of the Mendocino Fracture Zone. Journal of Geophysical Research 93, 2813.

Carr, S. D., Easton, R. M., Jamieson, R. A. \& Culshaw, N. G. (2000). Geologic transect across the Grenville orogen of Ontario and New York. Canadian Journal of Earth Sciences 37, 193-216.

Carrero Mustelier, E. \& Menke, W. (2021). Seismic anomalies in the southeastern North American asthenosphere as characterized with body wave travel times from highquality teleseisms. Tectonophysics. Elsevier B.V. 809, 228853.

Chapman, D. S. (1986). Thermal gradients in the continental crust. Geological Society Special Publication 24, 63-70.

Chen, L., Booker, J. R., Jones, A. G., Wu, N., Unsworth, M. J., Wei, W. \& Tan, H. (1996). Electrically conductive crust in southern Tibet from INDEPTH magnetotelluric surveying. Science 274, 1694-1696.

Chen, Y. J. (1992). Oceanic crustal thickness versus spreading rate. Geophysical Research Letters 19, 753-756.

Chen, Y. \& Morgan, W. J. (1990a). Rift valley/no rift valley transition at mid-ocean ridges. Journal of Geophysical Research 95, 17571.

Chen, Y. \& Morgan, W. J. (1990b). A Nonlinear Rheology Model for Mid-Ocean Ridge Axis Topography The relative size of the decoupling chamber to the size lated to form the theory for the oceanic of the plastic failure zone within the brittle plate determines the sphere and an iteration sch. Journal of Geophysical Research $\mathbf{9 5}$, $17,583-17,604$.

Cherniak, D. J. \& Dimanov, A. (2010). Diffusion in pyroxene, mica and amphibole. Reviews in Mineralogy and Geochemistry 72, 641-690.

Chiarenzelli, J., Regan, S., Peck, W. H., Selleck, B. W., Cousens, B., Baird, G. B. \& Shrady, C. H. (2010). Shawinigan arc magmatism in the Adirondack Lowlands as a consequence of closure of the Trans-Adirondack backarc basin. Geosphere 6, 900916.

Chiarenzelli, J., Selleck, B., Lupulescu, M., Regan, S., Bickford, M. E., Valley, P. \& McLelland, J. (2017). Lyon Mountain ferroan leucogranite suite: Magmatic response to extensional thinning of overthickened crust in the core of the Grenville orogen. 


\section{GSA Bulletin.}

Chiarenzelli, J., Valentino, D., Lupulescu, M., Thern, E. \& Johnston, S. (2011).

Differentiating Shawinigan and Sttawan orogenesis in the Central Adirondacks.

Geosphere 7, 2-22.

Chin, E. J., Lee, C. T. A., Luffi, P. \& Tice, M. (2012). Deep lithospheric thickening and refertilization beneath continental arcs: Case study of the $\mathrm{P}, \mathrm{T}$ and compositional evolution of peridotite xenoliths from the Sierra Nevada, California. Journal of Petrology 53, 477-511.

Christensen, N. I. (1966). Elasticity of ultrabasic rocks. Journal of Geophysical Research 71, 5921-5931.

Christensen, N. I. (1974). Compressional Wave Velocities in Possible the important relationship between density , of which. Journal of Geophysical Research 79, 407412.

Christensen, N. I. (1978). Ophiolites, seismic velocities and oceanic crustal structure. Tectonophysics 47, 131-157.

Christensen, N. I. (1996). Poisson's ratio and crustal seismology. Journal of Geophysical Research: Solid Earth 101, 3139-3156.

Christensen, N. I. \& Mooney, W. D. (1995). Seismic velocity structure and composition of the continental crust: a global view. Journal of Geophysical Research 100, 97619788.

Christensen, N. I. \& Ramananantoandro, R. (1971). Elastic moduli and anisotropy of dunite to 10 kilobars. Journal of Geophysical Research 76, 4003-4010.

Chu, R., Leng, W., Helmberger, D. V. \& Gurnis, M. (2013). Hidden hotspot track beneath the eastern United States. Nature Geoscience. Nature Publishing Group 6, 963-966.

Chu, X. \& Ague, J. J. (2015). Analysis of experimental data on divalent cation diffusion kinetics in aluminosilicate garnets with application to timescales of peak Barrovian metamorphism, Scotland. Contributions to Mineralogy and Petrology. Springer Berlin Heidelberg 170, 1-27.

Cipar, J. H., Garber, J. M., Kylander-Clark, A. R. C. \& Smye, A. J. (2020). Active crustal differentiation beneath the Rio Grande Rift. Nature Geoscience. Springer US 13, 758-763.

Clark, M. K., Bush, J. W. M. \& Royden, L. H. (2005). Dynamic topography produced by lower crustal flow against rheological strength heterogeneities bordering the Tibetan Plateau. Geophysical Journal International 162, 575-590.

Clark, M. K. \& Royden, L. H. (2000). Topographic ooze: Building the eastern margin of Tibet by lower crustal flow. Geology 28, 703-706.

Cline, C. J., Faul, U. H., David, E. C., Berry, A. J. \& Jackson, I. (2018). Redoxinfluenced seismic properties of uppermantle olivine. Nature. Nature Publishing Group 555, 355-358.

Connelly, J. N. (2006). Improved dissolution and chemical separation methods for Lu-Hf garnet chronometry. Geochemistry, Geophysics, Geosystems 7, 1-9.

Connolly, J. A. D. (2009). The geodynamic equation of state: What and how. Geochemistry, Geophysics, Geosystems 10.

Connolly, J. A. D. \& Khan, A. (2016). Uncertainty of mantle geophysical properties computed from phase equilibrium models. Geophysical Research Letters 43, 5026- 
5034.

Conrad, C. P. \& Lithgow-Bertelloni, C. (2002). How mantle slabs drive plate tectonics. Science 298, 207-209.

Cottrell, E., Birner, S., Brounce, M., Davis, F., Waters, L. \& Kelley, K. (2020). AGU Geophysical Monograph Redox variables and mechanisms in magmatism and volcanism. In: Neuville, D. R. \& Moretti, R. (eds) Wiley.

Cottrell, E. \& Kelley, K. A. (2011). The oxidation state of Fe in MORB glasses and the oxygen fugacity of the upper mantle. Earth and Planetary Science Letters. Elsevier B.V. 305, 270-282.

Cowie, P. A., Scholz, C. H., Edwards, M. \& Malinverno, A. (1993). Fault strain and seismic coupling on mid-ocean ridges. Journal of Geophysical Research: Solid Earth 98, 17911-17920.

Cox, R. T. \& Van Arsdale, R. B. (2002). The Mississippi Embayment, North America: A first order continental structure generated by the Cretaceous superplume mantle event. Journal of Geodynamics 34, 163-176.

Crowley, J. W., Katz, R. F., Huybers, P., Langmuir, C. H. \& Park, S.-H. (2015). Glacial cycles drive variations in the production of oceanic crust. Science 347, 1237-1240.

Cushing, E. M., Boswell, E. H. \& Hosman, R. L. (1964). General geology of the Mississippi embayment. Professional Paper 448-B, 448.

Dahl, P. S., Pomfrey, M. E. \& Foland, K. A. (2004). Slow cooling and apparent tilting of the Adirondack Lowlands, Grenville Province, New York, based on 40Ar/39Ar ages. Memoir of the Geological Society of America 197, 299-323.

Dallmeyer, R. D., Wright, J. E., Secor, D. T. \& Snoke, A. W. (1986). Character of the Alleghanian orogeny in the southern Appalachians: Part II. Geochronological constraints on the tectonothermal evolution of the eastern Piedmont in South Carolina. Geological Society of America Bulletin 97, 1329.

Danielson, J. J. \& Gesch, D. B. (2011). Global Multi-resolution Terrain Elevation Data 2010 (GMTED2010). U.S. Geological Survey Open-File Report 2011-1073.

Darling, R. S. (2013). Zircon-bearing, crystallized melt inclusions in peritectic garnet from the western Adirondack Mountains, New York State, USA. Geofluids 13, 453459.

Darling, R. S., Chou, I. M. \& Bodnar, R. J. (1997). An occurrence of metastable cristobalite in high-pressure garnet Granulite. Science 276, 91-93.

Darling, R. S., Florence, F. P., Lester, G. W. \& Whitney, P. R. (2004). Petrogenesis of prismatine-bearing metapelitic gneisses along the Moose River, west-central Adirondacks, New York. Memoir 197: Proterozoic Tectonic Evolution of the Grenville Orogen in North America. Geological Society of America, 325-336.

Dave, R. \& Li, A. (2016). Destruction of the Wyoming craton: Seismic evidence and geodynamic processes. Geology 44, 883-886.

Davidson, A. \& van Breemen, O. (1988). Baddeleyite-zircon relationships in coronitic metagabbro, Grenville Province, Ontario: implications for geochronology. Contributions to Mineralogy and Petrology 100, 291-299.

Dawson, J. B. \& Smith, J. V. (1982). Upper-mantle amphiboles: a review. Mineralogical Magazine 45, 35-46.

de Béthune, P., Laduron, D. \& Bocquet, J. (1975). Diffusion processes in resorbed garnets. Contributions to Mineralogy and Petrology 50, 197-204. 
Dégi, J., Abart, R., Török, K., Bali, E., Wirth, R. \& Rhede, D. (2010). Symplectite formation during decompression induced garnet breakdown in lower crustal mafic granulite xenoliths: Mechanisms and rates. Contributions to Mineralogy and Petrology 159, 293-314.

Demouchy, S. \& Bolfan-Casanova, N. (2016). Distribution and transport of hydrogen in the lithospheric mantle: A review. Lithos. Elsevier B.V. 240-243, 402-425.

Demouchy, S., Ishikawa, A., Tommasi, A., Alard, O. \& Keshav, S. (2015). Characterization of hydration in the mantle lithosphere: Peridotite xenoliths from the Ontong Java Plateau as an example. Lithos. Elsevier B.V. 212-215, 189-201.

Detrick, R. S., Needham, H. D. \& Renard, V. (1995). Gravity anomalies and crustal thickness variations along the Mid- Atlantic Ridge between $33^{\circ} \mathrm{N}$ and $40^{\circ} \mathrm{N}$. Journal of Geophysical Research 100, 3767-3787.

Dick, H. J. B., Lin, J. \& Schouten, H. (2003). An ultraslow-spreading class of ocean ridge. Nature 426, 405-412.

Dimanov, A. \& Dresen, G. (2005). Rheology of synthetic anorthite-diopside aggregates: Implications for ductile shear zones. Journal of Geophysical Research: Solid Earth 110, 1-24.

Dimanov, A., Dresen, G. \& Wirth, R. (1998). High-temperature creep of partially molten plagioclase aggregates. Journal of Geophysical Research: Solid Earth 103, 96519664.

Divins, D. (2003). Total sediment thickness of the world's oceans \& marginal seas. NOAA National Geophysical Data Center, Boulder, CO.

Douce, A. E. P. (1993). Titanium substitution in biotite: an empirical model with applications to thermometry, $\mathrm{O} 2$ and $\mathrm{H} 2 \mathrm{O}$ barometries, and consequences for biotite stability. Chemical Geology 108, 133-162.

Ducea, M. \& Saleeby, J. (1998). A case for delamination of the deep batholithic crust beneath the sierra nevada, california. International Geology Review 40, 78-93.

Duncan, R. A. (1984). Age progressive volcanism in the New England Seamounts and the opening of the central Atlantic Ocean. Journal of Geophysical Research 89, 9980-9990.

Durham, W. B., Mirkovich, V. V. \& Heard, H. C. (1987). Thermal diffusivity of igneous rocks at elevated pressure and temperature. Journal of Geophysical Research: Solid Earth 92, 11615-11634.

Eason, D. E., Dunn, R. A., Pablo Canales, J. \& Sohn, R. A. (2016). Segment-scale variations in seafloor volcanic and tectonic processes from multibeam sonar imaging, Mid-Atlantic Ridge Rainbow region $\left(35^{\circ} 45^{\prime}-36^{\circ} 35^{\prime} \mathrm{N}\right)$. Geochemistry, Geophysics, Geosystems 17, 3560-3579.

Eaton, D. W. \& Claire Perry, H. K. (2013). Ephemeral isopycnicity of cratonic mantle keels. Nature Geoscience. Nature Publishing Group 6, 967-970.

Edwards, R. L. \& Essene, E. J. (1988). Pressure, temperature and C-O-H fluid fugacities across the amphibolite-granulite transition, Northwest adirondack mountains, New York. Journal of Petrology 29, 39-72.

Ehrenberg, S. N. (1979). Garnetiferous ultramafic inclusions in minette from the Navajo volcanic field. The Mantle Sample: Inclusion in Kimberlites and Other Volcanics. Washington, D. C.: American Geophysical Union, 330-344.

Ellis, D. J. \& Green, D. H. (1979). An experimental study of the effect of Ca upon garnet- 
clinopyroxene Fe-Mg exchange equilibria. Contributions to Mineralogy and Petrology 71, 13-22.

Emslie, R. F. \& Hunt, P. A. (1990). Ages and Petrogenetic Significance of Igneous Mangerite-Charnockite Suites Associated with Massif Anorthosites, Grenville Province. The Journal of Geology 98, 213-231.

England, P. C., Walker, R. T., Fu, B. \& Floyd, M. A. (2013). A bound on the viscosity of the Tibetan crust from the horizontality of palaeolake shorelines. Earth and Planetary Science Letters. Elsevier 375, 44-56.

English, J. M. \& Johnston, S. T. (2004). The Laramide Orogeny: What Were the Driving Forces? International Geology Review 46, 833-838.

Ervin, C. P. \& McGinnis, L. D. (1975). Reelfoot rift: Reactivated precursor to the Mississippi embayment. Bulletin of the Geological Society of America 86, 12871295.

Escartín, J. et al. (2017). Tectonic structure, evolution, and the nature of oceanic core complexes and their detachment fault zones $\left(13^{\circ} 20^{\prime} \mathrm{N}\right.$ and $13^{\circ} 30^{\prime} \mathrm{N}$, Mid Atlantic Ridge). Geochemistry, Geophysics, Geosystems 18, 1451-1482.

Escartín, J., Cannat, M., Pouliquen, G., Rabain, A. \& Lin, J. (2001). Crustal thickness of V-shaped ridges south of the Azores: Interaction of the Mid-Atlantic Ridge ( $36^{\circ}$ $39^{\circ} \mathrm{N}$ ) and the Azores hot spot. Journal of Geophysical Research: Solid Earth 106, 21719-21735.

Escartín, J., Smith, D. K., Cann, J., Schouten, H., Langmuir, C. H. \& Escrig, S. (2008). Central role of detachment faults in accretion of slow-spreading oceanic lithosphere. Nature 455, 790-794.

Falus, G., Tommasi, A., Ingrin, J. \& Szabó, C. (2008). Deformation and seismic anisotropy of the lithospheric mantle in the southeastern Carpathians inferred from the study of mantle xenoliths. Earth and Planetary Science Letters 272, 50-64.

Fan, D., Fu, S., Yang, J., Tkachev, S. N., Prakapenka, V. B. \& Lin, J. F. (2019). Elasticity of single-crystal periclase at high pressure and temperature: The effect of iron on the elasticity and seismic parameters of ferropericlase in the lower mantle. American Mineralogist 104, 262-275.

Faul, U. \& Jackson, I. (2005). The seismological signature of temperature and grain size variations in the upper mantle. Earth and Planetary Science Letters 234, 119-134.

Faul, U. \& Jackson, I. (2015). Transient creep and strain energy dissipation: An experimental perspective. Annual Review of Earth and Planetary Sciences 43, 541569.

Feineman, M. D. \& DePaolo, D. J. (2003). Steady-state 226Ra/230Th disequilibrium in mantle minerals: Implications for melt transport rates in island arcs. Earth and Planetary Science Letters 215, 339-355.

Ferguson, D. J., Li, Y., Langmuir, C. H., Costa, K. M., McManus, J. F., Huybers, P. \& Carbotte, S. M. (2017). A 65 k.y. time series from sediment-hosted glasses reveals rapid transitions in ocean ridge magmas. Geology 45, 491-494.

Ferrero, S., Wannhof, I., Darling, R. S., Wunder, B., Laurent, O., Ziemann, M. A., Günter, C. \& O’Brien, P. J. (2019). Why Are They So Darn Big? The Role of Crustal Melting in the Formation of the Gore Mountain Mega Garnets (Adirondacks, US). AGU FAll Meeting.

Finlay, C. C. et al. (2010). International Geomagnetic Reference Field: The eleventh 
generation. Geophysical Journal International 183, 1216-1230.

Flament, N., Gurnis, M. \& Dietmar Müller, R. (2013). A review of observations and models of dynamic topography. Lithosphere 5, 189-210.

Florence, F. P., Darling, R. S. \& Orrell, S. E. (1995). Moderate pressure metamorphism and anatexis due to anorthosite intrusion, western Adirondack Highlands, New York. Contributions to Mineralogy and Petrology 121, 424-436.

Forsyth, D. \& Uyeda, S. (1975). On the Relative Importance of the Driving Forces of Plate Motion. Geophysical Journal International 43, 163-200.

Forsyth, D. W. (1985). Subsurface loading and estimates of the flexural rigidity of continental lithosphere. Journal of Geophysical Research 90.

Forsyth, D. W. (1992). Finite extension and low-angle normal faulting. Geology 20, $27-$ 30.

Forte, A. M., Dziewonski, A. M. \& Connell, R. J. O. (1995). Continent-Ocean Chemical Heterogeneity in the Mantle Based on Seismic Tomography. Science 268, 386-389.

Fountain, D. M. \& Christensen, N. I. (1989). Chapter 30: Composition of the continental crust and upper mantle; A review. Memoir of the Geological Society of America, 711-742.

Fowler, C. M. R. (2004). The Solid Earth. Cambridge University Press.

Freed, A. M. \& Bürgmann, R. (2004). Evidence of power-law flow in the Mojave desert mantle. Nature 430, 548-551.

Freed, A. M., Bürgmann, R. \& Herring, T. (2007). Far-reaching transient motions after Mojave earthquakes require broad mantle flow beneath a strong crust. Geophysical Research Letters 34, 1-5.

Frey, F. A. \& Prinz, M. (1978). Ultramafic inclusions from San Carlos, Arizona: Petrologic and geochemical data bearing on their petrogenesis. Earth and Planetary Science Letters 38, 129-176.

Fuhrman, M. L. \& Lindsley, D. H. (1988). Ternary-feldspar modeling and thermometry. American Mineralogist 73, 201-215.

Fullea, J., Afonso, J. C., Connolly, J. A. D., Fernàndez, M., García-Castellanos, D. \& Zeyen, H. (2009). LitMod3D: An interactive 3-D software to model the thermal, compositional, density, seismological, and rheological structure of the lithosphere and sublithospheric upper mantle. Geochemistry, Geophysics, Geosystems 10, 1-21.

Fullea, J., Muller, M. R. \& Jones, A. G. (2011). Electrical conductivity of continental lithospheric mantle from integrated geophysical and petrological modeling: Application to the Kaapvaal Craton and Rehoboth Terrane, southern Africa. Journal of Geophysical Research: Solid Earth 116, 1-32.

Gaetani, G. A., O’Leary, J. A., Shimizu, N., Bucholz, C. E. \& Newville, M. (2012). Rapid reequilibration of $\mathrm{H} 2 \mathrm{O}$ and oxygen fugacity in olivine-hosted melt inclusions. Geology 40, 915-918.

Gale, A., Dalton, C. A., Langmuir, C. H., Su, Y. \& Schilling, J. G. (2013). The mean composition of ocean ridge basalts. Geochemistry, Geophysics, Geosystems.

Gao, S., Kern, H., Liu, Y. S., Jin, S. Y., Popp, T., Jin, Z. M., Feng, J. L., Sun, M. \& Zhao, Z. Bin (2000). granulites from xenolith occurrences and adjacent exposed lower crustal sections : A comparative study from the. Journal of Geophysical Research 105, 18965-18976.

Garber, J. M. et al. (2018). Multidisciplinary Constraints on the Abundance of Diamond 
and Eclogite in the Cratonic Lithosphere. Geochemistry, Geophysics, Geosystems 19, 2062-2086.

German, C. R., Klinkhammer, G. P. \& Rudnicki, M. D. (1996). The Rainbow Hydrothermal Plume, $36^{\circ} 15^{\prime}$ N, MAR. Geophysical Research Letters 23, 2979 2982.

Gerya, T. (2009). Introduction to Numerical Geodynamic Modelling. Cambridge: Cambridge University Press.

Gerya, T. V., Perchuk, L. L. \& Burg, J. P. (2008). Transient hot channels: Perpetrating and regurgitating ultrahigh-pressure, high-temperature crust-mantle associations in collision belts. Lithos 103, 236-256.

Goes, S., Govers, R. \& Vacher, P. (2000). Shallow mantle temperatures under Europe from P and S wave tomography. Journal of Geophysical Research: Solid Earth 105, 11153-11169.

Goes, S., Hasterok, D., Schutt, D. L. \& Klöcking, M. (2020). Continental lithospheric temperatures: A review. Physics of the Earth and Planetary Interiors 306.

Goes, S. \& van der Lee, S. (2002). Thermal structure of the North American uppermost mantle inferred from seismic tomography. Journal of Geophysical Research 107.

Goff, J. A. (2015). Comment on "Glacial cycles drive variations in the production of oceanic crust." Science 349, 1065.

Goff, J. A., Zahirovic, S. \& Müller, R. D. (2018). No Evidence for Milankovitch Cycle Influence on Abyssal Hills at Intermediate, Fast, and Superfast Spreading Rates. Geophysical Research Letters 45, 10,305-10,313.

Goldblum, D. R. \& Hill, M. L. (1992). Enhanced Fluid Flow Resulting from Competency Contrast within a Shear Zone: The Garnet Ore Zone at Gore Mountain, NY. The Journal of Geology 100, 776-782.

Golos, E. M., Fang, H. \& van der Hilst, R. D. (2020). Variations in Seismic Wave Speed and VP/VS Ratio in the North American Lithosphere. Journal of Geophysical Research: Solid Earth 125.

Grand, S. P., Van Der Hilst, R. D. \& Widiyantoro, S. (1997). Global seismic tomography: A snapshot of convection in the earth. GSA Today 7, 1-7.

Grant, K., Ingrin, J., Lorand, J. P. \& Dumas, P. (2007). Water partitioning between mantle minerals from peridotite xenoliths. Contributions to Mineralogy and Petrology 154, 15-34.

Gréaux, S. \& Yamada, A. (2019). Density variations of Cr-rich garnets in the upper mantle inferred from the elasticity of uvarovite garnet. Comptes Rendus Geoscience 351, 95-103.

Green, D. H. \& Ringwood, A. E. (1970). Mineralogy of peridotitic compositions under upper mantle conditions. Physics of the Earth and Planetary Interiors 3, 359-371.

Green, E. C. R., White, R. W., Diener, J. F. A., Powell, R., Holland, T. J. B. \& Palin, R. M. (2016). Activity-composition relations for the calculation of partial melting equilibria in metabasic rocks. Journal of Metamorphic Geology 34, 845-869.

Griffin, W. L., O’Reilly, S. Y., Abe, N., Aulbach, S., Davies, R. M., Pearson, N. J., Doyle, B. J. \& Kivi, K. (2003). The origin and evolution of Archean lithospheric mantle. Precambrian Research 127, 19-41.

Grove, T. L., Baker, M. B. \& Kinzler, R. J. (1984). Coupled CaAl-NaSi diffusion in plagioclase feldspar: Experiments and applications to cooling rate speedometry. 
Geochimica et Cosmochimica Acta 48, 2113-2121.

Grove, T., Parman, S., Bowring, S., Price, R. \& Baker, M. (2002). The role of an H2Orich fluid component in the generation of primitive basaltic andesites and andesites from the Mt. Shasta region, N California. Contributions to Mineralogy and Petrology 142, 375-396.

Grujic, D. (2006). Channel flow and continental collision tectonics: An overview. Geological Society Special Publication 268, 25-37.

Gysi, A. P., Jagoutz, O., Schmidt, M. \& Targuisti, K. (2011). Petrogenesis of pyroxenites and melt infiltrations in the ultramafic complex of Beni Bousera, northern Morocco. Journal of Petrology 52, 1679-1735.

Hacker, B. R. (2008). H2O subduction beyond arcs. Geochemistry, Geophysics, Geosystems 9.

Hacker, B. R. \& Abers, G. A. (2004). Subduction Factory 3: An Excel worksheet and macro for calculating the densities, seismic wave speeds, and $\mathrm{H} 2 \mathrm{O}$ contents of minerals and rocks at pressure and temperature. Geochemistry, Geophysics, Geosystems 5, 1-7.

Hacker, B. R., Abers, G. A. \& Peacock, S. M. (2003a). Subduction factory 1. Theoretical mineralogy, densities, seismic wave speeds, and $\mathrm{H} 2 \mathrm{O}$ contents. Journal of Geophysical Research: Solid Earth 108, 1-26.

Hacker, B. R. \& Christie, J. M. (1990). Brittle/ductile and plastic/cataclastic transitions in experimentally deformed and metamorphosed amphibolite. , 127-147.

Hacker, B. R., Kelemen, P. B. \& Behn, M. D. (2015). Continental lower crust. Annual Review of Earth and Planetary Sciences 43, 167-205.

Hacker, B. R., Peacock, S. M., Abers, G. A. \& Holloway, S. D. (2003b). Subduction factory 2. Are intermediate-depth earthquakes in subducting slabs linked to metamorphic dehydration reactions? Journal of Geophysical Research: Solid Earth 108.

Hager, B. H. \& O'Connell, R. J. (1981). A simple global model of plate dynamics and mantle convection. Journal of Geophysical Research 86, 4843-4867.

Hamilton, E. L. (1978). Sound velocity-density relations in sea-floor sediments and rocks. Journal of the Acoustical Society of America 63, 366-377.

Hamilton, M. A., McLelland, J. \& Selleck, B. (2004). SHRIMP U-Pb zircon geochronology of the anorthosite-mangerite-charnockite- granite suite, Adirondack Mountains, New York: Ages of emplacement and metamorphism. Memoir of the Geological Society of America 197, 337-355.

Hammond, W. C. \& Humphreys, E. D. (2000). Upper mantle seismic wave attenuation: Effects of realistic partial melt distribution. Journal of Geophysical Research: Solid Earth 105, 10987-10999.

Hanchar, J. M., Miller, C. F., Wooden, J. L., Bennett, V. C. \& Staude, J. M. G. (1994). Evidence from xenoliths for a dynamic lower crust, eastern mojave desert, California. Journal of Petrology 35, 1377-1415.

Hanmer, S., Corrigan, D., Pehrsson, S. \& Nadeau, L. (2000). SW Grenville Province, Canada: The case against post-1.4 Ga accretionary tectonics. Tectonophysics 319, 33-51.

Hanson, R. E., Puckett, R. E., Keller, G. R., Brueseke, M. E., Bulen, C. L., Mertzman, S. A., Finegan, S. A. \& McCleery, D. A. (2013). Intraplate magmatism related to 
opening of the southern Iapetus Ocean: Cambrian Wichita igneous province in the Southern Oklahoma rift zone. Lithos. Elsevier B.V. 174, 57-70.

Harmon, N., Wang, S., Rychert, C. A., Constable, S. \& Kendall, J.-M. (2021). One-Sided Joint Inversion of Shear Velocity and Resistivity from the PI-LAB Experiment at the Equatorial Mid-Atlantic Ridge. 1-31.

Harrison, T. M., Copeland, P., Kidd, W. S. F. \& Yin, A. (1992). Raising tibet. Science 255, 1663-1670.

Harrison, T. M., Duncan, I. \& McDougall, I. (1985). Diffusion of 40Ar in biotite: Temperature, pressure and compositional effects. Geochimica et Cosmochimica Acta.

Harry, D. L. \& Leeman, P. (1995). Partial melting of melt metasomatized subcontinental mantle and the magma source potential of the lower lithosphere. Journal of Geophysical Research 100, 10255-10269.

Hayman, N. W., Grindlay, N. R., Perfit, M. R., Mann, P., Leroy, S. \& De Lépinay, B. M. (2011). Oceanic core complex development at the ultraslow spreading Mid-Cayman Spreading Center. Geochemistry, Geophysics, Geosystems 12, 1-21.

Heaman, L. M. \& Kjarsgaard, B. A. (2000). Timing of eastern North American kimberlite magmatism: Continental extension of the Great Meteor hotspot track? Earth and Planetary Science Letters 178, 253-268.

Helffrich, G. R., Stein, S. \& Wood, B. J. (1989). Subduction zone thermal structure and mineralogy and their relationship to seismic wave reflections and conversions at the slab/mantle interface. Journal of Geophysical Research 94, 753.

Hess, P. C. (1989). Origins of Igneous Rocks. Harvard University Press.

Hill, R. (1952). The elastic behaviour of a crystalline aggregate. Proceedings of the Physical Society. Section A 65, 349-354.

Hirschmann, M. M. (2000). Mantle solidus: Experimental constraints and the effects of peridotite composition. Geochemistry, Geophysics, Geosystems 1.

Hirth, G. \& Beeler, N. M. (2015). The role of fluid pressure on frictional behavior at the base of the seismogenic zone. Geology 43, 223-226.

Hirth, G. \& Kohlstedt, D. L. (2003). Rheology of the Upper Mantle and the Mantle Wedge: A View from the Experimentalists upper mantle. We first analyze experimental data to provide a critical review of flow. Geophysical Monograph Series 138, 83-105.

Hirth, G., Teyssier, C. \& Dunlap, W. J. (2001). An evaluation of quartzite flow laws based on comparisons between experimentally and naturally deformed rocks. International Journal of Earth Sciences 90, 77-87.

Ho, T., Priestley, K. \& Debayle, E. (2016). A global horizontal shear velocity model of the upper mantle from multimode love wave measurements. Geophysical Journal International 207, 542-561.

Hoffman, P. F. (1988). UNITED PLATES OF AMERICA, THE BIRTH OF A CRATON : and Growth of Laurentia. Annual Review of Earth and Planetary Sciences 16, 543-603.

Hokada, T. \& Harley, S. L. (2004). Zircon growth in UHT leucosome: Constraints from zircon-garnet rare earth elements (REE) relations in Napier Complex, East Antarctica. Journal of Mineralogical and Petrological Sciences 99, 180-190.

Holland, T. \& Blundy, J. (1994). Non-ideal interactions in calcic amphiboles and their 
bearing on amphibole-plagioclase thermometry. Contributions to Mineralogy and Petrology 116, 433-447.

Holland, T. J. B., Green, E. C. R. \& Powell, R. (2018). Melting of peridotites through to granites: A simple thermodynamic model in the system KNCFMASHTOCr. Journal of Petrology 59, 881-900.

Holland, T. J. B. \& Powell, R. (1998). An internally consistent thermodynamic data set for phases of petrological interest. Journal of Metamorphic Geology 16, 309-343.

Holland, T. J. B. \& Powell, R. (2011). An improved and extended internally consistent thermodynamic dataset for phases of petrological interest, involving a new equation of state for solids. Journal of Metamorphic Geology 29, 333-383.

Holland, T. \& Powell, R. (1996). Thermodynamics of order-disorder in minerals: II. Symmetric formalism applied to solid solutions. American Mineralogist 81, 14251437.

Holland, T. \& Powell, R. (2003). Activity-composition relations for phases in petrological calculations: an asymmetric multicomponent formulation. Contributions to Mineralogy and Petrology 145, 492-501.

Hollocher, K. (2008). Origin of big garnets in amphibolites during high-grade metamorphism, Adirondacks, NY. 21 st Keck Research Symposium in Geology.

Hooft, E. E. E., Detrick, R. S., Toomey, D. R., Collins, J. A. \& Lin, J. (2000). Crustal thickness and structure along three contrasting spreading segments of the MidAtlantic Ridge, $33.5^{\circ}-35^{\circ}$ N. Journal of Geophysical Research: Solid Earth 105, $8205-8226$.

Hopper, E. \& Fischer, K. M. (2018). The Changing Face of the LithosphereAsthenosphere Boundary: Imaging Continental Scale Patterns in Upper Mantle Structure Across the Contiguous U.S. With Sp Converted Waves. Geochemistry, Geophysics, Geosystems 19, 2593-2614.

Houseman, G. A. \& Molnar, P. (1997). Gravitational (Rayleigh-Taylor) instability of a layer with non-linear viscosity and convective thinning of continental lithosphere. Geophysical Journal International 128, 125-150.

Howell, S. M., Ito, G., Behn, M. D., Martinez, F., Olive, J. \& Escartín, J. (2016). Magmatic and tectonic extension at the Chile Ridge: Evidence for mantle controls on ridge segmentation. Geochemistry, Geophysics, Geosystems 17, 2354-2373.

Howell, S. M., Olive, J. A., Ito, G., Behn, M. D., Escartín, J. \& Kaus, B. (2019). Seafloor expression of oceanic detachment faulting reflects gradients in mid-ocean ridge magma supply. Earth and Planetary Science Letters. Elsevier B.V. 516, 176-189.

Huang, Y., Chubakov, V., Mantovani, F., Rudnick, R. L. \& McDonough, W. F. (2013). A reference Earth model for the heat-producing elements and associated geoneutrino flux. Geochemistry, Geophysics, Geosystems 14, 2003-2029.

Huebner, J. S. (1971). Buffering Techniques for Hydrostatic Systems at Elevated Pressures. Research Techniques for High Pressure and High Temperature.

Huet, B., Yamato, P. \& Grasemann, B. (2014). The Minimized Power Geometric model: An analytical mixing model for calculating polyphase rock viscosities consistent with experimental data. Journal of Geophysical Research: Solid Earth 119, 3897 3924.

Humphreys, E. D. \& Coblentz, D. D. (2007). North American dynamics and western U.S. tectonics. Reviews of Geophysics 45, 1-30. 
Humphreys, E. D. \& Dueker, K. G. (1994). Physical state of the western US upper mantle. Journal of Geophysical Research 99, 9635-9650.

Hutchinson, D. R., White, R. S., Cannon, W. F. \& Schulz, K. J. (1990). Keweenaw hot spot: geophysical evidence for a $1.1 \mathrm{Ga}$ mantle plume beneath the Midcontinent Rift System. Journal of Geophysical Research 95.

Ionov, D. A., Doucet, L. S. \& Ashchepkov, I. V. (2010). Composition of the lithospheric mantle in the siberian craton: New constraints from fresh peridotites in the Udachnaya-East Kimberlite. Journal of Petrology 51, 2177-2210.

Isachsen, Y. . (1969). Origin of anorthosite and related rocks (No. 18). Albany: University of the State of New York, State Education Department.

Isachsen, Y. W. (1975). Possible evidence for contemporary doming of the Adirondack Mountains, New York, and suggested implications for regional tectonics and seismicity. Tectonophysics 29, 169-181.

Ito, G. \& Behn, M. D. (2008). Magmatic and tectonic extension at mid-ocean ridges: 2. Origin of axial morphology. Geochemistry, Geophysics, Geosystems 9.

Jackson, I. \& Faul, U. H. (2010). Grainsize-sensitive viscoelastic relaxation in olivine: Towards a robust laboratory-based model for seismological application. Physics of the Earth and Planetary Interiors. Elsevier B.V. 183, 151-163.

Jagoutz, E., Palme, H., Hildegard Baddenhausen, K., Blum, M., Cendales, M., Dreibus, G., Spettel, B., Lorenz, V. \& Wänke, H. (1979). The abundances of major, minor and trace elements in the earth's mantle as derived from primitive ultramafic nodules. Proc. Lunar Planet. Sci. Conf. 10, 2031-50.

Jagoutz, O. \& Behn, M. D. (2013). Foundering of lower island-arc crust as an explanation for the origin of the continental Moho. Nature. Nature Publishing Group 504, 131134.

Jagoutz, O. \& Schmidt, M. W. (2012). The formation and bulk composition of modern juvenile continental crust: The Kohistan arc. Chemical Geology. Elsevier B.V. 298 299, 79-96.

Jakobsson, S. \& Oskarsson, N. (1994). The system C-O in equilibrium with graphite at high pressure and temperature: An experimental study. Geochimica et Cosmochimica Acta 58, 9-17.

James, D. E., Boyd, F. R., Schutt, D., Bell, D. R. \& Carlson, R. W. (2004). Xenolith constraints on seismic velocities in the upper mantle beneath southern Africa. Geochemistry, Geophysics, Geosystems $\mathbf{5}$.

Jamieson, R. A., Beaumont, C., Nguyen, M. H. \& Culshaw, N. G. (2007). Synconvergent ductile flow in variable-strength continental crust: Numerical models with application to the western Grenville orogen. Tectonics 26, 1-23.

Jamieson, R. A., Beaumont, C., Nguyen, M. H. \& Lee, B. (2002). Interaction of metamorphism, deformation and exhumation in large convergent orogens. Journal of Metamorphic Geology 20, 9-24.

Jamieson, R. A., Beaumont, C., Warren, C. J. \& Nguyen, M. H. (2010). The Grenville Orogen explained? Applications and limitations of integrating numerical models with geological and geophysical data. Canadian Journal of Earth Sciences 47, 517539.

Jaupart, C. \& Mareschal, J. (2007). Heat Flow and Thermal Structure of the Lithosphere. Volume 6: Crust and Lithosphere Dynamics. Elsevier, 217-251. 
Jennings, E. S. \& Holland, T. J. B. (2015). A simple thermodynamic model for melting of peridotite in the system NCFMASOCr. Journal of Petrology 56, 869-892.

Ji, S. \& Martignole, J. (1994). Ductility of garnet as an indicator of extremely high temperature deformation. Journal of Structural Geology 16, 985-996.

Jiang, F., Speziale, S., Shieh, S. R. \& Duffy, T. S. (2004). Single-crystal elasticity of andradite garnet to $11 \mathrm{GPa}$. Journal of Physics Condensed Matter 16.

Johnson, C. D. \& Carlson, W. D. (1990). The origin of olivine-plagioclase coronas in metagabbros from the Adirondack Mountains, New York. Journal of Metamorphic Geology 8, 697-717.

Jordan, T. H. (1975). The continental tectosphere. Reviews of Geophysics 13, 1.

Jordan, T. H. (1979). Mineralogies, densities and seismic velocities of garnet lherzolites and their geophysical implications. The Mantle Sample: Inclusion in Kimberlites and Other Volcanics. Washington, D. C.: American Geophysical Union, 1-14.

Jourdan, F., Marzoli, A., Bertrand, H., Cirilli, S., Tanner, L. H., Kontak, D. J., McHone, G., Renne, P. R. \& Bellieni, G. (2009). 40Ar/39Ar ages of CAMP in North America: Implications for the Triassic-Jurassic boundary and the $40 \mathrm{~K}$ decay constant bias. Lithos. Elsevier B.V. 110, 167-180.

Jull, M. \& McKenzie, D. (1996). The effect of deglaciation on mantle melting beneath Iceland. The effect of deglaciation on mantle melting beneath Iceland $101 \mathbf{B 1 0}$, 21815-21828.

Kaban, M. K., Schwintzer, P., Artemieva, I. M. \& Mooney, W. D. (2003). Density of the continental roots: Compositional and thermal contributions. Earth and Planetary Science Letters 209, 53-69.

Kaban, M. K., Tesauro, M., Mooney, W. D. \& Cloetingh, S. A. P. L. (2014). Density, temperature, and composition of the North American lithosphere - New insights from a joint analysis of seismic, gravity, and mineral physics data: 1 . Density structure of the crust and upper mantle. Geochemistry, Geophysics, Geosystems 15, 4781-4807.

Kampfmann, W. \& Berckhemer, H. (1985). High temperature experiments on the elastic and anelastic behaviour of magmatic rocks. Physics of the Earth and Planetary Interiors 40, 223-247.

Kane, M. F. \& Godson, R. H. (1989). A crust/mantle structural framework of the conterminous United States based on gravity and magnetic trends. , 383-404.

Kárason, H. \& van der Hilst, R. D. (2000). Constraints on mantle convection from seismic tomography. Geophysical Monograph Series, 257-276.

Karato, S. (1993). Importance of anelasticity in the interpretation of seismic tomography. Geophysical Research Letters 20, 1623-1626.

Karato, S. (2012). Deformation of Earth Materials. Cambridge: Cambridge University Press.

Karato, S. I. \& Park, J. (2018). On the origin of the upper mantle seismic discontinuities. Lithospheric Discontinuities.

Karato, S., Wang, Z., Liu, B. \& Fujino, K. (1995). Plastic deformation of garnets: systematics and implications for the rheology of the mantle transition zone. Earth and Planetary Science Letters 130, 13-30.

Karato, S. \& Wu, P. (1993). Rheology the Upper Mantle : Synthesis. Science 260, 771778. 
Katz, R. F. \& Weatherley, S. M. (2012). Consequences of mantle heterogeneity for melt extraction at mid-ocean ridges. Earth and Planetary Science Letters. Elsevier 335336, 226-237.

Kelbert, A., Bedrosian, P. A. \& Murphy, B. S. (2019). The first 3D conductivity model of the contiguous United States: Reflections on geologic structure and application to induction hazards. Geomagnetically Induced Currents from the Sun to the Power Grid 127-151.

Kelemen, P. B., A., H. \& A.R. Greene (2014). No Title. In: Rudnick, R. L. (ed.) Treatise on Geochemistry. Elsevier-Pergamon, 746-805.

Kelemen, P. B. \& Behn, M. D. (2016). Formation of lower continental crust by relamination of buoyant arc lavas and plutons. Nature Geoscience. Nature Publishing Group 9, 197-205.

Kelemen, P. B. \& Dick, H. J. B. (1995). Focused melt flow and localized deformation in the upper mantle: juxtaposition of replacive dunite and ductile shear zones in the Josephine peridotite, SW Oregon. Journal of Geophysical Research 100, 423-438.

Kelemen, P. B. \& Holbrook, W. S. (1995). Origin of thick, high-velocity igneous crust along the US east coast margin. Journal of Geophysical Research $\mathbf{1 0 0 .}$

Keller, D. S. \& Ague, J. J. (2019). Crystallographic and textural evidence for precipitation of rutile, ilmenite, corundum, and apatite lamellae from garnet. American Mineralogist 104, 980-995.

Kelley, K. A. \& Cottrell, E. (2012). The influence of magmatic differentiation on the oxidation state of $\mathrm{Fe}$ in a basaltic arc magma. Earth and Planetary Science Letters. Elsevier B.V. 329-330, 109-121.

Kelly, R. K., Kelemen, P. B. \& Jull, M. (2003). Buoyancy of the continental upper mantle. Geochemistry, Geophysics, Geosystems 4.

Kennett, B. L. N., Engdah, E. R. \& Buland, R. (1995). Constraints on seismic velocities in the Earth from traveltimes. 108-124.

Kern, H., Gao, S. \& Liu, Q.-S. (1996). Seismic properties and densities of middle and lower crustal rocks exposed along the North China Geoscience Transect. Earth and Planetary Science Letters 139, 439-455.

Khan, A. (2016). On Earth's Mantle Constitution and Structure from Joint Analysis of Geophysical and Laboratory-Based Data: An Example. Surveys in Geophysics 37, 149-189.

Khan, A., Koch, S., Shankland, T. J., Zunino, A. \& Connolly, J. A. D. (2015). Relationships Between Seismic Wave-Speed, Density, and Electrical Conductivity Beneath Australia from Seismology, Mineralogy, and Laboratory-Based Conductivity Profiles. The Earth's Heterogeneous Mantle. Cham: Springer International Publishing, 145-171.

Khan, A., Zunino, A. \& Deschamps, F. (2011). The thermo-chemical and physical structure beneath the North American continent from Bayesian inversion of surfacewave phase velocities. Journal of Geophysical Research: Solid Earth 116, 1-23.

Kil, Y. \& Wendlandt, R. F. (2004). Pressure and temperature evolution of upper mantle under the Rio Grande Rift. Contributions to Mineralogy and Petrology 148, 265280.

Kitchen, N. E. \& Valley, J. W. (1995). Carbon isotope thermometry in marbles of the Adirondack Mountains, New York. Journal of Metamorphic Geology 13, 577-594. 
Kleinrock, M. C., Tucholke, B. E., Lin, J. \& Tivey, M. A. (1997). Fast rift propagation at a slow-spreading ridge. Geology 25, 639-642.

Klemme, S. (2004). The influence of $\mathrm{Cr}$ on the garnet-spinel transition in the Earth's mantle: Experiments in the system $\mathrm{MgO}-\mathrm{Cr} 2 \mathrm{O} 3-\mathrm{SiO} 2$ and thermodynamic modelling. Lithos 77, 639-646.

Klemme, S., Ivanic, T. J., Connolly, J. A. D. \& Harte, B. (2009). Thermodynamic modelling of Cr-bearing garnets with implications for diamond inclusions and peridotite xenoliths. Lithos. Elsevier B.V. 112, 986-991.

Kohn, M. J. \& Spear, F. S. (1990). Two new geobarometers for garnet amphibolites, with applications to southeastern Vermont. American Mineralogist 75, 89-96.

Kono, Y., Ishikawa, M. \& Arima, M. (2004). Discontinuous change in temperature derivative of Vp in lower crustal rocks. Geophysical Research Letters 31, 1-4.

Kono, Y., Ishikawa, M., Harigane, Y., Michibayashi, K. \& Arima, M. (2009). P- and Swave velocities of the lowermost crustal rocks from the Kohistan arc: Implications for seismic Moho discontinuity attributed to abundant garnet. Tectonophysics. Elsevier B.V. 467, 44-54.

Kozlovsky, Y. A. (ed.) (1987). The superdeep well of the Kola Peninsula. Springer Berlin.

Kraner, M. L., Holt, W. E. \& Borsa, A. A. (2018). Seasonal Nontectonic Loading Inferred From cGPS as a Potential Trigger for the M6.0 South Napa Earthquake. Journal of Geophysical Research: Solid Earth 123, 5300-5322.

Kreemer, C., Blewitt, G. \& Klein, E. C. (2014). A geodetic plate motion and Global Strain Rate Model. Geochemistry, Geophysics, Geosystems 15, 3849-3889.

Kretz, R. (1982). Transfer and exchange equilibria in a portion of the pyroxene quadrilateral as deduced from natural and experimental data. Geochimica et Cosmochimica Acta 46, 411-421.

Krippner, A., Meinhold, G., Morton, A. C. \& Von Eynatten, H. (2014). Evaluation of garnet discrimination diagrams using geochemical data of garnets derived from various host rocks. Sedimentary Geology. Elsevier B.V. 306, 36-52.

Kroenke, L. W., Manghnani, M. H., Rai, C. S., Fryer, P. \& Ramananantoandro, R. (1976). Elastic Properties of Selected Ophiolitic Rocks from Papua New Guinea: Nature and Composition of Oceanic Lower Crust and Upper Mantle. , 407-421.

Kronenberg, A. K., Kirby, S. H. \& Pinkston, J. (1990). Basal slip and mechanical anisotropy of biotite. Journal of Geophysical Research 95.

Kudo, A. M., Brookins, D. G. \& Laughlin, A. W. (1972). Sr isotopic disequilibrium in lherzolites from the Puerco necks, New Mexico. Earth and Planetary Science Letters 15, 291-295.

Kumar, A., Fernàndez, M., Jiménez-Munt, I., Torne, M., Vergés, J. \& Afonso, J. C. (2020). LitMod2D_2.0: An Improved Integrated Geophysical-Petrological Modeling Tool for the Physical Interpretation of Upper Mantle Anomalies. Geochemistry, Geophysics, Geosystems 21, 1-19.

Kuo, B.-Y. \& Forsyth, D. W. (1988). Gravity anomalies of the ridge-transform system in the South Atlantic between 31 and 34.5? S: Upwelling centers and variations in crustal thickness. Marine Geophysical Researches 10, 205-232.

Kushiro, I. (2001). Partial Melting Experiments on Peridotite and Origin of Mid-Ocean Ridge Basalt. Annual Review of Earth and Planetary Sciences 29, 71-107. 
Kushiro, I. \& Yoder, H. S. (1966). Reactions and their bearing on the Basalt-Eclogite Transformation. Journal of Geophysical Research 7, 337-362.

Kustowski, B., Ekström, G. \& Dziewoński, A. M. (2008). Anisotropic shear-wave velocity structure of the earth's mantle: A global model. Journal of Geophysical Research: Solid Earth 113, 1-23.

Labails, C., Olivet, J. L., Aslanian, D. \& Roest, W. R. (2010). An alternative early opening scenario for the Central Atlantic Ocean. Earth and Planetary Science Letters. Elsevier B.V. 297, 355-368.

Lachenbruch, A. H., Sass, J. H. \& Galanis, S. P. (1985). Heat flow in southernmost California and the origin of the Salton Trough. Journal of Geophysical Research 90 , 6709.

Lambert, D. D., Unruh, D. M. \& Gilbert, M. C. (1988). Rb-Sr and Sm-Nd isotopic study of the Glen Mountains layered complex: initiation of rifting within the southern Oklahoma aulacogen. Geology 16, 13-17.

Langmuir, C. H., Klein, E. M. \& Plank, T. (1992). Petrological Systematics of MidOcean Ridge Basalts: Constraints on Melt Generation Beneath Ocean Ridges. , 183280.

Lasaga, A. C. (1979). Multicomponent exchange and diffusion in silicates. Geochimica et Cosmochimica Acta 43, 455-469.

Lau, H. C. P. \& Faul, U. H. (2019). Anelasticity from seismic to tidal timescales: Theory and observations. Earth and Planetary Science Letters. Elsevier B.V. 508, 18-29.

Lee, C.-T. A. (2003). Compositional variation of density and seismic velocities in natural peridotites at STP conditions: Implications for seismic imaging of compositional heterogeneities in the upper mantle. Journal of Geophysical Research: Solid Earth 108.

Lee, C.-T. \& Rudnick, R. L. (1999). Compositionally stratified cratonic lithosphere: petrology and geochemistry of peridotite xenoliths from the Labait tuff cone, Tanzania. International Kimberlite Conference 503-521.

Lee, C. T. A. (2006). Geochemical/petrologic constraints on the origin of cratonic mantle. Geophysical Monograph Series 164, 89-114.

Lee, C. T. A., Luffi, P. \& Chin, E. J. (2011). Building and destroying continental mantle. Annual Review of Earth and Planetary Sciences 39, 59-90.

Lee, E. J., Chen, P., Jordan, T. H., Maechling, P. B., Denolle, M. A. M. \& Beroza, G. C. (2014). Full-3-D tomography for crustal structure in Southern California based on the scattering-integral and the adjoint-wavefield methods. Journal of Geophysical Research: Solid Earth 119, 6421-6451.

Leeman, W. P., Lewis, J. F., Evarts, R. C., Conrey, R. M. \& Streck, M. J. (2005). Petrologic constraints on the thermal structure of the Cascades arc. Journal of Volcanology and Geothermal Research 140, 67-105.

Lévěque, J.-J., Rivera, L. \& Wittlinger, G. (1993). On the use of the checker-board test to assess the resolution of tomographic inversions. Geophysical Journal International 115, 313-318.

Levin, S. B. (1950). Genesis of some Adirondack garnet deposits. Bulletin of the Geological Society of America 61, 519-565.

Levin, V., Long, M. D., Skryzalin, P., Li, Y. \& López, I. (2018). Seismic evidence for a recently formed mantle upwelling beneath New England. Geology 46, 87-90. 
Li, C., Gao, H., Williams, M. L. \& Levin, V. (2018). Crustal Thickness Variation in the Northern Appalachian Mountains: Implications for the Geometry of 3-D Tectonic Boundaries Within the Crust. Geophysical Research Letters 45, 6061-6070.

Li, Z. X. et al. (2008a). Assembly, configuration, and break-up history of Rodinia: A synthesis. Precambrian Research 160, 179-210.

Li, Z. X. A., Lee, C. T. A., Peslier, A. H., Lenardic, A. \& Mackwell, S. J. (2008b). Water contents in mantle xenoliths from the Colorado Plateau and vicinity: Implications for the mantle rheology and hydration-induced thinning of continental lithosphere. Journal of Geophysical Research: Solid Earth 113.

Lin, J., Purdy, G. M., Schouten, H., Sempere, J. C. \& Zervas, C. (1990). Evidence from gravity data for focused magmatic accretion along the Mid-Atlantic Ridge. Nature 344, 627-632.

Lin, P. Y. P., Gaherty, J. B., Jin, G., Collins, J. A., Lizarralde, D., Evans, R. L. \& Hirth, G. (2016). High-resolution seismic constraints on flow dynamics in the oceanic asthenosphere. Nature. Nature Publishing Group 535, 538-541.

Liu, L. \& Gao, S. S. (2018). Lithospheric layering beneath the contiguous United States constrained by S-to-P receiver functions. Earth and Planetary Science Letters. Elsevier B.V. 495, 79-86.

Liu, Z. \& Buck, W. R. (2018). Magmatic controls on axial relief and faulting at midocean ridges. Earth and Planetary Science Letters. Elsevier B.V. 491, 226-237.

Lizarralde, D., Gaherty, J. B., Collins, J. A., Hirth, G. \& Kim, S. D. (2004). Spreadingrate dependence of melt extraction at mid-ocean ridges from mantle seismic refraction data. Nature 432, 744-747.

Lowry, A. R. \& Pérez-Gussinyé, M. (2011). The role of crustal quartz in controlling Cordilleran deformation. Nature 471, 353-359.

Luffi, P., Saleeby, J. B., Lee, C.-T. A. \& Ducea, M. N. (2009). Lithospheric mantle duplex beneath the central Mojave Desert revealed by xenoliths from Dish Hill, California. Journal of Geophysical Research 114.

Lupulescu, M. V., Chiarenzelli, J. R., Pullen, A. T. \& Price, J. D. (2011). Using pegmatite geochronology to constrain temporal events in the Adirondack Mountains. Geosphere 7, 23-39.

Luth, W. C., Jahns, R. H. \& Tuttle, O. F. (1964). The granite system at pressures of 4 to 10 kilobars. Journal of Geophysical Research 69, 759-773.

Luther, F. R. (1976). The Petrological Evolution of th Garnet Deposit at Gore Mountain, Warren County, New York. Lehigh University.

Ma, Z., Dalton, C. A., Russell, J. B., Gaherty, J. B., Hirth, G. \& Forsyth, D. W. (2020). Shear attenuation and anelastic mechanisms in the central Pacific upper mantle. Earth and Planetary Science Letters. Elsevier B.V. 536, 116148.

Macdonald, K. C., Fox, P. J., Alexander, R. T., Pockalny, R. \& Gente, P. (1996). Volcanic growth faults and the origin of Pacific abyssal hills. Nature 380, 125-129.

MacLeod, C. J., Searle, R. C., Murton, B. J., Casey, J. F., Mallows, C., Unsworth, S. C., Achenbach, K. L. \& Harris, M. (2009). Life cycle of oceanic core complexes. Earth and Planetary Science Letters. Elsevier B.V. 287, 333-344.

Makovsky, Y. et al. (1996). Structural elements of the southern Tethyan Himalaya rust from wide-angle seismic data. Tectonics 15, 997-1005.

Malaspina, N., Poli, S. \& Fumagalli, P. (2009). The oxidation state of metasomatized 
mantle wedge: Insights from C-O-H-bearing garnet peridotite. Journal of Petrology 50, 1533-1552.

Manning, C. E. (2018). Fluids of the Lower Crust: Deep Is Different. Annual Review of Earth and Planetary Sciences 46, 67-97.

Mao, N., Ito, J., Hays, J. F., Drake, J. \& Birch, F. (1970). Composition and elastic constants of Hortonolite dunite. Journal of Geophysical Research 75, 4071-4076.

Mareschal, J. C. \& Jaupart, C. (2013). Radiogenic heat production, thermal regime and evolution of continental crust. Tectonophysics. Elsevier B.V. 609, 524-534.

Mark, H. F., Collins, J. A., Lizarralde, D., Hirth, G., Gaherty, J. B., Evans, R. L. \& Behn, M. D. (2021). Constraints on the depth, thickness, and strength of the $G$ discontinuity in the central Pacific from $\mathrm{S}$ receiver functions. Journal of Geophysical Research: Solid Earth.

Mark, H. F., Lizarralde, D., Collins, J. A., Miller, N. C., Hirth, G., Gaherty, J. B. \& Evans, R. L. (2019). Azimuthal Seismic Anisotropy of 70-Ma Pacific-Plate Upper Mantle. Journal of Geophysical Research: Solid Earth 124, 1889-1909.

Marshall, E. W., Lassiter, J. C. \& Barnes, J. D. (2018). On the (mis)behavior of water in the mantle: Controls on nominally anhydrous mineral water content in mantle peridotites. Earth and Planetary Science Letters. Elsevier B.V. 499, 219-229.

Marshall, E. W., Lassiter, J. C., Barnes, J. D., Luguet, A. \& Lissner, M. (2017). Mantle melt production during the $1.4 \mathrm{Ga}$ Laurentian magmatic event: Isotopic constraints from Colorado Plateau mantle xenoliths. Geology 45, 519-522.

Marzoli, A. et al. (2018). The Central Atlantic Magmatic Province (CAMP): A Review. .

Matsukage, K. N., Kikuchi, S., Ono, S., Nishihara, Y. \& Kikegawa, T. (2010). Density and seismic velocities of chromitite body in oceanic mantle peridotite. American Mineralogist 95, 1422-1428.

Mazza, S. E., Gazel, E., Johnson, E. A., Kunk, M. J., McAleer, R., Spotila, J. A., Bizimis, M. \& Coleman, E. S. (2014). Volcanoes of the passive margin: The youngest magmatic event in eastern North America. Geology 42, 483-486.

McDonough, W. F. \& Sun, S. s. (1995). The composition of the Earth. Chemical Geology 120, 223-253.

McKenzie, D. (1985). The extraction of magma from the crust and mantle. Earth and Planetary Science Letters 74, 81-91.

McKenzie, D. (2000). Constraints on melt generation and transport from U-series activity ratios. Chemical Geology 162, 81-94.

McKenzie, D. P. (1969). Speculations on the Consequences and Causes of Plate Motions. Geophysical Journal of the Royal Astronomical Society 18, 1-32.

McLelland, J. (2016). Regional Geological Setting of the Adirondack Mountains, New York. Adirondack Journal of Environmental Studies 21, 4.

McLelland, J. \& Chiarenzelli, J. (1989). Age of Xenolith-Bearing Olivine Metagabbro, Eastern Adirondack Mountains, New York. The Journal of Geology 97, 373-376.

McLelland, J., Chiarenzelli, J., Whitney, P. \& Isachsen, Y. (1988). U-Pb zircon geochronology of the Adirondack Mountains and implications for their geologic evolution. Geology 16, 920.

McLelland, J., Daly, J. S. \& McLelland, J. M. (1996). The Grenville Orogenic Cycle (ca. 1350-1000 Ma): An Adirondack perspective. Tectonophysics 265, 1-28.

McLelland, J., Hamilton, M., Selleck, B., McLelland, J., Walker, D. \& Orrell, S. (2001). 
Zircon U-Pb geochronology of the Ottawan Orogeny, Adirondack Highlands, New York: regional and tectonic implications. Precambrian Research 109, 39-72.

McLelland, J. M., Bickford, M. E., Hill, B. M., Clechenko, C. C., Valley, J. W. \& Hamilton, M. A. (2004). Direct dating of Adirondack massif anorthosite by U-Pb SHRIMP analysis of igneous zircon: Implications for AMCG complexes. Bulletin of the Geological Society of America 116, 1299-1317.

McLelland, J. M. \& Chiarenzelli, J. R. (1990). Geochronological studies in the Adirondack Mountains and the implications of a Middle Proterozoic tonalitic suite. Geological Association of Canada Special Paper.

McLelland, J. M. \& Selleck, B. W. (2011). Megacrystic gore mountain-type garnets in the adirondack Highlands: Age, origin, and tectonic implications. Geosphere 7, 1194-1208.

McLelland, J. M., Selleck, B. W. \& Bickford, M. E. (2010a). Review of the Proterozoic evolution of the Grenville Province, its Adirondack outlier, and the Mesoproterozoic inliers of the Appalachians. Memoir of the Geological Society of America 206, 2149.

McLelland, J. M., Selleck, B. W. \& Bickford, M. E. (2013). Tectonic Evolution of the Adirondack Mountains and Grenville Orogen Inliers within the USA. Geoscience Canada 40, 318.

McLelland, J. M., Selleck, B. W., Hamilton, M. A. \& Bickford, M. E. (2010b). Late- to post-tectonic setting of some major proterozoic anorthosite - mangerite - charnockite - granite (AMCG) suites. Canadian Mineralogist 48, 729-750.

McLelland, J. \& Whitney, P. (1990). Anorogenic, bimodal emplacement of anorthositic, charnockitic, and related rocks in the Adirondack Mountains, New York. Special Paper of the Geological Society of America.

Mehl, L. \& Hirth, G. (2008). Plagioclase preferred orientation in layered mylonites: Evaluation of flow laws for the lower crust. Journal of Geophysical Research: Solid Earth 113, 1-19.

Meyer, B., Saltus, R. \& Chulliat, A. (2016). EMAG2: Earth magnetic anomaly grid (2arc-minute resolution) version 3. National Centers for Environmental Information, NOAA. Model.

Mezger, K., Essene, E. J. \& Halliday, A. N. (1992). Closure temperatures of the SmNd system in metamorphic garnets. Earth and Planetary Science Letters 113, 397-409.

Mezger, K., Essene, E. J., van der Pluijm, B. A. \& Halliday, A. N. (1993). U-Pb geochronology of the Grenville Orogen of Ontario and New York: constraints on ancient crustal tectonics. Contributions to Mineralogy and Petrology 114, 13-26.

Mezger, K., Hanson, G. N. \& Bohlen, S. R. (1989). High-precision UPb ages of metamorphic rutile: application to the cooling history of high-grade terranes. Earth and Planetary Science Letters 96, 106-118.

Mezger, K., Rawnsley, C. M., Bohlen, S. R. \& Hanson, G. N. (1991). U-Pb Garnet, Sphene, Monazite, and Rutile Ages: Implications for the Duration of High-Grade Metamorphism and Cooling Histories, Adirondack Mts., New York. The Journal of Geology 99, 415-428.

Miller, D. J. \& Christensen, N. I. (1994). Seismic signature and geochemistry of an island arc: a multidisciplinary study of the Kohistan accreted terrane, northern Pakistan. Journal of Geophysical Research 99. 
Miller, W. J. (1938). Genesis of Certain Adirondack Garnet Deposits. American Mineralogist 7.

Minshull, T. A., Muller, M. R. \& White, R. S. (2006). Crustal structure of the Southwest Indian Ridge at $66^{\circ} \mathrm{E}$ : Seismic constraints. Geophysical Journal International 166, 135-147.

Mitchell, A. L. \& Grove, T. L. (2015). Melting the hydrous, subarc mantle: the origin of primitive andesites. Contributions to Mineralogy and Petrology. Springer Berlin Heidelberg 170, 1-23.

Mooney, W. D. \& Kaban, M. K. (2010). The North American upper mantle: Density, composition, and evolution. Journal of Geophysical Research: Solid Earth 115, 124.

Morgan, P. \& Gosnold, W. D. (1989). Heat flow and thermal regimes in the continental United States. Memoir of the Geological Society of America 172, 493-522.

Morgan, W. J. (1983). Hotspot tracks and the early rifting of the atlantic. Developments in Geotectonics 19, 123-139.

Mori, T. \& Green, D. H. (1978). Laboratory Duplication of Phase Equilibria Observed in Natural Garnet Lherzolites. The Journal of Geology 86, 83-97.

Morris, E., Detrick, R. S., Minshull, T. A., Mutter, J. C., White, R. S., Su, W. \& Buhl, P. (1993). Seismic structure of oceanic crust in the western North Atlantic. Journal of Geophysical Research: Solid Earth 98, 13879-13903.

Müller, R. D., Sdrolias, M., Gaina, C. \& Roest, W. R. (2008). Age, spreading rates, and spreading asymmetry of the world's ocean crust. Geochemistry, Geophysics, Geosystems 9, 1-19.

Murphy, J. B. \& Keppie, J. D. (2005). The acadian orogeny in the northern appalachians. International Geology Review 47, 663-687.

Nasdala, L., Zhang, M., Kempe, U., Panczer, G., Gaft, M., Andrut, M. \& Plötze, M. (2003). Spectroscopic methods applied to zircon. Reviews in Mineralogy and Geochemistry 53, 427-467.

Nelson, K. D. et al. (1996). Partially molten middle crust beneath southern Tibet: Synthesis of project INDEPTH results. Science 274, 1684-1685.

Nestola, F., Periotto, B., Andreozzi, G. B., Bruschini, E. \& Bosi, F. (2014). Pressurevolume equation of state for chromite and magnesiochromite: A single-crystal X-ray diffraction investigation. American Mineralogist 99, 1248-1253.

Nickel, K. G. \& Green, D. H. (1985). Empirical geothermobarometry for garnet peridotites and implications for the nature of the lithosphere, kimberlites and diamonds. Earth and Planetary Science Letters 73, 158-170.

Nicolas, A., Boudier, F. \& Ildefonse, B. (1996). Variable crustal thickness in the Oman ophiolite: Implication for oceanic crust. Journal of Geophysical Research B: Solid Earth 101, 17941-17950.

O'Neill, H. S. C. (1987). Quartz-fayalite-iron and quartz-fayalite-magnetite equilibria and the free energy of formation of fayalite ( $\mathrm{Fe} 2 \mathrm{SiO} 4)$ and magnetite $(\mathrm{Fe} 3 \mathrm{O} 4)$. American Mineralogist.

O’Reilly, S. Y., Jackson, I. \& Bezant, C. (1990). Equilibration temperatures and elastic wave velocities for upper mantle rocks from eastern Australia: implications for the interpretation of seismological models. Tectonophysics 185, 67-82.

Olive, J.-A., Behn, M. D., Ito, G., Buck, W. R., Escartin, J. \& Howell, S. (2015). 
Sensitivity of seafloor bathymetry to climate-driven fluctuations in mid-ocean ridge magma supply. Science 350, 310-313.

Olive, J.-A., Behn, M. D., Ito, G., Buck, W. R., Escartin, J. \& Howell, S. (2016). Response to Comment on "Sensitivity of seafloor bathymetry to climate-driven fluctuations in mid-ocean ridge magma supply." Science 352, 1405-1405.

Olive, J. A., Behn, M. D. \& Tucholke, B. E. (2010). The structure of oceanic core complexes controlled by the depth distribution of magmaemplacement. Nature Geoscience. Nature Publishing Group 3, 491-495.

Olsen, K. H., Scott Baldridge, W. \& Callender, J. F. (1987). Rio Grande rift: An overview. Tectonophysics 143, 119-139.

Onstott, T. C. \& Peacock, M. W. (1987). Argon retentivity of hornblendes: A field experiment in a slowly cooled metamorphic terrane. Geochimica et Cosmochimica Acta 51, 2891-2903.

Oxburgh, E. R. \& Parmentier, E. M. (1978). Thermal processes in the formation of continental lithosphere. Philosophical Transactions of the Royal Society of London. Series A, Mathematical and Physical Sciences 288, 415-429.

Pakiser, L. C. (1963). Structure of the crust and upper mantle in the western United States. Journal of Geophysical Research 68, 5747-5756.

Pariso, J. E., Sempere, J. C. \& Rommevaux, C. (1995). Temporal and spatial variations in crustal accretion along the Mid- Atlantic Ridge $\left(29^{\circ}-31^{\circ} 30^{\prime} \mathrm{N}\right)$ over the last 10 m.y.: implications from a three-dimensional gravity study. Journal of Geophysical Research 100.

Parker, R. L. (1972). The Rapid Calculation of Potential Anomalies. Geophysical Journal of the Royal Astronomical Society 31, 447-455.

Parmentier, E. M. \& Morgan, J. P. (1990). Spreading rate dependence of threedimensional structure in oceanic spreading centres. Nature 348, 325-328.

Parnell-Turner, R., Escartín, J., Olive, J. A., Smith, D. K. \& Petersen, S. (2018). Genesis of corrugated fault surfaces by strain localization recorded at oceanic detachments. Earth and Planetary Science Letters. Elsevier B.V. 498, 116-128.

Paton, C., Hellstrom, J., Paul, B., Woodhead, J. \& Hergt, J. (2011). Iolite: Freeware for the visualisation and processing of mass spectrometric data. Journal of Analytical Atomic Spectrometry 26, 2508.

Pattison, D. R. M., Chacko, T., Farquhar, J. \& McFarlane, C. (2003). Temperatures of Granulite-facies Metamorphism: Constraints from Experimental Phase Equilibria and Thermobarometry Corrected for Retrograde Exchange. Journal of Petrology 44, 867-900.

Paulatto, M., Canales, J. P., Dunn, R. A. \& Sohn, R. A. (2015). Heterogeneous and asymmetric crustal accretion: New constraints from multibeam bathymetry and potential field data from the Rainbow area of the Mid-Atlantic Ridge $\left(36^{\circ} 15^{\prime} \mathrm{N}\right)$. Geochemistry, Geophysics, Geosystems 16, 2994-3014.

Pavese, A., Diella, V., Pischedda, V., Merli, M., Bocchio, R. \& Mezouar, M. (2001). Pressure-volume-temperature equation of state of andradite and grossular, by highpressure and -temperature powder diffraction. Physics and Chemistry of Minerals 28, 242-248.

Pearson, D. G., Canil, D. \& Shirey, S. B. (2003). Mantle Samples Included in Volcanic Rocks: Xenoliths and Diamonds. Treatise on Geochemistry. Elsevier, 171-275. 
Peck, W. H. \& Valley, J. W. (2004). Quartz-garnet isotope thermometry in the southern Adirondack Highlands (Grenville Province, New York). Journal of Metamorphic Geology 22, 763-773.

Peck, W. H., Valley, J. W., Corriveau, L., Davidson, A., McLelland, J. \& Farber, D. A. (2004). Oxygen-isotope constraints on terrane boundaries and origin of 1.18-1.13 Ga granitoids in the southern Grenville Province. Memoir of the Geological Society of America 197, 163-182.

Peercy, M. S. \& Bass, J. D. (1990). Elasticity of monticellite. Physics and Chemistry of Minerals 17, 431-437.

Percival, D. B. \& Walden, A. T. (1993). Spectral Analysis for Physical Applications. Cambridge University Press.

Perkins, D. \& Chipera, S. J. (1985). Garnet-orthopyroxene-plagioclase-quartz barometry: refinement and application to the English River subprovince and the Minnesota River valley. Contributions to Mineralogy and Petrology 89, 69-80.

Perry, H. K. C., Forte, A. M. \& Eaton, D. W. S. (2003). Upper-mantle thermochemical structure below North America from seismic-geodynamic flow models. Geophysical Journal International 154, 279-299.

Peselnick, L. \& Nicolas, A. (1978). Seismic anisotropy in an ophiolite peridotite: Application to oceanic upper mantle. Journal of Geophysical Research 83, 1227.

Petersen, M. D. et al. (2020). The 2018 update of the US National Seismic Hazard Model: Overview of model and implications. Earthquake Spectra 36, 5-41.

Phillips, J. D., Duval, J. S. \& Ambroziak, R. A. (1993). National geophysical data grids: Gamma-ray, gravity, magnetic and topographic data for the conterminous United States. ... Survey Digital Data Series.

Pilet, S., Baker, M. B., Müntener, O. \& Stolper, E. M. (2011). Monte Carlo simulations of metasomatic enrichment in the lithosphere and implications for the source of alkaline basalts. Journal of Petrology 52, 1415-1442.

Plank, T. \& Forsyth, D. W. (2016). Thermal structure and melting conditions in the mantle beneath the Basin and Range province from seismology and petrology. Geochemistry Geophysics Geosystems 17, 1312-1338.

Pokhilenko, L. N., Mal'Kovets, V. G., Kuz'Min, D. V. \& Pokhilenko, N. P. (2014). New data on the mineralogy of megacrystalline pyrope peridotite from the Udachnaya kimberlite pipe, Siberian Craton, Yakutian diamondiferous province. Doklady Earth Sciences 454, 179-184.

Pollack, H. N. \& Chapman, D. S. (1977). On the regional variation of heat flow, geotherms, and lithospheric thickness. Tectonophysics 38, 279-296.

Pollitz, F. F. \& Mooney, W. D. (2014). Seismic structure of the Central US crust and shallow upper mantle: Uniqueness of the Reelfoot Rift. Earth and Planetary Science Letters. Elsevier B.V. 402, 157-166.

Porreca, C., Selverstone, J. \& Samuels, K. (2006). Pyroxenite xenoliths from the Rio Puerco volcanic field, New Mexico: Melt metasomatism at the margin of the Rio Grande rift. Geosphere 2, 333-351.

Posner, E. S., Dera, P., Downs, R. T., Lazarz, J. D. \& Irmen, P. (2014). High-pressure single-crystal X-ray diffraction study of jadeite and kosmochlor. Physics and Chemistry of Minerals 41, 695-707.

Powell, R. \& Holland, T. (1999). Relating formulations of the thermodynamics of 
mineral solid solutions: Activity modeling of pyroxenes, amphiboles, and micas. American Mineralogist 84, 1-14.

Prelicz, R. M. (2005). Seismic anisotropy in peridotites from the Western Gneiss Region (Norway): Laboratory measurements at high PT conditions and fabric based model predictions. ETH Zurich.

Prior, D. J. et al. (1999). The application of electron backscatter diffraction and orientation contrast imaging in the SEM to textural problems in rocks. American Mineralogist 84, 1741-1759.

Purdy, G. M., Kong, L. S. L., Christeson, G. L. \& Solomon, S. C. (1992). Relationship between spreading rate and the seismic structure of mid-ocean ridges. Nature 355, 815-817.

Ranalli, G. (1997). Rheology of the lithosphere in space and time. Geological Society Special Publication 121, 19-37.

Rapp, R. P. \& Watson, E. B. (1995). Dehydration melting of metabasalt at 8-32 kbar: Implications for continental growth and crust-mantle recycling. Journal of Petrology 36, 891-931.

Rawlinson, N., Pozgay, S. \& Fishwick, S. (2010). Seismic tomography: A window into deep Earth. Physics of the Earth and Planetary Interiors 178, 101-135.

Regan, S. P., Chiarenzelli, J. R., McLelland, J. M. \& Cousens, B. L. (2011). Evidence for an enriched asthenospheric source for coronitic metagabbros in the Adirondack Highlands. Geosphere 7, 694-709.

Regan, S. P., Walsh, G. J., Williams, M. L., Chiarenzelli, J. R., Toft, M. \& McAleer, R. (2019). Syn-collisional exhumation of hot middle crust in the Adirondack Mountains (New York, USA): Implications for extensional orogenesis in the southern Grenville province. Geosphere 15, 1240-1261.

Reuss, A. (1928). Berechnung der Fliehgrenze von Mischkristallen auf Grund der Plastizittitsbedingung fiir Einkristalle. ZAMM-Journal of Applied Mathematics and Mechanics 8.

Rippe, D. \& Unsworth, M. (2010). Quantifying crustal flow in Tibet with magnetotelluric data. Physics of the Earth and Planetary Interiors. Elsevier B.V. 179, 107-121.

Riter, J. C. A. \& Smith, D. (1996). Xenolith constraints on the thermal history of the mantle below the Colorado Plateau. Geology 24, 267-270.

Ritsema, J., Deuss, A., Van Heijst, H. J. \& Woodhouse, J. H. (2011). S40RTS: A degree40 shear-velocity model for the mantle from new Rayleigh wave dispersion, teleseismic traveltime and normal-mode splitting function measurements. Geophysical Journal International 184, 1223-1236.

Rivers, T. (1997). Lithotectonic elements of the Grenville Province: Review and tectonic implications. Precambrian Research 86, 117-154.

Rivers, T. (2008). Assembly and preservation of lower, mid, and upper orogenic crust in the Grenville Province-Implications for the evolution of large hot long-duration orogens. Precambrian Research 167, 237-259.

Rivers, T. (2009). The Grenville Province as a large hot long-duration collisional orogen - insights from the spatial and thermal evolution of its orogenic fronts. Geological Society, London, Special Publications 327, 405-444.

Rivers, T. (2012). Upper-crustal orogenic lid and mid-crustal core complexes: Signature of a collapsed orogenic plateau in the hinterland of the Grenville Province. 
Canadian Journal of Earth Sciences 49, 1-42.

Rivers, T. (2015). Tectonic Setting and Evolution of the Grenville Orogen: An Assessment of Progress Over the Last 40 Years. Geoscience Canada 42, 77-124.

Rivers, T., Ketchum, J., Indares, A. \& Hynes, A. (2002). The High Pressure belt in the Grenville Province: architecture, timing, and exhumation. Canadian Journal of Earth Sciences 39, 867-893.

Romanowicz, B. (2003). Global mantle tomography: Progress status in the past 10 years. Annual Review of Earth and Planetary Sciences 31, 303-328.

Roth, S., Granot, R. \& Downey, N. J. (2019). Discrete characterization of abyssal hills: Unraveling temporal variations in crustal accretion processes at the $10^{\circ} 30^{\prime} \mathrm{N}$ segment, East Pacific Rise. Earth and Planetary Science Letters. Elsevier B.V. 525, 115762.

Royden, L. H., Burchfiel, B. C., King, R. W., Wang, E., Chen, Z., Shen, F. \& Liu, Y. (1997). Surface deformation and lower crustal flow in eastern Tibet. Science 276, 788-790.

Rubin, A. M. \& Pollard, D. D. (1988). Dike-induced faulting in rift zones of Iceland and Afar. Geology 16, 413-417.

Rudnick, R. L. \& Fountain, D. M. (1995). Nature and composition of the continental crust: A lower crustal perspective. Reviews of Geophysics 33, 267-309.

Ruscitto, D. M., Wallace, P. J., Johnson, E. R., Kent, A. J. R. \& Bindeman, I. N. (2010). Volatile contents of mafic magmas from cinder cones in the Central Oregon High Cascades: Implications for magma formation and mantle conditions in a hot arc. Earth and Planetary Science Letters. Elsevier B.V. 298, 153-161.

Russell, J. B., Gaherty, J. B., Lin, P. Y. P., Lizarralde, D., Collins, J. A., Hirth, G. \& Evans, R. L. (2019). High-Resolution Constraints on Pacific Upper Mantle Petrofabric Inferred From Surface-Wave Anisotropy. Journal of Geophysical Research: Solid Earth 124, 631-657.

Rybacki, E. \& Dresen, G. (2004). Deformation mechanism maps for feldspar rocks. Tectonophysics 382, 173-187.

Rybacki, E., Gottschalk, M., Wirth, R. \& Dresen, G. (2006). Influence of water fugacity and activation volume on the flow properties of fine-grained anorthite aggregates. Journal of Geophysical Research: Solid Earth 111.

Rychert, C. A., Harmon, N., Constable, S. \& Wang, S. (2020). The Nature of the Lithosphere-Asthenosphere Boundary. Journal of Geophysical Research: Solid Earth 125, 1-39.

Rychert, C. A., Tharimena, S., Harmon, N., Wang, S., Constable, S., Kendall, J. M., Bogiatzis, P., Agius, M. R. \& Schlaphorst, D. (2021). A dynamic lithosphereasthenosphere boundary near the equatorial Mid-Atlantic Ridge. Earth and Planetary Science Letters. Elsevier B.V. 566, 116949.

Saikia, U., Rychert, C., Harmon, N. \& Kendall, J. M. (2021). Upper Mantle Anisotropic Shear Velocity Structure at the Equatorial Mid-Atlantic Ridge Constrained by Rayleigh Wave Group Velocity Analysis From the PI-LAB Experiment. Geochemistry, Geophysics, Geosystems 22, 1-22.

Sammon, L. G., Gao, C. \& McDonough, W. F. (2020). Lower Crustal Composition in the Southwestern United States. Journal of Geophysical Research: Solid Earth 125, 114. 
Sandwell, D. T., Müller, R. D., Smith, W. H. F., Garcia, E. \& Francis, R. (2014). New global marine gravity model from CryoSat-2 and Jason-1 reveals buried tectonic structure. Science 346, 65-67.

Sarafian, E., Evans, R. L., Collins, J. a, Elsenbeck, J., Gaetani, G. a, Gaherty, J. B., Hirth, G. \& Lizarralde, D. (2015). The electrical structure of the central Pacific upper mantle constrained by the NoMelt experiment. Geochemistry, Geophysics, Geosystems 16, 1115-1132.

Scherer, E. E., Cameron, K. L. \& Blichert-Toft, J. (2000). Lu-Hf garnet geochronology: Closure temperature relative to the $\mathrm{Sm}-\mathrm{Nd}$ system and the effects of trace mineral inclusions. Geochimica et Cosmochimica Acta 64, 3413-3432.

Schettino, A. (2014). Quantitative Plate Tectonics. Cham: Springer International Publishing.

Schettino, A. \& Scotese, C. R. (2005). Apparent polar wander paths for the major continents (200 Ma to the present day): A palaeomagnetic reference frame for global plate tectonic reconstructions. Geophysical Journal International 163, 727-759.

Schmandt, B. \& Humphreys, E. (2011). Seismically imaged relict slab from the $55 \mathrm{Ma}$ Siletzia accretion to the northwest United States. Geology 39, 175-178.

Schmandt, B. \& Lin, F. C. (2014). P and S wave tomography of the mantle beneath the United States. Geophysical Research Letters 41, 6342-6349.

Schmandt, B., Lin, F. \& Karlstrom, K. E. (2015). Distinct crustal isostasy trends east and west of the Rocky Mountain Front. Geophysical Research Letters 42.

Schneider, C. A., Rasband, W. S. \& Eliceiri, K. W. (2012). NIH Image to ImageJ: 25 years of image analysis. Nature Methods 9, 671-675.

Scholz, C. H. (2002). The Mechanics of Earthquakes and Faulting. Cambridge University Press.

Schouten, H. \& Klitgord, K. D. (1982). The memory of the accreting plate boundary and the continuity of fracture zones. Earth and Planetary Science Letters 59, 255-266.

Schouten, H., Smith, D. K., Cann, J. R. \& Escartín, J. (2010). Tectonic versus magmatic extension in the presence of core complexes at slow-spreading ridges from a visualization of faulted seafloor topography. Geology 38, 615-618.

Schulte-Pelkum, V., Mahan, K. H., Shen, W. \& Stachnik, J. C. (2017). The distribution and composition of high-velocity lower crust across the continental U.S.:

Comparison of seismic and xenolith data and implications for lithospheric dynamics and history. Tectonics 36, 1455-1496.

Schutt, D. L. \& Lesher, C. E. (2006). Effects of melt depletion on the density and seismic velocity of garnet and spinel lherzolite. Journal of Geophysical Research: Solid Earth 111, 1-24.

Schutt, D. L. \& Lesher, C. E. (2010). Compositional trends among Kaapvaal Craton garnet peridotite xenoliths and their effects on seismic velocity and density. Earth and Planetary Science Letters. Elsevier B.V. 300, 367-373.

Schutt, D. L., Lowry, A. R. \& Buehler, J. S. (2018). Moho temperature and mobility of lower crust in the western United States. Geology 46, 219-222.

Scott, D. R. \& Stevenson, D. J. (1984). Magma solitons. Geophysical Research Letters 11, 1161-1164.

Searle, R. (2013). Mid-Ocean Ridges. Cambridge: Cambridge University Press.

Secor, D. T., Snoke, A. W. \& Dallmeyer, R. D. (1986). Character of the Alleghanian 
orogeny in the southern Appalachians: Part III. Regional tectonic relations.

Geological Society of America Bulletin 97, 1345-1353.

Seher, T., Crawford, W. C., Singh, S. C., Cannat, M., Combier, V. \& Dusunur, D. (2010). Crustal velocity structure of the Lucky Strike segment of the Mid-Atlantic Ridge at $37^{\circ} \mathrm{n}$ from seismic refraction measurements. Journal of Geophysical Research: Solid Earth 115, 1-28.

Seifert, K. E., Dymek, R. F., Whitney, P. R. \& Haskin, L. A. (2010). Geochemistry of massif anorthosite and associated rocks, Adirondack Mountains, New York. Geosphere 6, 855-899.

Selleck, B. W., McLelland, J. M. \& Bickford, M. E. (2005). Granite emplacement during tectonic exhumation: The Adirondack example. Geology 33, 781-784.

Seton, M. et al. (2012). Global continental and ocean basin reconstructions since 200Ma. Earth-Science Reviews. Elsevier B.V. 113, 212-270.

Shapiro, S. S., Hager, B. H. \& Jordan, T. H. (1999a). The continental tectosphere and Earth's long-wavelength gravity field. Developments in Geotectonics 24, 135-152.

Shapiro, S. S., Hager, B. H. \& Jordan, T. H. (1999b). Stability and dynamics of the continental tectosphere. Developments in Geotectonics 24, 115-133.

Sharga, P. J. (1986). Petrological and structural history of the lineated garnetiferous gneiss Gore Mountain, New York. Lehigh University.

Sharp, Z. D., Hazen, R. M. \& Finger, L. W. (1987). High-pressure crystal chemistry of monticellite, CaMgSiO4. American Mineralogist 72, 748-755.

Shaw, P. R. (1992). Ridge segmentation, faulting and crustal thickness in the Atlantic Ocean. Nature 358, 490-493.

Shaw, P. R. \& Jian Lin (1993). Causes and consequences of variation in faulting style at the Mid- Atlantic Ridge. Journal of Geophysical Research 98.

Shen, W. \& Ritzwoller, M. H. (2016). Crustal and uppermost mantle structure beneath the United States. Journal of Geophysical Research: Solid Earth 121, 4306-4342.

Shi, X., Kirby, E., Furlong, K. P., Meng, K., Robinson, R. \& Wang, E. (2015). Crustal strength in central Tibet determined from Holocene shoreline deflection around Siling Co. Earth and Planetary Science Letters. Elsevier B.V. 423, 145-154.

Shillington, D. J., Van Avendonk, H. J. A., Behn, M. D., Kelemen, P. B. \& Jagoutz, O. (2013). Constraints on the composition of the Aleutian arc lower crust from V P/VS. Geophysical Research Letters 40, 2579-2584.

Shinevar, W. J., Behn, M. D. \& Hirth, G. (2015). Compositional dependence of lower crustal viscosity. Geophysical Research Letters 42.

Shinevar, W. J., Behn, M. D., Hirth, G. \& Jagoutz, O. (2018). Inferring crustal viscosity from seismic velocity: Application to the lower crust of Southern California. Earth and Planetary Science Letters 494.

Shirey, S. B., Bender, J. F. \& Langmuir, C. H. (1987). Three-component isotopic heterogeneity near the Oceanographer transform, Mid-Atlantic Ridge. Nature 325, 217-223.

Sibson, R. H. (1982). Fault zone models, heat flow, and the depth distribution of earthquakes in the continental crust of the United States. $\langle I\rangle$ Bull. Seism. Soc. Amer $</ I>$. 72, 151-163.

Sim, S. J., Spiegelman, M. W., Stegman, D. R. \& Wilson, C. R. (2018). Melt focusing at mid ocean ridges. In AGU Fal. 
Simmons, G. (1964). Velocity of shear waves in rocks to 10 kilobars, 1. Journal of Geophysical Research 69, 1123-1130.

Simmons, N. A., Forte, A. M., Boschi, L. \& Grand, S. P. (2010). GyPSuM: A joint tomographic model of mantle density and seismic wave speeds. Journal of Geophysical Research: Solid Earth 115, 1-24.

Simmons, N. A., Forte, A. M. \& Grand, S. P. (2009). Joint seismic, geodynamic and mineral physical constraints on three-dimensional mantle heterogeneity: Implications for the relative importance of thermal versus compositional heterogeneity. Geophysical Journal International 177, 1284-1304.

Sims, K. W. . et al. (2002). Chemical and isotopic constraints on the generation and transport of magma beneath the East Pacific Rise. Geochimica et Cosmochimica Acta 66, 3481-3504.

Sinton, J. M. \& Detrick, R. S. (1992). Mid-ocean ridge magma chambers. Journal of Geophysical Research 97, 197-216.

Sláma, J. et al. (2008). Plešovice zircon - A new natural reference material for U-Pb and Hf isotopic microanalysis. Chemical Geology 249, 1-35.

Sleep, N. H. (1990). Monteregian Hotspot track: a long-lived mantle plume. Journal of Geophysical Research 95.

Smit, M. A., Scherer, E. E. \& Mezger, K. (2013). Lu-Hf and Sm-Nd garnet geochronology: Chronometric closure and implications for dating petrological processes. Earth and Planetary Science Letters. Elsevier B.V. 381, 222-233.

Smith, D. (1979). Hydrous minerals and carbonates in peridotite inclusions from the Green Knobs and Buell Park kimberlitic diatremes on the Colorado Plateau. In: Boyd, F. R. (ed.) The Mantle Sample: Inclusions in Kimberlites and Other Volcanics, 345-35.

Smith, D. (2000). Insights into the evolution of the uppermost continental mantle from xenolith localities on and near the Colorado Plateau and regional comparisons. Journal of Geophysical Research 105, 769-781.

Smith, D. \& Alexis Riter, J. C. (1997). Genesis and evolution of low-Al orthopyroxene in spinel peridotite xenoliths, Grand Canyon field, Arizona, USA. Contributions to Mineralogy and Petrology 127, 391-404.

Smith, D., Alexis Riter, J. C. \& Mertzman, S. A. (1999). Water-rock interactions, orthopyroxene growth, and Si-enrichment in the mantle: Evidence in xenoliths from the Colorado Plateau, southwestern United States. Earth and Planetary Science Letters 165, 45-54.

Smith, D. K., Escartín, J., Schouten, H. \& Cann, J. R. (2008). Fault rotation and core complex formation: Significant processes in seafloor formation at slow-spreading mid-ocean ridges (Mid-Atlantic Ridge, $13^{\circ}-15^{\circ} \mathrm{N}$ ). Geochemistry, Geophysics, Geosystems 9.

Smith, D. \& Levy, S. (1976). Petrology of the Green Knobs diatreme and implications for the upper mantle below the Colorado Plateau. Earth and Planetary Science Letters 29, 107-125.

Smith, H. A. \& Giletti, B. J. (1997). Lead diffusion in monazite. Geochimica et Cosmochimica Acta 61, 1047-1055.

Sobolev, S. V. \& Babeyko, A. Y. (1989). Phase transformations in the lower continental crust and its seismic structure. 311-320. 
Sobolev, S. V., Zeyen, H., Granet, M., Achauer, U., Bauer, C., Werling, F., Altherr, R. \& Fuchs, K. (1997). Upper mantle temperatures and lithosphere-asthenosphere system beneath the French Massif Central constrained by seismic, gravity, petrologic and thermal observations. Tectonophysics 275, 143-164.

Sobolev, S. V., Zeyen, H., Stoll, G., Werling, F., Altherr, R. \& Fuchs, K. (1996). Upper mantle temperatures from teleseismic tomography of French Massif Central including effects of composition, mineral reactions, anharmonicity, anelasticity and partial melt. Earth and Planetary Science Letters 139, 147-163.

Sobolev, S. V \& Babeyko, A. Y. U. (1994). Modeling of mineralogical composition, density and elastic wave velocities in anhydrous magmatic rocks. Surveys in Geophysics 15, 515-544.

Sparks, J. (2001). LASY BOY. An Excel program for processing ICP-MS data. Boston University, U.S.A.

Spear, F. S. (2014). The duration of near-peak metamorphism from diffusion modelling of garnet zoning. Journal of Metamorphic Geology 32, 903-914.

Spear, F. S. \& Markussen, J. C. (1997). Mineral zoning, P-T-X-M phase relations, and metamorphic evolution of some Adirondack granulites, New York. Journal of Petrology 38, 757-783.

Spearman, C. (1904). The Proof and Measurement of Association Between Two Things. American Journal of Psychology. Appleton-Century-Crofts.

Spencer, K. J., Hacker, B. R., Kylander-Clark, A. R. C., Andersen, T. B., Cottle, J. M., Stearns, M. A., Poletti, J. E. \& Seward, G. G. E. (2013). Campaign-style titanite U$\mathrm{Pb}$ dating by laser-ablation ICP: Implications for crustal flow, phase transformations and titanite closure. Chemical Geology. Elsevier B.V. 341, 84-101.

Steinberger, B. \& Becker, T. W. (2018). A comparison of lithospheric thickness models. Tectonophysics. Elsevier B.V. 746, 325-338.

Stixrude, L. \& Lithgow-Bertelloni, C. (2011). Thermodynamics of mantle minerals - II. Phase equilibria. Geophysical Journal International 184, 1180-1213.

Storm, L. C. \& Spear, F. S. (2005). Pressure, temperature and cooling rates of granulite facies migmatitic pelites from the southern Adirondack Highlands, New York. Journal of Metamorphic Geology 23, 107-130.

Storm, L. C. \& Spear, F. S. (2009). Application of the titanium-in-quartz thermometer to pelitic migmatites from the Adirondack Highlands, New York. Journal of Metamorphic Geology 27, 479-494.

Stover, C. W. \& Coffman, J. L. (1993). Seismicity of the United States 1568-1989 (Revised). U.S.G.S. Professional Paper 1527.

Streepey, M. M., Johnson, E. L., Mezger, K. \& van der Pluijm, B. A. (2001). Early history of the Carthage-Colton shear zone, Grenville Province, Northwest Adirondacks, New York (U.S.A.). Journal of Geology 109, 479-492.

Sun, S. -s. \& McDonough, W. F. (1989). Chemical and isotopic systematics of oceanic basalts: implications for mantle composition and processes. Geological Society, London, Special Publications 42, 313-345.

Sundberg, M. \& Cooper, R. F. (2010). A composite viscoelastic model for incorporating grain boundary sliding and transient diffusion creep; Correlating creep and attenuation responses for materials with a fine grain size. Philosophical Magazine 90, 2817-2840. 
Syono, Y., Fukai, Y. \& Ishikawa, Y. (1971). Anomalous Elastic Properties of Fe 2 TiO 4. Journal of the Physical Society of Japan 31, 471-476.

Takei, Y. (2017). Effects of Partial Melting on Seismic Velocity and Attenuation: A New Insight from Experiments. Annual Review of Earth and Planetary Sciences 45, 447470.

Tan, Y. J., Tolstoy, M., Waldhauser, F. \& Wilcock, W. S. D. (2016). Dynamics of a seafloor-spreading episode at the East Pacific Rise. Nature. Nature Publishing Group 540, 261-265.

Tesauro, M., Kaban, M. K., Mooney, W. D. \& Cloetingh, S. A. P. L. (2014). Density, temperature, and composition of the North American lithosphere-New insights from a joint analysis of seismic, gravity, and mineral physics data: 2 . Thermal and compositional model of the upper mantle. Geochemistry, Geophysics, Geosystems 15, 4781-4807.

Thatcher, W. \& Pollitz, F. F. (2008). Temporal evolution of continental lithospheric strength in actively deforming regions. GSA Today 18, 4-11.

Thomas, W. A. (2006). Tectonic inheritance at a continental margin. GSA Today 16, 411.

Till, C. B. (2017). A review and update of mantle thermobarometry for primitive arc magmas. American Mineralogist 102, 931-947.

Till, C. B., Grove, T. L., Carlson, R. W., Donnelly-Nolan, J. M., Fouch, M. J., Wagner, L. S. \& Hart, W. K. (2013). Depths and temperatures of <10.5 Ma mantle melting and the lithosphere-asthenosphere boundary below southern Oregon and northern California. Geochemistry, Geophysics, Geosystems 14, 864-879.

Tivey, M. A. \& Tucholke, B. E. (1998). Magnetization of 0-29 Ma ocean crust on the Mid-Atlantic Ridge, $25^{\circ} 30^{\prime}$ to $27^{\circ} 10^{\prime}$ N. Journal of Geophysical Research: Solid Earth 103, 17807-17826.

Tokle, L., Stunitz, H. \& Hirth, G. (2013). The effect of muscovite on the fabric evolution of quartz under general shea. AGU Fall Meeting.

Tolstoy, M. (2015). Mid-ocean ridge eruptions as a climate valve. Geophysical Research Letters 42, 1346-1351.

Tolstoy, M., Harding, A. J. \& Orcutt, J. A. (1993). Crustal thickness on the Mid-Atlantic Ridge: Bull's-eye gravity anomalies and focused accretion. Science 262, 726-729.

Tomkins, H. S., Powell, R. \& Ellis, D. J. (2007). The pressure dependence of the zirconium-in-rutile thermometer. Journal of Metamorphic Geology 25, 703-713.

Tommasi, A., Godard, M., Coromina, G., Dautria, J. M. \& Barsczus, H. (2004). Seismic anisotropy and compositionally induced velocity anomalies in the lithosphere above mantle plumes: A petrological and microstructural study of mantle xenoliths from French Polynesia. Earth and Planetary Science Letters 227, 539-556.

Tommasi, A. \& Ishikawa, A. (2014). Microstructures, composition, and seismic properties of the Ontong Java Plateau mantle root. Geochemistry, Geophysics, Geosystems 15, 4547-4569.

Tommasi, A., Vauchez, A. \& Ionov, D. A. (2008). Deformation, static recrystallization, and reactive melt transport in shallow subcontinental mantle xenoliths (Tok Cenozoic volcanic field, SE Siberia). Earth and Planetary Science Letters 272, 6577.

Tucholke, B. E., Behn, M. D., Buck, W. R. \& Lin, J. (2008). Role of melt supply in 
oceanic detachment faulting and formation of megamullions. Geology 36, 455-458.

Tucholke, B. E., Lin, J. \& Kleinrock, M. C. (1998). Megamullions and mullion structure defining oceanic metamorphic core complexes on the Mid-Atlantic Ridge. Journal of Geophysical Research: Solid Earth 103, 9857-9866.

Tucholke, B. E., Lin, J., Kleinrock, M. C., Tivey, M. A., Reed, T. B., Goff, J. \& Jaroslow, G. E. (1997). Segmentation and crustal structure of the western MidAtlantic Ridge flank, $25^{\circ} 25^{\prime}-27^{\circ} 10^{\prime} \mathrm{N}$ and 0-29 m.y. Journal of Geophysical Research: Solid Earth 102, 10203-10223.

Tullis, J. (2002). Deformation of granitic rocks: Experimental studies and natural examples. Reviews in Mineralogy and Geochemistry 51, 51-95.

Tullis, J. \& Wenk, H.-R. (1994). Effect of muscovite on the strength and lattice preferred orientations of experimentally deformed quartz aggregates. Materials Science and Engineering: A 175, 209-220.

Turcotte, D. \& Schubert, G. (2014). Geodynamics. Cambridge University Press.

Turner, A. J., Katz, R. F. \& Behn, M. D. (2015). Grain-size dynamics beneath mid-ocean ridges: Implications for permeability and melt extraction. Geochemistry, Geophysics, Geosystems 16, 925-946.

Turner, A. J., Katz, R. F., Behn, M. D. \& Keller, T. (2017). Magmatic Focusing to MidOcean Ridges: The Role of Grain-Size Variability and Non-Newtonian Viscosity. Geochemistry, Geophysics, Geosystems 18, 4342-4355.

Unsworth, M. J. et al. (2005). Crustal rheology of the Himalaya and Southern Tibet inferred from magnetotelluric data. Nature 438, 78-81.

Valley, J. W., Bohlen, S. R., Essene, E. J. \& Lamb, W. (1990). Metamorphism in the adirondacks: II. The role of fluids. Journal of Petrology 31, 555-596.

Valley, P. M., Hanchar, J. M. \& Whitehouse, M. J. (2011). New insights on the evolution of the Lyon Mountain Granite and associated Kiruna-type magnetite-apatite deposits, Adirondack Mountains, New York State. Geosphere 7, 357-389.

van der Hilst, R. D., Engdahl, E. R. \& Spakman, W. (1993). Tomographic inversion of P and $\mathrm{pP}$ data for aspherical mantle structure below the northwest Pacific region. Geophysical Journal International 115, 264-302.

Van der Wal, D., Chopra, P., Drury, M. \& Gerald, J. F. (1993). Relationships between dynamically recrystallized grain size and deformation conditions in experimentally deformed olivine rocks. Geophysical Research Letters 20, 1479-1482.

Van Schmus, W. R. (1992). Tectonic setting of the Midcontinent Rift system. Tectonophysics 213, 1-15.

Van Schmus, W. R. \& Hinke, W. J. (1985). The Midcontinent Rift System. Annual Review of Earth and Planetary Sciences 13, 345-383.

Vasiukov, D. M. et al. (2018). Sound velocities of skiagite-iron-majorite solid solution to $56 \mathrm{GPa}$ probed by nuclear inelastic scattering. Physics and Chemistry of Minerals. Springer Berlin Heidelberg 45, 397-404.

Venzke, E. (ed) (2013). Global Volcanism Program, 2013. Volcanoes of the World, v. 4.10.0. .

Vermeesch, P. (2018). IsoplotR: A free and open toolbox for geochronology. Geoscience Frontiers 9, 1479-1493.

Villiger, S., Ulmer, P. \& Müntener, O. (2007). Equilibrium and fractional crystallization experiments at $0.7 \mathrm{GPa}$; the effect of pressure on phase relations and liquid 
compositions of tholeiitic magmas. Journal of Petrology 48, 159-184.

von Seckendorff, V. \& O’Neill, H. S. C. (1993). An experimental study of Fe-Mg partitioning between olivine and orthopyroxene at 1173, 1273 and $1423 \mathrm{~K}$ and 1.6 GPa. Contributions to Mineralogy and Petrology 113, 196-207.

Wang, T., Lin, J., Tucholke, B. \& Chen, Y. J. (2011). Crustal thickness anomalies in the North Atlantic Ocean basin from gravity analysis. Geochemistry, Geophysics, Geosystems 12, 1-25.

Wang, Y., Forsyth, D. W., Rau, C. J., Carriero, N., Schmandt, B., Gaherty, J. B. \& Savage, B. (2013). Fossil slabs attached to unsubducted fragments of the Farallon plate. Proceedings of the National Academy of Sciences of the United States of America 110, 5342-5346.

Wang, Z. \& Ji, S. (2001). Elasticity of six polycrystalline silicate garnets at pressure up to 3.0 GPa. American Mineralogist 86, 1209-1218.

Wass, S. Y. (1973). Plagioclase-spinel intergrowths in alkali basaltic rocks from the Southern Highlands, N.S.W. Contributions to Mineralogy and Petrology 38, 167175.

Wasteneys, H., McLelland, J. \& Lumbers, S. (1999). Precise zircon geochronology in the Adirondack Lowlands and implications for revising plate-tectonic models of the Central Metasedimentary Belt and Adirondack Mountains, Grenville Province, Ontario and New York. Canadian Journal of Earth Sciences.

Watts, A. B. (2001). Isostasy and Flexure of the Lithosphere. Cambridge University Press.

Weatherall, P. et al. (2015). A new digital bathymetric model of the world's oceans. Earth and Space Science 2, 331-345.

Wei, W. (1995). Revised age calibration points for the geomagnetic polarity time scale. Geophysical Research Letters 22, 957-960.

White, R. W., Powell, R. \& Clarke, G. L. (2002). The interpretation of reaction textures in Fe-rich metapelitic granulites of the Musgrave Block, central Australia: constraints from mineral equilibria calculations in the system $\mathrm{K} 2 \mathrm{O}-\mathrm{FeO}-\mathrm{MgO}-$ Al2O3-SiO2-H2O-TiO2-Fe2O3. Journal of Metamorphic Geology 20, 41-55.

White, R. W., Powell, R., Holland, T. J. B., Johnson, T. E. \& Green, E. C. R. (2014a). New mineral activity-composition relations for thermodynamic calculations in metapelitic systems. Journal of Metamorphic Geology 32, 261-286.

White, R. W., Powell, R., Holland, T. J. B. \& Worley, B. A. (2000). The effect of TiO2 and $\mathrm{Fe} 2 \mathrm{O} 3$ on metapelitic assemblages at greenschist and amphibolite facies conditions: mineral equilibria calculations in the system $\mathrm{K} 2 \mathrm{O}-\mathrm{FeO}-\mathrm{MgO}-\mathrm{Al} 2 \mathrm{O} 3-$ $\mathrm{SiO} 2-\mathrm{H} 2 \mathrm{O}-\mathrm{TiO} 2-\mathrm{Fe} 2 \mathrm{O} 3$. Journal of Metamorphic Geology 18, 497-511.

White, R. W., Powell, R. \& Johnson, T. E. (2014b). The effect of Mn on mineral stability in metapelites revisited: new a - $\mathrm{x}$ relations for manganese-bearing minerals. Journal of Metamorphic Geology 32, 809-828.

White, W. M. \& Schilling, J. G. (1978). The nature and origin of geochemical variation in Mid-Atlantic Ridge basalts from the Central North Atlantic. Geochimica et Cosmochimica Acta 42, 1501-1516.

Whitmeyer, S. J. \& Karlstrom, K. E. (2007). Tectonic model for the Proterozoic growth of North America. Geosphere 3, 220-259.

Whitney, P. R. (1972). Spinel Inclusions in Plagioclase of Metagabbros from the 
Adirondack Highlands. 57.

Whitney, P. R. \& McLelland, J. M. (1973). Origin of coronas in metagabbros of the Adirondack mts., N. Y. Contributions to Mineralogy and Petrology 39, 81-98.

Wiedenbeck, M. et al. (2004). Further Characterisation of the 91500 Zircon Crystal. Geostandards and Geoanalytical Research 28, 9-39.

Wiedenbeck, M., Alle, P., Corfu, F., Griffin, W. L., Meier, M., Oberli, F., Quadt, A. VON, Roddick, J. C. \& Spiegel, W. (1995). Three natural zircon Standards for UTh-Pb, Lu-Hf, Trace Elemenend, and REE Analyses. Geostandards and Geoanalytical Research 19, 1-23.

Williams, C. F. \& Deangelo, J. (2011). Evaluation of Approaches and Associated Uncertainties in the Estimation of Temperatures in the Upper Crust of the Western United States. GRC Transactions 1599-1605.

Wilshire, H., Meyer, C. E., Nakata, J. K., Calk, L. C., Shervais, J. W., Nielson, J. E. \& Schwarzman, E. C. (1988). Mafic and ultramfic xenoliths from volcanic rocks of the western US. USGS Publication 1-397.

Wolf, M. B. \& Wyllie, P. J. (1995). Liquid segregation parameters from amphibolite dehydration melting experiments. Journal of Geophysical Research: Solid Earth 100, 15611-15621.

Wong, M. S., Williams, M. L., McLelland, J. M., Jercinovik, M. J. \& Kowalkoski, J. (2012). Late Ottawan extension in the eastern Adirondack Highlands: Evidence from structural studies and zircon and monazite geochronology. Bulletin of the Geological Society of America 124, 857-869.

Wood, B. J. \& Banno, S. (1973). Garnet-orthopyroxene and orthopyroxeneclinopyroxene relationships in simple and complex systems. Contributions to Mineralogy and Petrology 42, 109-124.

Woodland, A. B., Angel, R. J., Koch, M., Kunz, M. \& Miletich, R. (1999). Equations of state for $\mathrm{Fe} 32+\mathrm{Fe} 23+\mathrm{Si} 3 \mathrm{O} 12$ "skiagite" garnet and Fe2SiO4 - Fe3O4 spinel solid solutions. Journal of Geophysical Research: Solid Earth 104, 20049-20058.

Woollard, G. P. (1965). The Bouguer Gravity Anomaly Map of the United States. Eos, Transactions American Geophysical Union 46, 197-202.

Workman, R. K. \& Hart, S. R. (2005). Major and trace element composition of the depleted MORB mantle (DMM). Earth and Planetary Science Letters 231, 53-72.

Wu, F. Y., Xu, Y. G., Zhu, R. X. \& Zhang, G. W. (2014). Thinning and destruction of the cratonic lithosphere: A global perspective. Science China Earth Sciences 57, 28782890.

Xiong, Z., Liu, X., Shieh, S. R., Wang, F., Wu, X., Hong, X. \& Shi, Y. (2015). Equation of state of a synthetic ulvöspinel, (Fe1.94Ti0.03)Ti1.00O4.00, at ambient temperature. Physics and Chemistry of Minerals 42, 171-177.

Xu, J., Zhang, D., Fan, D., Downs, R. T., Hu, Y. \& Dera, P. K. (2017). Isosymmetric pressure-induced bonding increase changes compression behavior of clinopyroxenes across jadeite-aegirine solid solution in subduction zones. Journal of Geophysical Research: Solid Earth 122, 142-157.

Xu, L., Mei, S., Dixon, N., Jin, Z., Suzuki, A. M. \& Kohlstedt, D. L. (2013). Effect of water on rheological properties of garnet at high temperatures and pressures. Earth and Planetary Science Letters. Elsevier B.V. 379, 158-165.

Yang, X. \& Gao, H. (2018). Full-Wave Seismic Tomography in the Northeastern United 
States: New Insights Into the Uplift Mechanism of the Adirondack Mountains. Geophysical Research Letters 45, 5992-6000.

Yuan, H. \& Romanowicz, B. (2010). Lithospheric layering in the North American craton. Nature. Nature Publishing Group 466, 1063-1068.

Yuan, H., Romanowicz, B., Fischer, K. M. \& Abt, D. (2011). 3-D shear wave radially and azimuthally anisotropic velocity model of the North American upper mantle. Geophysical Journal International 184, 1237-1260.

Zandt, G., Gilbert, H., Owens, T. J., Ducea, M., Saleeby, J. \& Jones, C. H. (2004). Active foundering of a continental arc root beneath the southern Sierra Nevada in California. Nature 431, 41-46.

Zhang, L., Ahsbahs, H., Kutoglu, A. \& Geiger, C. A. (1999). Single-crystal hydrostatic compression of synthetic pyrope, almandine, spessartine, grossular and andradite garnets at high pressures. Physics and Chemistry of Minerals 27, 52-58.

Zhu, W., Gaetani, G. A., Fusseis, F., Montesi, L. G. J. \& De Carlo, F. (2011). Microtomography of Partially Molten Rocks: Three-Dimensional Melt Distribution in Mantle Peridotite. Science 332, 88-91.

Ziberna, L., Klemme, S. \& Nimis, P. (2013). Garnet and spinel in fertile and depleted mantle: Insights from thermodynamic modelling. Contributions to Mineralogy and Petrology 166, 411-421.

Zoback, M. Lou \& Mooney, W. D. (2003). Lithospheric buoyancy and continental intraplate stresses. International Geology Review 45, 95-118.

Zoback, M. D. \& Townend, J. (2001). Implications of hydrostatic pore pressures and high crustal strength for the deformation of intraplate lithosphere. Tectonophysics 336, $19-30$.

Zunino, A., Khan, A., Cupillard, P. \& Mosegaard, K. (2016). Constitution and Structure of Earth's Mantle: Insights from Mineral Physics and Seismology. Integrated Imaging of the Earth: Theory and Applications 219-243. 